\title{
DEVELOPMENT OF A TEST METHOD TO EVALUATE DURABILITY OF PAVEMENT JOINTS UNDER WINTER CONDITIONS
}

by

\author{
Conrad Babicz \\ B.Eng., Ryerson University, Ontario, Canada, 2017
}

\author{
A thesis \\ presented to Ryerson University \\ in partial fulfilment of the \\ requirements for the degree of \\ Master of Applied Science \\ in the program of \\ Civil Engineering
}

Toronto, Ontario, Canada, 2019

(C) Conrad Babicz, 2019 


\section{Author's Declaration}

I hereby declare that I am the sole author of this thesis. This is a true copy of the thesis, including any required final revisions, as accepted by my examiners.

I authorize Ryerson University to lend this thesis to other institutions or individuals for the purpose of scholarly research

I further authorize Ryerson University to reproduce this thesis by photocopying or by other means, in total or in part, at the request of other institutions or individuals for the purpose of scholarly research.

I understand that my thesis may be made electronically available to the public. 


\title{
Development of a Test Method to Evaluate Durability of Pavement Joints under Winter Conditions
}

\author{
Conrad Babicz \\ Master of Applied Science, 2019 \\ Civil Engineering \\ Ryerson University
}

\begin{abstract}
In areas with cold winters, premature failure in concrete pavement joints is a frequent phenomenon, yet there is no standard test method for evaluating their durability. In this study, the effectiveness of several evaluation techniques for concrete joint durability were evaluated. Concrete slabs with saw cuts representing joints were made, and exposed to different freezing and thawing/ wetting cycles, and different salt solutions ( $\mathrm{NaCl}, \mathrm{CaCl}_{2}$, and $\mathrm{MgCl}_{2}$ ). The durability of the joints was evaluated using measures of strength loss, mass loss, and a visual inspection. It was found that under these exposure conditions, the strength loss and visual inspection modes of evaluation could discern different levels of damage between different types of exposures, and also different concrete mixes (e.g. Different cement contents, strength and the presence or absence of SCM). Further research is required to evaluate the effects of sealants, saturated bases, and higher salt concentrations.
\end{abstract}




\section{Acknowledgements}

It's been an incredible privilege to have had the opportunity to work on this project. I've been very fortunate to have all the help I've had, and I'm very grateful to everyone who helped make this possible.

I owe many thanks to my thesis supervisor, Dr. Medhat Shehata, for all of his support and guidance for this work, giving me direction from start to finish.

I am very grateful for all of the help from the civil engineering technical staff at Ryerson University, Domenic Valle, Nidal Jaalouk, Bilal Baradie, Khaleel Stoney, and Robin Luong, as well as the help from research assistants Ramy Elbakari and Adam Cybart, and Dr. Shehata's entire research team.

Thank you to Melissa Titherington of the MTO for her knowledge and support on the project.

The authors acknowledge the support of the Ministry of Transportation Ontario (MTO) in the funding of this project. 


\section{Dedication}

This thesis is dedicated to my parents. This work would not have been possible without your unwavering love, support, and dedication. I don't say it enough, but I love you, thank you.

This work is also dedicated to the reader and all those who seek knowledge to improve the world. 


\section{Table of Contents}

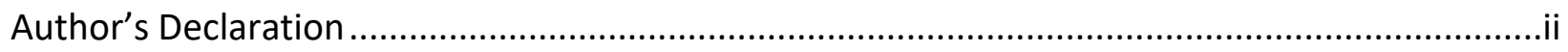

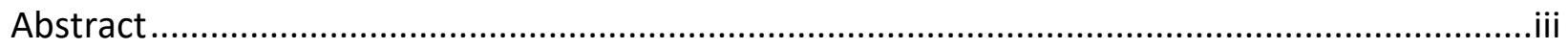

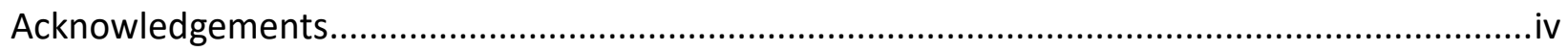

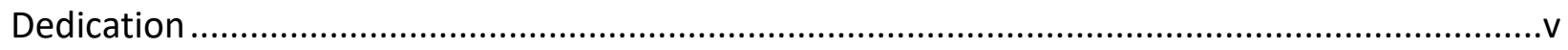

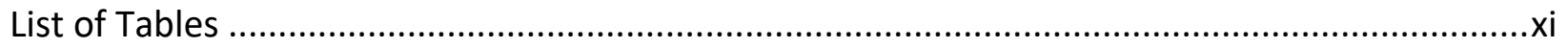

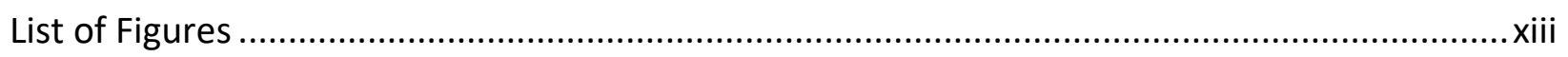

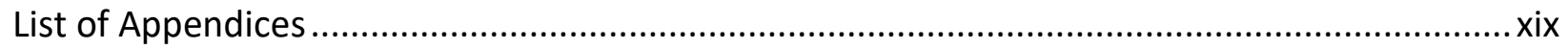

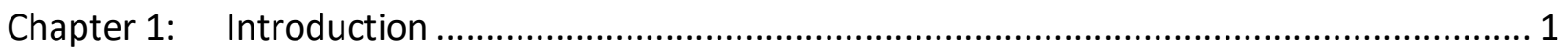

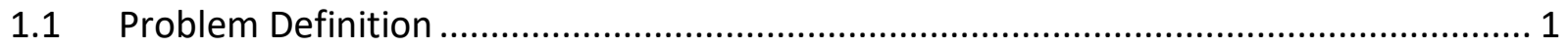

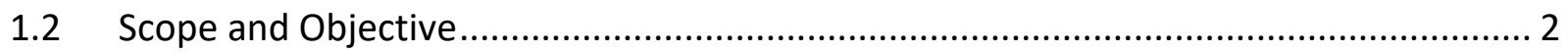

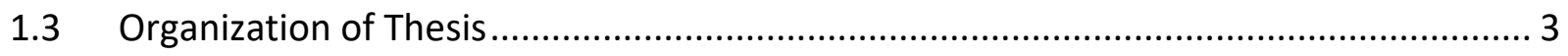

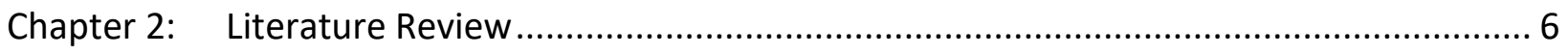

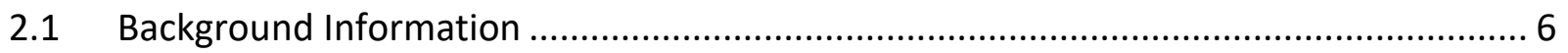

2.2 Case Studies of Concrete Pavements Damaged Early in their Life Cycles .................... 7

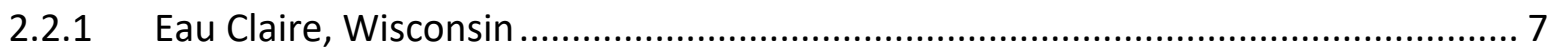

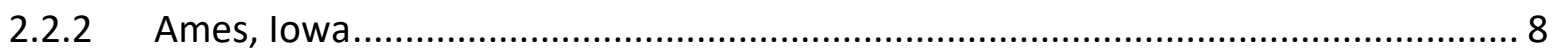

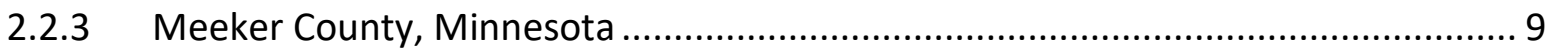

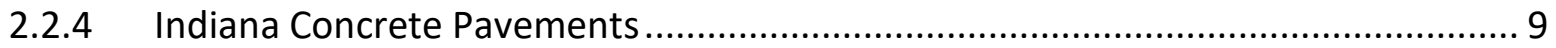


2.3 Freeze-thaw and wet-dry damage with salt exposure

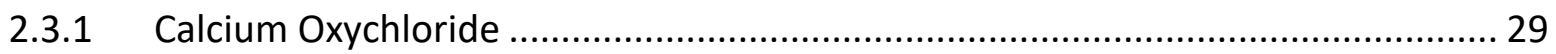

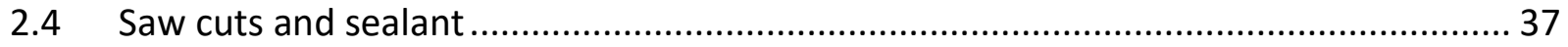

2.5 Flexural Strength of Concrete and Fatigue Loading ........................................... 42

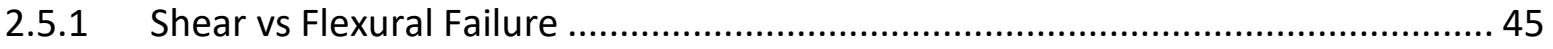

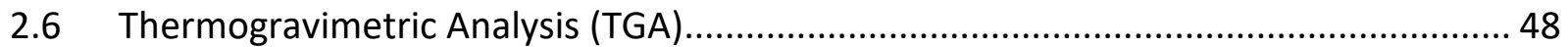

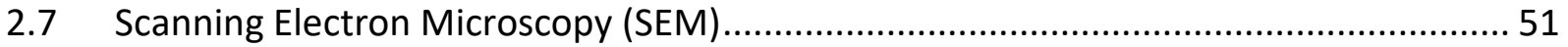

2.7.1 Scanning Electron Microscopy Sample Preparation .......................................... 53

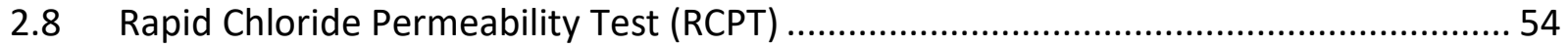

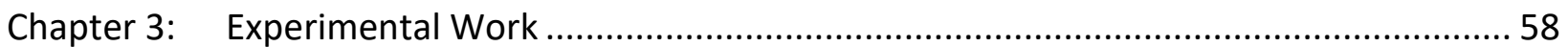

3.1 Sample Preparation and Consistency Tests .......................................................... 58

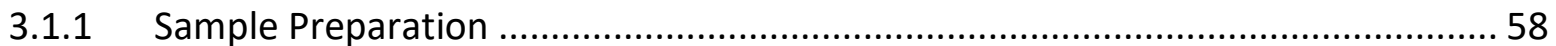

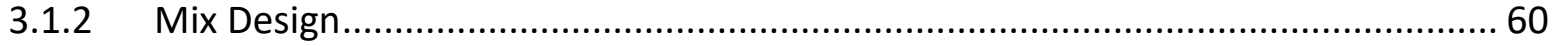

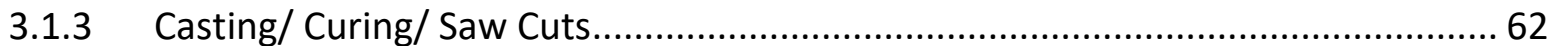

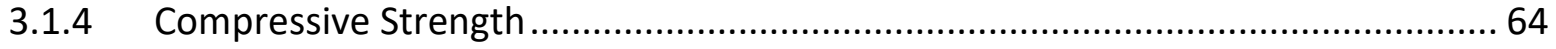

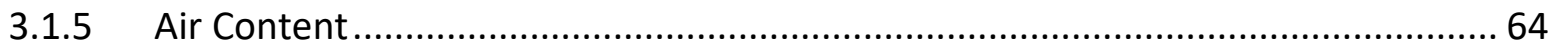

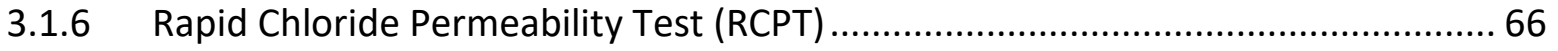

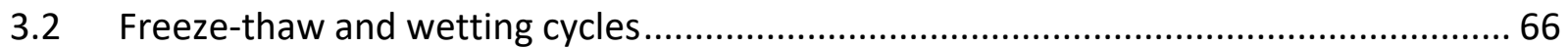

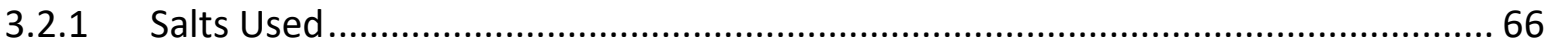




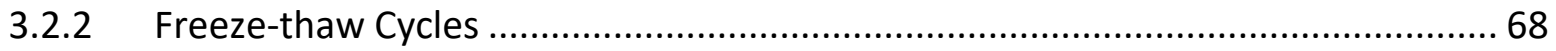

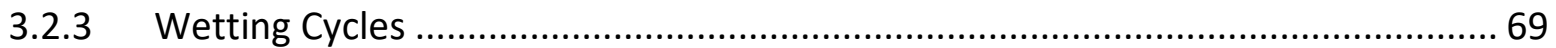

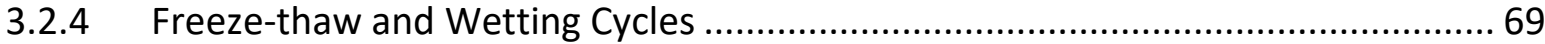

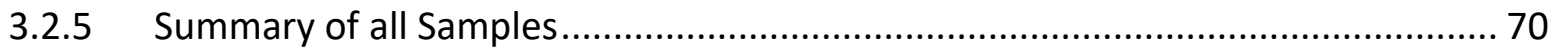

3.3 Proposed Evaluation Techniques .............................................................................. 70

3.3.1 Visual Inspection (Visual Index) ...................................................................... 71

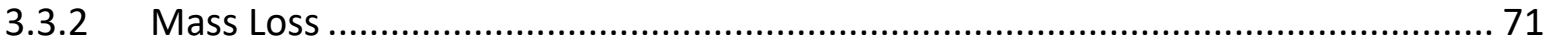

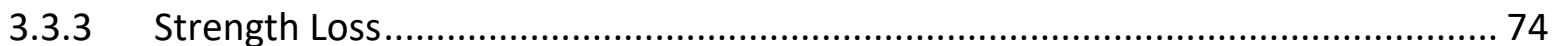

3.4 Scanning Electron Microscope ……………….......................................................... 79

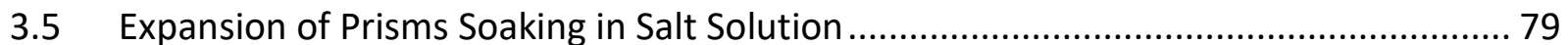

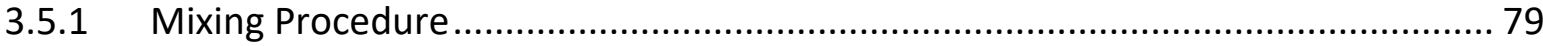

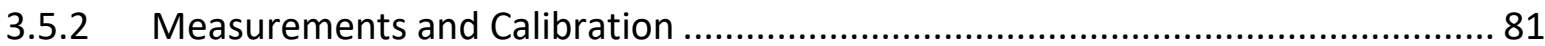

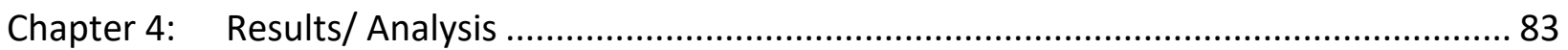

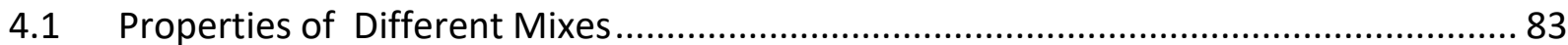

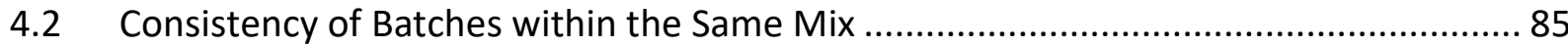

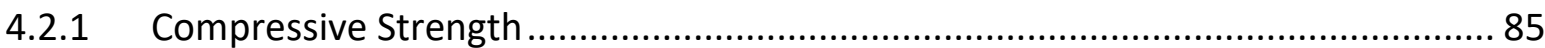

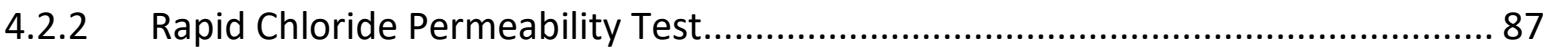

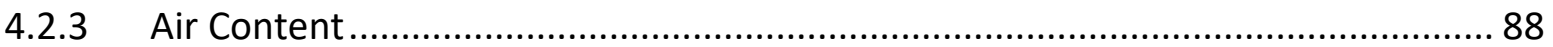

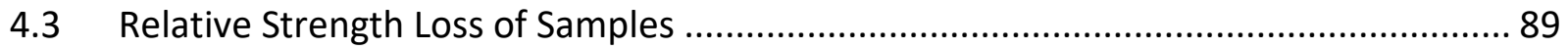




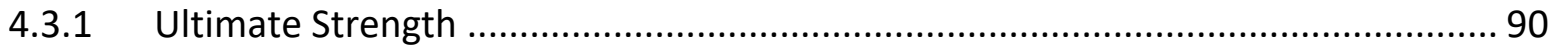

4.3.2 The Role of Concrete Strength and Cement Content ......................................... 92

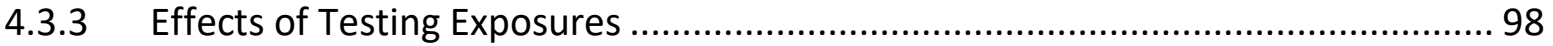

4.3.4 Testing Under Flexural Fatigue .................................................................. 114

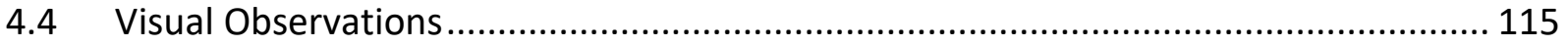

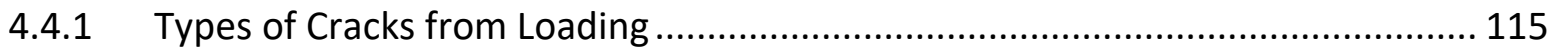

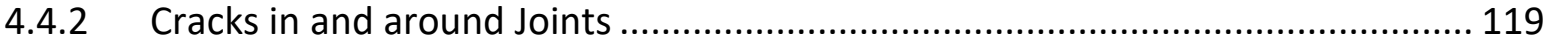

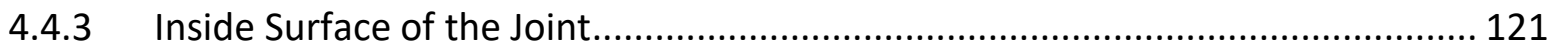

4.4.4 Visual Index Development .............................................................................. 127

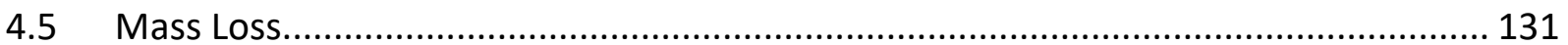

4.5.1 Mass Loss Results and Issues .......................................................................... 131

4.6 Expansion of Prisms Soaking in Salt Solution Results ............................................. 135

Chapter 5: Conclusions, Limitations, \& Recommendations ............................................... 138

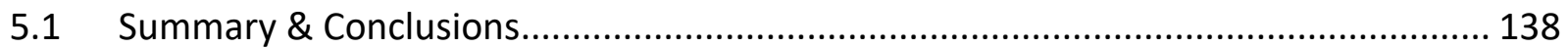

5.1.1 Methods of Evaluation:................................................................................. 138

5.1.2 Effects of Different Exposure and Concrete Strength: .................................... 139

5.2 Research Limitations .......................................................................................... 141

5.3 Recommendations for Further Studies ............................................................ 141 


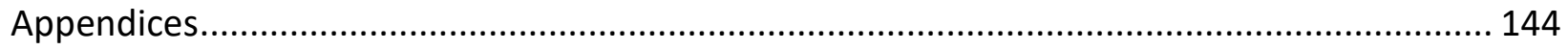

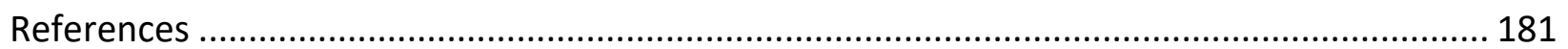




\section{List of Tables}

Table 3-1 Summary of concrete slabs made 58

Table 3-2 Concentrations used for different types of salt solutions and exposure conditions used for testing. 67

Table 3-3 Explanation of cycles (FT, W, and FTW) that the samples underwent. 68

Table 3-4 All cyclical exposures and different mixes used. 70

Table 4-1 Total amount of paste (and paste constituents) per cubic meter of concrete for the three different concrete mixes, and average measured air content.

Table 4-2 Average 28-day compressive strength, RCPT, and air content of the different mixes. 84 Table 4-3 Average 28-day compressive strength of 3 cylinders for the batches of the $45 \mathrm{MPa}$ (30\% slag replacement) mix. 86

Table 4-4 Average 28-day compressive strength of 3 cylinders for the batches of the $30 \mathrm{MPa}$ mix

Table 4-5 Average 28-day compressive strength of 3 cylinders for the batches of the $55 \mathrm{MPa}$ mix.

Table 4-6 Average RCPT values and testing age for all mixes. 88

Table 4-7 Measured air content for each batch of concrete. 89

Table 4-8 One-tailed t-test analysis for $30 \mathrm{MPa}$ mix samples and $55 \mathrm{MPa}$ mix samples (load

values)

Table 4-9 One-tailed t-test analysis for $30 \mathrm{MPa}$ mix samples and $55 \mathrm{MPa}$ mix samples (relative strength). 95 
Table 4-10 Comparisons between $10 \% \mathrm{CaCl}_{2} \mathrm{FTW}$ samples of different mixes/ cement contents.

Table 4-11 Comparisons of mass loss and strength between the $3 \%$ and $10 \% \mathrm{NaCl}$ FT samples

(45 MPa mix). 101

Table 4-12 Relative strength compared with 28-day compressive strength (30 MPa mix, wetting cycles). 112

Table 4-13 Samples that underwent fatigue loading. 114

Table 4-14 The presence of cracks around the joints of samples from different mixes ...... 120

Table 4-15 Visual index created for rating concrete joint deteriorated based on the surface. . 128 Table 4-16 Visual index created for rating concrete joint deteriorated based on the inside of the joint 130

Table 4-17 Freeze-thaw cycles experienced by different cyclical exposures 134 


\section{List of Figures}

Figure 2-1 A concrete pavement distressed early in its life cycle (Taylor et al., 2012)............... 8

Figure 2-2 Scanning Electron Microscopy image of damaged concrete core from a longitudinal joint with ettringite filling in the air void (left) and several air voids filled with ettringite (right),

(del Mar Arribas- Colon, 2008) 10

Figure 2-3 Damage from scaling of different solutions and different concentrations on air-

entrained and non air-entrained concrete (Verbeck \& Klieger, 1957).

Figure 2-4 Levels of physical and chemical deterioration recorded from different magnesium

chloride concentrations (Farnam et al., 2015)

Figure 2-5 Figure illustrating that if two concretes have the same air content but different sized

air voids, that the spacing factor would be different. Klieger (1978)..... 14

Figure 2-6 TG and DTA curves for Friedel's salt (Birnin-Yauri \& Glasser, 1998)...... 17

Figure 2-7 Phase diagram of sodium chloride and water (Farnam et al., 2015c).

Figure 2-8 (a) DTG curves for cement pastes exposed to different sodium chloride concentrations, and (b) amount of Fridel's salt present given different sodium chloride concentrations (Qiao et al., 2018) 18

Figure 2-9 An air void in damaged concrete filled with ettringite (Stark \& Bollman, 2000) ....... 20

Figure 2-10 Effect of ettringite-filled voids on capillary suction (Stark \& Bollman, 2000) .......... 20

Figure 2-11 Phase diagram for calcium chloride and water (Farnam et al., 2015b) .....

Figure 2-12 Decreases in flexural strength (relative to control) of pastes exposed to different $\mathrm{CaCl}_{2}$ concentrations and different temperatures (Qiao et al., 2018b) 
Figure 2-13 Phase diagram of magnesium chloride and freezing temperatures of different salts at different concentrations (Farnam et al., 2015) 23

Figure 2-14 Freezing temperatures $\left({ }^{\circ} \mathrm{F}\right.$ ) of water with salts at different concentrations (Sutter et al., 2008). 24

Figure 2-15 Photo of concrete with cracked aggregate caused by D-cracking of susceptible aggregate caused by freeze-thaw cycles (Alexander and Mindess, 2014)...... 25

Figure 2-16 Concrete sample soaked in $\mathrm{MgCl}_{2}$ solution for 56 days at $40^{\circ} \mathrm{F}\left(4.4{ }^{\circ} \mathrm{C}\right)$, with SEM image on the right. The paste expanded and an arrow is pointing to a crack in the SEM image (Taylor et al., 2016)

Figure 2-17 The damage increases from freeze-thaw cycles (measured by decrease of dynamic modulus) with higher degree of saturation of concrete (Farnam et al., 2015c) .....

Figure 2-18 Damage in concrete exposed to $15 \% \mathrm{MgCl}_{2}$ and $17 \% \mathrm{CaCl}_{2}$, held at $4.4^{\circ} \mathrm{C}$ for 500 days (Peterson et al., 2013). 28

Figure 2-19 Calcium oxychloride formation for different calcium hydroxide contents of cement paste (Suraneni et al., 2016) 30 Figure 2-20 Amount of calcium oxychloride present for pastes with differing amounts of calcium hydroxide present (Suraneni et al., 2018). 31

Figure 2-21 Reduction of calcium oxychloride formation with increasing replacement of cement with SCM (a: fly ash, b: slag, c: silica fume). The dashed line represents the expected drop in calcium oxchloride formation from just dilution of cement, the solid line captures this effect plus the additional reduction of available calcium hydroxide (Monical et al., 2013). 
Figure 2-22 Calcite barrier forming around calcium hydroxide, preventing further reaction with calcium chloride deicing salt (Ghantous et al., 2016).

Figure 2-23 BSE image of calcium oxychloride hydrate, $\mathrm{CaCl}_{2} \cdot \mathrm{Ca}(\mathrm{OH})_{2} \cdot 2 \mathrm{H}_{2} \mathrm{O}$ (left) and magnesium oxychloride hydrate crystals (right) near brucite (Peterson et al., 2013). 34

Figure 2-24 Chloride penetration depth of mortar samples soaked in low concentration (7.3\% $\mathrm{NaCl}, 7.3 \% \mathrm{CaCl}_{2}, 6.2 \% \mathrm{MgCl}_{2}$ ) salt solutions (Peterson et al., 2013) ..... 35

Figure 2-25 Stereoscopic microscope image of calcium oxychloride $\left(3 \mathrm{CaO} \cdot \mathrm{CaCl}_{2} \cdot 15 \mathrm{H}_{2} \mathrm{O}\right.$ phase) formed on the surface of concrete exposed to high $\mathrm{CaCl}_{2}$ concentration (Peterson et al., 2013).

Figure 2-26 Stereoscopic images and XRD data of the hydrated calcium oxychloride phase (top) and dehydrated calcium oxychloride phases after drying. Some calcite and portlandite were also formed in the drying process (Peterson et al., 2013)

Figure 2-27 The effect of the time of saw cutting on ravelling and cracking (lowa State University, 2004) 38

Figure 2-28 Diagram of different type of joint sealants for joints in concrete pavements (American Concrete Pavement Association, 2018)

Figure 2-29 Concrete's compressive strength after having experienced different amounts of fatigue loading cycles (Lu et al., 2017).

Figure 2-30 Concrete's compressive strength after undergoing different amounts of freeze-thaw cycles (Lu et al., 2017). 45

Figure 2-31 (a) Flexural strength for different loading rates. (b) Flexural strength for different notch to depth ratios. 
Figure 2-32 Schematic of shear compression failure in a deep beam, with crushed concrete at the load point (Osman, 2008). 47

Figure 2-33 TGA test results showing DTG curves for identifying ettringite and Friedel's salt (Shi

et al., 2017). 49

Figure 2-34 DTG curves of concrete exposed to $\mathrm{MgCl}_{2}$ solution. $\mathrm{CSH}$ : calcium silicate hydrate.

$\mathrm{MH}: \mathrm{Mg}(\mathrm{OH})_{2} . \mathrm{CH}: \mathrm{Ca}(\mathrm{OH})_{2}$. FS: Friedel's salt. Cc: $\mathrm{CaCO}_{3}$. (Qiao et al., 2018c) ..... 50

Figure 2-35 Image of Portland cement mortar from BSE (Scrivener, 2004)

Figure 2-36 Chloride penetration through damaged and undamaged cores from taken from a distressed pavement (Del Mar Arribas-Colón et al., 2012).

Figure 2-37 Results of average charge passed during RCPT test of Ordinary Portland Cement (OPC) and other cement blends ( $F=$ fly ash, $S=$ silica fume, $B=$ blast furnace slag) (Ahmed et al., 2008) 57

Figure 3-1 The two types of slabs used in the experiment: square slabs, $200 \mathrm{~mm} \times 200 \mathrm{~mm} 120$ $\mathrm{mm}$ (left) and rectangular slabs, $300 \mathrm{~mm} \times 100 \mathrm{~mm} \times 120 \mathrm{~mm}$ (right). 59

Figure 3-2 A rectangular slab with a sealed joint to prevent leaking of salt solution.

Figure 3-3 Removing material from inside the joint of a concrete slab and collecting it inside a container.

Figure 3-4 Square slab in the designed loading setup with adjustable rollers to load both the square and the rectangular slabs....... 75

Figure 3-5 Cross sectional view of sample loading setup. 76 Figure 3-6 The Humboldt Length Comparator H-3250D with a comparator rod in place, used for measuring length changes of prisms. 80 
Figure 4-1 Average relative strength of different salt solutions and cyclical exposures for the three different concrete mixes used (the $45 \mathrm{MPa}$ mix, $30 \mathrm{MPa}$ mix, and $55 \mathrm{MPa}$ mix)

Figure 4-2 Comparative average strength (of 3 specimens per sample) and relative strength under the same cyclical exposure but having different cement contents. Error bars represent one standard deviation.

Figure 4-3 Relative strength of tested samples with FT samples highlighted. 100

Figure 4-4 SEM image of 3\% $\mathrm{CaCl}_{2} \mathrm{FT}$ sample with cracks between air voids, and locations that were scanned with EDS. 103

Figure 4-5 SEM image of undamaged entrained air voids in $3 \% \mathrm{CaCl}_{2} \mathrm{FT}$ sample without any cracks in or around the air voids. 104

Figure 4-6 Relative strength of tested samples with FTW samples highlighted. 106 Figure 4-7 10\% $\mathrm{CaCl}_{2}$ FTW samples after 50 total cycles, $45 \mathrm{MPa}$ mix (top left) $55 \mathrm{MPa}$ mix mix (top right), and $55 \mathrm{MPa}$ mix $10 \% \mathrm{MgCl}_{2} \mathrm{FTW}$ (bottom). 108

Figure 4-8 Relative strength of samples, with the samples exposed to only wetting highlighted.

Figure 4-9 Control slab tested to ultimate failure with rollers, in which the crack that had formed was not confined to the section immediately above the saw cut........ 116 Figure 4-10 10\% $\mathrm{CaCl}_{2}$ FT sample with the crack extending up and away from the joint rather than staying confined within the area directly above the saw cut.

Figure 4-11 Control slab tested to ultimate failure, which had experienced some cracking above the roller support (left side of the image). 118 
Figure 4-12 Cracks in and around the joint of slabs exposed to FT before loading. A crack and efflorescence below the joint of a $3 \% \mathrm{CaCl}_{2} \mathrm{FT}$ sample (top left), some efflorescence and a thin crack on the bottom surface of a $3 \% \mathrm{MgCl}_{2} \mathrm{FT}$ sample (top right), cracks inside the joint of a $3 \%$ $\mathrm{CaCl}_{2}$ sample (bottom left), and a crack visible on the bottom surface of a slab connecting to the saw cut of a $3 \% \mathrm{CaCl}_{2}$ sample (bottom right).

Figure 4-13 A view inside the joint (after loading) of the $10 \% \mathrm{NaCl} F T W\left(\mathrm{H}_{2} \mathrm{O}\right)$ sample (left) and the $10 \% \mathrm{CaCl}_{2}$ FTW sample (right), both from the $45 \mathrm{MPa}$ mix.

Figure 4-14 Inside the joints of different samples after loading: 15\% $\mathrm{NaCl} W$ (top left), $15 \%$ $\mathrm{MgCl}_{2} \mathrm{~W}$ (top right), and $3 \% \mathrm{MgCl}_{2} \mathrm{FT}$ (bottom).

Figure 4-15 SEM images showing differences in paste of samples exposed to different salt solutions, from left to right: $3 \% \mathrm{NaCl} \mathrm{FT}, 3 \% \mathrm{CaCl}_{2} \mathrm{FT}, 3 \% \mathrm{MgCl}_{2} \mathrm{FT}$. 125

Figure 4-16 SEM images of a sample exposed to $3 \% \mathrm{MgCl}_{2}$ FT with a crack present between entrained air voids (left) and entrained air voids without a connecting crack (right). 126

Figure 4-17 Average mass loss $\left(\mathrm{g} / \mathrm{m}^{2}\right)$ of the different conditions that slabs underwent. 132 Figure 4-18 Comparison of the slabs with the most mass loss from surface scaling: $10 \% \mathrm{CaCl}_{2}$ FTW (1.68 g/m² mass loss) with spalling around the joint and surface scaling (left) and $3 \% \mathrm{NaCl}$ FT (1.30 g/m² mass loss) with mostly surface scaling (right) 133 Figure 4-19 Average strain (change in length divided by initial length) for concrete prisms exposed to $15 \%$ salt solutions at room temperature. 136 


\section{List of Appendices}

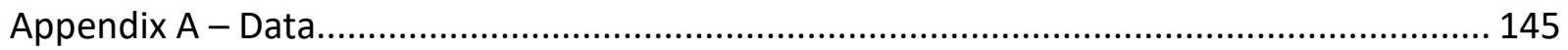

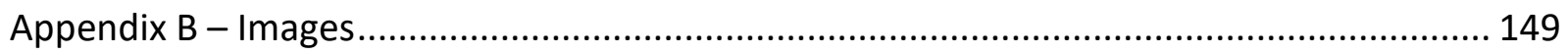

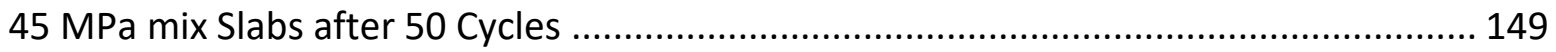

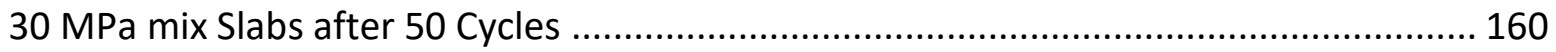

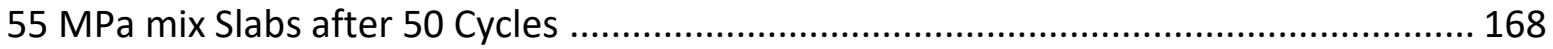

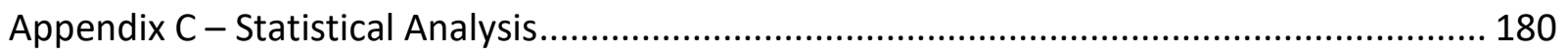




\section{Chapter 1: Introduction}

\subsection{Problem Definition}

Some Portland Cement Concrete (PCC) Pavements in Ontario (and the northern United States) have experienced significant deterioration, especially around the joints, after having been in service for only a few years. This damage has been experienced in both transverse and longitudinal joints. At the present time, there is no standard test method for evaluating concrete pavement joint durability, despite the abundance of research on the mechanism of this damage. This thesis provides a new proposed test method - comprised of three proposed evaluation techniques - that can be used in the development of a standard test method for evaluating PCC pavement joint durability. This test method uses procedures that are based on standard testing for salt scaling as well as new procedures and evaluation criteria. The proposed evaluation criteria measure damage in concrete slab samples exposed to lab conditions replicating the environmental conditions that pavements are exposed to.

Some of the cases of early failing PCC pavements appeared to be sound at the surface, but after cores were taken, it was found that deterioration was already beginning below the surface. This deterioration started as cracks around the bottom of the joint, developing upwards, and later stages of deterioration showed surface cracks and spalling around the joint. It was hypothesized that this damage was caused by physical and chemical damage from freeze-thaw cycles of saturated concrete, wetting cycles, the presence of deicing salts, and vehicular loads. 
Two types of damage at concrete pavement joints were observed:

1. Spalling around the joints.

2. Cracking at the base of the saw cut that has moved upwards, which is often not noticeable until there is severe damage.

Based on inspections in the field, the joint sealant was found damaged, and there was often a fair amount of standing water around the joints, even after extended periods without rain (Taylor et al., 2016). As an example, there was still standing water in the joint after two weeks without rain in one case. Past research noted that this damage could occur in both poorly and adequately air entrained concrete pavements (Lee et al., 1998; Zhang, 2013; Taylor et al., 2016; Spragg et al., 2011; Castro et al., 2011).

\subsection{Scope and Objective}

The objective of this research was the development of a new test method to evaluate PCC pavement joint durability. In this test, three evaluation techniques were proposed and used to quantify the damage in concrete slab samples, with the goal of the research being determining the efficacy of these proposed techniques in differentiating between different systems (different mix designs, types of deicing salts, and exposure conditions).

The durability issue has been observed very early in the life cycle of PCC pavements (i.e. after only several years), with cracks starting to form from the bottom of the joint and propagating upwards, resulting in spalling. Other observations include recessed paste inside the joints, infilled material (such as ettringite) inside the air voids of damaged concrete, sealants not being intact, and poor permeability below the surface of the pavement. 
Three evaluation techniques were proposed for evaluating the durability of PCC pavements: strength loss, visual inspection (visual index), and mass loss. The strength loss was measured by centre-point loading the weakened slab samples and comparing the strengths of slabs. It was not meant to replicate a real PCC pavement failure, but rather, it was meant to evaluate if cyclical exposure to salt solutions and freezing/ thawing/ wetting had weakened the concrete. That is to say, the strength loss test was only to be used as a measure of strength loss from exposure to deicing salts and different temperature cycles.

The proposed visual inspection and visual index evaluation techniques were similar to other visual inspection methods ( $\mathrm{ACl}$ Committee 201, 2008) and other standards that make use of visual indices (ASTM C672, 2012). A visual index was created for both the surface of the slabs and the inside of the joint. The inside of the joint can be viewed easily after having been loaded to failure from the proposed strength loss evaluation technique (mid-point loading of inverted slabs).

The mass loss procedure was simply a measure of the material that had scaled/ spalled off the concrete samples, which was a similar procedure to the standard test for salt scaling (ASTM C1645-16, 2016).

\subsection{Organization of Thesis}

The organization of this thesis is divided into five chapters as follows:

Chapter 1 provides the problem definition, scope of the research, objective of the research, and organization of the thesis. 
Chapter 2 gives background information on PCC pavement durability and early PCC pavement deterioration, case studies, and research related to the proposed testing.

Chapter 3 covers the experimental design, including:

- Section 3.1, the preparation of the samples used in the study, including the procedure for the compressive strength and air voids tests.

- Section 3.2, sample exposure conditions meant to accelerate the deterioration: a description of the 50 cycles that all slab samples undergo in this research (freeze-thaw and/or wetting), and salt solutions used.

- Section 3.3, the three proposed evaluation techniques: strength loss, mass loss, and visual inspection.

- Section 3.4, the use of scanning electron microscopy (SEM), including sample preparation for SEM and testing.

- Section 3.5, expansion of prisms soaked in salt solution: the casting of the prisms, preparation, and measuring of the cylinders.

Chapter 4 provides results and analysis for each of the performed experiments, including the three proposed evaluation techniques (strength loss, mass loss, and visual index).

- The consistency of different batches of concrete are examined using the compressive strength and air content.

- The relative strength loss of samples is examined for different mix designs, salt solutions, and exposure conditions. 
- Visual observations are noted, along with the establishment of a visual index for rating the surface and insides of joints.

- Mass loss per area values of samples with different exposure conditions are presented and discussed.

- The effects of different salts on expansion of concrete are presented and discussed The expansion data of prisms exposed to different salt solutions is given.

Chapter 5 is an overall summary with recommendations, limitations of the research, and conclusions. 


\section{Chapter 2: Literature Review}

\subsection{Background Information}

Premature concrete pavement deterioration, especially around the joints, has been observed not only in Ontario, but in several northern states in the USA as well. The damage seen around concrete pavement joints includes cracks, spalling, faulting, ravelling, cracks around the aggregate/ interfacial transition zone, and damage around the joint seal (Jain, 2004; Van Dam et al., 2005; Zhang, 2013). This damage can be physical, such as freeze-thaw damage of saturated concrete, or chemical interactions, such as paste deterioration, or formation of expansive products like calcium oxychloride (Taylor et al., 2016). Zhang et al. (2015) found that subsurface permeability also played an important role in concrete pavement joint deterioration: in the presence of freezing and thawing, poor subsurface permeability led to joints becoming damaged quickly. In the study, the distressed concrete cores were found to have higher water-cement ratios than the undamaged cores.

Past research (Zhang, 2013; Taylor et al., 2016; Spragg et al., 2011; Castro et al., 2011) has examined how this damage can be reduced, and suggestions include a low w/c ratio, using supplementary cementing materials, having an adequate air entrainment, having cements with a high Calcium to Silica ratio in cements that are susceptible to oxychloride formation, good drainage at all points of the pavement to ensure that the joints stay dry, penetrating sealants that will slow the ingress of salts, water, and other compounds from entering the concrete microstructure, limiting how often salt is applied to the roads, and having an appropriate mix design. Zhang and Taylor (2012) suggested that freezing and thawing may weaken a concrete 
pavement by damaging the susceptible interfacial transition zone up until the point of vehicular loading having high enough stress to remove the aggregate, exposing another weaker area of concrete, where the cycle can continue. The interfacial transition zone is considered more susceptible to damage than the rest of the concrete because it is more permeable than the rest of the paste (Cwirzen \& Penttala 2005). Wang et al. (2018) write that ion transfer and paste expansion around the ITZ are large contributors to the damage seen in premature concrete joint failure.

Spalling has been observed when one or more of the following have been present: bad consolidation, permeable concrete with a low resistance to freezing and thawing, weak material used at the pavement joints, and improper finishing. Spalling has also been seen when water has accumulated in the joint and freeze-thaw cycles have taken place (Del Mar Arribas-Colón et al., 2012).

\subsection{Case Studies of Concrete Pavements Damaged Early in their Life Cycles}

\subsubsection{Eau Claire, Wisconsin}

This is a case study from Taylor et al. (2012). Two streets were built in 1997 by different contractors. One was experiencing significant deterioration and the other was not. Cores were taken from the centre of the slabs and at the joints. Concrete cores from the centre of the slabs seemed fine in both the well and poor performing roads. The poor performing road appeared to have chemical damage from the core taken at the joint, and both cores at the joint had ettringite present in the air voids. Cracks were observed in the interfacial transition zone of the damaged core. 


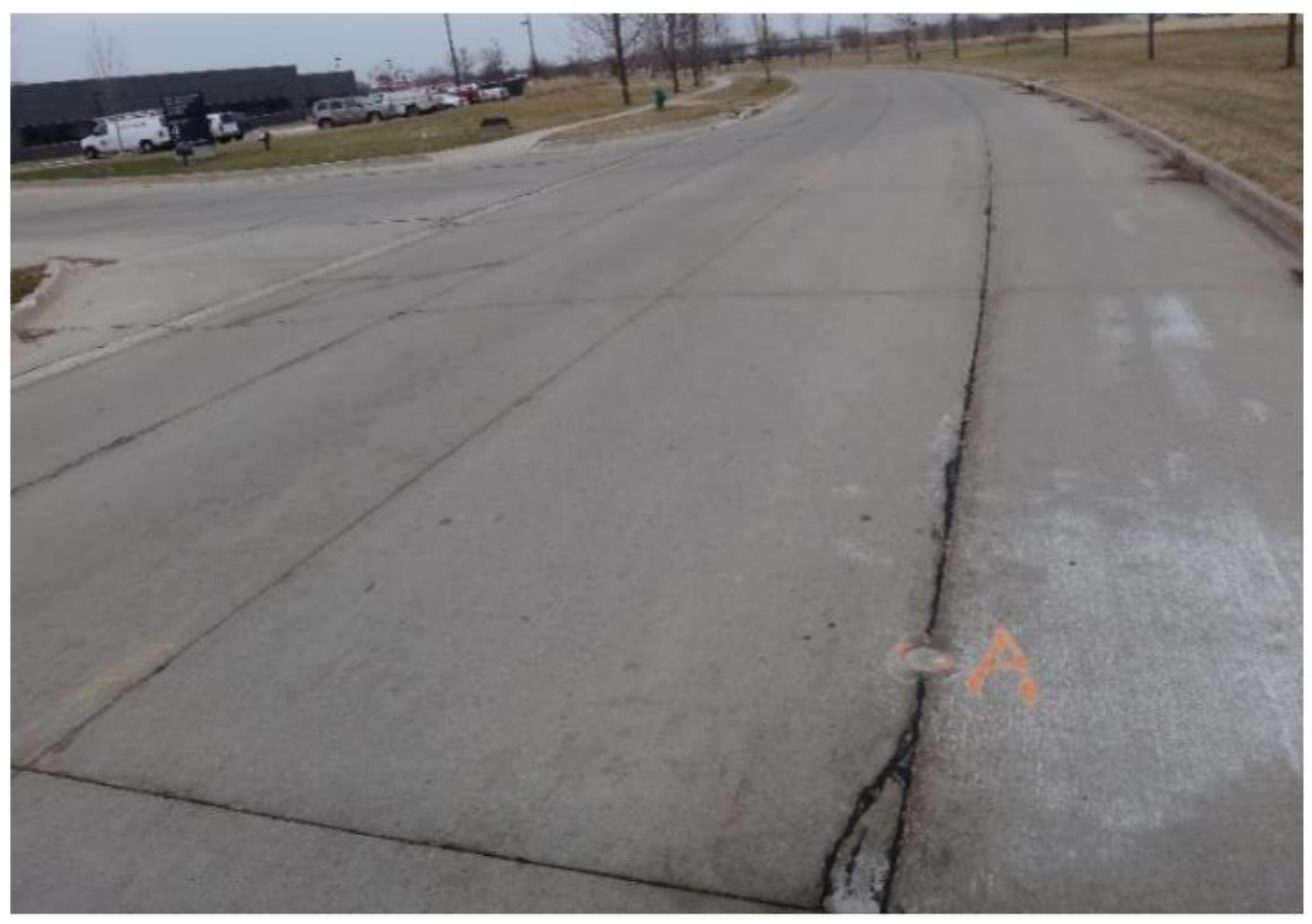

Figure 2-1 A concrete pavement distressed early in its life cycle (Taylor et al., 2012).

\subsubsection{Ames, lowa}

This is a case study from Taylor et al. (2012). Deterioration was seen in a two-lane concrete road paved in 1997, thirteen years after it had been paved. Core samples were taken at damaged and undamaged joints, and the air content was found to be adequate in both cases, although the water-cement ratio was found to be higher around the joint. In the cores from the damaged joint, ettringite was seen in the air voids. After wetting, it was found that the pavement around the joint would stay wet for longer, with Zhang (2013) suggesting that this was likely due to the presence of salt slowing the rate of evaporation. Zhang (2013) also found from later investigations that the permeability of the base layer below the concrete had a very low 
permeability, and that it was extremely low in freezing temperatures. It was hypothesized that because only a small portion of the road was damaged, but the rest was in a fine condition, that this poor concrete was because of an issue with batching concrete.

\subsubsection{Meeker County, Minnesota}

This is a case study from Zhang (2013). Two cores were taken, one from a joint that was distressed, and one from a sound joint. The difference between these two joints was that the sealant used was completely intact in the sound core, and the sealant had debonded in the distressed core. This case highlights the importance of the sealant staying intact to prevent water from entering the joint and damaging it. The water-cement ratio was also found to be higher in the core taken from the distressed joint.

\subsubsection{Indiana Concrete Pavements}

Del Mar Arribas-Colón et al. (2012) note several similar cases in Indiana concrete pavements, where a total of 36 cores were taken from four different locations, with cores taken from distressed and sound areas, and from both longitudinal joints (where more damage was seen) and transverse joints (where some damage was seen). Upon analysis, the cores taken from the centre of the slabs had much better quality concrete: they had an adequate air void system, lower absorption, better resistance to freezing and thawing, and more empty air voids. On the other hand, the cores taken from the damaged areas had many air voids filled with ettringite, Friedel's salt, or both, microcracks, and high rates of absorption. The cores taken from the undamaged joints had better quality air entrainment than the cores from the damaged joints, but they still had higher absorption than cores taken from the centre of the slabs. 

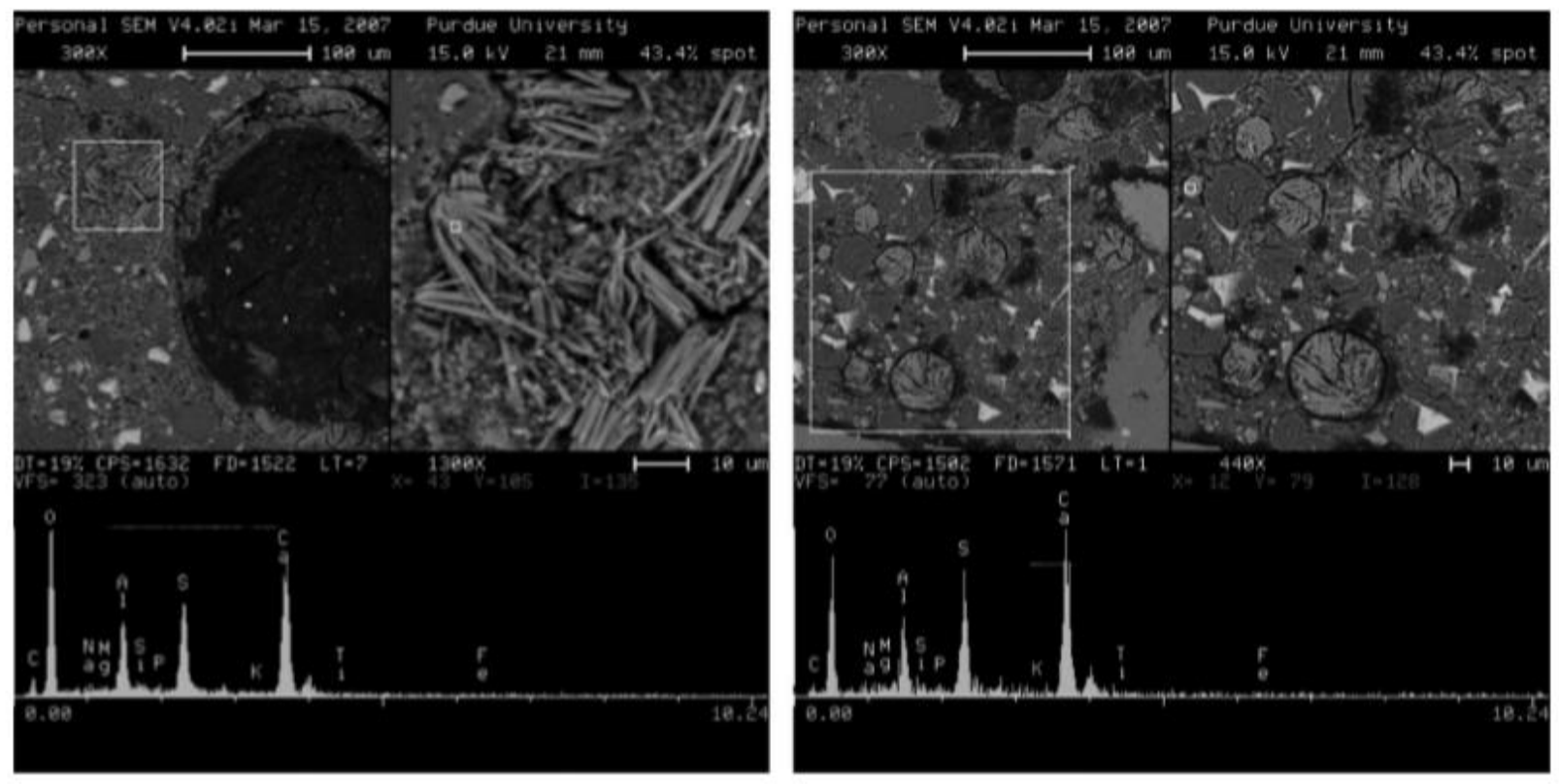

Figure 2-2 Scanning Electron Microscopy image of damaged concrete core from a longitudinal joint with ettringite filling in the air void (left) and several air voids filled with ettringite (right), (del Mar Arribas- Colon, 2008)

Zhang (2013) and Taylor et al. (2012) stated that since saturation of the joints seems to be essential to their performance, it is of utmost importance to limit the permeability of the paste by taking measures such as using a low water-cement ratio and using supplementary cementing materials.

In the case of Trunk Highway 169 in Minnesota, premature deterioration (severe cracking and spalling at the concrete surface) was found to be due to inadequate air content after cores were taken. After investigation, it was found that the air content was inadequate at the surface because of improper vibration during construction - this was one example that highlighted a case where proper construction techniques could have prevented premature concrete pavement deterioration. 
Marks and Dubberke (1996) reported that although many lowa pavements have had a long service life (50+ years) without having had experienced any significant deterioration, they have experienced their share of some pavements with early deterioration, and they have overcome some of these problems. In the later 1950 s, some early pavement deterioration was observed to have happened due to D-cracking. Selection of only aggregates that are not susceptible to Dcracking had solved this problem. However, pavement deterioration was seen again in the 1990s in lowa, and upon investigation of cores, it was found that there was (what was assumed to be) ettringite in the air voids.

\subsection{Freeze-thaw and wet-dry damage with salt exposure}

Freeze-thaw cycles with salt solution can also cause damage in concrete, which can be physical or chemical, and negatively affect the air-void system, surface scaling, and strength. The highest scaling damage with sodium chloride and calcium chloride are observed at concentrations of 24\% (Verbek \& Kleiger, 1957; Marchand et al., 1999), with higher and lower concentrations causing less damage. Concrete slabs undergoing freeze-thaw cycles experience the most scaling damage at this salt concentration, and less scaling damage at higher and lower salt concentrations. Gulati \& Hagy (1982) explain that the cause of scaling damage is because the salt solution that freezes over the concrete sticks to it, and the differential thermal expansion between the two materials causes stresses to increase and pieces of concrete to scale off. 


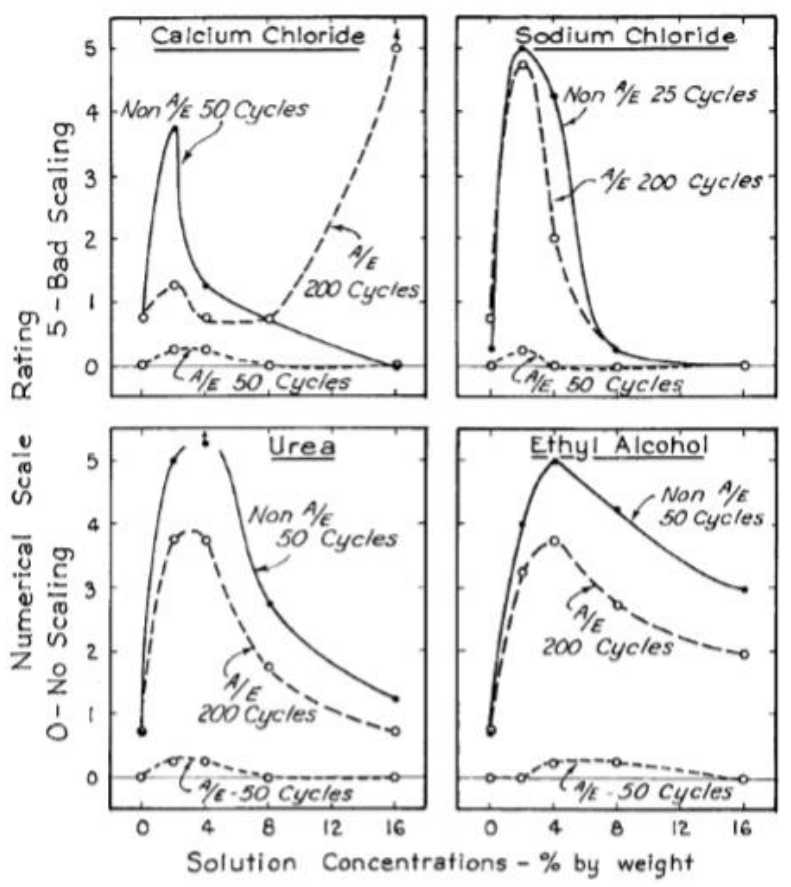

Figure 2-3 Damage from scaling of different solutions and different concentrations on air-entrained and non air-entrained concrete (Verbeck \& Klieger, 1957)

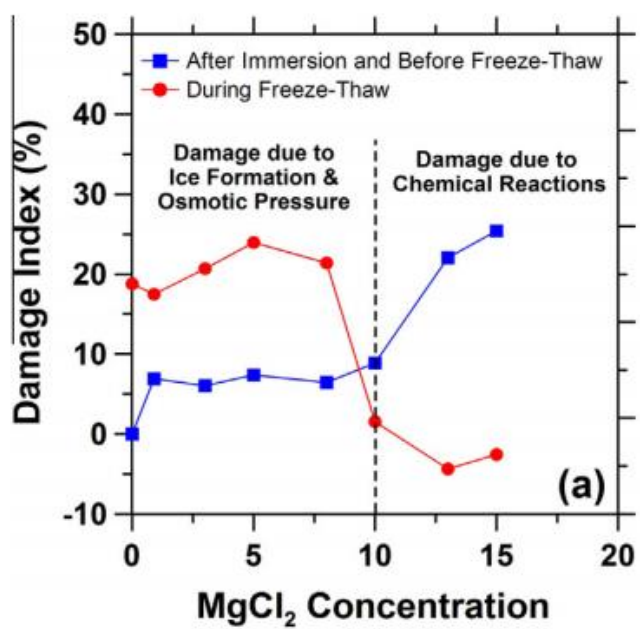

(\% by mass)

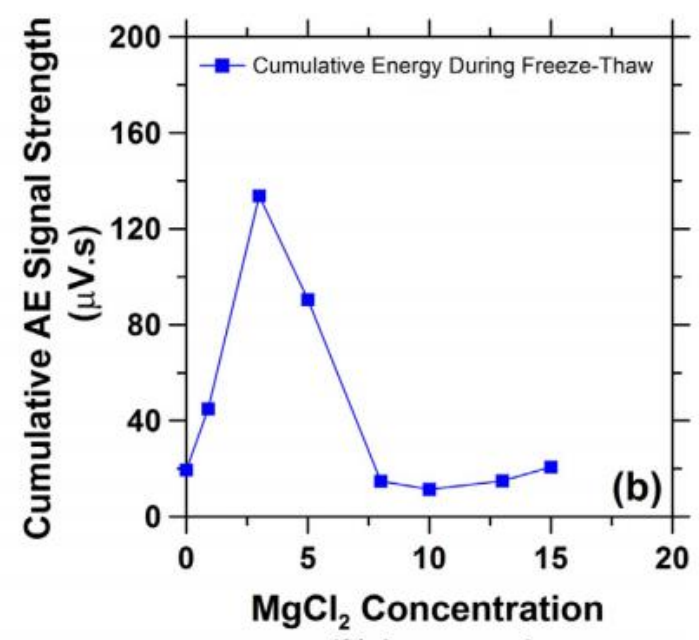

(\% by mass)

Figure 2-4 Levels of physical and chemical deterioration recorded from different magnesium chloride concentrations (Farnam et al., 2015) 
Not only does salt cause scaling damage in concrete, but salt crystallization in supersaturated conditions can damage concrete (Zhang, 2013). Past research (Correns, 1949; Thaulow \& Sahu, 2004) shows that salt crystallization can result in stresses high enough in confined spaces in concrete to create cracks. This is achieved through efflorescence, and has been demonstrated using a supersaturated sodium sulphate solution as an example: sodium sulphate is stable as mirabilite below $32^{\circ} \mathrm{C}$ and stable as thenardite above $32^{\circ} \mathrm{C}$. At $30^{\circ} \mathrm{C}, 40 \mathrm{~g}$ of mirabilite can be soluble in $100 \mathrm{~g}$ of water, but at $10^{\circ} \mathrm{C}$, the solubility is as low as $9 \mathrm{~g}$ per $100 \mathrm{~g}$ of water. If the temperature drops quickly, the stress resulting from the crystallization of the supersaturated solution could reach $16 \mathrm{MPa}$, several times concrete's tensile strength capacity (Thaulow \& Sahu, 2004). Zhang and Taylor (2012) showed that it was more likely for cracks to form around the aggregate (around the ITZ) in concrete samples with a higher water-cement ratio, where more salt accumulated and greater distresses were present.

Cody et al. (1996) have shown that the damage of wet-dry cycles increases with higher salt concentrations, which is important because salt concentrations increase over time with repeated salt solution applications, as is the case with subsequent snowstorms (Darwin, 2008). Tensile stresses may also affect concrete pavements, and other sources of these stresses in concrete include concrete shrinkage, changes in moisture conditions, different temperatures, and traffic loads (Del Mar Arribas-Colón et al., 2012).

Water, which freezes at $0^{\circ} \mathrm{C}$ at zero gauge pressure (Akyurt et al., 2002), has its volume increase by $9 \%$, which causes internal tensile stresses to act on the concrete (Pigeon \& Pleau, 1995). The adequacy of the air void system is also an important factor in concrete's resistance to freezing and thawing; medium sized pores result in concrete with more damage than concrete with small 
or large sized pores because water can enter, but it is difficult for the water to leave through evaporation (Pigeon \& Pleau, 1995).

Not only are the sizes of the pores important, but the spacing between the pores are important as well. Klieger (1978) stated that if two air concrete mixes are of the same air content, that having more air voids that are more closely spaced together would be more effective than having fewer, larger, farther apart spaced air voids. This is illustrated in the figure below. Power (1954) wrote that a spacing factor of less than $0.2 \mathrm{~mm}$ results in effective protection against freeze-thaw cycles.
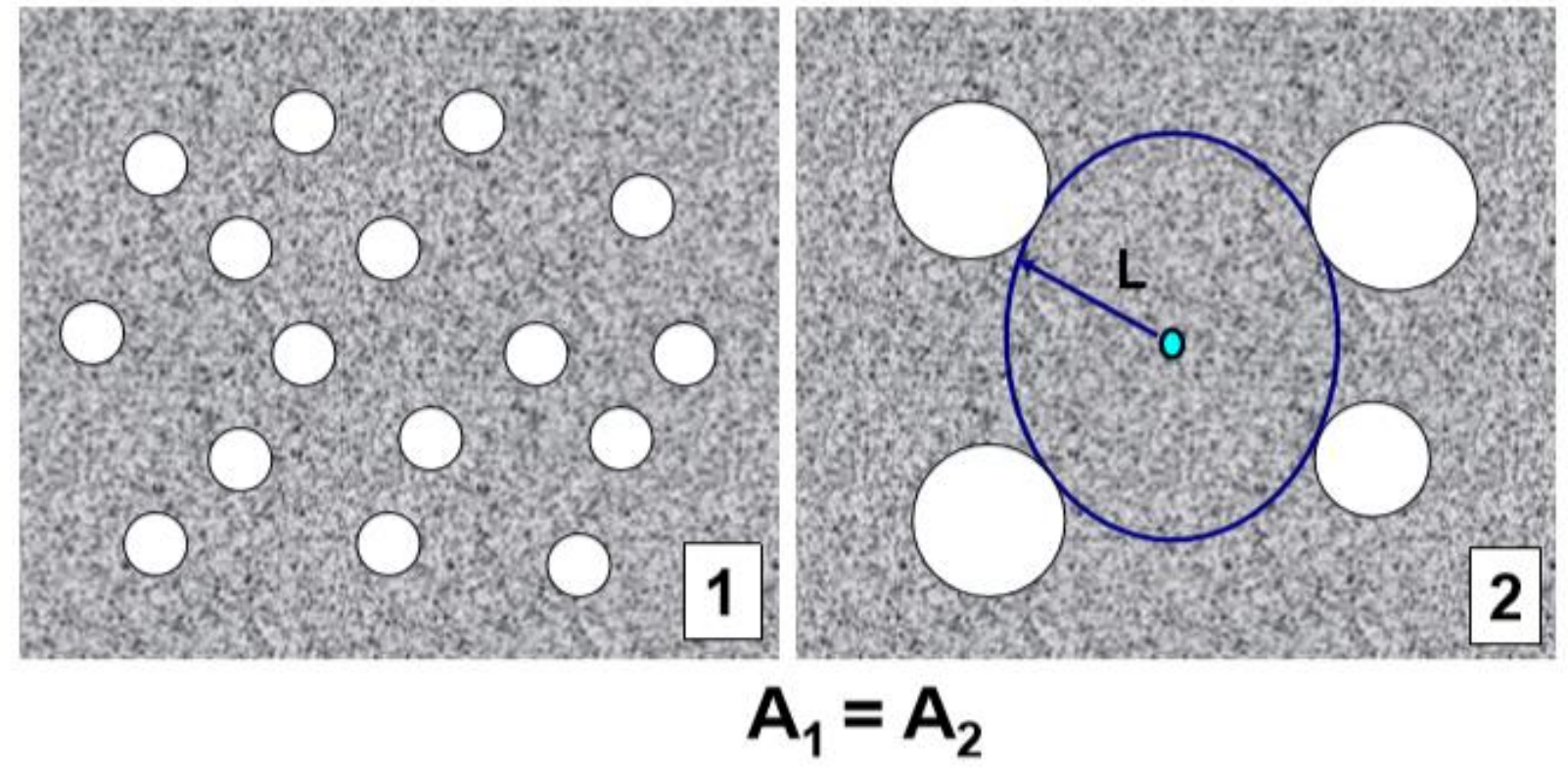

Figure 2-5 Figure illustrating that if two concretes have the same air content but different sized air voids, that the spacing factor would be different. (Klieger, 1978)

Salt scaling by itself may not be detrimental to concrete and cause only surface damage (Zhang, 2013), but as the surface of the concrete scales off, it becomes susceptible to further damage 
because the inner surface of the concrete is exposed, cracks widen, and harmful chemical/ moisture can more easily enter the exposed concrete surface (Valenza and Scherer 2007). A study by the South Dakota Department of Transportation (Sutter et al., 2008) found that there was "significant evidence" that calcium chloride and magnesium chloride chemically reacted with concrete pavements in detrimental ways. Damage included cracking in the pavement, higher permeability, and decreased compressive strength. They found that sodium chloride is the fastest to penetrate through concrete, which can lead to steel reinforcement corrosion. The formation of expansive oxychlorides and dissolution of hardened cement paste is to blame in general for the damage. Supplementary cementing materials such as slag and fly ash were found to reduce this damage.

Cody et al (1996), Taylor (1997), Lee et al. (2000), and Sutter et al. (2006) have shown that there are chemical effects of deicers on hardened cement paste. Lee et al. (1998) found that the chloride in deicers was particularly harmful to concrete because it encourages decalcification of concrete and transforming ettringite into chloroaluminate. Magnesium chloride has the property of converting calcium silicate hydrate to magnesium silicate hydrate, which is a non-cementitious material.

Research (Betancourt, 2009; Darwin, 2007) has shown that the damage in concrete exposed to deicing salts to be much more severe with calcium chloride and magnesium chloride compared to sodium chloride (which is to be expected after examining the equations of products formed from concrete and different salts). Concrete undergoing freeze-thaw cycles and exposed to calcium chloride and magnesium chloride experienced both physical damage (crystal formation in pores) and chemical damage, lower durability, and significantly weaker concrete (Darwin, 
2007). Sodium chloride was shown to have the least harmful short-term and long-term effects. As for the concentrations, Darwin (2007) showed that at low concentrations, calcium chloride and sodium chloride were less impactful, and magnesium chloride caused notable damage. At higher concentrations, sodium chloride had a greater effect, but still did relatively little damage. As for calcium chloride and magnesium chloride, they caused significant damage regarding material loss, material stiffness, and strength.

$\mathrm{NaCl}$ can react with calcium hydroxide in the concrete as follows (Sutter et al., 2008):

$$
2 \mathrm{NaCl}+\mathrm{Ca}(\mathrm{OH})_{2}->\mathrm{CaCl}_{2}+2 \mathrm{Na}(\mathrm{OH}) \quad \text { Equation 2-1 }
$$

The calcium chloride formed in this reaction can further react with the aluminate phases of the cement to form Friedel's salt in the following reaction (Galan et al., 2015; Shi, 2001):

$$
\mathrm{CaCl}_{2}+3 \mathrm{Ca}(\mathrm{OH})_{2}+12 \mathrm{H}_{2} \mathrm{O}=3 \mathrm{Ca}(\mathrm{OH})_{2} \cdot \mathrm{CaCl}_{2} \cdot 12 \mathrm{H}_{2} \mathrm{O} \quad \text { Equation 2-2 }
$$

Qiao et al (2018) suggest that the damage seen from using $\mathrm{NaCl}$ on concrete may be due to the crystallization pressure from Friedel's salt in concrete pores. 


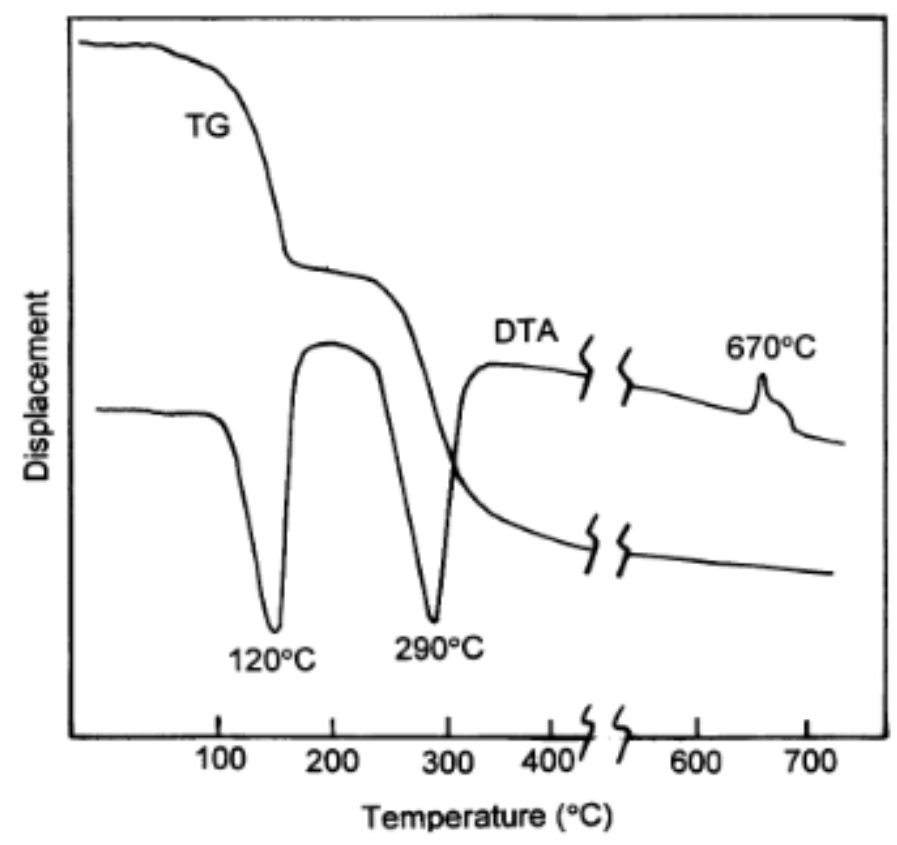

Figure 2-6 TG and DTA curves for Friedel's salt (Birnin-Yauri \& Glasser, 1998).

The formation of Friedel's salt with $\mathrm{NaCl}$ can also be shown by the following equations (Smith et al., 2019):

$$
\begin{array}{ll}
3 \mathrm{CaO} \cdot \mathrm{Al}_{2} \mathrm{O}_{3}+\mathrm{Ca}(\mathrm{OH})_{2}+2 \mathrm{NaCl}+10 \mathrm{H}_{2} \mathrm{O}=\mathrm{Ca}_{4} \mathrm{Al}_{2}(\mathrm{OH})_{12} \mathrm{Cl}_{2} \cdot 4 \mathrm{H}_{2} \mathrm{O}+2 \mathrm{NaOH} & \text { Equation 2-3 } \\
\mathrm{Ca}_{4} \mathrm{Al}_{2}(\mathrm{OH})_{12} \mathrm{SO}_{4} \cdot 6 \mathrm{H} 2 \mathrm{O}+2 \mathrm{NaCl}=\mathrm{Ca}_{4} \mathrm{Al}_{2}(\mathrm{OH})_{12} \mathrm{Cl}_{2} \cdot 4 \mathrm{H}_{2} \mathrm{O}+\mathrm{Na}_{2} \mathrm{SO}_{4}+2 \mathrm{H}_{2} \mathrm{O} \quad \text { Equation 2-4 }
\end{array}
$$




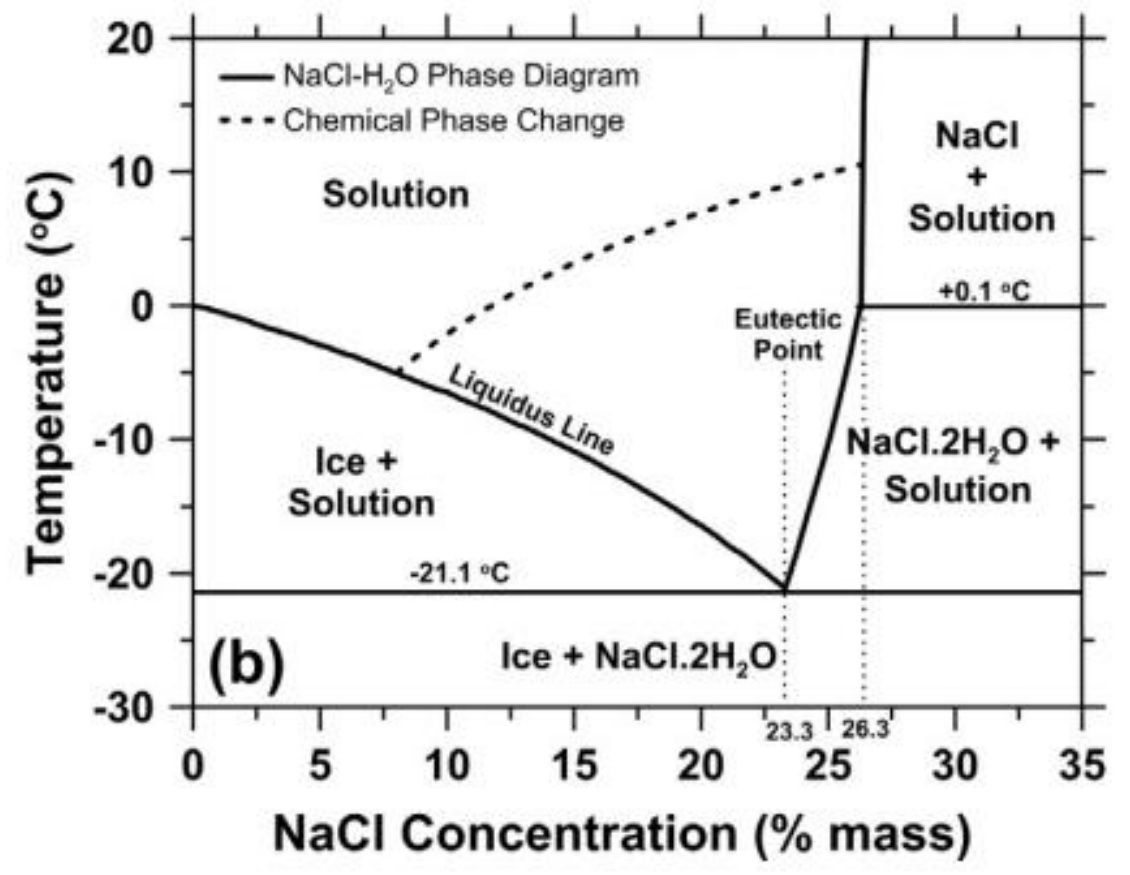

Figure 2-7 Phase diagram of sodium chloride and water (Farnam et al., 2015c).
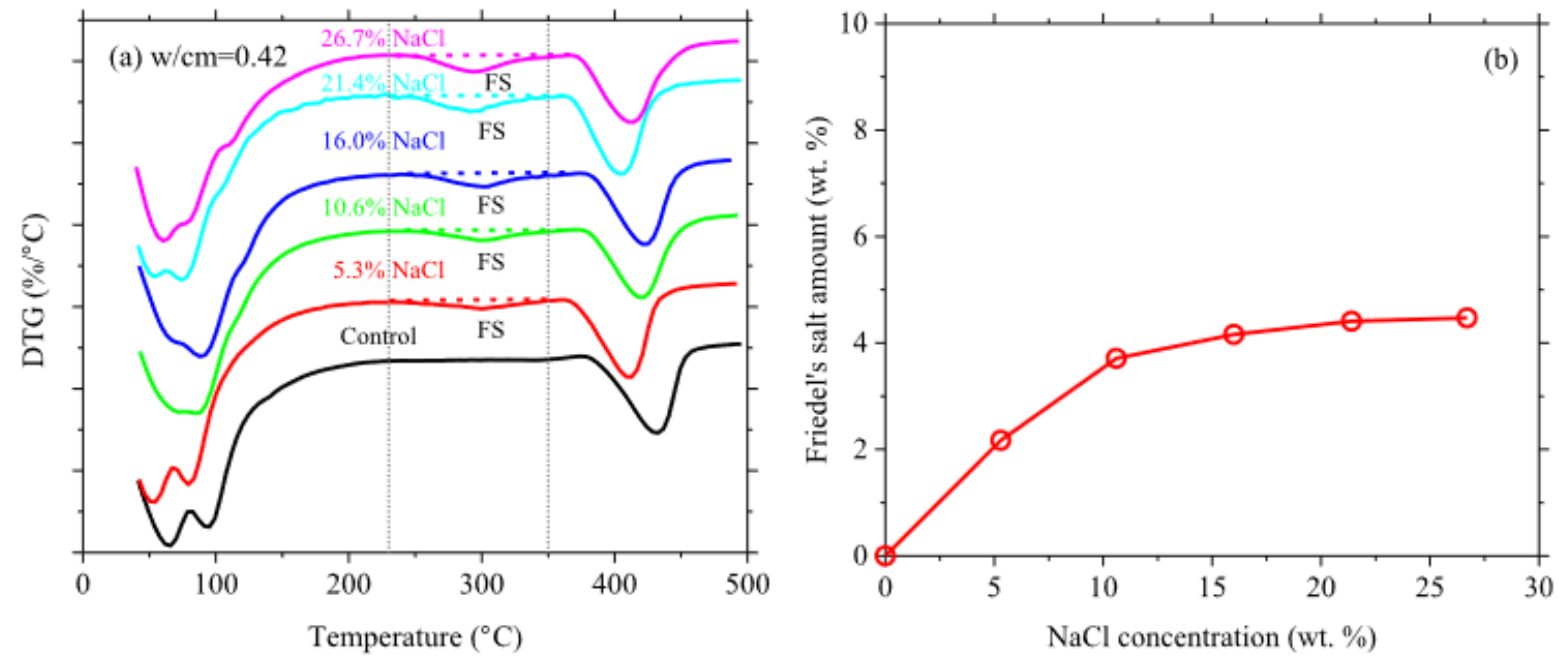

Figure 2-8 (a) DTG curves for cement pastes exposed to different sodium chloride concentrations, and (b) amount of Fridel's salt present given different sodium chloride concentrations (Qiao et al., 2018) 
In past research that examined cored samples from concrete pavements that deteriorated early in their life cycles, it was found that the microstructure of concrete from sections with damaged joints (when compared to non-damaged sections) had air voids filled or partially filled with ettringite ( $3 \mathrm{CaO} \mathrm{Al} \mathrm{O}_{3} 3 \mathrm{CaSO}_{4} 32 \mathrm{H}_{2} \mathrm{O}$ ) or Friedel's salt ( $3 \mathrm{CaO} \mathrm{Al} \mathrm{O}_{3} \mathrm{CaCl}_{2} 10 \mathrm{H}_{2} \mathrm{O}$ ) (Jones et al., 2013). Stark and Bollman (2000) suggested that freeze-thaw cycles with $3 \% \mathrm{NaCl}$ could cause monosulphate to react and form Friedel's salt and ettringite. They also state that ettringite can form with or without deicing salts when freeze-thaw cycles take place. Ettringite that grows in the air voids of concrete may reduce concrete's resistance to freeze-thaw damage by reducing the efficacy of the voids because they are already filled (Diamond, 1996; Ouyang \& Lane, 1999; Stark \& Bollmann, 2000; Del Mar Arribas-Colón et al., 2012). Researchers had thought that ettringite formation caused cracking (Lee et al., 1998), but more recent research (Detwiler \& Powers-Couche, 1999) shows that cracks seem to have formed from freeze-thaw damage, and the ettringite formed in the cracks, rather than having caused the cracks in the first place. Stark and Bollman (2000) also found that the capillary suction of concrete increases with the presence of ettringite in air voids. 


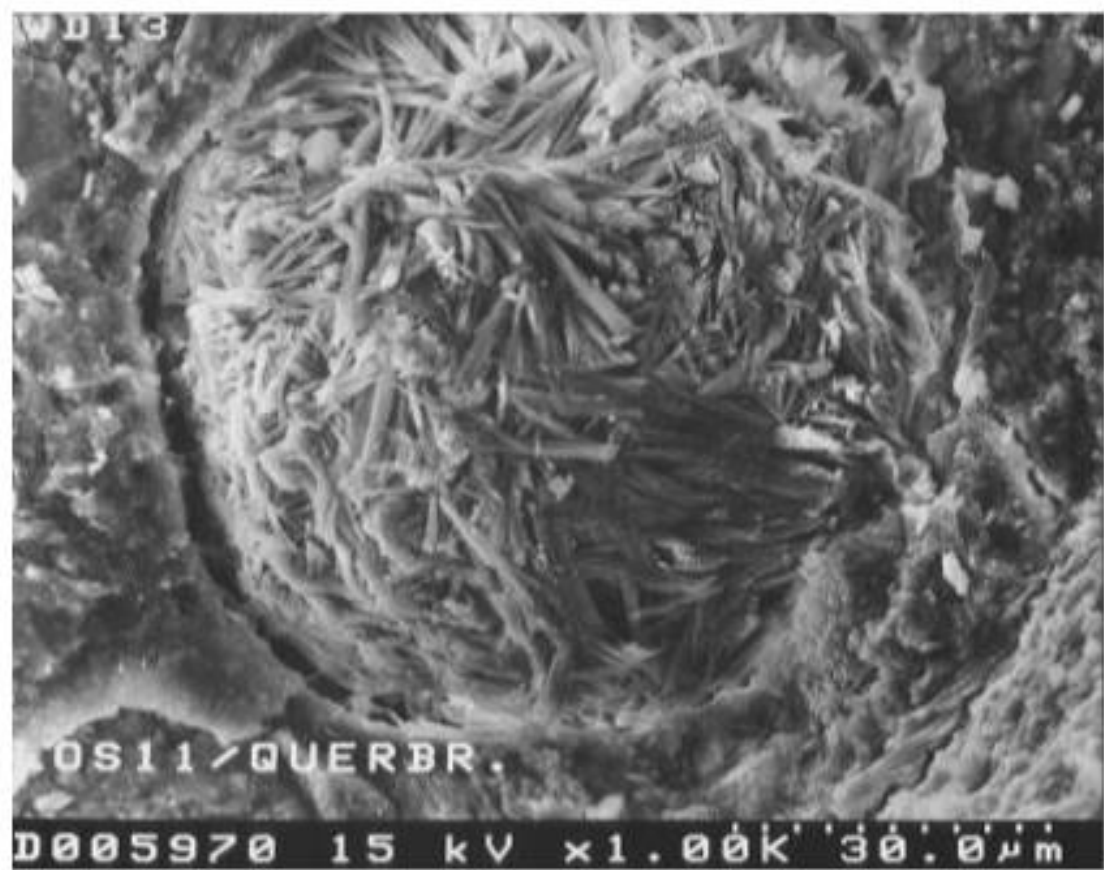

Figure 2-9 An air void in damaged concrete filled with ettringite (Stark \& Bollman, 2000)

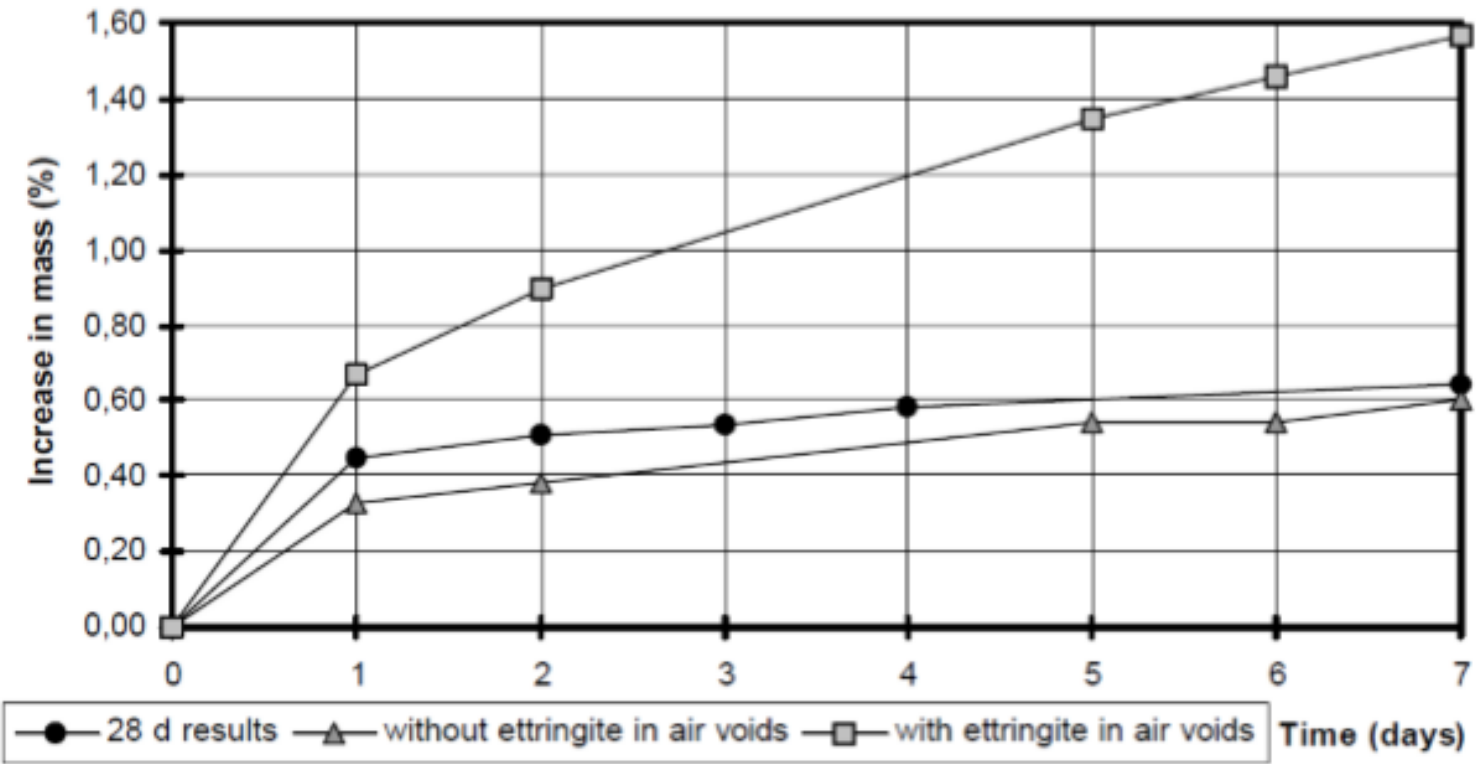

Figure 2-10 Effect of ettringite-filled voids on capillary suction (Stark \& Bollman, 2000) 
The damage in concrete from using $\mathrm{CaCl}_{2}$ as a deicer is from $\mathrm{Ca}(\mathrm{OH})_{2}$ reacting with $\mathrm{CaCl}_{2}$ and $\mathrm{H}_{2} \mathrm{O}$. This reaction forms calcium oxychloride, which causes expansive damage in concrete above freezing temperature. The formation of calcium oxychloride can also limit the amount of fluids that can enter the concrete. It was found that calcium oxychloride forms rapidly at concentrations greater than $11.3 \% \mathrm{CaCl}_{2}$ (Farnam et al., 2015b).

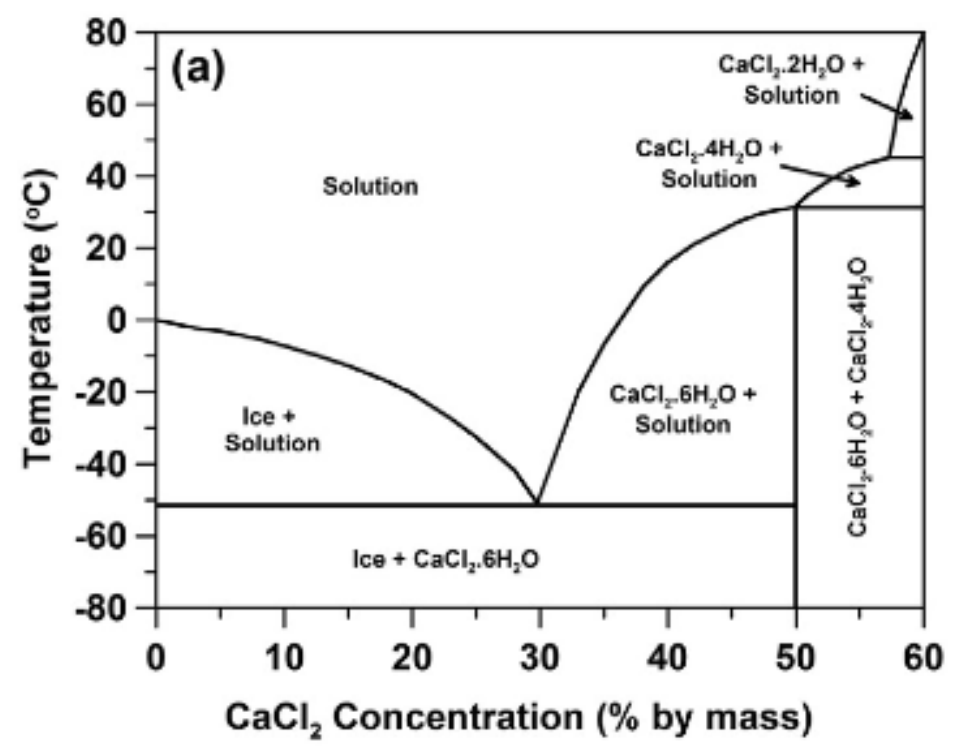

Figure 2-11 Phase diagram for calcium chloride and water (Farnam et al., 2015b)

Collepardi et al. (1994) stated that calcium oxychloride forms in concrete exposed to $\mathrm{CaCl}_{2}$ by reacting with the $\mathrm{Ca}(\mathrm{OH})$ from cement products:

$$
3 \mathrm{Ca}(\mathrm{OH})_{2}+\mathrm{CaCl}_{2}+12 \mathrm{H}_{2} \mathrm{O}->3 \mathrm{CaO} \cdot \mathrm{CaCl}_{2}+15 \mathrm{H}_{2} \mathrm{O}
$$

Equation 2-5

Collepardi et al. (1994) noted that replacing cement with slag (around 50\%) could reduce this damage. Some researchers (Brown et al., 2004) suggest that oxychloride and Friedel's salt cannot both exist at equilibrium. 
Qiao et al. (2018b) write that calcium chloride's reaction with calcium hydroxide to form calcium oxychloride reduces the strength of concrete and causes expansion. The reduction in strength can be mitigating by adding supplementary cementing materials or lowering the water-cement ratio.
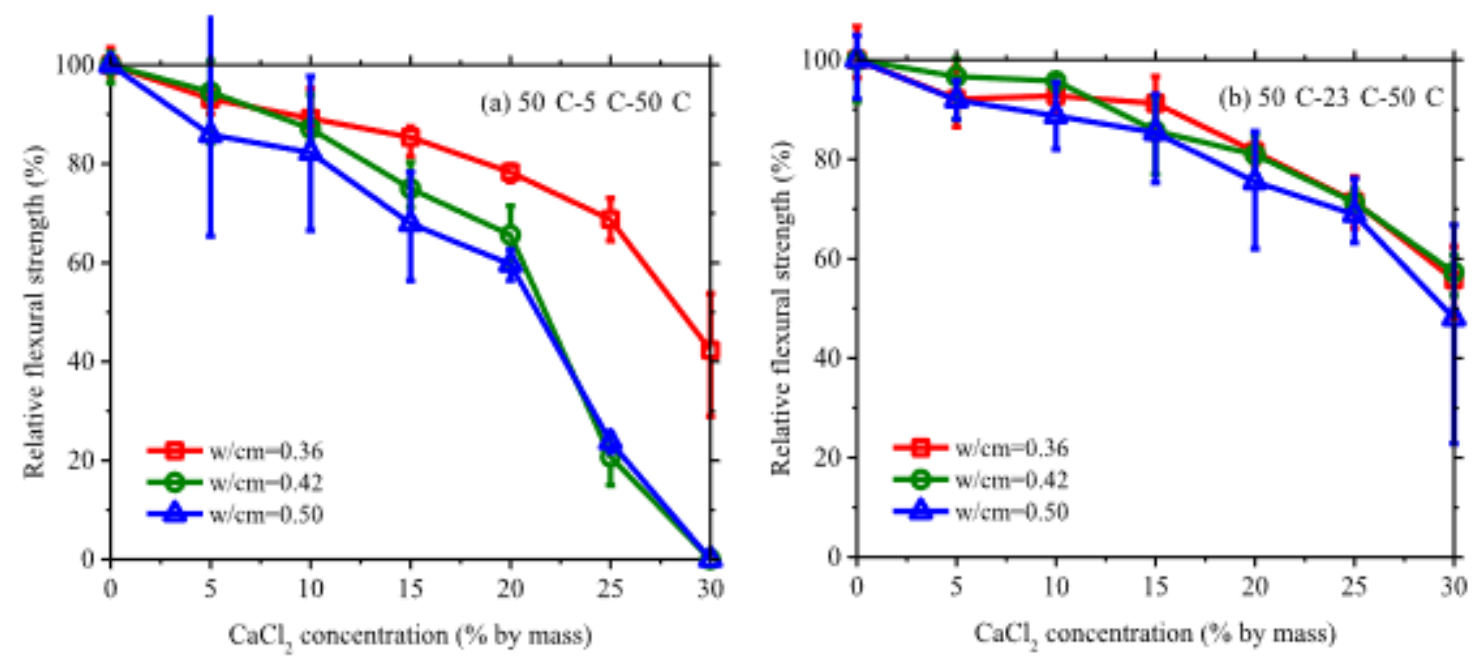

Figure 2-12 Decreases in flexural strength (relative to control) of pastes exposed to different $\mathrm{CaCl}_{2}$ concentrations and different temperatures (Qiao et al., 2018b)

$\mathrm{MgCl}_{2}$ can chemically react with cement to form brucite $\left(\mathrm{Mg}(\mathrm{OH})_{2}\right)$, Friedel's salts, magnesium silicate hydrate, magnesium oxychloride, and secondary calcium oxychloride (Farnam et al., 2015a). The formation of some of these reaction products are considered very harmful to concrete.

Magnesium chloride causing concrete deterioration has been attributed to these reactions (Sutter et al., 2006):

$$
\begin{array}{cc}
\mathrm{Ca}(\mathrm{OH})_{2}+\mathrm{MgCl}_{2}>\mathrm{Mg}(\mathrm{OH})_{2}+\mathrm{CaCl}_{2} & \text { Equation 2-6 } \\
\mathrm{C}-\mathrm{S}-\mathrm{H}+\mathrm{MgCl}_{2}->\mathrm{M}-\mathrm{S}-\mathrm{H}+\mathrm{CaCl}_{2} & \text { Equation 2-7 } \\
3 \mathrm{Ca}(\mathrm{OH})_{2}+\mathrm{CaCl}_{2}+12 \mathrm{H}_{2} \mathrm{O}->3 \mathrm{CaO} \cdot \mathrm{CaCl}_{2} \cdot 15 \mathrm{H}_{2} \mathrm{O} & \text { Equation 2-8 }
\end{array}
$$


The first equation here is detrimental in several ways: portlandite is converted to brucite, $\mathrm{CaCl}_{2}$ is produced (which can react to form calcium oxychloride), and the $\mathrm{pH}$ decreases from about 12.6 to less than 9 (Sutter et al., 2006). The formation of M-S-H from $\mathrm{MgCl}_{2}$ reacting with $\mathrm{C}-\mathrm{S}-\mathrm{H}$ was reported (Lee et al., 1998) to be most harmful to concrete, because M-S-H and brucite are not cementitious materials. $\mathrm{MgCl}_{2}$ lowers the freezing temperature to points lower than what the freezing temperature would be if using other salts such as $\mathrm{NaCl}$ (Farnam et al., 2015a).
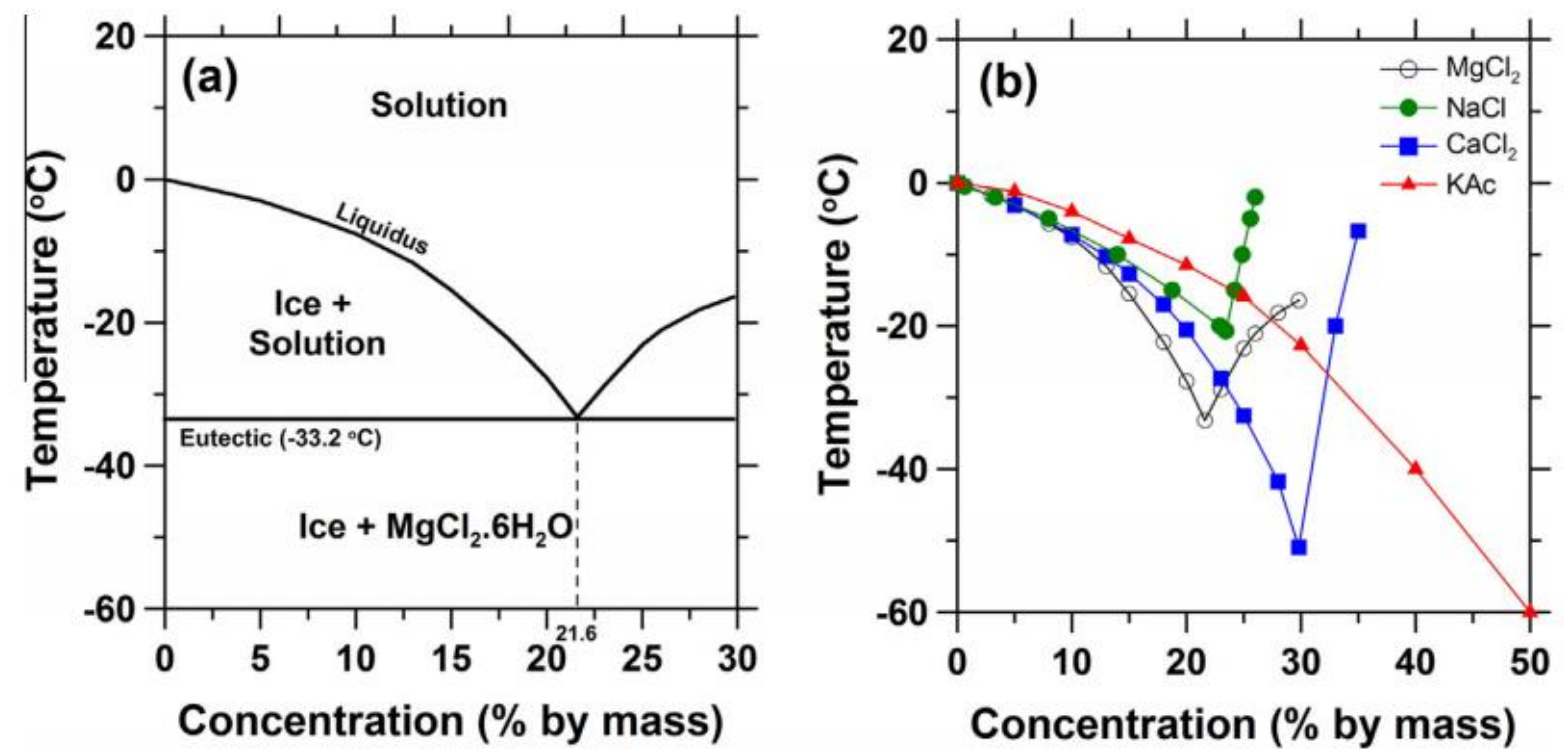

Figure 2-13 Phase diagram of magnesium chloride and freezing temperatures of different salts at different concentrations (Farnam et al., 2015) 


\begin{tabular}{lll|}
\hline$-*-$ Magnesium Chloride & $-\mathrm{O}$ Calcium Chloride \\
$-\square-$ Calcium Magnesium Acetate & $---15^{1 / 4 \mathrm{~F}}$
\end{tabular}

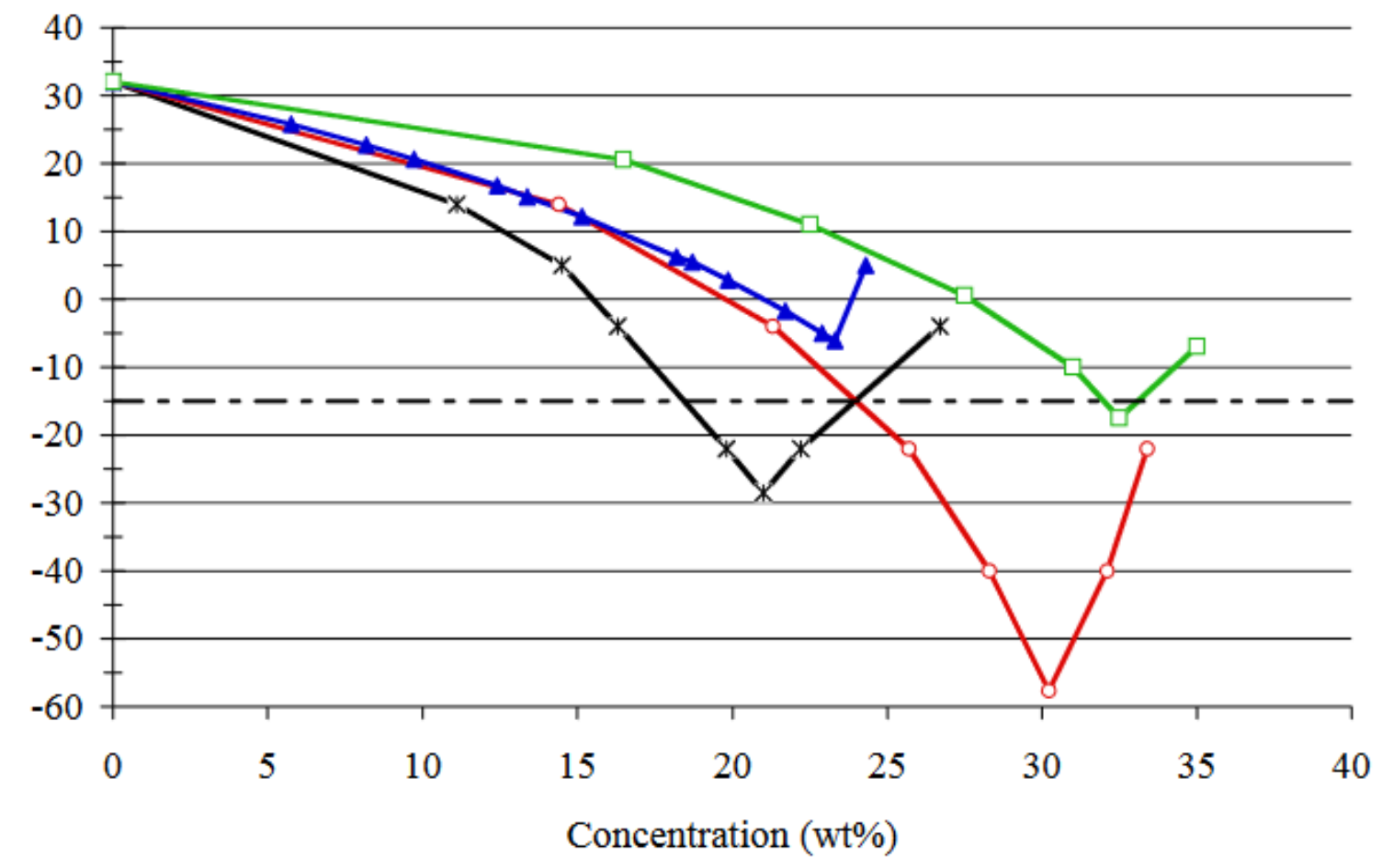

Figure 2-14 Freezing temperatures $\left({ }^{\circ} \mathrm{F}\right)$ of water with salts at different concentrations (Sutter et al., 2008).

Taylor et al. (2012) found evidence suggesting that the damage forming early in deteriorated concrete forms in the interfacial transition zone. The interfacial transition zone is a $10-50 \mu \mathrm{m}$ thick area between aggregate and cement paste in concrete which is more porous because of the discontinuity of homogeneous materials (Cwirzen \& Penttala, 2005). Other research has also suggested that the interfacial transition zone has the highest permeability (Wang \& Ueda, 2011, Winslow \& Liu, 1990), with mercury intrusion porosimetry showing that the pore volume in concrete increases with larger sized aggregate (Mehta, 1986). Mondal et al. (2009) found that the average modulus for the ITZ was about $25-30 \%$ weaker than that of the paste. 
It is important to note that it is not just the weak interfacial transition zone that is responsible for deterioration in concrete from freeze-thaw cycles. D-cracking, the cracking of the aggregate itself, is possible in aggregate that is not durable; aggregate with medium sized pores are least durable, similarly to air entrainment in concrete (Alexander \& Mindess, 2014; Pigeon \& Pleau, 1995; Marks \& Dubberke, 1982).

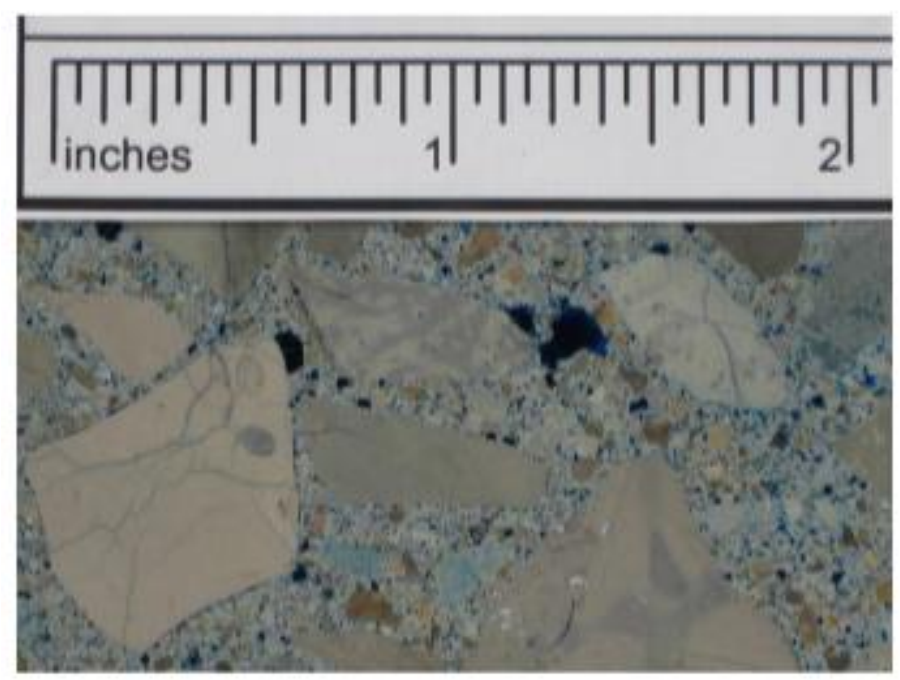

Figure 2-15 Photo of concrete with cracked aggregate caused by D-cracking of susceptible aggregate caused by freeze-thaw cycles (Alexander \& Mindess, 2014)

One test that Taylor et al. (2012) performed included creating half-inch thick slices of concrete with exposed surfaces that were set to soak facedown in a solution: either water, $3 \% \mathrm{NaCl}$, or $3 \%$ $\mathrm{MgCl}_{2}$. All of these tests were performed at a constant $40^{\circ} \mathrm{F}$ (above freezing), and the results were similar to previous tests (Sutter et al., 2008; Farnam et al., 2015): exposure to the $\mathrm{NaCl}$ solution that held above freezing temperatures had negligible damage, and the concrete soaking in the $\mathrm{MgCl}_{2}$ solution had its paste expand and debond from the aggregate. The suggestion given for 
this was the formation of calcium oxychloride (Taylor et al., 2012; Sutter et al., 2008; Farnam et al., 2015a).

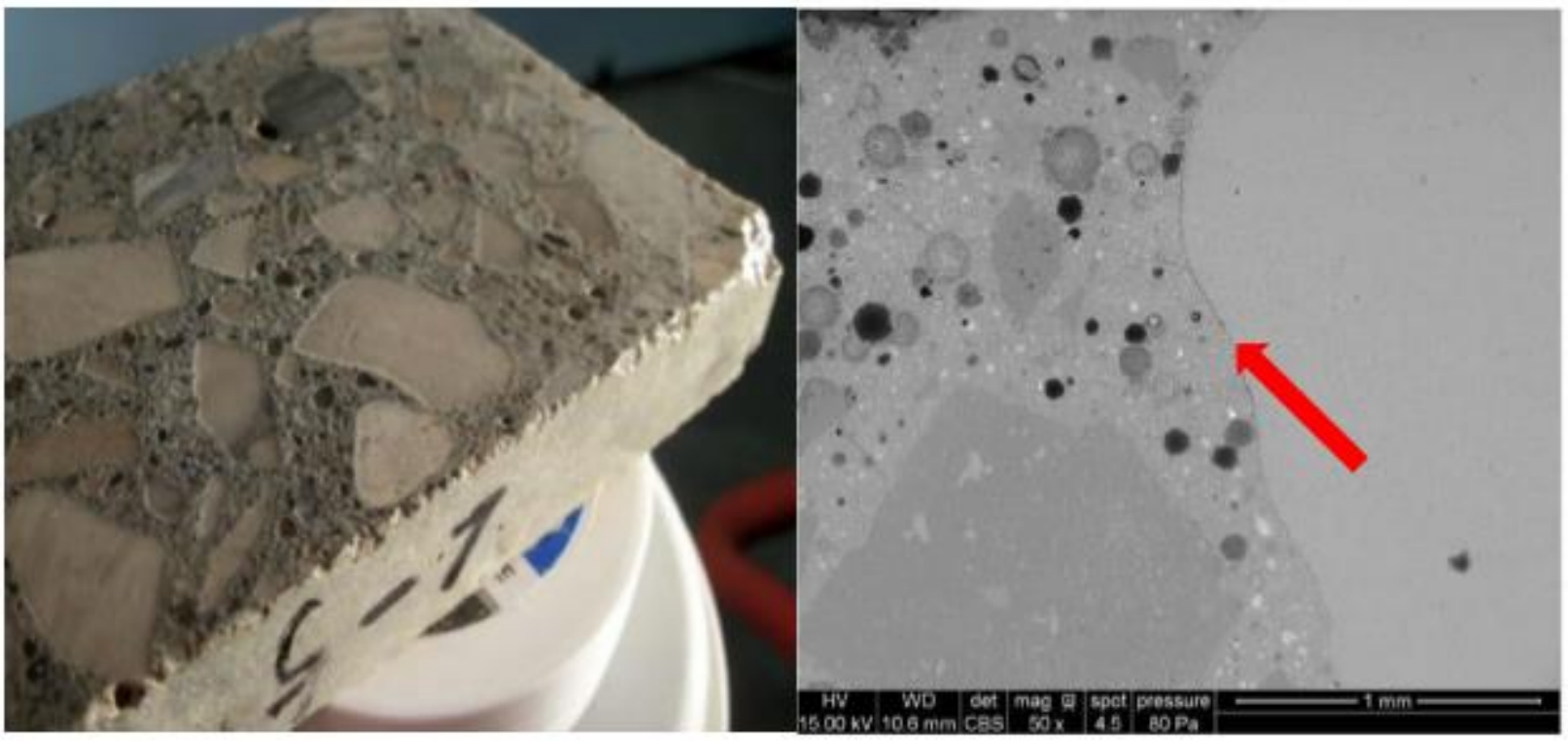

Figure 2-16 Concrete sample soaked in $\mathrm{MgCl}_{2}$ solution for 56 days at $40^{\circ} \mathrm{F}\left(4.4^{\circ} \mathrm{C}\right)$, with $\mathrm{SEM}$ image on the right. The paste expanded and an arrow is pointing to a crack in the SEM image (Taylor et al., 2016)

In past experiments, solutions with lower salt concentrations (less than $10 \% \mathrm{MgCl}_{2}$ ) had physical damage from ice formation (Farnam et al., 2015a). The samples with high concentrations of $\mathrm{MgCl}_{2}$ did not show damage from freeze-thaw cycles, with Farnam et al. (2015a) suggesting that this may be because "a large portion of solution in concrete pores was consumed by the chemical reactions to form magnesium/calcium oxychlorides (solid phases at room temperature, i.e., $\left.23^{\circ} \mathrm{C}\right) . "$ The pores of the sample would stay unsaturated, since the pores would not allow more solution to enter because they were already full. Solutions with higher $\mathrm{MgCl}_{2}$ concentrations (greater than 10\%) had damage from chemical reactions between $\mathrm{MgCl}_{2}$ and the cement at room 
temperature (Farnam, 2015a) In the experiment performed by Sutter et al. (2006), it was found that calcium oxychloride formed after samples were soaked in a $15 \% \mathrm{MgCl}_{2}$ solution for 84 days. A 2013 report by Jones et al. found that concrete's saturation is very important on how much damage will occur from freeze-thaw cycles. Fagerlund (1977) showed that damage can occur after just a single freeze-thaw cycle if the concrete's saturation is above a critical value (around $86-88 \%)$. Li et al. (2012) have found that a saturation value of around $86-88 \%$ is critical and that damage occurs from just a few freeze-thaw cycles regardless of air content; the benefit of air entrainment is that it takes air entrained concrete a longer time to reach these levels of saturation. Likewise, it was shown that there was little damage in concrete below a critical degree of saturation, even with many freeze-thaw cycles. An important fact to mention here is that both $\mathrm{CaCl}_{2}$ and $\mathrm{MgCl}_{2}$ can significantly slow down the rate at which solution evaporates from concrete, keeping the saturation higher (Zhang, 2013).

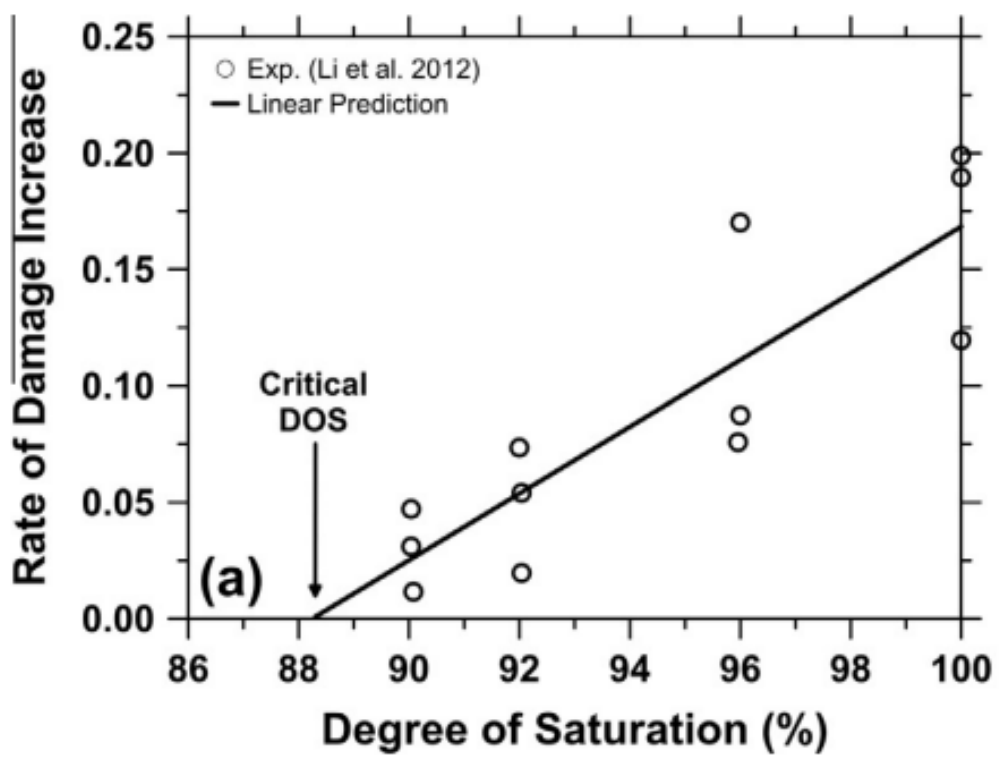

Figure 2-17 The damage increases from freeze-thaw cycles (measured by decrease of dynamic modulus) with higher degree of saturation of concrete (Farnam et al., 2015c) 
The role of saturation is important in the damage that occurs from freeze-thaw cycles, but it was also found that even greater damage occurs in the presence of deicing salts (Jones et al., 2013). This may be because it was seen in research that samples with deicing salts showed higher degrees of saturation than samples without deicing salts at the same relative humidity (Jones et al., 2013). Research (Farnam, 2014; Peterson et al., 2013) has shown that deicing salts can cause damage at pavement joints with just wetting and drying cycles, i.e., without any freeze-thaw cycles.

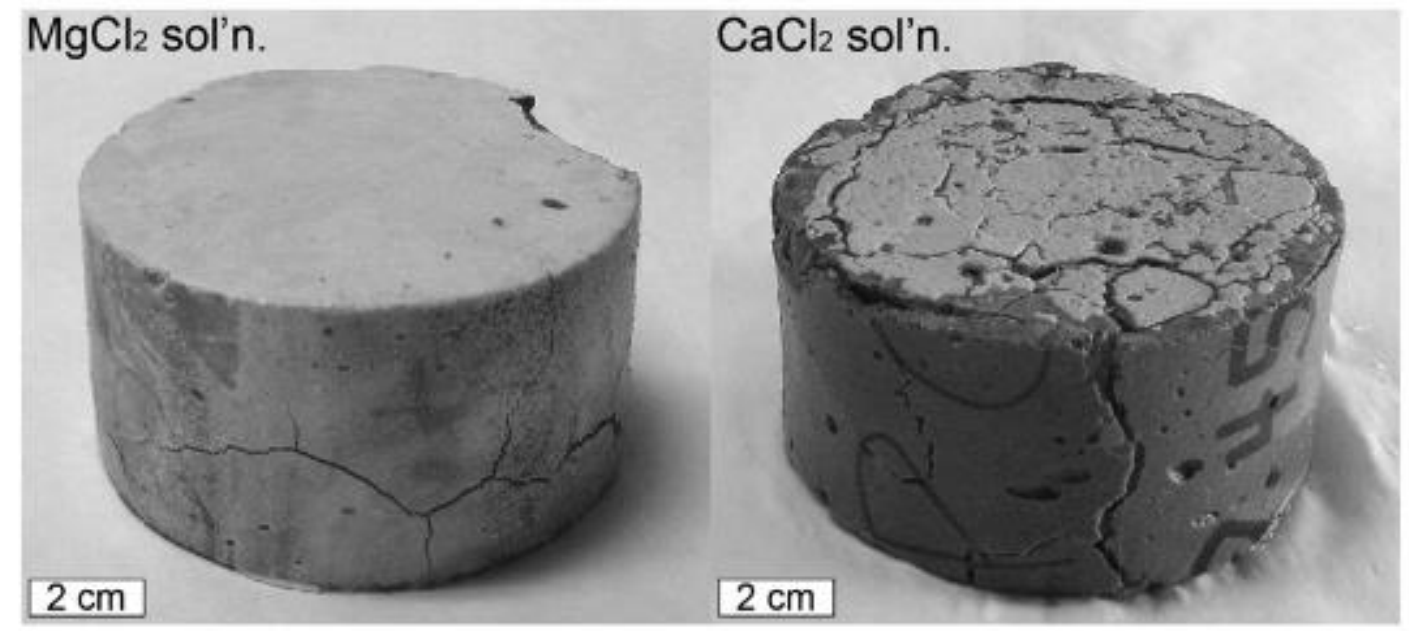

Figure 2-18 Damage in concrete exposed to $15 \% \mathrm{MgCl}_{2}$ and $17 \% \mathrm{CaCl}_{2}$, held at $4.4^{\circ} \mathrm{C}$ for 500 days (Peterson et al., 2013).

Not only is the damage from freeze-thaw cycles important, but wetting-drying cycles can also cause damage. Again, the presence of deicing salts increases the expected damage. The permeability of concrete plays a strong role in the deterioration it will experience from chemical attack (Del Mar Arribas-Colón et al., 2012). Deicing salts are especially problematic because concrete that becomes saturated with fluid containing deicing salts can become more saturated, and they can stay saturated for longer periods of time (Jones et al., 2013). 
Standing water has been found when damaged joints have been inspected through the use of boreholes (which had experienced, deterioration starting at the bottom of the slab, moving upwards, suggesting poor drainage below the slabs), even after extended periods without rain (Taylor et al., 2016). The reason that there was water in the joints was because the sealant had not been a perfect seal and had not prevented water from entering the joint. The sealant may have pulled away from one of the walls of the joints, allowing water to enter. This water present in the joint could increase the saturation around the joint. Also, the water moving down through the concrete to the subbase could increase the saturation around the crack through which it travels. However, in the case that a crack does not form below the saw cut, the location of higher saturation will be pooled around the joint instead, which can lead to increased salt concentration and the harmful effects related to that. These harmful effects include Friedel salt filling air voids,

oxychloride formation, or the calcium in calcium silicate hydrate being chemically replaced to form non-cementitious materials such as magnesium silicate hydrate (Jones et al., 2013). This could explain the case of failure that starts from the bottom of the saw cut, but some research has hypothesized that the failure that occurs at the surface may be from freeze-thaw cycles and/ or salt crystallization (Scherer, 1999).

\subsubsection{Calcium Oxychloride}

Suraneni et al. (2016) examined the potential of calcium oxychloride formation from salt blends, and the correlation between calcium hydroxide available and calcium oxychloride formation. 


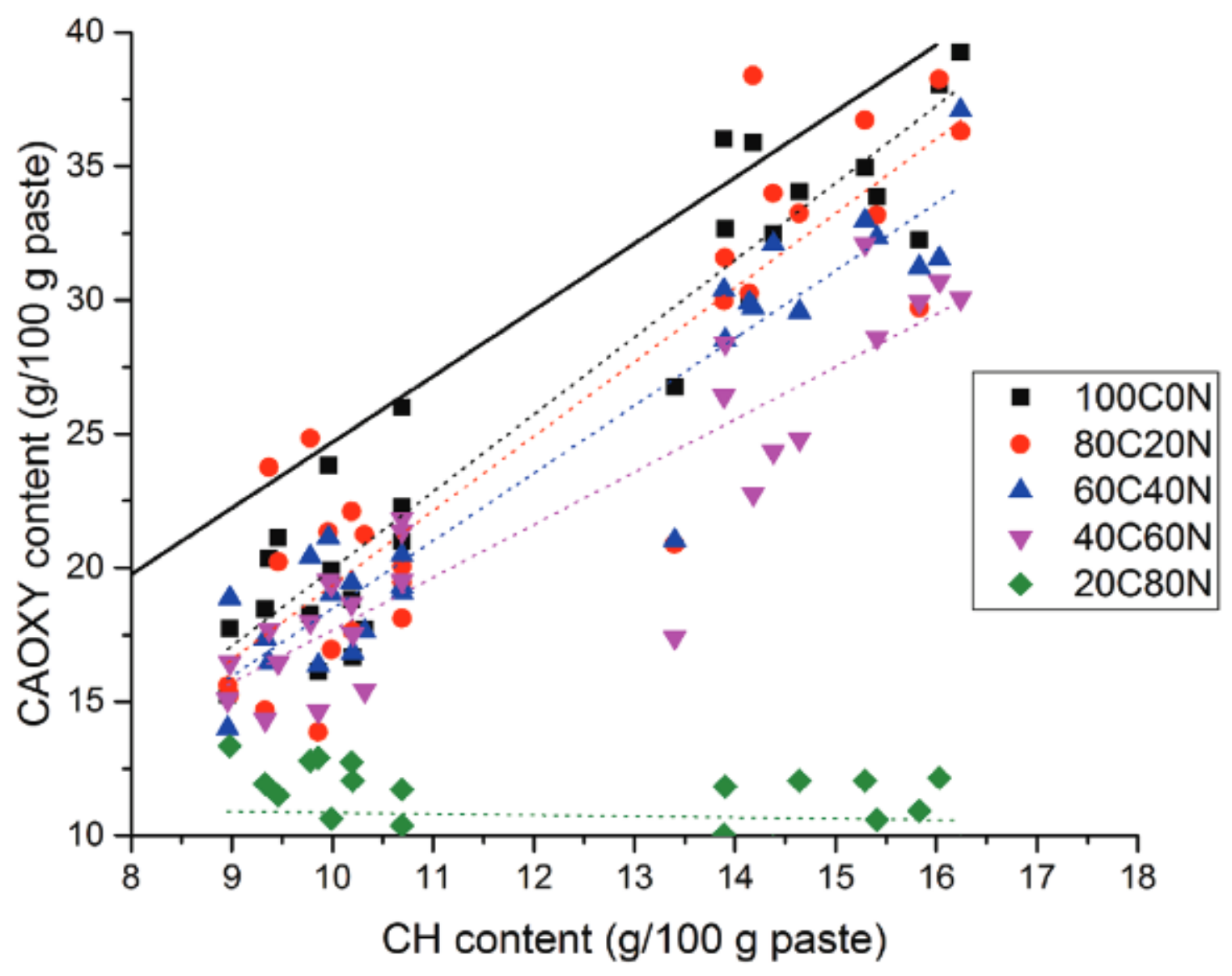

Figure 2-19 Calcium oxychloride formation for different calcium hydroxide contents of cement paste (Suraneni et al., 2016)

In the above figure, calcium oxychloride (referred to as CAOXY on the Y-Axis) formation was compared to calcium hydroxide (labelled as $\mathrm{CH}$ ) content in paste, with different salt blends applied to the concrete. The salt blends were mixes of calcium chloride and sodium chloride. Higher calcium hydroxide availability generally resulted in more calcium oxychloride formation, especially when more calcium chloride was used compared to sodium chloride.

This is further illustrated through the work of Suraneni et al. (2018) who found that the higher the calcium hydroxide content of the paste was, the more calcium oxychloride had formed. 


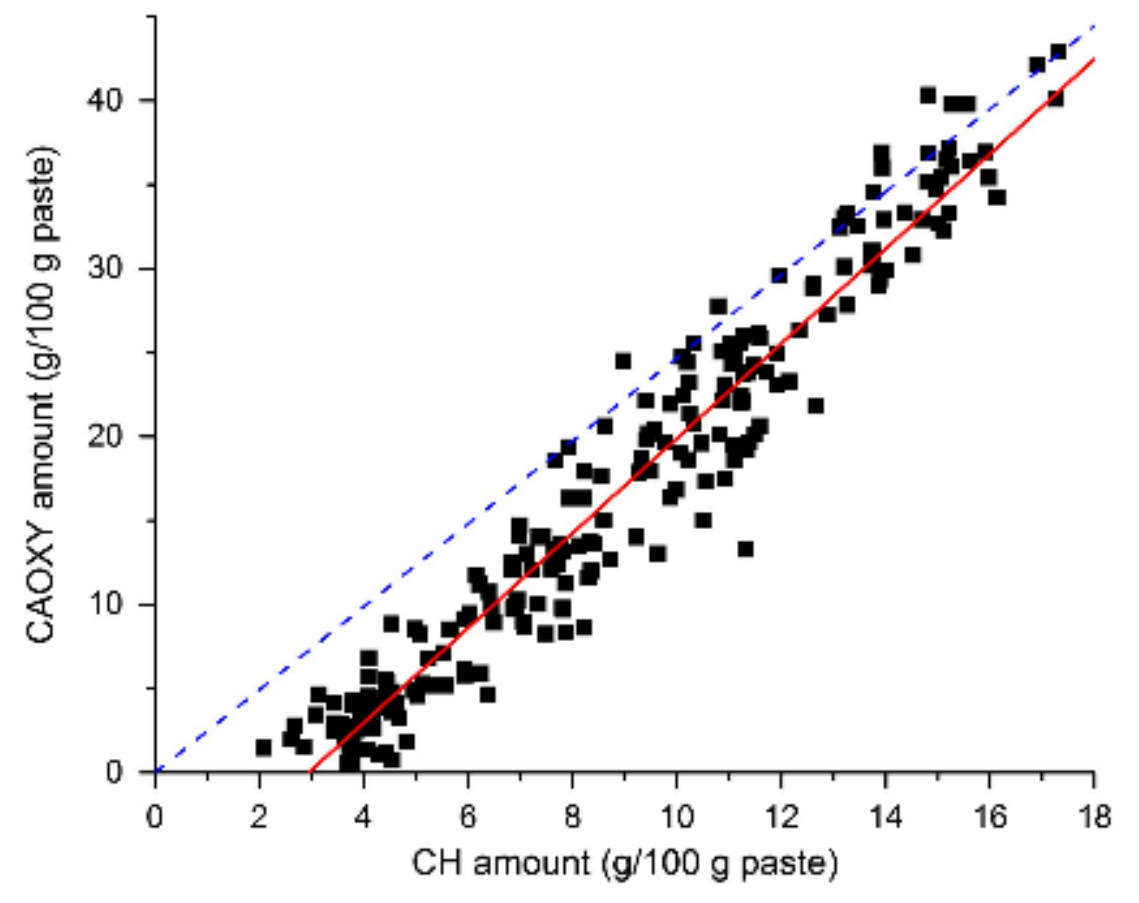

Figure 2-20 Amount of calcium oxychloride present for pastes with differing amounts of calcium hydroxide present (Suraneni et al., 2018).

It has been found that not only freezing, scaling, and salt crystallization have been found to cause damage in concrete; the reaction of calcium hydroxide $(\mathrm{Ca}(\mathrm{OH}))$ in concrete with calcium chloride deicing salts can form calcium oxychloride (Farnam et al., 2015a - the influence of...).

$$
3 \mathrm{Ca}(\mathrm{OH})_{2}+\mathrm{CaCl}_{2}+15 \mathrm{H}_{2} \mathrm{O}=\mathrm{CaCl}_{2} \cdot 3 \mathrm{Ca}(\mathrm{OH})_{2} \cdot 15 \mathrm{H}_{2} \mathrm{O} \text { (calcium oxychloride) Equation 2-9 }
$$

Monical et al. (2016) examined the effects of using supplementary cementing materials on the damage from calcium oxychloride. It was found that diluting the cement by replacing it with SCMs decreased the formation of calcium oxychloride. SCMs like fly ash and silica fume can react with calcium hydroxide, further limiting the formation of calcium oxychloride by reducing the amount of available calcium hydroxide available to react with the calcium chloride salt. Similarly, slag could also decrease the amount of calcium hydroxide available because its alkali activation can 
change the pH (Monical et al., 2016). It was also found that fly ash and slag replacing cement (with concentrations between $1 \%$ and $60 \%$ ) both similarly reduce calcium oxychloride formation, a reduction of $0.0052-0.0056[(\mathrm{~J} /$ g-paste $) /(\mathrm{J} / \mathrm{g}$-oxychloride $)]$. This reduction of calcium oxychloride formation with the presence of SCMs is more effective than simply reducing the total available cement, suggesting that the other mentioned benefits of using SCMs (i.e. less calcium hydroxide is available) are in fact beneficial.

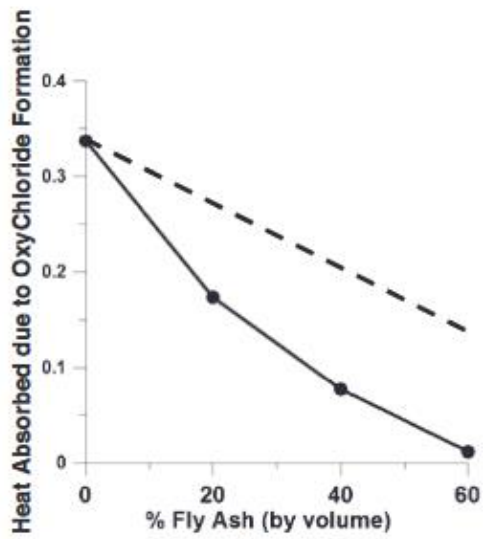

(a)

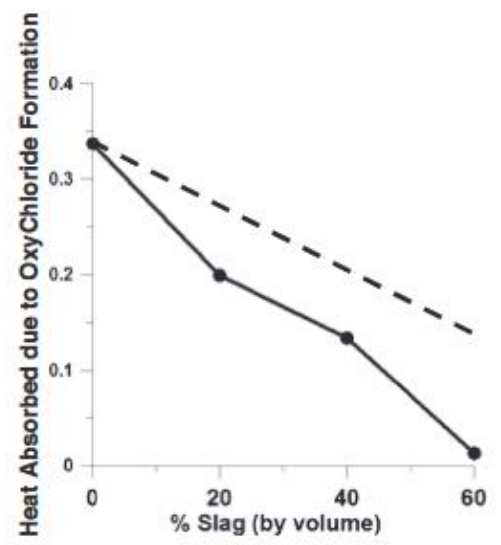

(b)

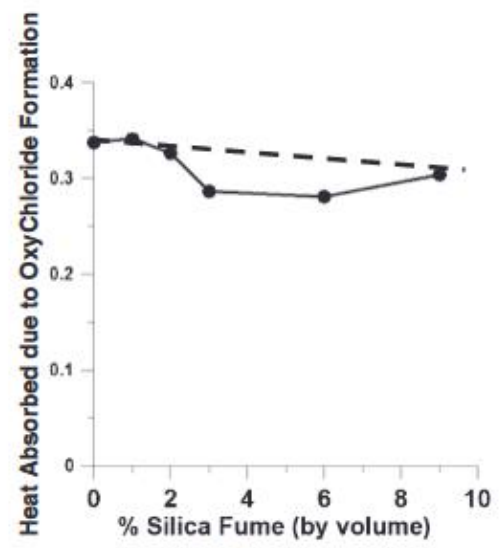

(c)

Figure 2-21 Reduction of calcium oxychloride formation with increasing replacement of cement with SCM (a: fly ash, b: slag, c: silica fume). The dashed line represents the expected drop in calcium oxchloride formation from just dilution of cement, the solid line captures this effect plus the additional reduction of available calcium hydroxide (Monical et al., 2013).

Ghantous et al. (2016) found that carbonation, which also involves a reaction with calcium hydroxide (which is necessary for calcium oxychloride formation), limits the formation of calcium oxychloride. The equation of carbonation is concrete is shown below (Thiery, 2006).

$$
\mathrm{Ca}(\mathrm{OH})_{2}+\mathrm{H}_{2} \mathrm{CO}_{3}=\mathrm{CaCO}_{3}+2 \mathrm{H}_{2} \mathrm{O}
$$


Ghantous et al. (2016) wrote that with higher the degrees of carbonation, less calcium oxychloride would form. However, it was not necessary for complete carbonation to prevent calcium oxychloride formation. It was hypothesized that a carbonized barrier of calcite $\left(\mathrm{CaCO}_{3}\right)$ forms around some available calcium hydroxide, which renders it protected against reaction with deicing salts, stopping the formation of calcium oxychloride. Ghantous et al. (2016) suggests that carbonation treatment around joints may help prevent oxychloride formation and protect these concrete pavement joints that are failing prematurely, pointing to examples where carbonation has been used to treat concrete, such as Haselbach and Thomas (2014), and Zhan et al. (2013).
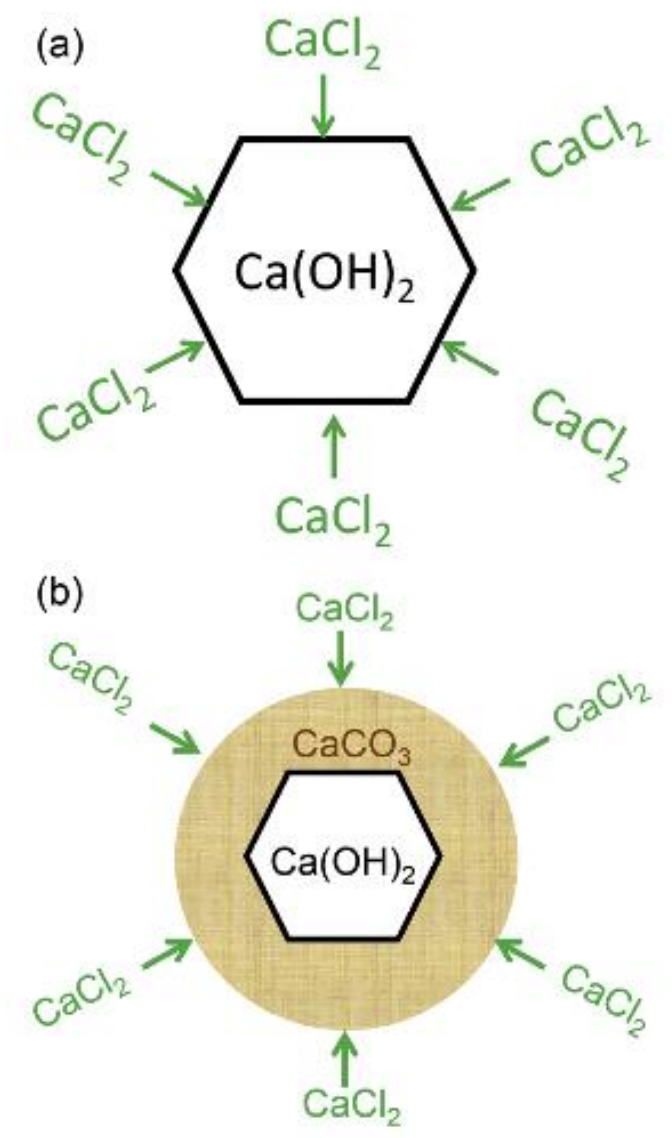

Figure 2-22 Calcite barrier forming around calcium hydroxide, preventing further reaction with calcium chloride deicing salt (Ghantous et al., 2016). 
Peterson et al. (2013) wrote that calcium oxychloride hydrate forms through the equation:

$$
12 \mathrm{H}_{2} \mathrm{O}+\mathrm{Ca}^{2+}+2 \mathrm{Cl}^{-}+3 \mathrm{Ca}(\mathrm{OH})_{2}=3 \mathrm{CaO} \cdot \mathrm{CaCl}_{2} \cdot 15 \mathrm{H}_{2} \mathrm{O}
$$

Equation 2-11

They stated that it was expected that this reaction would only take place in the presence of high concentrations of calcium oxychloride, but as was previously discussed, the formation of calcium oxychloride can take place in the presence of magnesium chloride solution. This step-wise reaction takes place by the production of calcium chloride as a product of magnesium chloride reacting with portlandite $\left(\mathrm{Ca}(\mathrm{OH})_{2}\right)$ to form brucite $\left(\mathrm{Mg}(\mathrm{OH})_{2}\right)$. This equation is shown below (Peterson et al., 2013):

$$
\mathrm{Mg}^{2+}+2 \mathrm{Cl}^{-}+\mathrm{Ca}(\mathrm{OH})_{2}=\mathrm{Mg}(\mathrm{OH})_{2}+\mathrm{Ca}^{2+}+2 \mathrm{Cl}^{-}
$$

Peterson et al. (2013) also observed magnesium precipitates that were identified as magnesium oxychloride, which could form further calcium oxychloride through the equation:

$$
8 \mathrm{H}_{2} \mathrm{O}+6 \mathrm{Mg}^{2+}+12 \mathrm{Cl}^{-}+5 \mathrm{Ca}(\mathrm{OH})_{2}=2 \mathrm{Mg}_{3}(\mathrm{OH})_{5} \mathrm{Cl} \cdot 4 \mathrm{H}_{2} \mathrm{O}+5 \mathrm{Ca}^{2+}+10 \mathrm{Cl}^{-}
$$
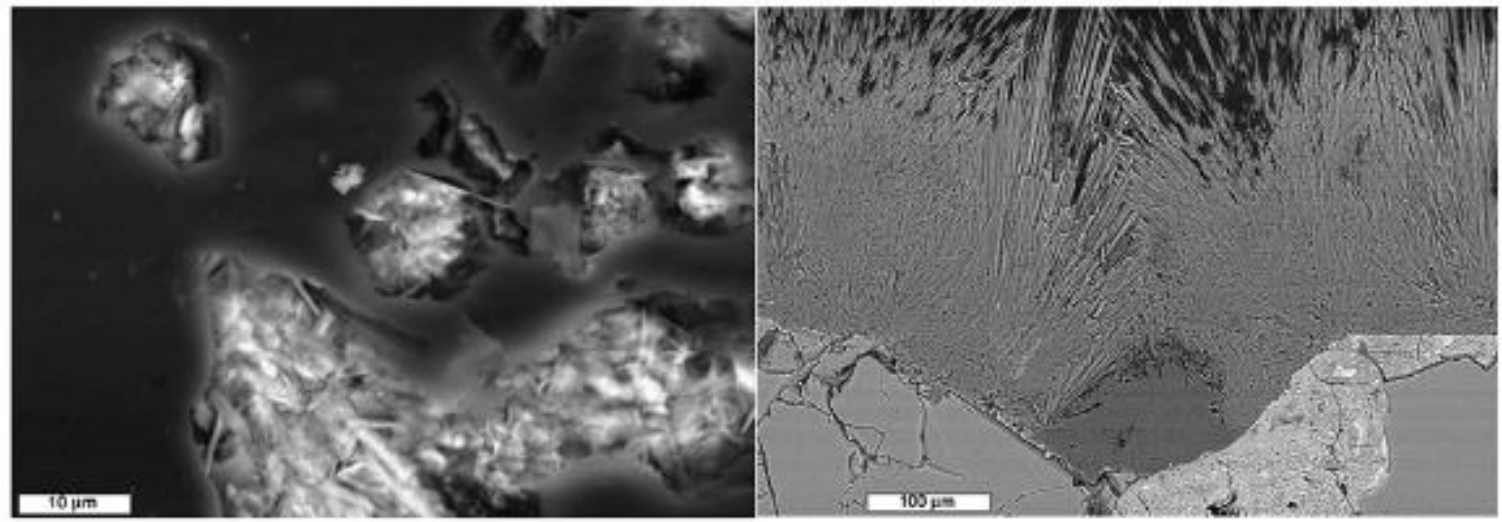

Figure 2-23 BSE image of calcium oxychloride hydrate, $\mathrm{CaCl}_{2} \cdot \mathrm{Ca}(\mathrm{OH})_{2} \cdot 2 \mathrm{H}_{2} \mathrm{O}$ (left) and magnesium oxychloride hydrate crystals (right) near brucite (Peterson et al., 2013). 
Peterson et al. (2013) identified what the crystals were in the following way: concrete and mortar specimens were soaked in chloride solutions $\left(\mathrm{NaCl}, \mathrm{CaCl}_{2}\right.$, and $\left.\mathrm{MgCl}_{2}\right)$, and after 500 days of soaking at $5^{\circ} \mathrm{C}$, crystals were observed to have precipitated at the surface of the $\mathrm{CaCl}_{2}$ sample. These crystals were collected after the testing period had been completed and the crystals were immediately examined under a stereoscopic microscope. They were later crushed and used for XRD. The exterior of the mortar samples also underwent the same procedure, both immediately after testing and after sitting in ambient conditions for 24 hours. After stereomicroscope and XRD, the samples were vacuum impregnated with epoxy and dried at $50^{\circ} \mathrm{C}$ for a day, and billets were prepared. SEM, BSE, and EDS were used to get a quantitative analysis of the phases present in the sample. The chloride penetration at different depths were also examined.
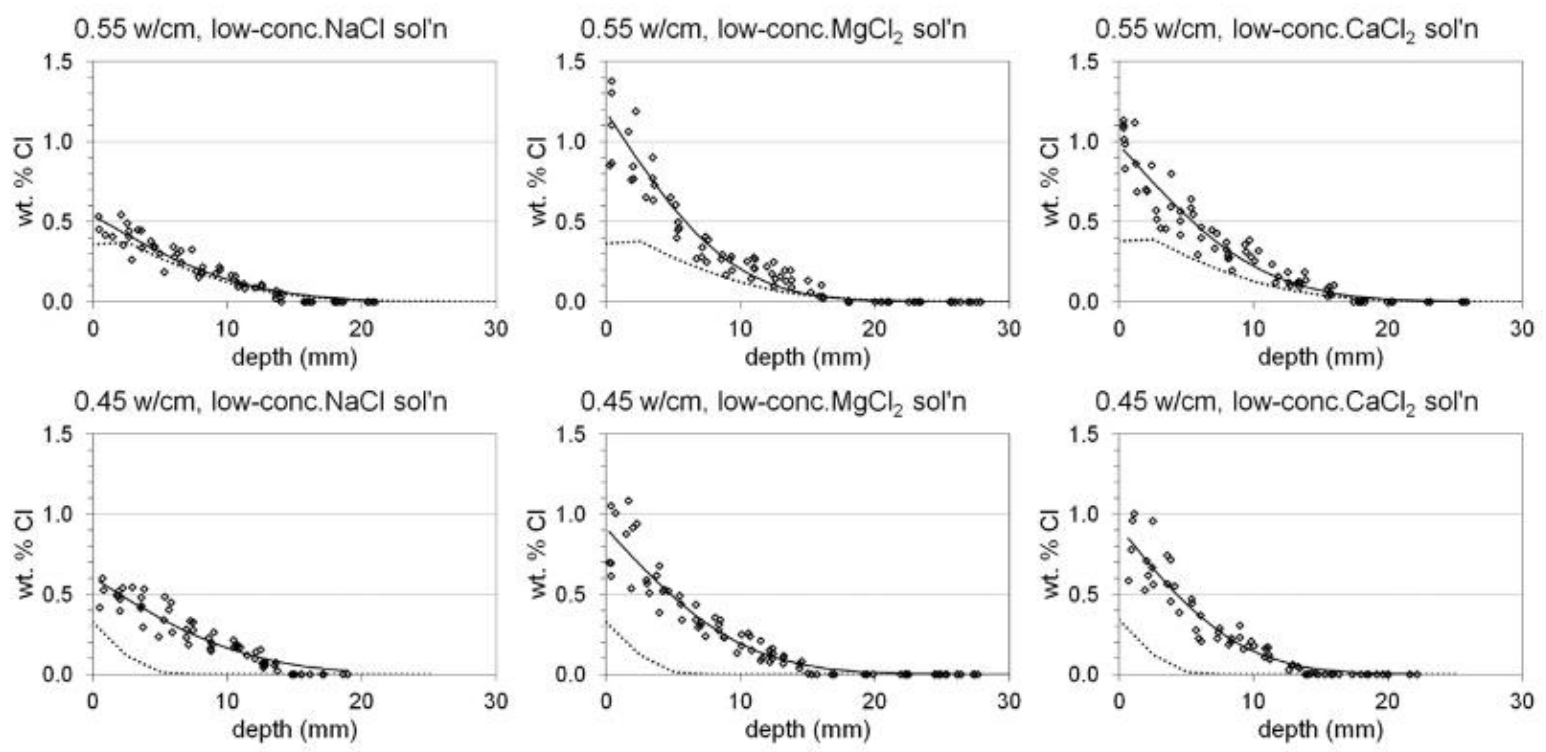

Figure 2-24 Chloride penetration depth of mortar samples soaked in low concentration $(7.3 \% \mathrm{NaCl}$, 7.3\% $\mathrm{CaCl}_{2}, 6.2 \% \mathrm{MgCl}_{2}$ ) salt solutions (Peterson et al., 2013) 
Research (Peterson et al., 2013; Monosi \& Collepardi, 1990; Shi, 2001; Schollbach \& Pöllmann, 2010) has identified two phases of calcium oxychloride hydrate, one forming at $5^{\circ} \mathrm{C}$, and one forming at temperatures above $20^{\circ} \mathrm{C}$. $3 \mathrm{CaO} \cdot \mathrm{CaCl}_{2} \cdot 15 \mathrm{H}_{2} \mathrm{O}$ crystals formed on the surface of concrete samples exposed to $17 \% \mathrm{CaCl}_{2}$ held at $4.4^{\circ} \mathrm{C}$ for 500 days.

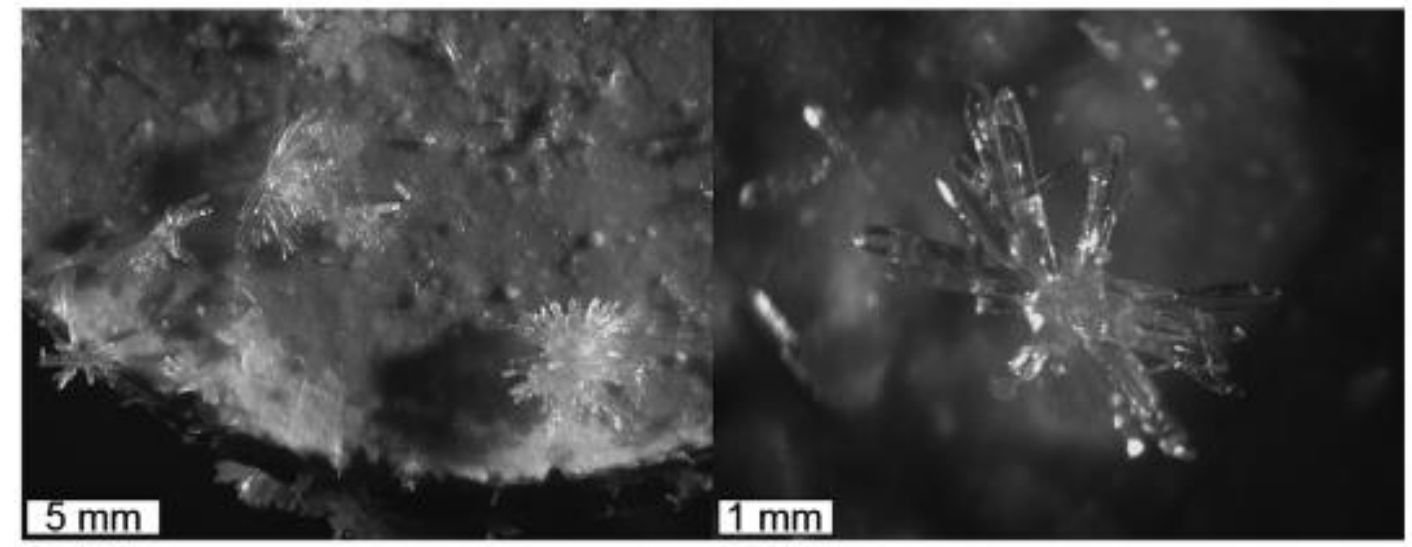

Figure 2-25 Stereoscopic microscope image of calcium oxychloride $\left(3 \mathrm{CaO} \cdot \mathrm{CaCl}_{2} \cdot 15 \mathrm{H}_{2} \mathrm{O}\right.$ phase) formed on the surface of concrete exposed to high $\mathrm{CaCl}_{2}$ concentration (Peterson et al., 2013).

As mentioned, Peterson et al. (2013) looked at stereoscopic images and XRD of the hydrated phase of calcium oxychloride, which formed on the concrete sample itself when exposed to high concentration (17\%) $\mathrm{CaCl}_{2}$ solution, and was held at a low temperature. After these crystals were examined, they were immediately dried and examined again. During the drying process, the phase of the calcium oxychloride had changed to $\mathrm{CaCl}_{2} \cdot \mathrm{Ca}(\mathrm{OH})_{2} \cdot 2 \mathrm{H}_{2} \mathrm{O}$, and from XRD, the peaks had suggested that some calcite and portlandite had also formed, according to past research done by Monosi \& Collepardi (1990) and the Joint Committee on Powder Diffraction Standards (JCPDS). The references they used for the peaks of each compound were JCPDS \#02-1099 for the dehydrated calcium oxychloride phase, and JCPDS \#02-0280 for hydrate calcium oxychloride. 

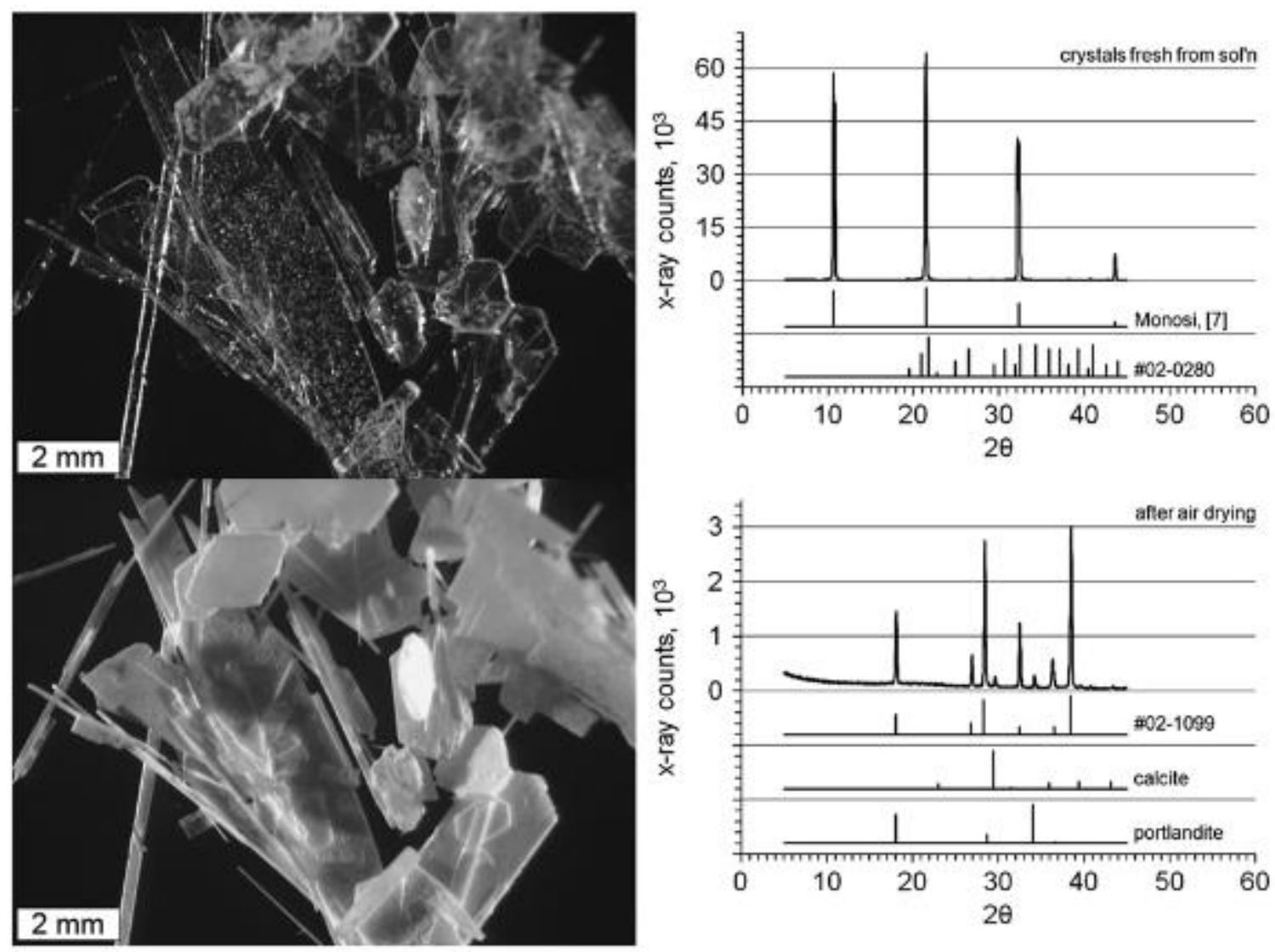

Figure 2-26 Stereoscopic images and XRD data of the hydrated calcium oxychloride phase (top) and dehydrated calcium oxychloride phases after drying. Some calcite and portlandite were also formed in the drying process (Peterson et al., 2013)

\subsection{Saw cuts and sealant}

Saw cuts are introduced at intervals to control for random cracking by creating a section that is weaker, where cracks will form to relieve stress (Raoufi et al., 2009). This induces a crack below the saw cut, which removes the issue of random cracking (lowa State University, 2004). Early saw-cutting has some issues like ravelling or spalling, while late saw cutting may create microcracks when stresses reach $40-50 \%$ of the concrete's tensile strength which leads to random cracks, reducing the pavement's durability (Mindess, Young, \& Darwin, 2003; Weiss \& Chariton, 
2002). These microcracks may make it easier for the concrete to become more saturated, resulting in more damage (Yang et al., 2006). However, the crack underneath a saw cut joint may not form if the pavement is very strong, if the joints are spaced closely together, or if the pavements are designed to be thick (Castro et al., 2011). Zhang et al. (2015) studied the importance of the interfacial transition zone on resistance to freezing and thawing. It was found that sawn joints fair worse than formed joints, and the quality of the interfacial transition zone was an important factor, because salt solutions could enter the interfacial transition zone with little resistance, placing this zone of the concrete at risk of damage from expansion. They presented data that improving the quality of the interfacial transition zone (by means such as using an aggregate that has better bonding to cement paste) would improve the concrete pavement's resistance to early damage in its service life.

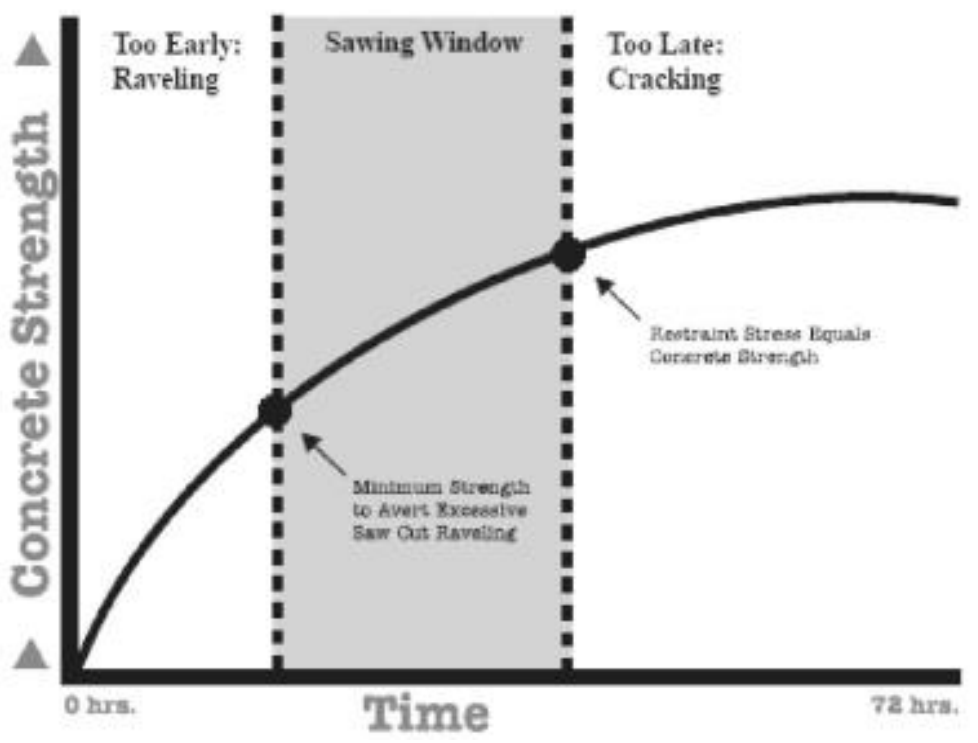

Figure 2-27 The effect of the time of saw cutting on ravelling and cracking (lowa State University, 2004) 
These joints in concrete are often sealed to prevent the ingress of harmful particles, but they are sometimes left open. In order to get the full benefit of using a sealant in these joints, the seal must be installed properly and adequately maintained. There are several options when sealing joints, and there are considerations that must be kept in mind when deciding to use and maintain the technology from different approaches (Jones et al., 2013).

Sealing or filling concrete joints is important to consider when designing a pavement for a long service life, which is often the case for a rigid concrete pavement. The installation and maintenance of the sealant/ filling is important for its usefulness. The goal of sealant/ filler is to prevent surface water, deicing chemicals, and incompressible materials from entering the joints in the pavement (Jones et al., 2013). An improper seal may actually trap these materials inside the joint, where they would cause more damage than if they were allowed to leave freely through evaporation or suction from a tire passing over the joint. Most of the water that enters a pavement is through the surface, although water can enter from other sources, such as from the sides or from below. Attempting to make the joint seal completely watertight is often considered impractical. Case studies should be examined to make a decision that is appropriate for the climate where the road is located, and the experience of the contractors performing the work is important.

Across the United States, different states have had different experiences with different approaches to joints. Wisconsin was the first state in the USA to use open, unsealed, unfilled joints. They later found that this was better for high speed roads, and Wisconsin now seals the joints of lower speed roads. California has had a similar experience. On the other hand, 
Minnesota and North Dakota have found that sealed joints work better than open joints. As another alternative, New York has seen good performance with filled reservoir joints.

There are two main types of sealant materials that are used in concrete joints: formed-in-place, and preformed compression seals. For all sealants, the following properties are important for long-term success (Jones et al., 2013): ability to stretch/ deform, low modulus of elasticity, initial cohesion and long-term cohesion (important for formed-in-place, not compression seals), compatibility with surrounding materials (concrete, back rods, etc.), durability (to resist hardening and oxidation over time), resistance to jet fuel (if the pavement is used for an airport). One type of a formed-in-place sealant is a hot-pour sealant, which, as the name implies, is a sealant that is poured into place while it is hot. These sealants must be heated before they are used, and even heating throughout is of utmost importance.

On the other hand, silicone formed-in-place sealants also exist, which should be stored between $2^{\circ} \mathrm{C}$ and $32^{\circ} \mathrm{C}$ until they are used, and they are suitable for areas with large temperature ranges. Self-leveling silicone sealants flow into a shape, and roads with this sealant can be opened to traffic after 3 hours. The sealant finishes curing completely after 21 days. There is another type of silicone sealant called non-sag silicone sealants, which requires tooling to be placed properly. If this sealant is used on a road, the road can be opened to traffic after just 25 to 90 minutes, and the sealant fully cures after 14 days.

Compression seals are seals that are solid when inserted into a joint and function by being in constant compression to stay in place. For this reason, the temperature at the time these seals are installed and how far the joints can expand are important, because if the joint expands too much, the seal will no longer be under compression and it will be useless. Also, in cold 
temperatures, the seal can become too loose if it is not compressed enough. On the other hand, if the compression is too high for too long, the webs of the seal can stick together or permanently deform (called compression set). Research recommends that these seals should be designed so that they are under a constant compression of $20-50 \%$ of their maximum compression (American Concrete Pavement Association, 2018).

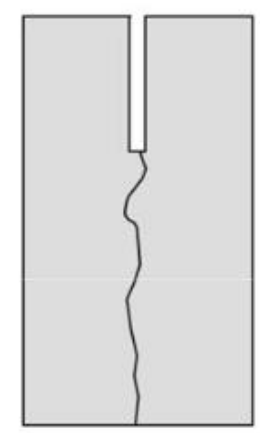

Unfilled (open)

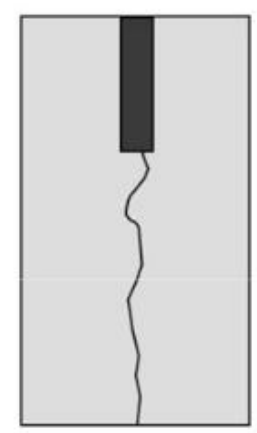

Filled (in single saw cut)

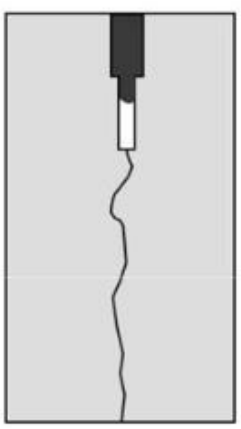

Filled (in reservoir cut)

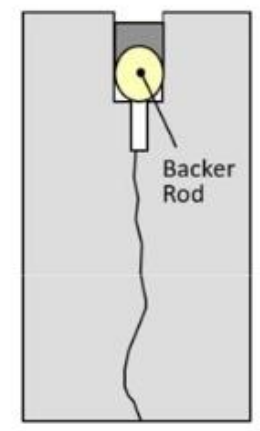

Sealed (in reservoir cut)

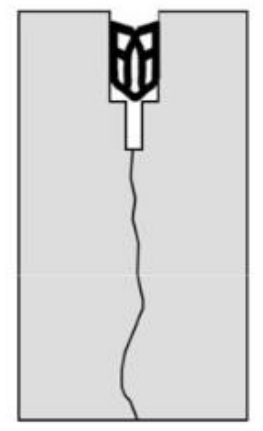

Compression Seal (in reservoir cut)

Figure 2-28 Diagram of different type of joint sealants for joints in concrete pavements (American Concrete Pavement Association, 2018)

Joints should be cut to be as narrow as possible because it should be considered that they may need to be sealed again in the future. However, if joints are cut too narrow, it may be difficult to properly clean them and seal them.

Formed-in-place sealants are often designed with a common sealant shape factor (ratio of the width to the depth of the sealant). This depends on how wide the saw cut is and where the backer rod is placed. It is recommended that silicone sealants are not flush with the pavement and have a $6-10 \mathrm{~mm}$ recess, so they do not come in contact with passing tires. Hot-pour sealants, on the 
other hand, should be flush with the pavement (American Concrete Pavement Association, 2018).

How much joints move is also especially important for compression seals, so that they can stay within their required percentage of compression throughout their lives to avoid becoming too loose or experiencing compression set. The factors used to calculate the expansion and contraction of concrete joints include: friction (note: friction factor is not considered when doing resealing), slab length, coefficient of thermal expansion, difference between maximum and minimum temperature that the concrete experiences, and shrinkage factor (American Concrete Pavement Association, 2018).

At the time of writing, an accelerated test method for concrete pavement joint deterioration has not yet been developed.

\subsection{Flexural Strength of Concrete and Fatigue Loading}

The elastic flexure formula for a simple beam can be expressed as:

$$
\sigma=\mathrm{My} / \mathrm{I}
$$

Where $\sigma$ is the flexure stress at the surface, $M$ is the moment acting on the section, $y$ is the depth from the neutral axis to the surface, and I is the moment of inertia (Riley et al., 2007).

Concrete's tensile strength is estimated as roughly $1 / 10$ of its compressive strength. Cope et al. (2002) suggest that 6.7 times the square root of concrete's compressive strength can be used to estimate its tensile strength (when units are psi). They also suggest using 4 times the square root of the compressive strength as a more conservative estimate. Albright (1987) gives a suggestion for this estimation specifically for pavement structures to raise the compressive strength to the 
power of $2 / 3$ and multiply by 2.3 (again, units being in psi). If a concrete with a strength of 30 $\mathrm{MPa}$ is used, the estimations of its flexural strength when using these four methods (and converting back to $\mathrm{MPa}$ ) would be $3 \mathrm{MPa}, 3.047 \mathrm{MPa}, 1.819 \mathrm{MPa}$, and 4.226 $\mathrm{MPa}$. These values are important to consider because if the stress is too low (i.e. less than $40-50 \%$ of concrete's maximum strength), fatigue damage may not take place (Mindess, Young, \& Darwin, 2003).

Because the long-term durability of concrete is dependent not only on its ultimate strength, but on its resistance to time-dependent and cyclical exposures, which can affect its mechanical properties (Zanuy et al., 2009). Some of these time-dependent or cyclical exposures include drying shrinkage, vehicular loads, and freeze-thaw cycles. All of these factors must be considered when determining how concrete will perform in the long-term.

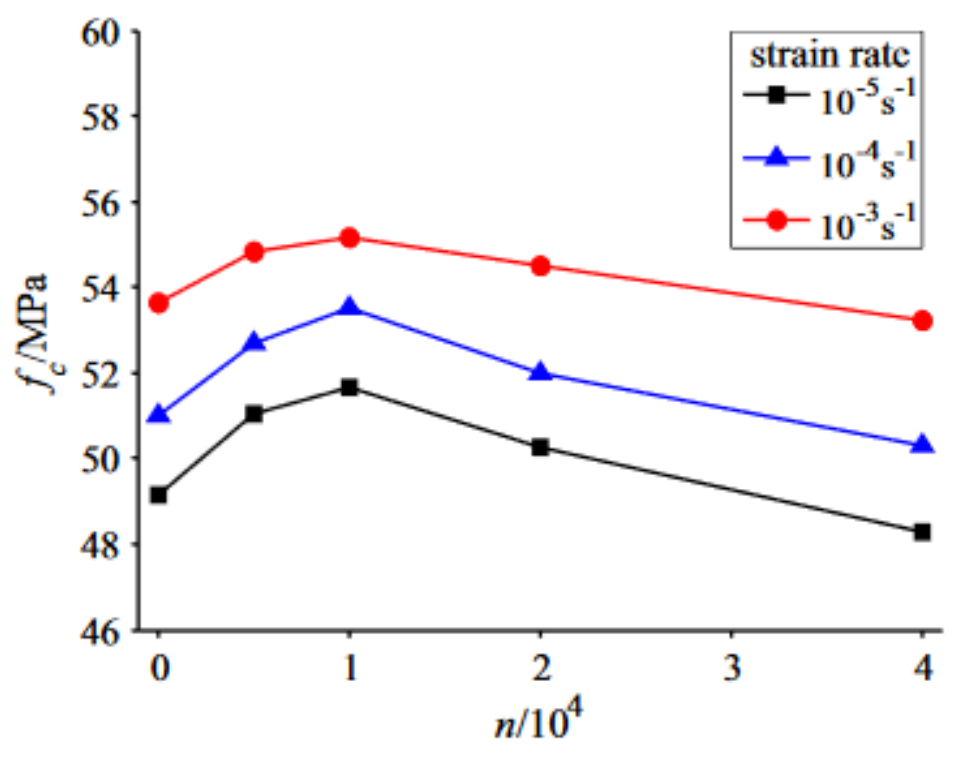

Figure 2-29 Concrete's compressive strength after having experienced different amounts of fatigue loading cycles (Lu et al., 2017) 
Some studies (Hasan et al., 2008, Hong et al., 2012) examined the effects of freezing and thawing on concrete's resistance to fatigue loading. Research from Soroushian \& Elzafraney, (2004) suggested that repeated fatigue loading in concrete structures created microcracks, and that freeze-thaw cycles widened the cracks. Estimating a concrete's serviceability or resistance to fatigue has been found to be difficult for several reasons: concrete is far from being a homogeneous material, with more vulnerable zones (such as the inelastic fracture process zone) which plays a role in the propagation of cracks (Bhowmik \& Ray, 2018).

Other research (Lu et al., 2017; Li et al., 2011; Qiao et al., 2015) has also looked at the effects of fatigue loading, freeze-thaw exposure, and both fatigue loads and freezing-thawing on the concrete and its strength. Lu et al. (2017) found that exposing concrete to freezing and thawing before fatigue loading made the concrete much weaker than if it first underwent fatigue loading and then was exposed to freezing and thawing. The damage was also observed through the use of microscopy, which revealed the formation of microcracks from the exposure. A finding from the study was that as the number of freeze-thaw cycles increased, the compressive strength of the concrete decreased proportionally. It was also found that the number of fatigue cycles that the concrete had initially undergone before being exposed to freezing and thawing had weakened its resistance, because the fatigue loading could have caused some initial microcracking before the concrete was exposing to the freezing and thawing conditions. 


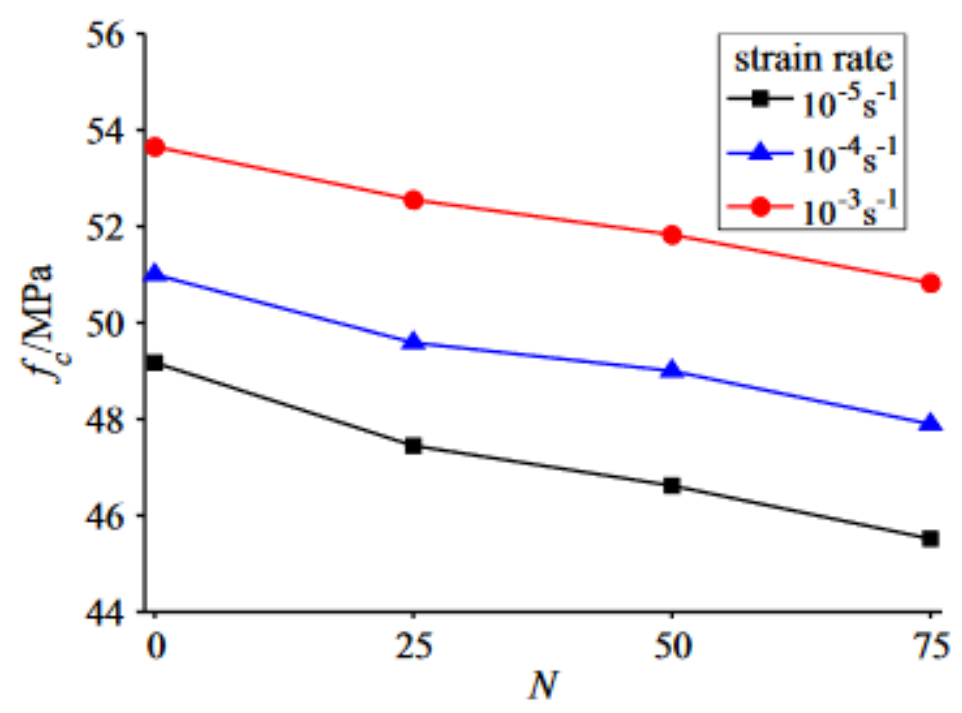

Figure 2-30 Concrete's compressive strength after undergoing different amounts of freeze-thaw cycles (Lu et al., 2017)

Hong et al. (2012) found that freeze-thaw cycles with salt solution caused greater damage than freeze-thaw cycles with just water, and this was reflected in the data from the fatigue testing: the concrete could withstand less cycles of fatigue loading at the same load when exposed to salt solution compared to water.

\subsubsection{Shear vs Flexural Failure}

Some research has been conducted on notched beams and shear vs flexural failure. Carloni et al. (2018) tested concrete beams with a notch depth of one third of the beam depth. The nominal stress was calculated as being a flexural failure, and the depth of the concrete above the notch was considered. The authors write that further investigation into the effect of width on different sized notched beams is necessary for a more complete understanding, especially for beams with smaller depths. Depths of $70 \mathrm{~mm}$ and $150 \mathrm{~mm}$, and widths of $35 \mathrm{~mm}, 70 \mathrm{~mm}$, and $150 \mathrm{~mm}$ were 
used in the study. The authors also write that larger widths may be problematic because of the presence of friction not allowing the fracture energy to be properly evaluated.

Meng et al. (2017) found that an increased loading rate resulted in higher flexural strength when testing notched beams of various notch-to-depth ratios $(1 / 6,1 / 3$, and $1 / 2)$.
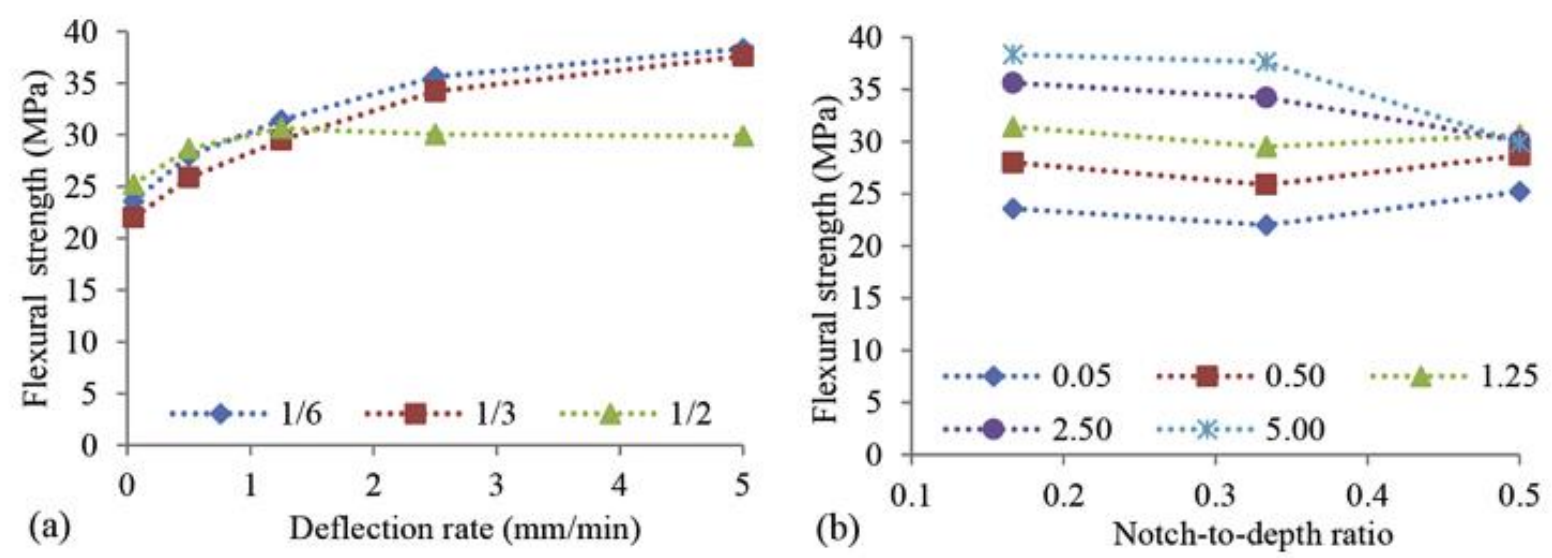

Figure 2-31(a) Flexural strength for different loading rates. (b) Flexural strength for different notch to depth ratios.

Patel et al. (2014) wrote that how a beam behaves depends on its span and depth. Although a beam with a depth to span ratio of 0.5 or greater is considered to be a deep beam, research from Patel et al. (2014) suggests that deep beam action may start when this ratio is even as low as 0.25 .

The role of the ratio of shear span (distance from centre load to support, in the case of centrepoint loading) to depth was also examined in past research (Osman, 2008). As an example, Osman (2008) wrote that the mode of failure (i.e. shear or bending failure) strongly depends on this 
ratio. A shear-span to depth ratio of greater than 6 is much more likely to fail from bending. A shear-span to depth ratio of $2.5-6$ is more likely to have a shear failure. When the shear-span to depth ratio approaches $1-2.5$, shear compression failure occurs, which is characterized by diagonal shear cracks, as previously seen, and crushed concrete at the point of the load.

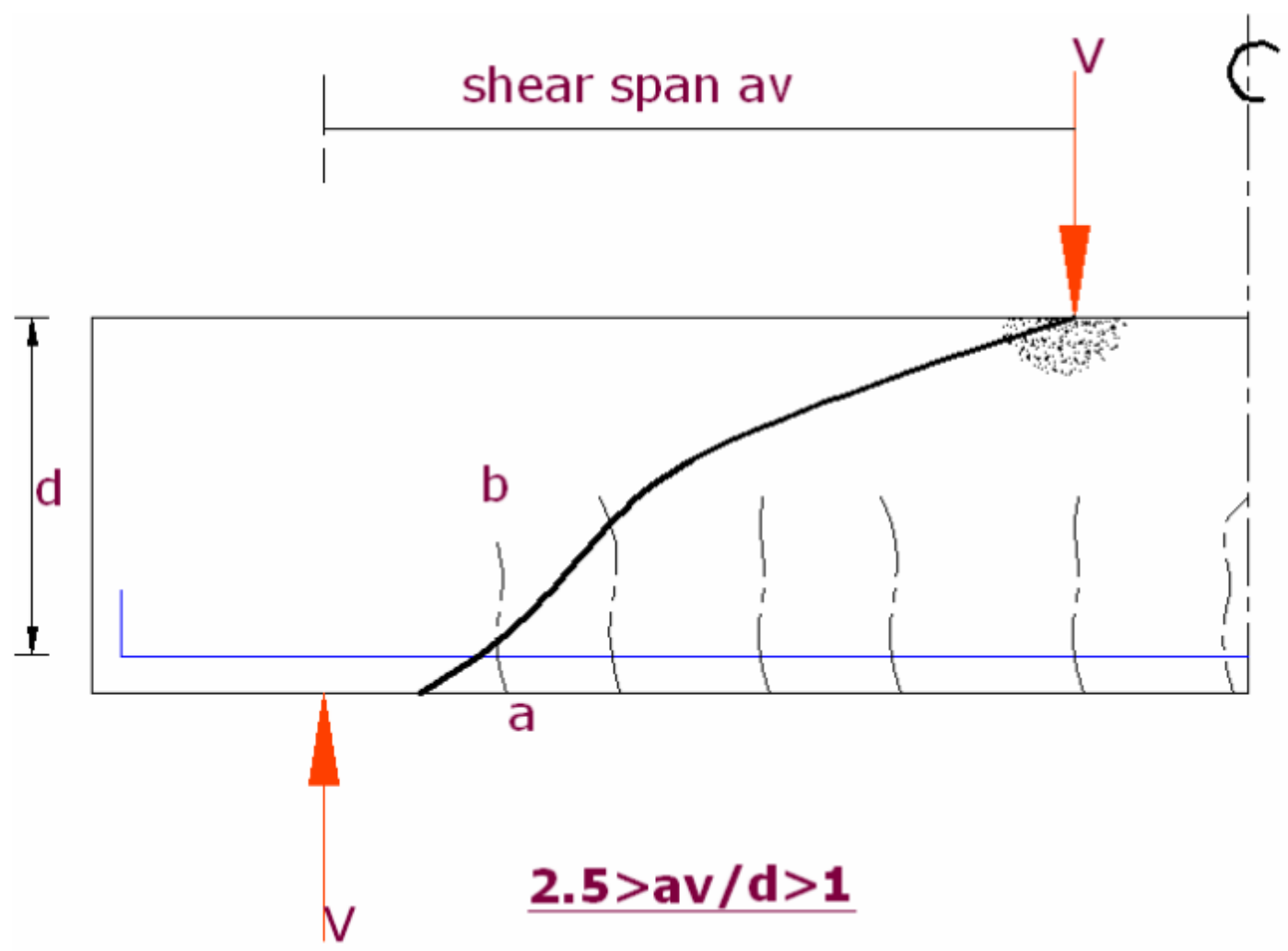

Figure 2-32 Schematic of shear compression failure in a deep beam, with crushed concrete at the load point (Osman, 2008).

When the shear-span to depth ratio gets as low 1 or lower, the diagonal shear cracks that form are formed in approximately a straight line between the support and the loading point. 


\subsection{Thermogravimetric Analysis (TGA)}

When analyzing concrete's resistance to chloride ingress, the total chloride content and the depth that the chloride has penetrated through the concrete is considered. The chloride considered for calculating the chloride content includes the chloride that is bound to Friedel's salt $\left(\mathrm{Ca}_{4} \mathrm{Al}_{2}(\mathrm{OH})_{12} \mathrm{Cl}_{2} \cdot 4 \mathrm{H}_{2} \mathrm{O}\right)$, chloride adsorbed to the calcium silicate hydrate phase, and free chloride ions, which are in the pore solution (Tang et al., 2011; Bertolini et al., 2013; De Weerdt et al., 2014). Different studies give different suggestions for which kind of chloride has the greatest contribution: Loser et al. (2010) found that most of the chlorides are found in the pore solution, while others (Galan \& Glasser, 2015; Justnes, 1998; Yuan et al., 2009) write that the majority of chloride is due to binding with the tricalcium aluminate and tetracalcium aluminoferrite phases by forming Friedel's salt. Another older view (Tang \& Lars-Olaf, 1998) is that the chloride physically adsorbing to the calcium silicate hydrate is responsible for a large portion of the total chloride, but this depends on the ratio of calcium to silica (which can affect the charge) and the $\mathrm{pH}$ level. However, recent research has questioned the extent of this contribution and suggested that the penetration of chlorides is not slowed by adhesion (Seigneur et al., 2016). TGA is a method that can be used to analyze the physically and chemically bound chlorides, and the chlorides found in Friedel's salt (Shi et al., 2017).

As for identifying the presence and quantity of Friedel's salts, XRD is another method that can be used which is appropriate for samples made of paste, but the results are less accurate when examining mortar because of the presence of quartz in sand. Using TGA, on the other hand, is more accurate because the quarts does not add more thermal peaks as noise to the data being 
observed (Shi et al., 2017). Past research has used TGA to analyze Friedel's salt in paste and mortar (Shi et al., 2017; De Weerdt et al., 2015; Geng et al., 2015; Jain et al., 2010).

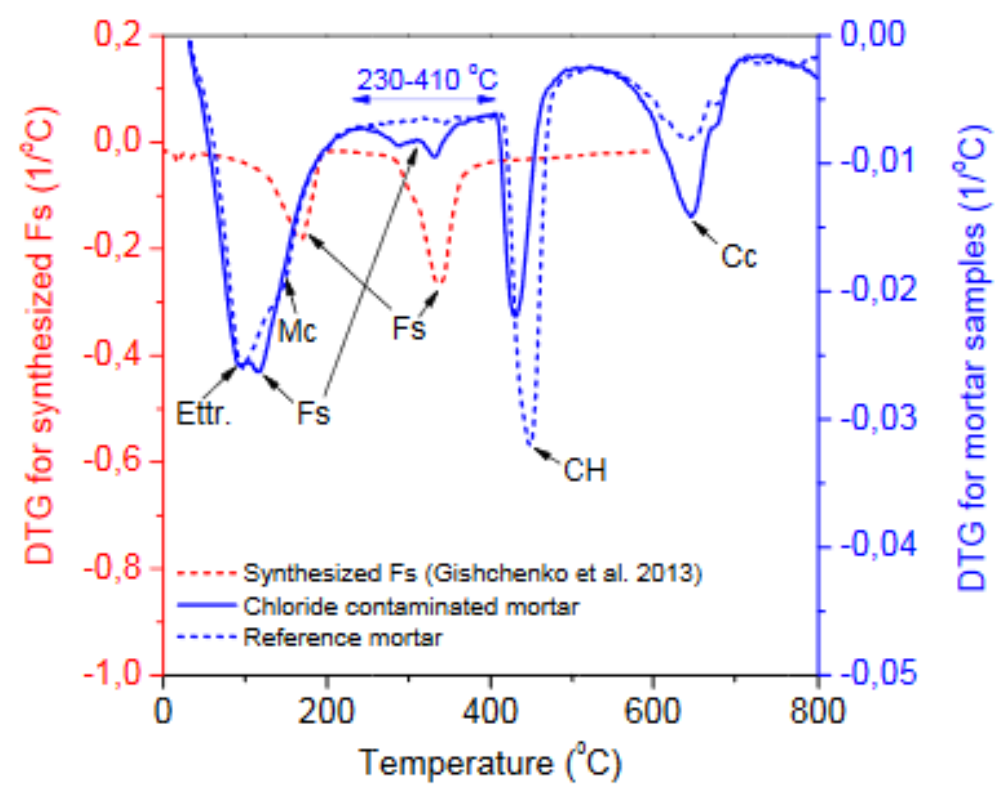

Figure 2-33 TGA test results showing DTG curves for identifying ettringite and Friedel's salt (Shi et al., 2017).

The main peaks in the DTG curve the first occur in the range of $30^{\circ}-180^{\circ} \mathrm{C}$, and around $180^{\circ}-$ $450^{\circ} \mathrm{C}$ (Shi et al., 2017). Some studies have observed these two peaks individually (Shi et al., 2017; Grishchenko et al., 2013; Birnin-Yauri, 1998), but in another case, the second peak was seen to be splitting (Lothenbach, 2016). Although there has been no explanation to account for these differences, the ratio of weight losses comparing the lower and higher temperature peaks were 4:6, and Grishchenko et al. (2013) explained that this is because of the structural makeup of Friedel's salts: main layers made up of $\left[\mathrm{Ca}_{4} \mathrm{Al}_{2}(\mathrm{OH})_{12}\right]^{2+}$, which has twelve hydroxyl molecules, and interlayers composed of chloride and four water molecules, having a negative charge. 


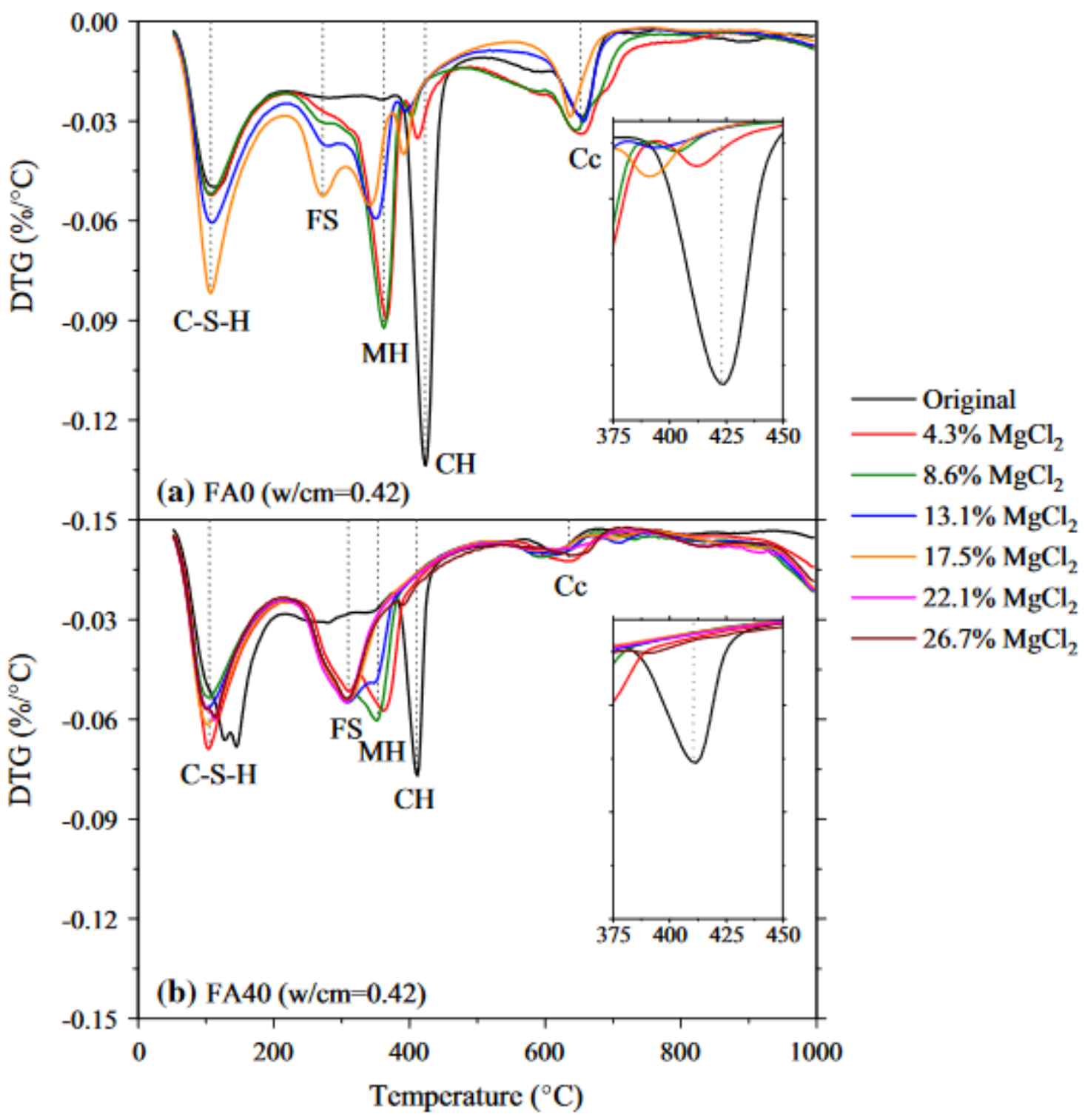

Figure 2-34 DTG curves of concrete exposed to $\mathrm{MgCl}_{2}$ solution. $\mathrm{CSH}$ : calcium silicate hydrate. $\mathrm{MH}$ : $\mathrm{Mg}(\mathrm{OH})_{2}$. $\mathrm{CH}: \mathrm{Ca}(\mathrm{OH})_{2}$. FS: Friedel's salt. $\mathrm{Cc}: \mathrm{CaCO}_{3}$. (Qiao et al., 2018c)

These peaks were associated with the following temperatures: below $200^{\circ} \mathrm{C}$ for $\mathrm{CSH}$ and $\mathrm{MSH}$, $230-410^{\circ} \mathrm{C}$ for Friedel's salt, $350-450^{\circ} \mathrm{C}$ for brucite, $400-450^{\circ} \mathrm{C}$ for calcium hydroxide, and $550-$ $700^{\circ} \mathrm{C}$ for calcium carbonate (Qiao et al., 2018c). 


\subsection{Scanning Electron Microscopy (SEM)}

Scanning Electron Microscopy has not only been used to examine and investigate concrete and cement paste for years, but split-quadrant backscatter-mode SEM together with energydispersive X-ray spectrometry (EDX) can provide more information than any other technique used to examine concrete (Diamond, 2004).

The SEM functions through generating and focusing an electron beam over the surface of concrete being examined. The signals from this process can be analyzed to create an image by using either backscattered electrons or secondary electrons, which are measured and the information is used to create images (Balendran et al., 1998). The way these electrons behave is largely based on the atomic number of the material being tested. Materials with a higher atomic level have more electrons backscattered, because the electrons are farther from the centre of the atom and have higher energy. The opposite is true for materials with a lower atomic level, whose electrons have less energy. These materials with higher energy electrons appear in the generated images as brighter, and the darker areas of the images are from phases that are made up of atoms with lower atomic numbers, where less electrons are backscattered (Sahu et al., 2004). As such, in resulting images of dry concrete that has been impregnated with epoxy, the backscattered electrons from the epoxy in comparison to the other phases in concrete is very low, so the epoxy (and any cracks filled with epoxy) will appear much darker in images. 


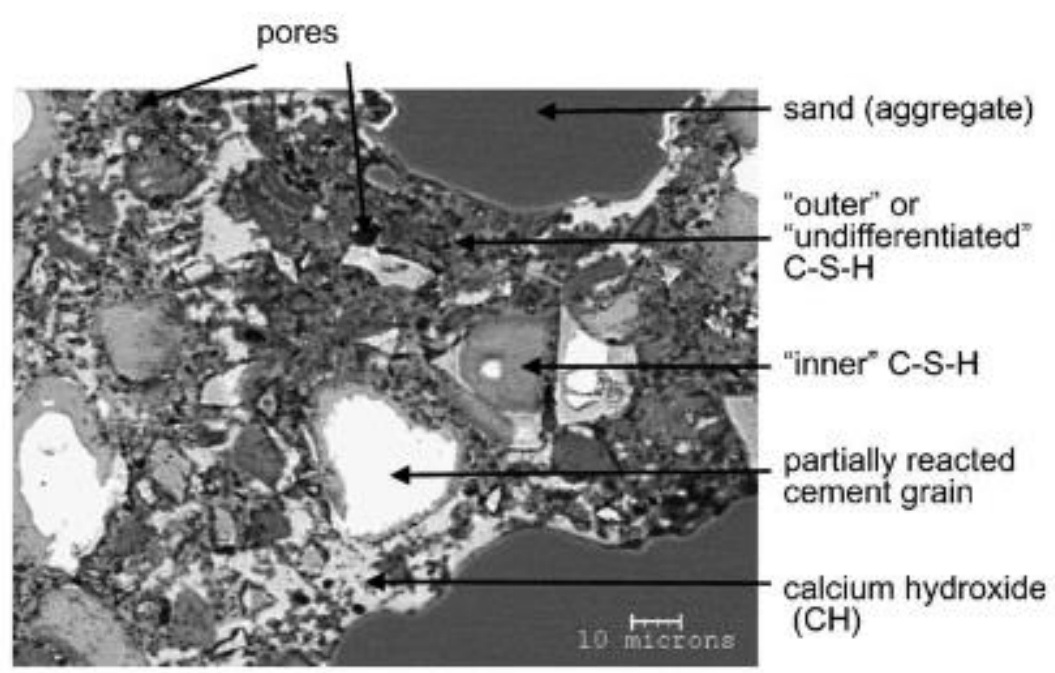

Figure 2-35 Image of Portland cement mortar from BSE (Scrivener, 2004)

Secondary electron-mode SEM was an earlier technique used than the more recent backscattermode SEM, and it made use of fractured concrete surfaces, and image topography is the basis of forming images in this case (Diamond, 2004). On the other hand, backscattered electron-mode SEM uses concrete that is flat and polished, and these images are formed based on what the level of electron density is in different parts of the concrete. A benefit of energy dispersive X-ray spectrometers is that they can be used simultaneously along with a SEM and provide data instantly on the chemical makeup of what is being observed: data is given on what percentages of the surface are made up of which elements (Balendran et al, 1998).

As examples of what is possible with SEM, Sahu et al. (2004) have demonstrated that is possible to determine the water-cement ratio in mature concrete using SEM, and Brown et al. (2004) were able to distinguish changes in the internal structure of concrete when it was subjected to either sodium sulphate or magnesium sulphate. 
In Sahu et al's (2004) research regarding measuring the water-cement ratio of hardened conrete, dried concrete samples were impregnated with epoxy. These portions of the concrete that were filled with epoxy show up as darker than the phases of the concrete such as calcium silicate hydrate or the aggregate, because it has the lowest backscatter intensity. By making certain parameters like brightness, contrast, and the working distance the same, consistent results can be obtained for evaluating the water-cement ratio of hardened concrete paste, and these results are comparable to other tests which do the same thing, such as optical fluorescent microscopy (Sahu et al, 2004).

\subsubsection{Scanning Electron Microscopy Sample Preparation}

Orr (1983) has written that sample preparation for SEM analysis can be done within two hours of testing, and that using gold to coat the fracture surface has shown to be effective. Issues with sample preparation have been highlighted by French (1991), such as the possibility of missing crystallites in polished samples, or the sample could be altered in unwanted ways during preparation, (Kjellsen et al., 1990, Scrivener \& Pratt, 1984). However, as Balendran et al (2004) write, these issues seem to have been alleviated with new techniques such as impregnating the concrete with a low viscosity epoxy under a vacuum. Since drying is required for sample preparation for SEM, an alternative to ensure that cracking at the interfacial transition zone does not take place is to replace the sample's water with ethanol, and then fill that space with epoxy (Balendran et al., 2004; Struble, 1987). As for analyzing the images from SEM, phases of cement can be distinguished by their level of brightness: unhydrated cement is bright, calcium hydroxide is slightly darker, other hydrated products are darker still, and pores/ cracks appear as black in images (Kjellsen et al., 1990, 1991; Balendran et al., 2004). 


\subsection{Rapid Chloride Permeability Test (RCPT)}

The testing for RCPT (Rapid Chloride Permeability Test) is based on ASTM C1202 - 19, Standard Test Method for Electrical Indication of Concrete's Ability to Resist Chloride Ion Penetration. This test is based on measuring the how much current passes through a specimen of concrete. The mechanisms of chloride transport through concrete include diffusion, absorption, and hydrostatic pressure (Stanish, Hootin, Thomas, 2001). Diffusion across a chloride ion concentration gradient is the most common: the chloride ions move from a higher to a lower concentration. Another possibility is absorption: if a concrete surface is exposed to water with chlorides, the water can be absorbed by the surface of the concrete, and with it, some of the chlorides can penetrate into the concrete. The depth of this chloride penetration is rather limited, although it does help some of the initial chlorides to enter concrete. This can be more detrimental with the presence of shallow reinforcements, or concrete damaged at the surface. Lastly, chloride can penetrate through concrete in the presence of hydrostatic pressure, but this is unlikely to occur in real world situations (Stanish, Hootin \& Thomas, 2001).

The concrete specimen used for ASTM C1202 - 19 is a $50 \mathrm{~mm}$ thick, $100 \mathrm{~mm}$ diameter concrete core or cylinder, with a $60 \mathrm{~V}$ potential difference maintained across the sample, and one of the samples immersed in sodium chloride, and the other end in sodium hydroxide. It is also noted in the ASTM standard for the test that the RCPT test is suitable for research and development, and that the age of the concrete has a significant effect on the test results: older concrete generally continues to cure and becomes less permeable over time. 
Aldea et al. (2000) performed research on the replacement of cement with slag in percentages of $0 \%, 25 \%, 50 \%$, and $75 \%$. They found that there was little effect on concrete's compressive strength in slag replacements of up to $50 \%$, and with higher replacements of slag, it was found that there was a drop in compressive strength. They found that permeability significantly decreased as the amount of cement replaced with slag increased (when regular curing conditions were observed, which is of concern in this study).
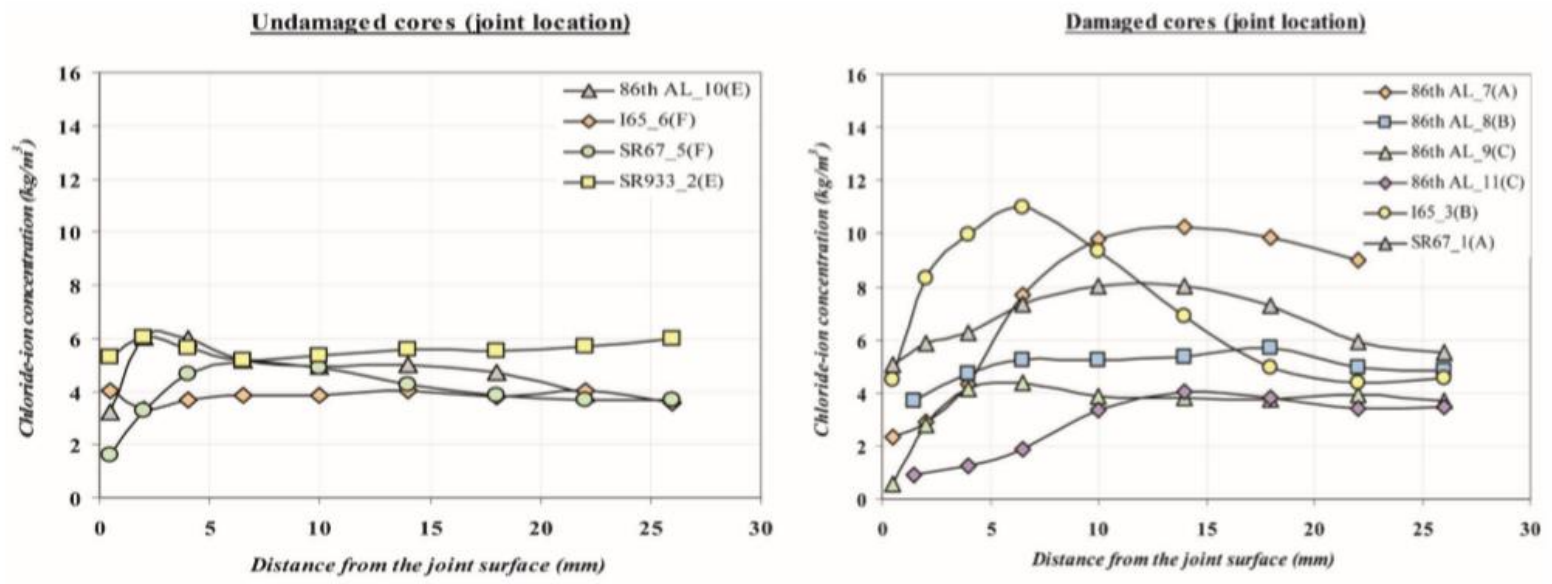

Figure 2-36 Chloride penetration through damaged and undamaged cores from taken from a distressed pavement (Del Mar Arribas-Colón et al., 2012).

Past research (Ahmed, Kayali \& Anderson, 2008) has shown that supplementary cementing materials in binary or ternary blends of cement resulted in lower permeability values from the ASTM RCPT test. It was suggested that slag's pozzolanic properties may be even more effective than silica fume in lowering the permeability of chloride through concrete. Other pozzolanic materials used as supplementary cementing materials, such as metakaolin, have had their 
properties and effects on concrete durability studied as well (Ramezanianpour \& Jovein, 2012). Metakaolin is a pozzolanic material of interest because it is a primary product formed by heating kaolin to $700-800^{\circ} \mathrm{C}$ (Klimesch, Ray, 1998; Klimesch, Ray, 1997), as opposed to something like slag, which is a byproduct. Metakaolin's pozzolanic activity is such that its reaction with $\mathrm{Ca}(\mathrm{OH})_{2}$ at room temperature produces C-S-H gel (He, Osbaeck \& Makovicky, 1995; Zhang \& Malhotra, 1995). Other research has examined the pozzolanic effect of metakaolin (Curcio \& DeAngelis, 1998; Coleman \& Page, 1997).

Although the addition of silica fume may decrease permeability in concrete when added to cement, it has been observed that adding silica fume to mixes with slag may be unnecessary, and may even be detrimental to strength and permeability (Ahmed, Kayali \& Anderson, 2008). The same is true when silica fume is added to cement mixtures with fly ash. This has been hypothesized to be because the silica fume is more aggressive in its hydration, limiting the effectiveness of the hydration of the fly ash. As for the case of silica fume and blast furnace slag, the detrimental effect of the addition of silica fume has been again attributed to how quickly the silica fume reacts, and that it limits how much calcium hydroxide is available for the slag to further react with.

Ground granulated blast furnace slag has been shown to be even more effective than silica fume in reducing the permeability of concrete when examining RCPT data (Ahmed, Kayali \& Anderson, 2008). 


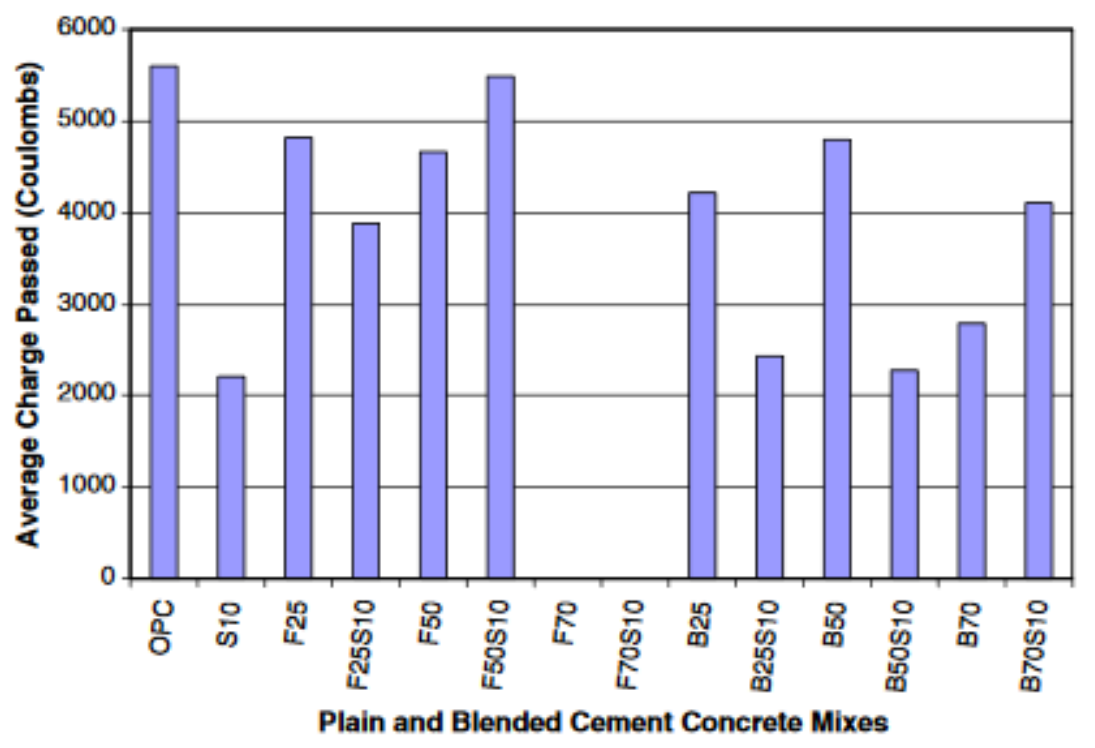

Figure 2-37 Results of average charge passed during RCPT test of Ordinary Portland Cement (OPC) and other cement blends ( $F=$ fly ash, $S=$ silica fume, B = blast furnace slag) (Ahmed et al., 2008)

However, researchers (Shi, Caldwell, 1998) have shared limitations of the study: they stated that the pore solution chemistry may be altered by with the introduction of supplementary cementing materials. For example, silica fume can reduce the concentrations of $\mathrm{Na}^{+}, \mathrm{K}^{+}$, and $\mathrm{OH}^{-}$, while fly ash can decrease the concentration of $\mathrm{Ca}^{2+}$ and $\mathrm{OH}^{-}$in the pores. 


\section{Chapter 3: $\quad$ Experimental Work}

\subsection{Sample Preparation and Consistency Tests}

\subsubsection{Sample Preparation}

Concrete slabs with joints saw cut into them were made to undergo 50 total cycles of freezethaw and/ or wetting cycles. The samples underwent either all freeze-thaw cycles, all wetting cycles at $36^{\circ} \mathrm{C}$, or alternating freeze-thaw and wetting cycles (switching every 5 cycles, for a total of 25 freeze-thaw and 25 wetting cycles).

Three different mix designs were used, named based on the strength of the mix: $45 \mathrm{MPa}, 30 \mathrm{MPa}$, and $55 \mathrm{MPa}$. A high cement content (350 kg cement/ $\mathrm{m}^{3}$ of concrete), medium cement content (300 kg cement $/ \mathrm{m}^{3}$ of concrete), and low cement content ( $270 \mathrm{~kg}$ cement $/ \mathrm{m}^{3}$ of concrete) were used to evaluate the impact of cement content at a fixed $\mathrm{w} / \mathrm{cm}$ ratio of 0.48 , concrete strength, and concrete quality on deterioration. The $45 \mathrm{MPa}$ mix included slag (which replaced $30 \%$ of the cement), but the $30 \mathrm{MPa}$ and $55 \mathrm{MPa}$ mixes did not. A summary of the concrete slabs made is shown in Table 3-1, below.

Table 3-1 Summary of concrete slabs made

\begin{tabular}{|c|c|c|c|c|}
\hline $\begin{array}{c}\text { Mix } \\
\text { Name }\end{array}$ & $\begin{array}{c}\text { Cement } \\
\text { Content }\end{array}$ & $\begin{array}{c}\text { \% Cement } \\
\text { Replaced with } \\
\text { Slag }\end{array}$ & $\begin{array}{c}\text { W/c } \\
\text { ratio }\end{array}$ & Shape (length x width x depth) \\
\hline $45 \mathrm{MPa}$ & $350 \mathrm{~kg} / \mathrm{m}^{3}$ & 30 & 0.48 & Square $(200 \mathrm{~mm} \times 200 \mathrm{~mm} \times 120 \mathrm{~mm})$ \\
\hline $30 \mathrm{MPa}$ & $300 \mathrm{~kg} / \mathrm{m}^{3}$ & 0 & 0.48 & $\begin{array}{c}\text { Rectangular }(300 \mathrm{~mm} \times 100 \mathrm{~mm} \times 120 \\
\mathrm{mm})\end{array}$ \\
\hline $55 \mathrm{MPa}$ & $270 \mathrm{~kg} / \mathrm{m}^{3}$ & 0 & 0.48 & $\begin{array}{c}\text { Rectangular }(300 \mathrm{~mm} \times 100 \mathrm{~mm} \times 120 \\
\mathrm{mm})\end{array}$ \\
\hline
\end{tabular}


Two shapes of slabs were made: square slabs, and rectangular slabs. The slabs were originally designed as square-shaped slabs, with dimensions of $200 \mathrm{~mm} \times 200 \mathrm{~mm} \times 120 \mathrm{~mm}$ (length $\times$ width $x$ depth). Later, it was decided to use rectangular-shaped slabs instead of the square slabs, with dimensions of $300 \mathrm{~mm} \times 100 \mathrm{~mm} \times 120 \mathrm{~mm}$ (length $\times$ width $\times$ depth). This change was made because it seemed that the joint and the area immediately surrounding the joint were of particular interest regarding deterioration, because this is where the damage would start. It was theorized that a longer joint would have allowed more opportunity to observe what degradation phenomena could be taking place.

Mass loss was originally proposed to evaluate the damage experienced by the concrete. Certain measures were taken to reduce scaling damage, such as using different salt concentrations that would result in less scaling.
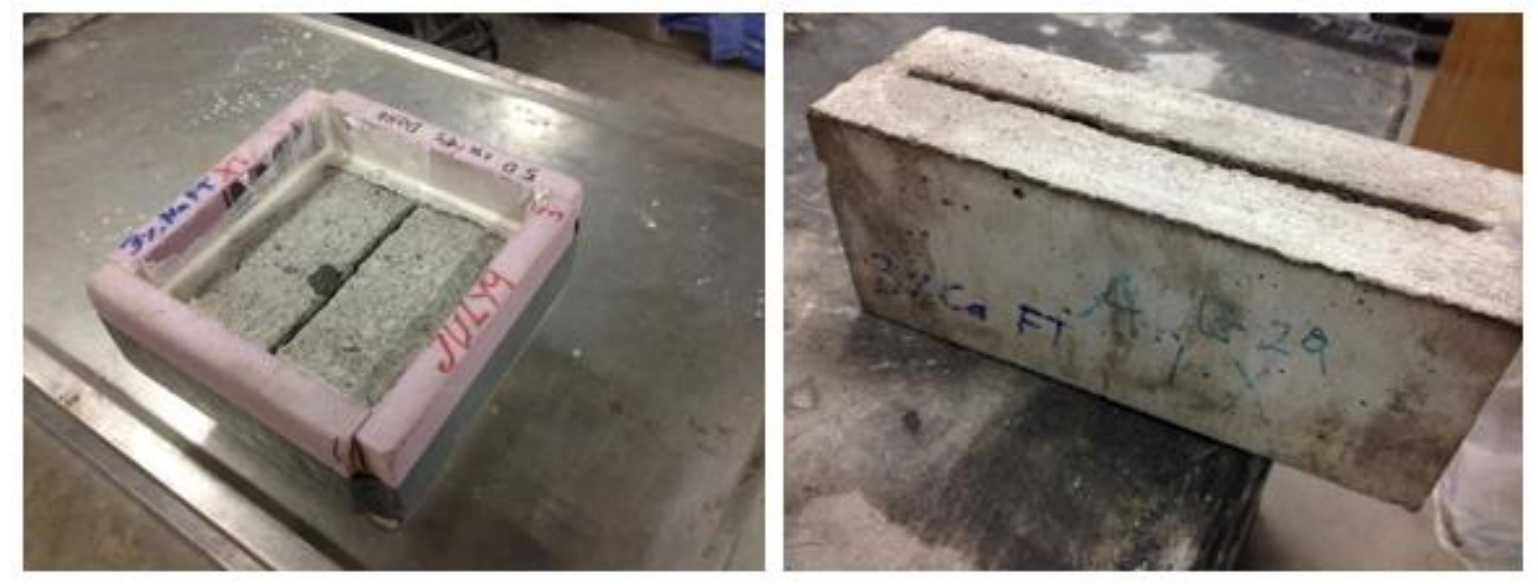

Figure 3-1 The two types of slabs used in the experiment: square slabs, $200 \mathrm{~mm} \times 200 \mathrm{~mm} 120 \mathrm{~mm}$ (left) and rectangular slabs, $300 \mathrm{~mm} \times 100 \mathrm{~mm} \times 120 \mathrm{~mm}$ (right).

Because this change from the square slabs to the rectangular slabs was chronological, the slabs made with the $45 \mathrm{MPa}$ mix, were all square $(200 \mathrm{~mm} \times 200 \mathrm{~mm} \times 120 \mathrm{~mm})$, and the samples 
made with the other two mixes (i.e. the $30 \mathrm{MPa}$ mix and $55 \mathrm{MPa}$ mix) were rectangular (300 mm $\times 100 \mathrm{~mm} \times 120 \mathrm{~mm})$.

In addition to the concrete slabs, concrete prisms were cast with the low cement content mix ( $270 \mathrm{~kg} / \mathrm{m}^{3}$ cement). These prisms were $30.48 \mathrm{~cm}$ by $7.62 \mathrm{~cm}$ by $7.62 \mathrm{~cm}$ (12 inches by 3 inches by 3 inches). They were cast with studs at the ends according to ASTM C157/C157M Test Method for Length Change of Hardened Hydraulic-Cement Mortar and Concrete, and measured according to ASTM C490/C490M Practice for Use of Apparatus for the Determination of Length Change of Hardened Cement Paste, Mortar, and Concrete.

\subsubsection{Mix Design}

Three concrete mix designs were used: one for a high cement content, one for a medium cement content, and one for a low cement content. The amount of cement for each of these respective mixes was $350 \mathrm{~kg} / \mathrm{m}^{3}, 300 \mathrm{~kg} / \mathrm{m}^{3}$, and $270 \mathrm{~kg} / \mathrm{m}^{3}$. For the high cement content mix, $30 \%$ of the cement was replaced with blast furnace slag. The resulting strengths of the mix designs were 45 $\mathrm{MPa}, 30 \mathrm{MPa}$, and $55 \mathrm{MPa}$, respectively.

A water to cementing materials ratio of 0.48 was used for the mix designs. The coarse aggregate used was a limestone aggregate, supplied by Lafarge from the Dundas Quarry, with a dry-rodded density of $1686.2 \mathrm{~kg} / \mathrm{m}^{3}$. The fine aggregate was from the Caledon Quarry. The cement used was St. Lawrence General Use cement.

As for chemical admixtures, water reducer and air entrainer were both used in every mix. The water reducer that was used was MasterPozzolith 210, and the air entrainer that was used was MasterAir AE 200. These two brands were specified to be able to function properly if used 
together. These products came with suggested ranges of how much should be used in a concrete mix. The recommendation for the water reducer, MasterPozzolith 210, was $130 \mathrm{~mL}$ to $390 \mathrm{~mL}$ per $100 \mathrm{~kg}$ of cementitious materials. The recommendation for the air entrainer, MasterAir AE 200 , was $8 \mathrm{~mL}$ to $98 \mathrm{~mL}$ per $100 \mathrm{~kg}$ of cementitious materials. The maximum recommended value for the water reducer ( $390 \mathrm{~mL}$ per $100 \mathrm{~kg}$ of cementitious materials) was found to give a desirable slump value during casting (around $50 \mathrm{~mm}$ slump). Using $75 \%$ of the maximum range for the air entrainment (75.5 mL per $100 \mathrm{~kg}$ of cementitious materials) was found to give required air content values (i.e. around 5-6\%) when testing fresh concrete with the pressure method, ASTM C231. As an example, for a $25 \mathrm{~L}$ mix of concrete, that equated to $26.3 \mathrm{~mL}$ of water reducer and $3.6 \mathrm{~mL}$ of air entrainer.

The values for the mix design were determined as follows: first, a cement content was selected (either $350 \mathrm{~kg} / \mathrm{m}^{3}$ for the high cement mix, $300 \mathrm{~kg} / \mathrm{m}^{3}$ for the medium cement mix, or $270 \mathrm{~kg} / \mathrm{m}^{3}$ for the low cement mix). Next, since a fixed water-cement ratio of 0.48 was used, the amount of water required was calculated. The volume of coarse aggregate was determined according to the fineness modulus of the fine aggregate. A goal of $6 \%$ volume of the concrete being air was assumed for the mix design. All of the known values of volume of each material per cubic meter were subtracted from one cubic meter to determine the volume of the sand.

The mixing procedure was as follows:

- 1 minute mixing SSD (saturated surface dry) coarse aggregate and oven-dry fine aggregate

- 30 seconds adding half of the total water while mixing

- 30 seconds mixing 
- 1 minute break

- 30 seconds adding cement (or cement/slag mixture) while mixing

- 30 seconds adding the other half of the water (with admixtures mixed into the water) while mixing

- 1 minute mixing

- 1 minute break

- 2 minutes mixing

- 2 minutes break

- 2 minutes mixing

\subsubsection{Casting/ Curing/ Saw Cuts}

All slabs were allowed to cure in a moist room ( $100 \%$ relative humidity, $23^{\circ} \mathrm{C}$ ) for 14 hours, after which the concrete slabs were demoulded and a joint ( $6 \mathrm{~mm} \pm 1 \mathrm{~mm}$ width, $75 \pm 1 \mathrm{~mm}$ depth) was saw cut into the centre of the slabs, lengthwise. The insides of the joints were cleaned of debris with a hose and the slabs were left to cure for another six days in the moist room. Following this initial curing period, the slabs were left in a shrinkage room for another six days, which was the same temperature, but $50 \%$ relative humidity. For the slabs other than the first batch of the slabs (i.e. the $45 \mathrm{MPa} \mathrm{mix}$ ), the slabs immediately went to the shrinkage room for the entire duration after the saw cut, rather than spending 6 days in the moist room and then the rest of the time in the shrinkage room.

Figure 3-2, below, shows a rectangular concrete slab sample with the side of the joint sealed to prevent the salt solution from leaking. The procedure for sealing the joint is discussed below. 


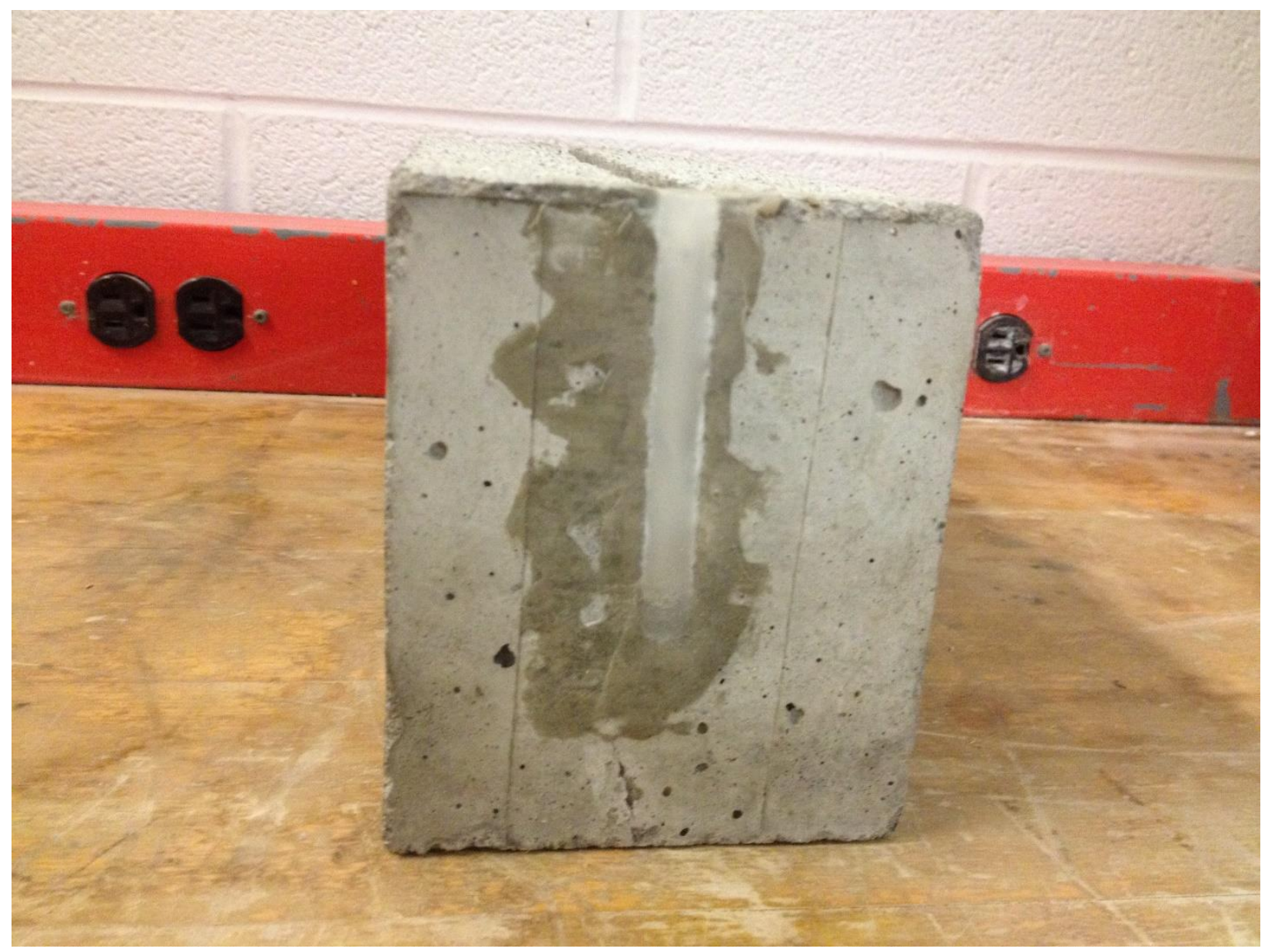

Figure 3-2 A rectangular slab with a sealed joint to prevent leaking of salt solution.

After the last day in the shrinkage room, the samples were removed to ambient conditions where the joints were sealed, and a dike was installed to prevent leakage and salt solution from running off the surface. The joints were sealed as follows: two pieces of double-sided tape (approximately 1-2 $\mathrm{mm}$ thick, and with a length approximately equal to the depth of the saw cut) were held lengthwise, with the centre of each strip aligned with the edge of the other strip. Next, each strip was folded over the opposite piece, and this newly formed thicker piece of double-sided tape was guided into the concrete joint. Next, an epoxy (LePage PL) was squeezed over the outside of the double-sided tape that was placed into the joint. After this had dried, more epoxy was applied 
over the sides of the concrete, and pieces of Styrofoam extending above the surface of the slabs were added. The slabs were left in these conditions for a day so that the epoxy could dry, and then their freeze-thaw and wetting cycles began.

\subsubsection{Compressive Strength}

For each batch of concrete that was used to create concrete slabs for testing, concrete cylinders (100 mm diameter $\times 200 \mathrm{~mm}$ height) were also made from the same batch. These concrete cylinders were made to ensure consistency (of compressive strength and RCPT) between different batches of each concrete mix. At an age of 28 days, the compressive strength of the concrete cylinders was measured by loading the cylinders to failure, with at least three cylinders being used for each mix. This was performed according to ASTM C39. The compressive strength values were obtained to see if there was any variability in the strength of one mix to another and what effect that would have had on the loading results (e.g. T-tests were performed to see if stronger mixes resulted in stronger samples when doing the strength loss test).

\subsubsection{Air Content}

Fresh concrete was taken from each batch of concrete used for slabs to measure the air void content of the concrete. $7 \mathrm{~L}$ was needed to fill the vessel used for the test. Since the air void content of concrete is very important in its resistance to freeze-thaw damage, it was important to have consistency in the air void content, so that any variation in damage was indeed from the samples' exposure conditions and not from a difference in the concrete's ability to resist freezethaw damage. Despite the fact that the same amount of air entrainment was used for each mix, the air content was still measured for each batch to ensure consistency in the concrete's 
resistance to freeze-thaw cycles. Furthermore, this was done to ensure that differences in the damage being observed from freeze-thaw cycles was due to different exposure conditions, not just a difference in the effectiveness of air entrainment.

The air content was determined using ASTM Standard C138/C138M Test Method for Density (Unit Weight), Yield, and Air Content (Gravimetric) of Concrete. Before testing, the head of the air pressure apparatus was pumped up to full pressure (with valves closed) followed by an immediate release of pressure, to clear any water or bubbles that may have been present within the piece. The same was done with the valves open, to clear any bubbles or debris that may have been present within the valves. To begin the test, the $7 \mathrm{~L}$ container was filled with fresh concrete in thirds. After each third was filled, the surface of the concrete was rodded with a $1.27 \mathrm{~cm}(0.5$ inch) thick rod 25 times, not striking the bottom of the container, and going to the depth of approximately 1 inch above the previous layer. After each layer was rodded, the sides of the container were firmly struck with a rubber headed mallet several times. After the third layer was filled, rodded, and the sides of the container were struck, the surface was levelled with the rod. Excess concrete was wiped from the container where the lid would rest. The lid was clamped in place onto the container. The valves were opened, and water was repeatedly added into one of the valves with a syringe until the water was seen to be leaving from the opposite valve, which ensured that there was no air present between the surface of the concrete and the base of the lid. The valves were then closed, the lid was pumped to the desired pressure, and the release switch was pressed, which then revealed the air content of the concrete mixture. 


\subsubsection{Rapid Chloride Permeability Test (RCPT)}

Concrete cylinders were also made from the same batches as the slabs and used for the Rapid Chloride Permeability Test. This test was performed according to ASTM C1202, Electrical Indication of Concrete's Ability to Resist Chloride Ion Penetration. This was to ensure that the concrete used in each slab had a consistent permeability value, despite being made from concrete batches prepared on different days. These tests were performed by an external lab.

\subsection{Freeze-thaw and wetting cycles}

\subsubsection{Salts Used}

The salts that were used for the slabs undergoing freeze-thaw/ wetting cycles and the prisms for expansion were sodium chloride, calcium chloride, and magnesium chloride. The concentrations used for the freeze-thaw and wetting cycles were 3\%, 10\%, and 15\%. Freeze-thaw cycles were conducted at concentrations of $3 \%$ and $10 \%$. Wetting cycles were conducted at concentrations of $10 \%$ and $15 \%$. In addition to the salts used for freeze-thaw and wetting cycles of concrete slabs, the concrete prisms for expansion were soaking in $15 \%$ salt solutions.

With the freezer in the experiments set to $-18^{\circ} \mathrm{C}$, salt solutions beyond a certain concentration would no longer freeze. As the samples underwent their cyclical exposure, some of the solution would evaporate during the thawing period of the freeze-thaw cycles or during the wetting cycles while in the $36^{\circ} \mathrm{C}$ oven. In these cases, more salt solution would be added to replace the evaporated water, effectively increasing the salt concentration beyond their initial levels, as can also be seen in the field in the case of repeatedly subsequent snowfalls. Thus, the lower concentration samples (i.e. $3 \%$ and $10 \%$ salt solution) were chosen for freeze-thaw cycles, 
because starting with a $15 \%$ salt solution and gradually increasing it would very quickly result in a solution that cannot freeze. The freezing temperature of salt solutions of different concentrations was discussed in Section 2.3, Freeze-thaw and wet-dry damage with salt exposure.

Also, water without salt was used for some of the slabs for wetting cycles. These slabs were undergoing freeze-thaw and wet-dry cycles (alternating every 5 cycles). The freeze-thaw cycles would use salt solution as was normally done, but during wetting cycles, plain water without any salt would replace the evaporated solution. An identical set of three slabs underwent the same procedure with salt solution during the wetting phase, to examine the importance of wetting with salt solution vs wetting with water.

The table below summarizes the salt solutions and cycles used for the testing.

Table 3-2 Concentrations used for different types of salt solutions and exposure conditions used for testing.

\begin{tabular}{|c|c|c|c|}
\hline Type of Salt & Freeze-thaw & Wetting & Freeze-thaw and wetting \\
\hline $\mathrm{NaCl}$ & $3 \%, 10 \%$ & $15 \%$ & $\begin{array}{c}10 \%, \text { and 10\% (with just water } \\
\text { used during wetting) }\end{array}$ \\
\hline $\mathrm{CaCl}_{2}$ & $3 \%, 10 \%$ & $15 \%$ & $10 \%$ \\
\hline $\mathrm{MgCl}_{2}$ & $3 \%$ & $15 \%$ & $10 \%$ \\
\hline
\end{tabular}

The cycles that the samples underwent are listed in the table below. A detailed description follows in the sections below. 
Table 3-3 Explanation of cycles (FT, W, and FTW) that the samples underwent

\begin{tabular}{|c|c|c|}
\hline Exposure Name & Explanation & Cycles Performed \\
\hline Freeze-thaw (FT) & $\begin{array}{c}\text { Freeze at }-18^{\circ} \mathrm{C} \text { for } 8 \text { hours, } \\
\text { thaw at room temperature } \\
\text { for } 16 \text { hours. }\end{array}$ & $\begin{array}{c}50 \text { repeated freezing and } \\
\text { thawing cycles. }\end{array}$ \\
\hline Wetting (W) & $\begin{array}{c}\text { Samples left in } 36^{\circ} \mathrm{C} \text { oven for } \\
3.5 \text { days, then the } \\
\text { evaporated solution was } \\
\text { refilled. }\end{array}$ & $\begin{array}{c}50 \text { repeated cycles of wetting } \\
\text { at high temperature. }\end{array}$ \\
\hline Freeze-thaw/ wetting (FTW) & $\begin{array}{c}5 \text { cycles of FT followed by } 5 \\
\text { cycles of W, alternating until } \\
\text { all cycles are complete. }\end{array}$ & $\begin{array}{c}50 \text { total cycles: } 25 \mathrm{FT} \text { cycles } \\
\text { and } 25 \mathrm{~W} \text { cycles. }\end{array}$ \\
\hline
\end{tabular}

The reason that 50 cycles were used was because this proposed evaluation technique was based on the current standard salt scaling test which involves 50 cycles of freezing/ thawing. It is thought that the 50 cycles will provide accelerated results in a reasonable period of time.

\subsubsection{Freeze-thaw Cycles}

The freeze-thaw cycles were performed according to ASTM C672, Standard Test Method for Scaling Resistance of Concrete Surfaces Exposed to Deicing Chemicals. The slabs, with salt solution in the joints and/ or above the surface (depending on if they were the earlier slabs that had dikes, or the later slabs that did not) underwent the following procedure:

- Samples were placed into the freezer at $-18^{\circ} \mathrm{C}$ for $8 \pm 2$ hours.

- Samples were removed from the freezer and left in ambient conditions for $16 \pm 2$ hours, where they thawed.

- During thawing, there was the possibility of some solution evaporating. If any evaporation had taken place, the slabs were topped off with the salt solution that had evaporated, and the cycles continued. 
These cycles were repeated for the FT samples until a total of 50 cycles had been reached.

\subsubsection{Wetting Cycles}

The wetting cycles differed from wet-dry cycles, and were completed as follows:

- Samples were placed into an oven set to $36^{\circ} \mathrm{C}$. This temperature was selected because the salt crystals could form into different phases at higher temperatures.

- Samples were left to dry for 3-4 days (Monday - Friday, or Friday - Monday) after having their joints refilled with salt solution.

These cycles were repeated for the wetting samples until a total of 50 cycles had been reached.

These samples were considered wetting cycles and not wet-dry cycles for two reasons. Firstly, the goal was to develop an accelerated test. Thus, combining the wetting phase with the drying phase (by keeping the samples in the $36^{\circ} \mathrm{C}$ oven the entire time) ultimately reduced the total time required to complete one cycle. Secondly, the calcium chloride and magnesium chloride did not experience complete drying when left in the oven at this temperature, even when left there for several weeks. This was similar to what was experienced in some field conditions and past research showing that calcium chloride and magnesium chloride solutions take longer to evaporate (Farnam et al., 2015b; Spragg et al., 2011; Wang et al., 2018). Thus, since no complete drying took place, these were not wet-dry cycles, but rather, wetting at high temperature.

\subsubsection{Freeze-thaw and Wetting Cycles}

The FTW samples had been exposed to alternating FT and W cycles, as outlined above, alternating between FT and W every 5 cycles. These cycles continued until a total of 50 cycles had been reached. 


\subsubsection{Summary of all Samples}

A list of all of the cyclical exposures and all of the concrete mixes are shown in Table 3-4, below.

Table 3-4 All cyclical exposures and different mixes used.

\begin{tabular}{|c|c|}
\hline $\begin{array}{l}\text { Mix Name (Compressive } \\
\text { Strength) }\end{array}$ & $\begin{array}{l}\text { Sample Procedure (Salt Solution and } \\
\text { Cycles) }\end{array}$ \\
\hline $45 \mathrm{MPa}$ & $3 \% \mathrm{NaCl} \mathrm{FT}$ \\
\hline $45 \mathrm{MPa}$ & $10 \% \mathrm{NaCl} \mathrm{FT}$ \\
\hline $45 \mathrm{MPa}$ & $10 \% \mathrm{CaCl}_{2} \mathrm{FT}$ \\
\hline $45 \mathrm{MPa}$ & $3 \% \mathrm{NaCl} F \mathrm{FTW}$ \\
\hline $45 \mathrm{MPa}$ & $10 \% \mathrm{NaCl} F T W$ \\
\hline $45 \mathrm{MPa}$ & $10 \% \mathrm{NaCl}$ FTW (H2O during wetting) \\
\hline $45 \mathrm{MPa}$ & $10 \% \mathrm{CaCl}_{2} \mathrm{FTW}$ \\
\hline $30 \mathrm{MPa}$ & $3 \% \mathrm{CaCl}_{2} \mathrm{FT}$ \\
\hline $30 \mathrm{MPa}$ & $3 \% \mathrm{MgCl}_{2} \mathrm{FT}$ \\
\hline $30 \mathrm{MPa}$ & $15 \% \mathrm{NaCl} W$ \\
\hline $30 \mathrm{MPa}$ & $15 \% \mathrm{MgCl}_{2} \mathrm{~W}$ \\
\hline $30 \mathrm{MPa}$ & $15 \% \mathrm{CaCl}_{2} \mathrm{~W}$ \\
\hline $55 \mathrm{MPa}$ & $3 \% \mathrm{NaCl} F \mathrm{~T}$ \\
\hline $55 \mathrm{MPa}$ & $3 \% \mathrm{CaCl}_{2} \mathrm{FT}$ \\
\hline $55 \mathrm{MPa}$ & $3 \% \mathrm{MgCl}_{2} \mathrm{FT}$ \\
\hline $55 \mathrm{MPa}$ & $15 \% \mathrm{CaCl}_{2} \mathrm{~W}$ \\
\hline $55 \mathrm{MPa}$ & $10 \% \mathrm{MgCl}_{2} \mathrm{FTW}$ \\
\hline $55 \mathrm{MPa}$ & $15 \% \mathrm{MgCl}_{2} \mathrm{~W}$ \\
\hline $55 \mathrm{MPa}$ & $10 \% \mathrm{CaCl}_{2} \mathrm{FTW}$ \\
\hline $55 \mathrm{MPa}$ & $15 \% \mathrm{MgCl}_{2} \mathrm{~W}$ \\
\hline $55 \mathrm{MPa}$ & $15 \% \mathrm{NaCl} W$ \\
\hline
\end{tabular}

\subsection{Proposed Evaluation Techniques}

Visual inspection, mass loss, and strength loss were used to evaluate the damage that occurred from freeze-thaw and wetting cycles. How these tests were performed is explained in the following sections. 


\subsubsection{Visual Inspection (Visual Index)}

A visual index was developed to assess the deterioration that had taken place in concrete based on a visual inspection as a qualitative measurement. A scale of 1-5 was created, with 1 being the least damaged concrete, gradually increasing to 5 being the most damaged concrete. Representative samples were selected and photographed to give examples of how the visual index could be used as a measure. A similar scale, but with a rating of 1-3, was also used for quantifying the inside of the joint, rather than the surface of the concrete.

The index created from the visual inspection was not created to necessarily correlate directly with other quantitative measures such as mass loss. The visual index was created to evaluate to what extent the damage observed in the concrete slabs was representative of the damage seen in the concrete pavements failing early in their life cycles. As an example, a sample could have had a high mass loss value from excessive scaling, but spalling around the joint was considered more representative of the damage in pavements. In this case, the mass loss value would be relatively high, but the visual index created would give the sample score suggesting that the severity of damage was low.

\subsubsection{Mass Loss}

Mass loss was a quantitative test performed to assess the deterioration of the concrete slabs subjected to different exposure conditions and salt solutions.

As the freeze-thaw and wetting cycles progressed, the concrete slabs experienced surface scaling, cracking, and spalling. This scaled and spalled material was used in the summation of the 
mass loss. The dike around the edges of each concrete sample kept the loose material within the joint of the slab or on the surface of the slab.

The mass loss was collected and calculated as follows: after the concrete slabs had undergone their fifty cycles, they were left in ambient laboratory conditions for all of the solution to evaporate. After the solution had evaporated, the joint sealant (covering the side of the joints) was removed by pulling it out from the top to the bottom. The slab was tilted and shaken, with the open end of the joint angled into a plastic container to collect all of the debris that had accumulated in the joint. The same was done with the sealant on the joint on the opposite side because it was possible that some material had stuck to the sealant.

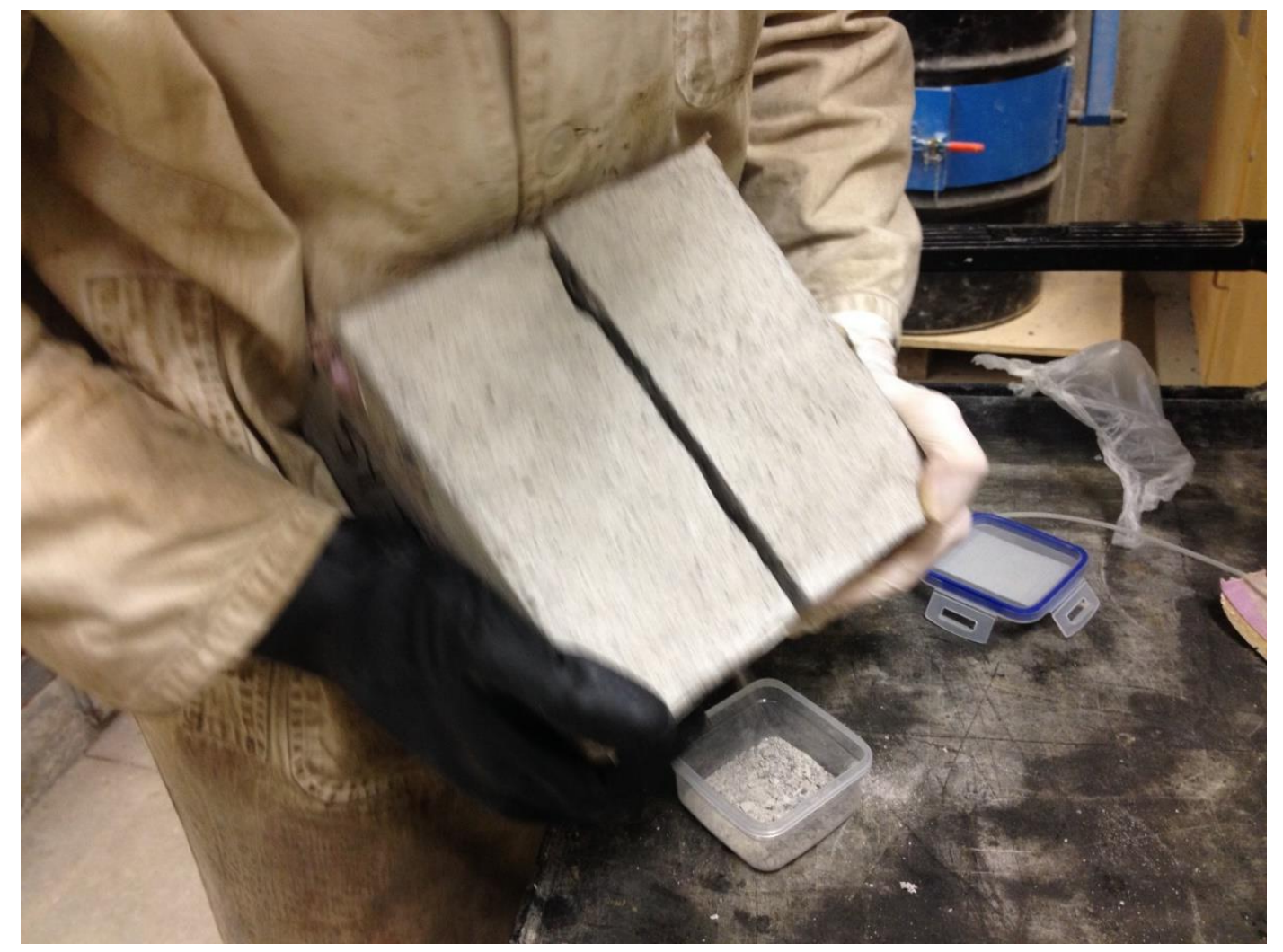

Figure 3-3 Removing material from inside the joint of a concrete slab and collecting it inside a container. 
With the scaled/ damaged material in the container, enough acetone was added into the container to cover the scaled/ spalled concrete material. The acetone was used to remove water that may have been present in the concrete material. The containers were wrapped with cling wrap, and the airtight containers were closed, and allowed to sit like this for at least one week.

After this period of soaking in acetone was completed, the concrete samples were placed into paper cupcake moulds. These moulds with the samples were placed into the desiccator, with silica gel and soda lime sitting in the bottom of the desiccator to prevent moisture and carbonation from affecting the weight.

The desiccator was attached to a vacuum pump, and the vacuum pump removed any air in the desiccator. The desiccator was placed in a heat room $\left(38^{\circ} \mathrm{C}\right)$ for one week to ensure that any acetone still present would dissolve. During this week in the heat room, the desiccator was attached to the vacuum pump and vacuumed daily. However, after the desiccator's first day in the heat room, when it was removed to be vacuumed again, the silica gel and soda lime were replaced. This was because after the first day of being in the heat room, it was expected that the silica gel would have changed from a blue colour to a pink colour, indicating that it had absorbed as much moisture as it could, and that it would have to be replaced to continue to be able to reduce the moisture level in the desiccator. For this reason, the desiccator was monitored daily, and in the instances where it was necessary to replace the silica gel or soda lime, this was done before the vacuuming was repeated. 
After the samples had been in the desiccator in the heat room for at least a week, it was deemed that the concrete had sufficiently dried, so the samples were weighed. This mass was recorded as the mass loss value.

\subsubsection{Strength Loss}

Two methods of measuring the strength loss of the slab samples were proposed:

1. A centre-point loading setup with a single static load for failure being recorded.

2. Fatigue loading, with the load alternating between a maximum and minimum value, and the number of loading cycles to failure being recorded.

Ultimately, the first option was selected.

It is also important to note that the proposed strength loss evaluation technique was not meant to replicate a failure the way that PCC pavements fail in the field. Rather, this test was a measure of the strength loss of the concrete slabs after being exposed to deicing salts and freezing/ thawing conditions.

\subsubsection{Loading Apparatus and Loading Procedure}

The loading apparatus that was designed for loading started with a stainless-steel base plate, with angles welded to it for supporting the rollers in place. Vertical bars were also welded to the plate to centre a horizontal rod for loading above the sample's joint. The base plate had a width of $22.86 \mathrm{~cm}$ and a length of $35.56 \mathrm{~cm}$, giving it enough room for either of the slab configurations (i.e. square slabs and rectangular slabs). Four pairs of angles were welded onto the plate, each pair spaced $2.54 \mathrm{~cm}$ ( 1 inch) apart, so that a $2.54 \mathrm{~cm}$ roller (a stainless-steel bar with a diameter of one inch) could be held securely in place during loading. The pairs of angles were spaced so 
that the outer edges of the rollers would align with the outer edges of the slabs when the slabs were placed above them. That is to say, the two pairs of inner rollers had an outside to outside distance of $100 \mathrm{~mm}$, and the two outer rollers had an outside to outside distance of $200 \mathrm{~mm}$, matching the width of the $100 \mathrm{~mm} \times 300 \mathrm{~mm} \times 120 \mathrm{~mm}$ slab and the $200 \mathrm{~mm} \times 200 \mathrm{~mm} \times 120$ $\mathrm{mm}$ slab, respectively. This means that the centre-to-centre distance of the rollers were $74.6 \mathrm{~mm}$ or $174.6 \mathrm{~mm}$, depending on if the square or the rectangular slabs were being loaded, which dictated the placement of the rollers.

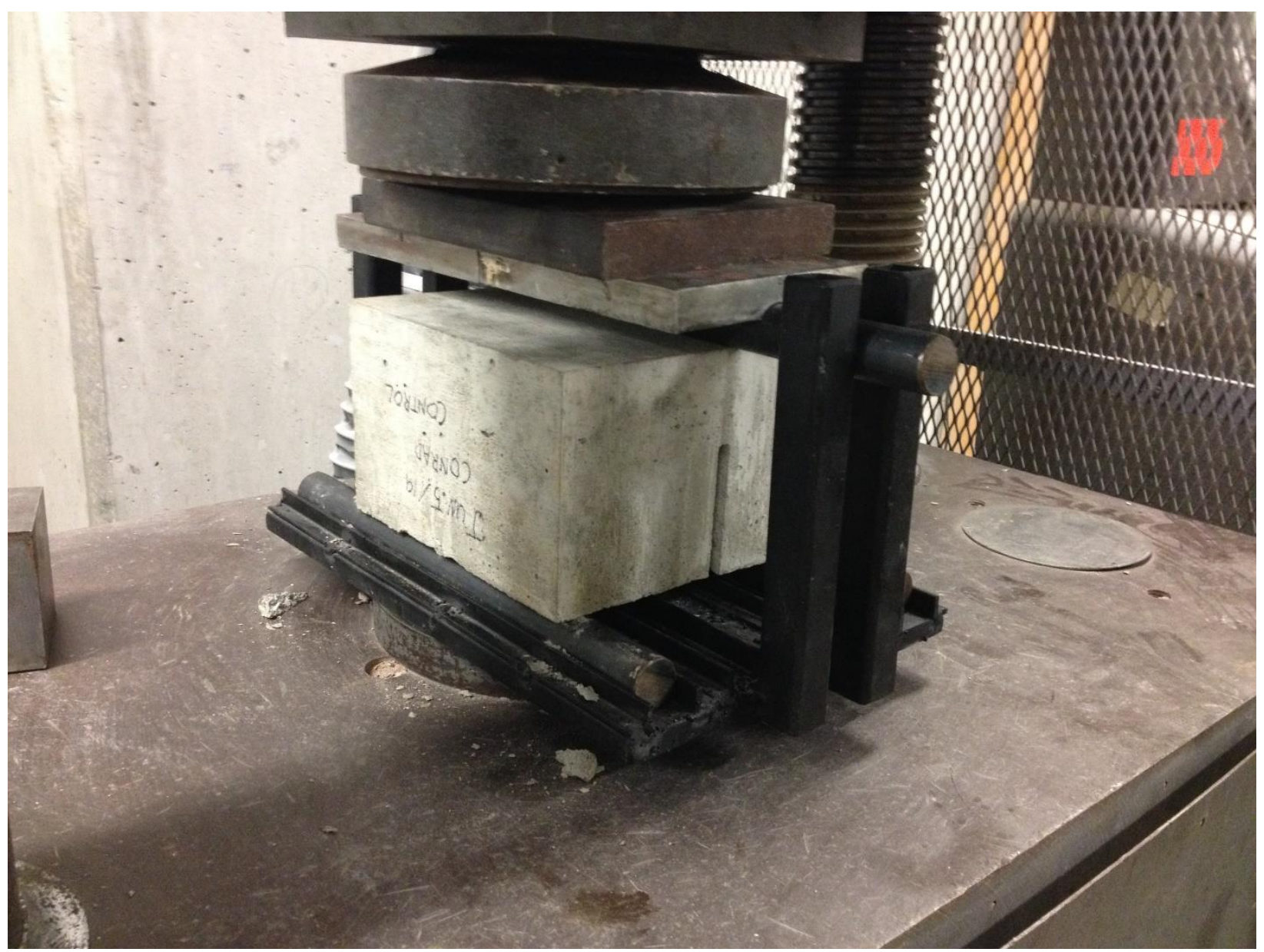

Figure 3-4 Square slab in the designed loading setup with adjustable rollers to load both the square and the rectangular slabs. 
Vertical bars were welded on the side of the base plate, $25.4 \mathrm{~mm}$ apart, and spaced equally away from the centre line. This allowed the top roller to be placed in the centre of the sample, avoiding eccentric loading on the sample. This also avoided torsional loading on the sample by keeping the rod parallel with the joint in the concrete slabs.

A schematic diagram showing a cross-sectional view of the loading setup is shown in the figure below.

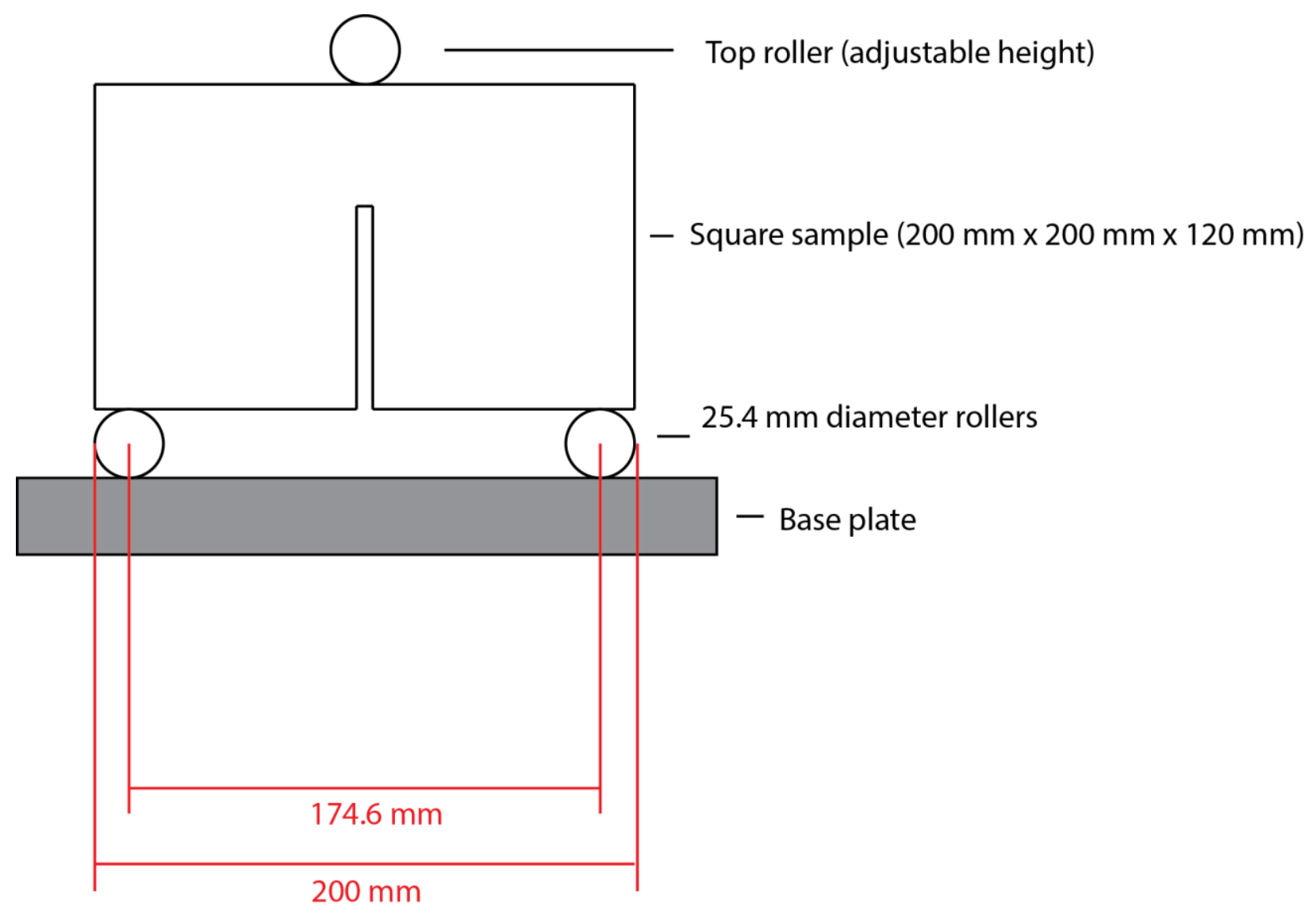

Figure 3-5 Cross-sectional view of sample loading setup. 


\subsubsection{Fatigue Loading}

It was hypothesized that fatigue loading in the field (in the form of vehicular loads) may play a role in further damaging the concrete that is already weakened from the physical and chemical damage from salts and freeze-thaw cycles. This project did not include such testing, but it could be implemented through interrupting freeze-thaw/ wetting cycles periodically and temporarily loading the slabs under fatigue loading before returning them to continue their freeze-thaw/ wetting cycles.

However, the experiments in this thesis did include some limited fatigue testing. Fatigue loading in these experiments was applied at the end of the exposure cycles using an MTS machine. The ramp applied for the initial loading of the fatigue testing was a load applied at a rate of 1 $\mathrm{kN} /$ minute to ensure that the sample would not immediately fail from a sudden load being applied. This loading rate of $1 \mathrm{kN} /$ minute increased from a load of $0 \mathrm{kN}$ until the maximum load for the cyclical loading was reached, after which the load on the sample oscillated from $1 \mathrm{kN}$ to its maximum load $(7 \mathrm{kN})$ at a rate of $5 \mathrm{~Hz}$. The reason that the minimum load applied on the samples at all times was $1 \mathrm{kN}$ and not $0 \mathrm{kN}$ was to ensure that the sample would be held in place and to avoid impact loading; if the load had returned to $0 \mathrm{kN}$ each time, the loading head of the machine would have to lose contact with the sample, making it not physically secure in its place, and also causing an impact load each time the load would be applied again. By setting the minimum load to $1 \mathrm{kN}$, the loading head was constantly in contact with the sample, the sample was secured in place, and no impact loading took place.

Fatigue loading was not used in this test because it was found that static loading was more effective. This was because an appropriate loading range could not be determined for carrying 
out fatigue loading to sample failure, because the level of deterioration between different exposures was significantly different. Samples that underwent fatigue loading would either fail immediately before the first maximum load value was reached, or they would not fail at all after 125,000 cycles of fatigue loading.

\subsubsection{Load Adjustment Based on Variability of Saw Cut}

The depth and width of the saw cut could vary because the cut was made using a saw, and the measurement/ cut made by the saw operator might not be exact every time. With a different depth of the saw cut, the value for " $y$ " in stress = My/I would be different, and the moment of inertia (I) would be different depending on the width of the saw cut. Since the values of y and I could vary from one sample to another, the value of $\mathrm{M}$ could be adjusted to ensure that the stress in the concrete was consistent across all samples being tested.

As an example, if the width of the joint was $5 \mathrm{~mm}$ instead of the standard $6 \mathrm{~mm}$, and the length of the joint was $77 \mathrm{~mm}$ instead of the standard $75 \mathrm{~mm}$, the load during testing could be changed to adjust the moment the sample experiences so that this sample with a slightly varied saw cut would have the same stress as a standard sample being loaded with the same amount of force. With a joint depth of $77 \mathrm{~mm}$ instead of $75 \mathrm{~mm}$, the remaining depth of the section would be 43 $\mathrm{mm}$ instead of $45 \mathrm{~mm}$. This means that $\mathrm{y}$, the neutral axis, would have a value of $21.5 \mathrm{~mm}$ rather than $22.5 \mathrm{~mm}$, and that $\mathrm{h}$, the depth used in the moment of inertia calculation, would be $43 \mathrm{~mm}$ instead of $45 \mathrm{~mm}$. 


\subsection{Scanning Electron Microscope}

A chisel was used to remove small chunks from the concrete slabs that had completed the fifty freeze-thaw and/ or wetting cycles. These pieces of concrete from the deteriorated slabs were required to be sufficiently dried before being carbon coated and prepared for analysis under SEM. The pieces of concrete were placed into a desiccator with silica gel and soda lime, the desiccator was hooked up to a vacuum pump via a rubber tube, the air was removed from the desiccator using the vacuum, and the desiccator was stored in a warm room $\left(38^{\circ} \mathrm{C}\right)$. For one week, the desiccator was removed from the heat room daily and attached to the vacuum pump again. As for the carbon coating, this was performed by the Earth Sciences lab at University of Toronto. The concrete samples were prepared for SEM without the use of water (to not disrupt or affect the salts present from the exposure conditions during testing).

The carbon-coated samples had a small dab of conductive paint put onto the surface before being placed into the SEM machine. The concrete samples were observed using the SEM for any peculiarities such as infilled material, cracks, filled air voids, and salt crystallization. EnergyDispersive X-ray Spectrometry (EDS) was used to analyze the chemical composition of areas of interest. Pictures were taken of areas of interest, and reports were automatically generated showing selected areas and the chemical makeup of selected points.

\subsection{Expansion of Prisms Soaking in Salt Solution}

\subsubsection{Mixing Procedure}

The mixing procedure for the concrete prisms was the same as the mixing procedure for the concrete slabs. A water-cement ratio of 0.48 was used, which was the same as the concrete slabs 
used for freeze-thaw and wetting cycles. Air-entrainment admixture was excluded in this mix design. The concrete prisms were cast in stainless steel moulds with dimensions $30.48 \mathrm{~cm}$ by 7.62 $\mathrm{cm}$ by $7.62 \mathrm{~cm}$ (12 inches by 3 inches by 3 inches). Steel studs with rounded ends (which would be used for measuring the change in length of the concrete) were aligned in the mould before the fresh concrete was placed in the moulds. Measurements were taking using a Humboldt Length Comparator H-3250D, with measurements taken to the nearest $0.002 \mathrm{~mm}$. A photo of the apparatus with a comparative rod is shown below.

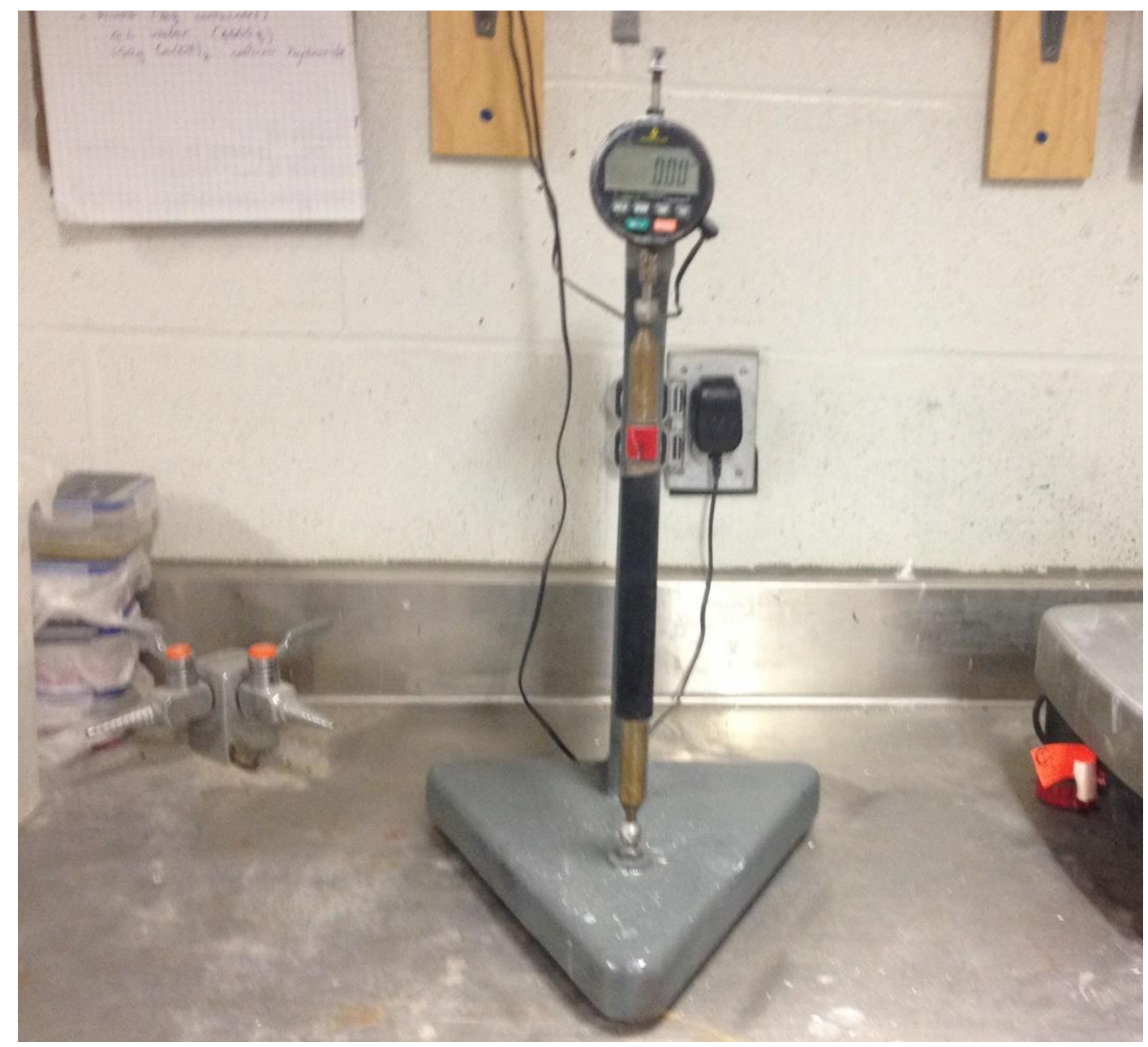

Figure 3-6 The Humboldt Length Comparator H-3250D with a comparator rod in place, used for measuring length changes of prisms. 


\subsubsection{Measurements and Calibration}

The procedure for measurements and calibration was taken from ASTM C157/C157M Test Method for Length Change of Hardened Hydraulic-Cement Mortar and Concrete.

After curing and demoulding, the concrete prisms had their length measured to the nearest 0.002 mm using the Humboldt Length Comparator H-3250D, and the initial lengths after demoulding were recorded. These measurements were taken using a comparative rod with a recorded length. Since this comparative rod was used regularly, a second comparative rod was also kept aside in the lab and used less frequently to ensure that the original comparative rod had a consistent length. A length comparison could be taken between these two rods in the event of one of the rods showing a gradual change in length over time.

After the demoulding measurements were taken, the prisms were placed into lime water (10\% Calcium Hydroxide by mass, to ensure a saturated solution condition), as was instructed in ASTM C157/C157M Test Method for Length Change of Hardened Hydraulic-Cement Mortar and Concrete. After one day in lime water, the prisms were measured again before being placed into a solution of either $15 \%$ sodium chloride, $15 \%$ calcium chloride, or $15 \%$ magnesium chloride. This is a difference between the procedure for these experiments and the ASTM C1293 - 18A procedure (which also involved measuring hardened cement mortar/ concrete prisms): in the standard, it is explicitly stated to not allow the concrete prisms to touch the water. This difference existed because in the case of salt solution reacting with the cement paste in concrete, it was necessary for the solution to be in contact with the concrete for the reactions to take place. Another difference was that the prisms were stored horizontally, rather than vertically, as seen 
in ASTM C1293 - 18A. This was for convenience and ease of transporting the prisms. Containers with a smaller total volume could be used for storing the samples horizontally compared to storing them vertically, meaning the total weight of the container (including the samples and the solution required to cover the samples) would be much lighter and easier to move.

Comparative length readings were taken when the samples reached an age of 7 days, 28 days, 56 days, and 3 months, and 6 months to measure changes in length from being soaked in different salt solutions. Despite the aggregate not being reactive, some reaction was expected to take place because of the salts reacting with the concrete and producing expansive products. It was expected that the highest expansion would be seen in the prisms that were soaked in magnesium chloride or calcium chloride, and the least expansion being seen in the prisms soaked in sodium chloride. That said, it was expected that the expansion rate would diminish over time, given that the aggregate was not reactive.

In ASTM C1293 - 18A, the container used to hold the prisms was stored at $38 \pm 2{ }^{\circ} \mathrm{C}$ for the duration of testing and placed into room temperature $\left(23 \pm 2{ }^{\circ} \mathrm{C}\right)$ for $16 \pm 4$ hours before measurements were taken to ensure that the differences in length measurements were from chemical reactions, not from thermal expansion. This difference was not a concern for the procedure used for soaking prisms in salt solution in these experiments, because the containers were stored at room temperature for the duration of the test and while measurements were taken. In the ASTM C1293 - 18A standard, a higher temperature is used to accelerate the expansion seen, but a higher temperature may not necessarily increase the rate of expansion of concrete prisms with unreactive aggregate soaking in salt solution. 


\section{Chapter 4: $\quad$ Results/ Analysis}

The results for all of the tests performed in these experiments are discussed in this chapter. The goal of this research was to determine the efficacy of the proposed tests in evaluating concrete pavement joint deterioration.

\subsection{Properties of Different Mixes}

As was discussed in Chapter 3, three different concrete mixes were used, with several samples for each mix. The mixes made were the following:

- $45 \mathrm{MPa}: 350 \mathrm{~kg} / \mathrm{m}^{3}$ cement content (with $30 \%$ cement replaced with slag)

- $30 \mathrm{MPa}: 300 \mathrm{~kg} / \mathrm{m}^{3}$ cement content (no cement replacement with any SCM)

- $55 \mathrm{MPa}: 270 \mathrm{~kg} / \mathrm{m}^{3}$ cement content (no cement replacement with any SCM)

The $\mathrm{w} / \mathrm{c}$ ratio was the same for all mixes (i.e. 0.48 ), and the intended air content was the same, so the total paste varied between each mix. The table below summarizes the different paste content of the mixes.

Table 4-1 Total amount of paste (and paste constituents) per cubic meter of concrete for the three different concrete mixes, and average measured air content.

\begin{tabular}{|c|c|c|c|c|c|}
\hline Mix & $\begin{array}{c}\text { Total Paste } \\
\left(\mathbf{m}^{\mathbf{3}}\right)\end{array}$ & Cement $\mathbf{( k g )}$ & Slag $\mathbf{( k g )}$ & Water $\mathbf{( k g )}$ & Air $\left(\mathbf{m}^{\mathbf{3}} \mathbf{)}\right.$ \\
\hline 45 MPa Mix & 0.3337 & 280 & 70 & 168 & 5.27 \\
\hline $30 \mathrm{MPa}$ Mix & 0.3014 & 300 & 0 & 144 & 6.22 \\
\hline $55 \mathrm{MPa}$ Mix & 0.2693 & 270 & 0 & 129.6 & 5.4 \\
\hline
\end{tabular}


Since the mixes had different paste contents and different amounts of SCMs replacing cement, the average strength, RCPT, and even air content were slightly different between mixes. These results are summarized in the table below.

Table 4-2 Average 28-day compressive strength, RCPT, and air content of the different mixes.

\begin{tabular}{|c|c|c|c|}
\hline $\begin{array}{c}\text { Mix Name (Compressive } \\
\text { Strength) }\end{array}$ & $\begin{array}{c}\text { 28-Day Compressive } \\
\text { Strength (MPa) }\end{array}$ & $\begin{array}{c}\text { RCPT (age of 1 } \\
\text { year) }\end{array}$ & Air Content (\%) \\
\hline 45 MPa Mix & 45.49 & 504.89 & 5.27 \\
\hline 30 MPa Mix & 29.62 & 1817.31 & 6.22 \\
\hline 55 MPa Mix & 53.77 & 1333.49 & 5.4 \\
\hline
\end{tabular}

What stands out the most here is that the compressive strength for the $300 \mathrm{~kg} / \mathrm{m}^{3}$ cement content mix (30 MPa mix) was the lowest, and significantly lower than the other two mixes, which both had similar 28-day compressive strengths. This difference may be attributed to some consistent error in the mixing/ measuring of the $30 \mathrm{MPa}$ mix, because the difference in strength was not expected to be so great. However, the consistently within each mix was most important, because the final results were compared within mixes, not between mixes.

There are also other less significant factors that explain some of the differences in strength between the mixes. Because of the fact that the same w/c ratio was used for every mix, the 55 MPa mix (with the lowest cement content) was very dry and difficult to work with. Any bleeding that would have happened in this mix would have had a much more significant effect on the concrete because it would be a greater relative change in the $\mathrm{w} / \mathrm{c}$ ratio. The slag replacing $30 \%$ of the cement in the $45 \mathrm{MPa}$ mix also explains why the strength in this mix was higher.

Also note that the RCPT test results were obtained late, suggesting that the values are lower than what they would have been if they were performed at an age of 56 days because more hydration 
has occurred. The tests were performed at ages of roughly 1 year and are discussed in depth later in this chapter.

\subsection{Consistency of Batches within the Same Mix}

Consistency within batches of the same mix design is a key element for developing a test method because the properties of each batch of the same mix must be similar so that they can be compared to each other. As an example, if one batch of concrete was much weaker than another, it could lead to the false conclusion that a certain type of exposure is much more damaging than it actually is, which is why it is important that the strength of each batch of the same mix is similar. This goal was achieved, and the results are presented below.

As discussed in Chapter 3, samples were prepared from several batches of concrete, and three different mixes were used. Tests such as air content, RCPT, compressive strength were used to ensure that the quality of the concrete was consistent throughout.

\subsubsection{Compressive Strength}

The 28-day strength of the cylinders for each sample (each representative batch) is shown in the tables below. Three cylinders were used for each sample. Since three different mix designs were used, it was expected that each would have a different average strength, so differences should be analyzed within mix designs, not between them. 
Table 4-3 Average 28-day compressive strength of 3 cylinders for the batches of the $45 \mathrm{MPa}$ ( $30 \%$ slag replacement) mix.

\begin{tabular}{|c|c|c|}
\hline Date Casted & $\begin{array}{l}\text { Procedure (Salt solution and } \\
\text { cycles) }\end{array}$ & $\begin{array}{l}\text { Average Cylinder Compressive Strength } \\
\qquad(\mathrm{MPa})\end{array}$ \\
\hline 25-Jun & $3 \% \mathrm{NaCl} F \mathrm{~F}$ & 49.25 \\
\hline 09-Jul & $3 \% \mathrm{NaCl} \mathrm{FT}$ & 44.60 \\
\hline 26-Jun & $10 \% \mathrm{NaCl} \mathrm{FT}$ & 39.73 \\
\hline 05-Jul & $10 \% \mathrm{CaCl}_{2} \mathrm{FT}$ & 45.99 \\
\hline 27-Jun & $3 \% \mathrm{NaCl} F T W$ & 44.09 \\
\hline 11-Jul & $3 \% \mathrm{NaCl} F T W$ & 47.14 \\
\hline 03-Jul & $10 \% \mathrm{NaCl} F \mathrm{FT}$ & 45.64 \\
\hline 04-Jul & $10 \% \mathrm{NaCl} F T W(\mathrm{H} 2 \mathrm{O})$ & 45.74 \\
\hline 09-Jul & $10 \% \mathrm{CaCl}_{2} \mathrm{FTW}$ & 47.20 \\
\hline
\end{tabular}

The average 28-day compressive strength of the samples was $45.49 \mathrm{MPa}$. The sample with the highest 28-day compressive strength was June 25, 3\% NaCl FT (which had a 3 cylinder average of 49.25 MPa), and the lowest was June $26,10 \% \mathrm{NaCl} F T$ (which had a 3 cylinder average of 39.73 $\mathrm{MPa}$ ). The next lowest is June $27,3 \% \mathrm{NaCl}$ FTW (which had a 3 cylinder average of $44.09 \mathrm{MPa}$ ).

Table 4-4 Average 28-day compressive strength of 3 cylinders for the batches of the $30 \mathrm{MPa}$ mix.

\begin{tabular}{|c|c|c|}
\hline Date Casted & $\begin{array}{c}\text { Procedure (Salt solution and } \\
\text { cycles) }\end{array}$ & $\begin{array}{c}\text { Average Cylinder Compressive Strength } \\
\text { (MPa) }\end{array}$ \\
\hline Aug 29(1) & $3 \% \mathrm{CaCl}_{2} \mathrm{FT}$ & 30.2957 \\
\hline $16-\mathrm{Aug}$ & $3 \% \mathrm{MgCl}_{2} \mathrm{FT}$ & 31.0863 \\
\hline $21-\mathrm{Aug}$ & $15 \% \mathrm{NaCl} \mathrm{W}$ & 26.5887 \\
\hline $23-\mathrm{Aug}$ & $15 \% \mathrm{MgCl}_{2} \mathrm{~W}$ & 31.983 \\
\hline Aug 29(2) & $15 \% \mathrm{CaCl}_{2} \mathrm{~W}$ & 28.1447 \\
\hline
\end{tabular}

The average 28-day compressive strength of the samples was $29.62 \mathrm{MPa}$. The sample with the highest 28-day compressive strength was August 23, $15 \% \mathrm{MgCl}_{2} \mathrm{~W}$ (which had a 3 cylinder average of $31.98 \mathrm{MPa}$ ), and the lowest was August 21 (which had a 3 cylinder average of 26.59 $\mathrm{MPa})$. 
Table 4-5 Average 28-day compressive strength of 3 cylinders for the batches of the $55 \mathrm{MPa}$ mix.

\begin{tabular}{|c|c|c|}
\hline Date Casted & $\begin{array}{c}\text { Procedure (Salt solution and } \\
\text { cycles) }\end{array}$ & $\begin{array}{c}\text { Average Cylinder Compressive Strength } \\
\text { (MPa) }\end{array}$ \\
\hline $27-\mathrm{Oct}$ & $3 \% \mathrm{NaCl} \mathrm{FT}^{\mathrm{F} T}$ & 53.43 \\
\hline $27-\mathrm{Oct}$ & $3 \% \mathrm{CaCl}_{2} \mathrm{FT}$ & 53.43 \\
\hline $20-\mathrm{Oct}$ & $3 \% \mathrm{MgCl}_{2} \mathrm{FT}$ & 55.15 \\
\hline $03-\mathrm{Nov}$ & $15 \% \mathrm{CaCl}_{2} \mathrm{~W}$ & 53.39 \\
\hline $03-\mathrm{Nov}$ & $10 \% \mathrm{MgCl}_{2} \mathrm{FTW}$ & 53.39 \\
\hline $20-\mathrm{Oct}$ & $15 \% \mathrm{MgCl}_{2} \mathrm{~W}$ & 55.15 \\
\hline $10-\mathrm{Nov}$ & $10 \% \mathrm{CaCl}_{2} \mathrm{FTW}$ & 53.12 \\
\hline $10-\mathrm{Nov}$ & $10 \% \mathrm{MgCl}_{2} \mathrm{FTW}$ & 53.12 \\
\hline $27-\mathrm{Oct}$ & $15 \% \mathrm{NaCl}^{\mathrm{W}}$ & 53.43 \\
\hline
\end{tabular}

The average 28-day compressive strength of the samples was $53.77 \mathrm{MPa}$. The sample with the highest 28-day compressive strength was October 20, which was both $15 \% \mathrm{MgCl}_{2} \mathrm{~W}$ and $15 \% 3 \%$ $\mathrm{MgCl}_{2} \mathrm{FT}$ (which had a 3 cylinder average of $55.15 \mathrm{MPa}$ ), and the lowest was November 10, which was both $10 \% \mathrm{CaCl}_{2} \mathrm{FTW}$ and $15 \% \mathrm{MgCl}_{2} \mathrm{~W}$ (which had a 3 cylinder average of $53.12 \mathrm{MPa}$ ).

\subsubsection{Rapid Chloride Permeability Test}

The RCPT test results are shown below. RCPT was an important test because the permeability of concrete is a very important measure of its resistance to chemical damage; if ions can penetrate through concrete more easily, it can get damaged sooner. However, the importance of this test on early concrete pavement joint deterioration needs further investigation because it has been shown that $\mathrm{CaCl}_{2}$ and $\mathrm{MgCl}_{2}$ can fill the outer pores of concrete, limiting further ingression (Farnam et al., 2015a; Spragg et al., 2011).

Again, since three different mix designs were used (with different cement contents, total paste contents, and SCM replacements of cement), it was expected that each mix would have a very 
different RCPT value, so differences should be analyzed within mix designs, not between them.

The results are shown below.

Table 4-6 Average RCPT values and testing age for all mixes.

\begin{tabular}{|c|c|c|c|}
\hline Mix & $\begin{array}{c}\text { Average RCPT for } \\
\text { Mix }\end{array}$ & RCPT Rating & Testing Age \\
\hline $45 \mathrm{MPa}$ & 504.89 & Very low & 389 days \\
\hline $30 \mathrm{MPa}$ & 1817.31 & Low & 347 days \\
\hline $55 \mathrm{MPa}$ & 1333.49 & Low & 271 days \\
\hline
\end{tabular}

\subsubsection{Air Content}

The intended air content was the same for each mix (i.e. 6\%), despite the slightly different paste content. It was important that all of the air content values were similar so that comparisons in the damage could be attributed to the salt solution and cyclical exposure, rather than the air void system within the concrete. The table below shows the air content results for all of the samples. 
Table 4-7 Measured air content for each batch of concrete.

\begin{tabular}{|c|c|c|}
\hline Mix (Cement Content-Mix \#) & $\begin{array}{c}\text { Sample Procedure (Salt } \\
\text { Solution and Cycles) }\end{array}$ & Measured Air Content (\%) \\
\hline $45 \mathrm{MPa}$ & $3 \% \mathrm{NaCl} \mathrm{FT}$ & 4.5 \\
\hline $45 \mathrm{MPa}$ & $3 \% \mathrm{NaCl} \mathrm{FT}$ & 5.4 \\
\hline $45 \mathrm{MPa}$ & $10 \% \mathrm{NaCl} \mathrm{FT}$ & 7.1 \\
\hline $45 \mathrm{MPa}$ & $10 \% \mathrm{CaCl}_{2} \mathrm{FT}$ & 4.8 \\
\hline $45 \mathrm{MPa}$ & $3 \% \mathrm{NaCl} F T W$ & 5.6 \\
\hline $45 \mathrm{MPa}$ & $3 \% \mathrm{NaCl} F T W$ & 5.1 \\
\hline $45 \mathrm{MPa}$ & $10 \% \mathrm{NaCl} F T W$ & 5.6 \\
\hline $45 \mathrm{MPa}$ & $10 \% \mathrm{NaCl} F T W(\mathrm{H} 2 \mathrm{O})$ & 4.1 \\
\hline $45 \mathrm{MPa}$ & $10 \% \mathrm{CaCl}_{2} \mathrm{FTW}$ & 5.2 \\
\hline $30 \mathrm{MPa}$ & $3 \% \mathrm{CaCl}_{2} \mathrm{FT}$ & 6.6 \\
\hline $30 \mathrm{MPa}$ & $3 \% \mathrm{MgCl}_{2} \mathrm{FT}$ & 6.5 \\
\hline $30 \mathrm{MPa}$ & $15 \% \mathrm{NaCl} W$ & 6 \\
\hline $30 \mathrm{MPa}$ & $15 \% \mathrm{MgCl}_{2} \mathrm{~W}$ & 5.9 \\
\hline $30 \mathrm{MPa}$ & $15 \% \mathrm{CaCl}_{2} \mathrm{~W}$ & 6.1 \\
\hline $55 \mathrm{MPa}$ & $3 \% \mathrm{NaCl} \mathrm{FT}$ & 5.6 \\
\hline $55 \mathrm{MPa}$ & $3 \% \mathrm{CaCl}_{2} \mathrm{FT}$ & 5.6 \\
\hline $55 \mathrm{MPa}$ & $3 \% \mathrm{MgCl}_{2} \mathrm{FT}$ & 4.9 \\
\hline $55 \mathrm{MPa}$ & $15 \% \mathrm{CaCl}_{2} \mathrm{~W}$ & 5.5 \\
\hline $55 \mathrm{MPa}$ & $10 \% \mathrm{MgCl}_{2} \mathrm{FTW}$ & 5.5 \\
\hline $55 \mathrm{MPa}$ & $15 \% \mathrm{MgCl}_{2} \mathrm{~W}$ & 4.9 \\
\hline $55 \mathrm{MPa}$ & $10 \% \mathrm{CaCl}_{2} \mathrm{FTW}$ & 5.5 \\
\hline $55 \mathrm{MPa}$ & $15 \% \mathrm{MgCl}_{2} \mathrm{~W}$ & 5.5 \\
\hline $55 \mathrm{MPa}$ & $15 \% \mathrm{NaCl} W$ & 5.6 \\
\hline
\end{tabular}

\subsection{Relative Strength Loss of Samples}

Concrete slabs exposed to freezing, thawing, wetting, and different salt solutions were tested to see what effect these conditions had on their strength. The experiment served its purpose in capturing significant differences in strength between different samples, showing that different exposures of salt solution and combinations of freezing/ thawing and wetting cause vastly different deterioration. This result was strengthened by the fact that the properties of the concrete were consistent within concrete mixes, meaning that any differences could be 
attributed to the salt solution used and type of cyclical exposure during testing. The types of deicing salts used and the temperature ranges that samples are exposed to play a significant role in concrete pavement joint deterioration.

\subsubsection{Ultimate Strength}

Each of the slabs (three for each type of exposure) were tested as outlined in Chapter 3: the slabs were centre-point loaded to fail in the weakest section (the section immediately below the joint). The strength values of the samples were compared within each of the three mix designs (i.e. the samples from the $45 \mathrm{MPa}$ mix were only compared with samples from the $45 \mathrm{MPa}$ mix, the samples from the $30 \mathrm{MPa}$ mix were only compared with samples from the $30 \mathrm{MPa}$ mix, etc.), and comparisons were made between different exposure conditions and different salt solutions.

These results (average values for the three slabs of each type of exposure) are shown below. The data is presented as follows: the largest average relative strength sample for each mix was set to $100 \%$, and each sample's average strength was expressed as a percentage relative to the strongest one of its mix. Note that the results in the following figures are presented for each mix, and the effects of different cycles are explained in depth in the following paragraphs. 
(a)

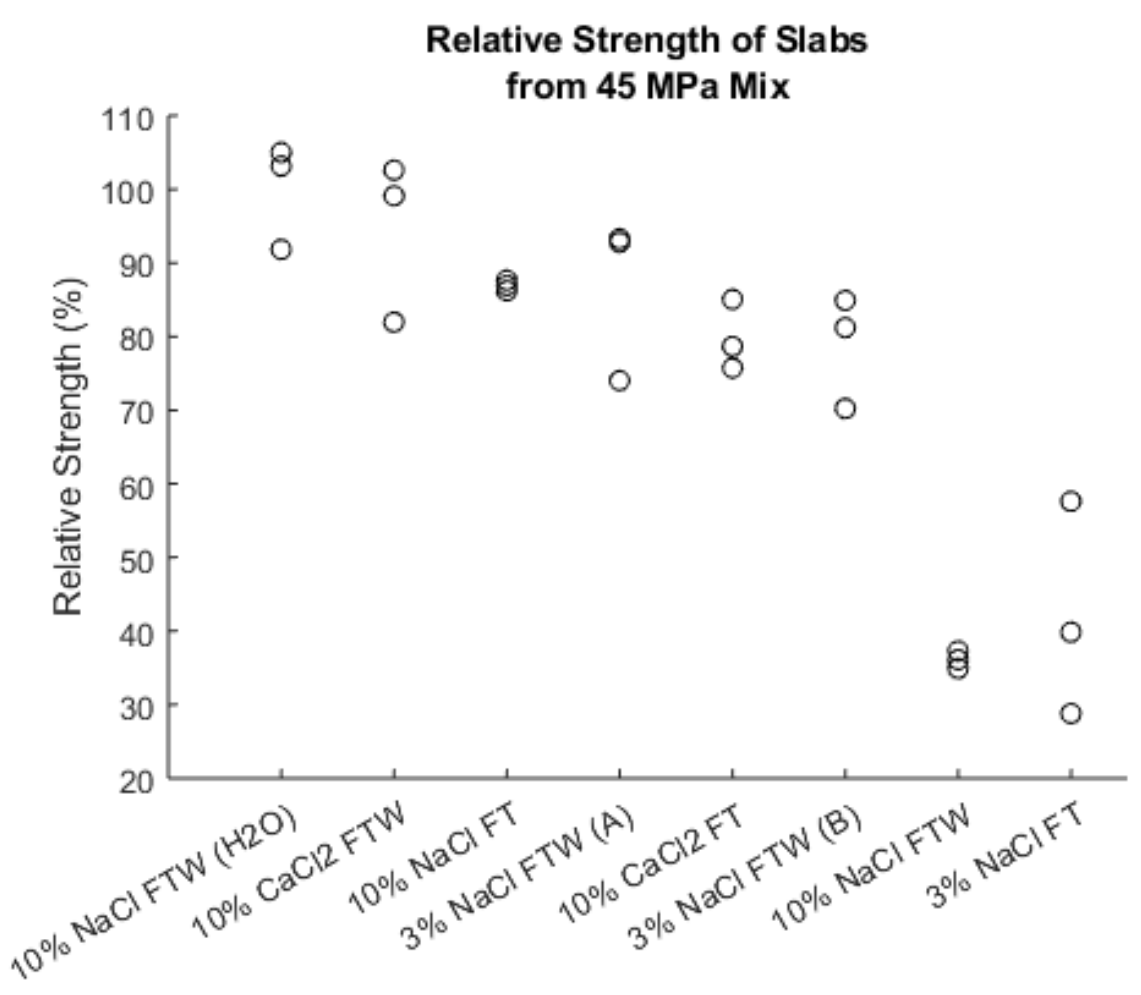

(b)

Type of Salt and Exposure Condition

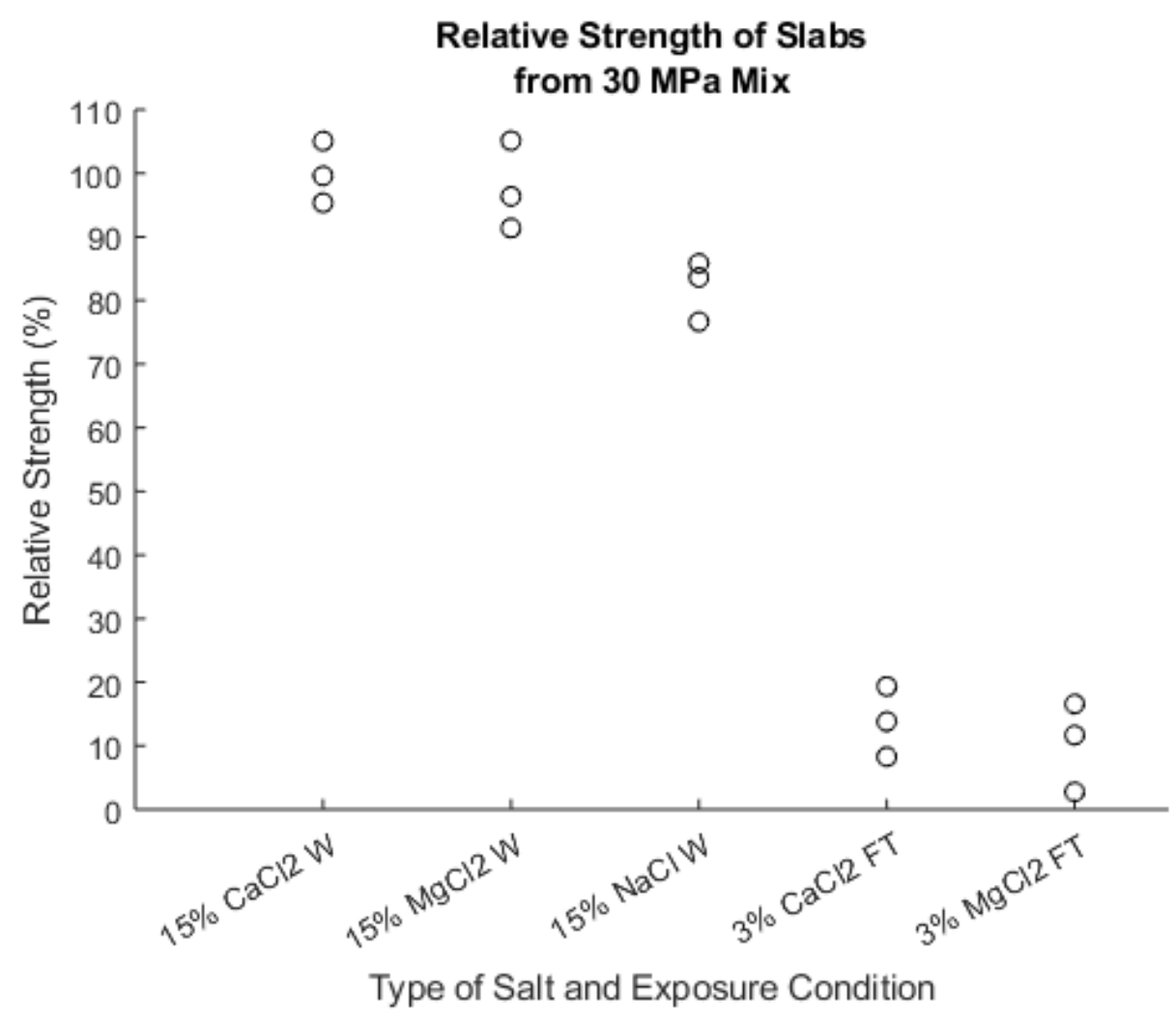


(c)

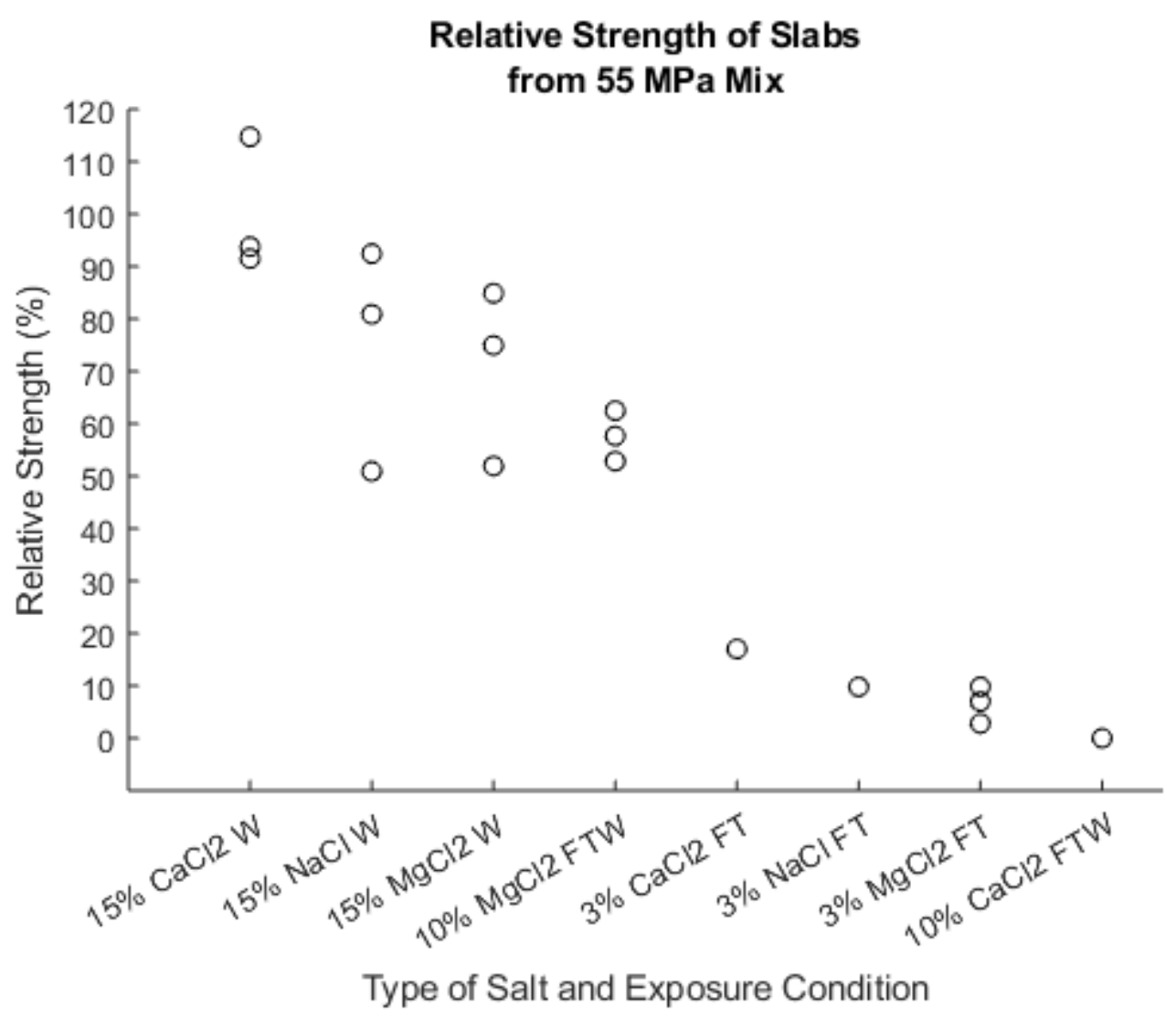

Figure 4-1 Relative strength of different salt solutions and cyclical exposures for the three different concrete mixes used: (a) the $45 \mathrm{MPa}$ mix, (b) $30 \mathrm{MPa}$ mix, and (c) $55 \mathrm{MPa}$ mix. Each sample consisted of 3 specimens

\subsubsection{The Role of Concrete Strength and Cement Content}

The role that cement content plays on the strength of the concrete was examined by comparing samples of the same exposure conditions but different cement contents. These results are shown in Figure 4-2 below. 


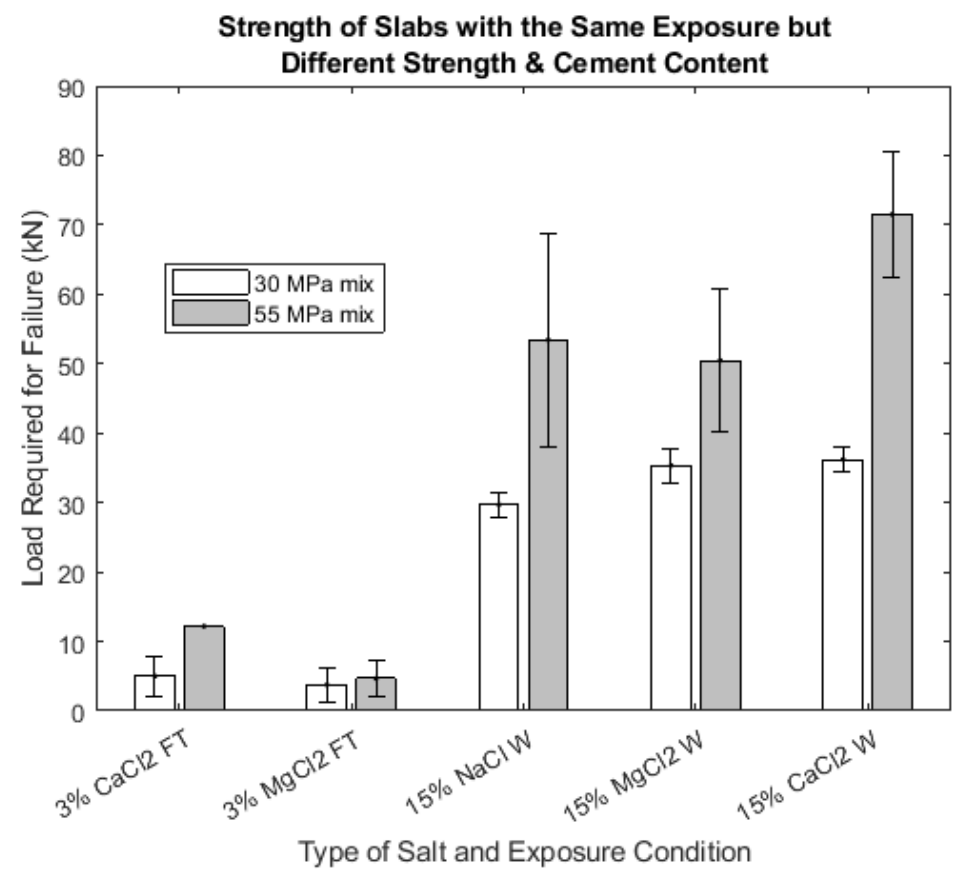

Figure 4-2 Comparative average strength (of 3 specimens per sample) under the same cyclical exposure but having different cement contents. Error bars represent one standard deviation.

The statistical analysis of the significance of these differences is summarized in the table below.

The F-test to check for differences in variance is presented in Appendix $\mathrm{C}$. The $3 \% \mathrm{CaCl}_{2} \mathrm{FT}$ sample was not included in the analysis because not enough samples were available for analysis (some samples broke before the test was completed). 
Table 4-8 One-tailed t-test analysis for $30 \mathrm{MPa}$ mix samples and $55 \mathrm{MPa}$ mix samples (load values).

\begin{tabular}{|c|c|c|c|c|c|}
\hline $\begin{array}{c}\text { Exposure } \\
\text { Type }\end{array}$ & $\mathbf{t}$ Stat & $\mathbf{t}$ Critical & $\mathbf{P}(\mathbf{T} \leq \mathbf{t})$ & \multicolumn{2}{|c|}{ Difference is statistically significant? } \\
\cline { 5 - 6 } & & & $\begin{array}{c}\text { 95\% confidence } \\
\text { interval }\end{array}$ & $\begin{array}{c}\text { 90\% confidence } \\
\text { interval }\end{array}$ \\
\hline $3 \% \mathrm{MgCl} 2 \mathrm{FT}$ & -0.44769 & 2.131847 & 0.338776 & No & No \\
\hline $15 \% \mathrm{NaCl} \mathrm{W}$ & -2.66633 & 2.919986 & 0.058286 & No & Yes \\
\hline $\begin{array}{c}15 \% \mathrm{MgCl} 2 \\
\mathrm{~W}\end{array}$ & -2.12326 & 2.919986 & 0.083858 & No & Yes \\
\hline $15 \% \mathrm{CaCl} 2 \mathrm{~W}$ & -6.56321 & 2.919986 & 0.011218 & Yes & Yes \\
\hline
\end{tabular}

Only the $15 \% \mathrm{CaCl}_{2} \mathrm{~W}$ sample was found to be statistically significant if using a $95 \%$ confidence interval. However, if a $90 \%$ confidence interval is used (considering that only a small amount of samples were used), then the $15 \% \mathrm{NaCl} \mathrm{W}$ and $15 \% \mathrm{MgCl}_{2} \mathrm{~W}$ were also found to be statistically significant.

There are several reasons for these significant differences. Firstly, a lower cement content (as is seen in the $55 \mathrm{MPa}$ mix) provides better resistance against calcium oxychloride formation because less calcium hydroxide is available. Secondly, the compressive strength of the $55 \mathrm{MPa}$ mix was much higher than of the $30 \mathrm{MPa}$ mix. The RCPT value of the $55 \mathrm{MPa}$ mix was also lower. These results show the importance of concrete quality on how well slabs will perform in this proposed test. However, these differences become less apparent as the samples are more deteriorated, as is shown by the examples of the $3 \% \mathrm{MgCl}_{2} \mathrm{FT}$ and $3 \% \mathrm{CaCl}_{2} \mathrm{FT}$ samples.

The same analysis was also performed with relative strength instead of load values to see if the relative loss of strength was significant between different mixes. 


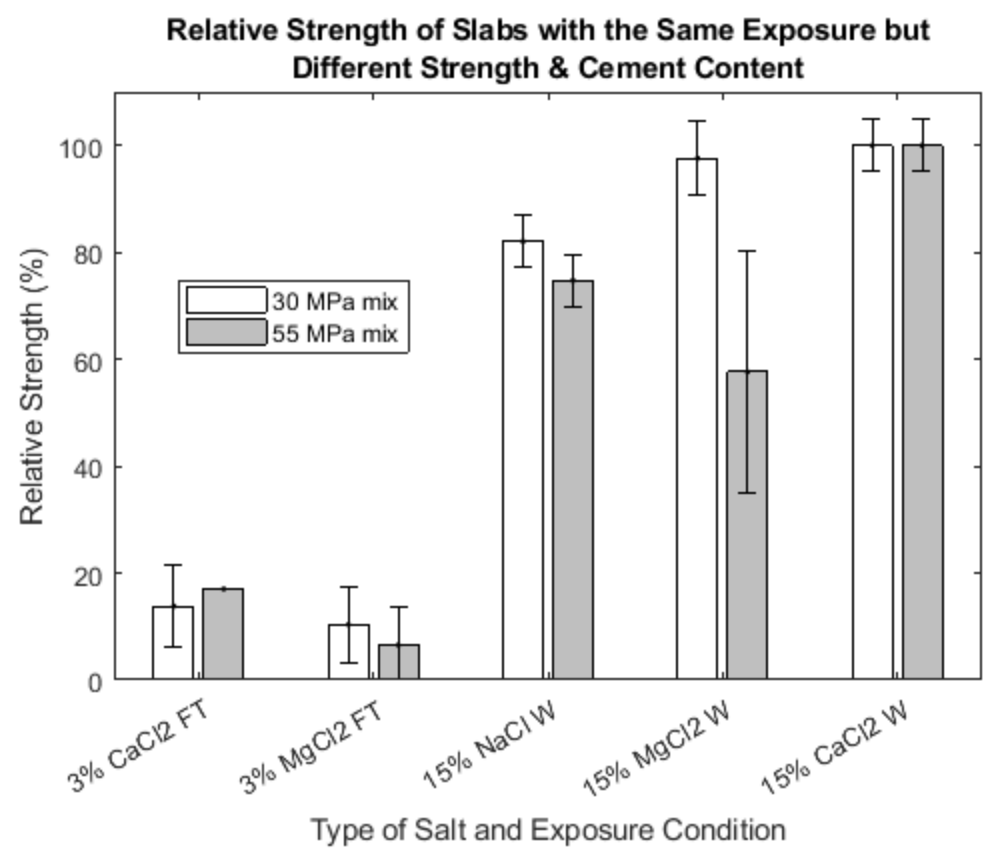

Figure 4-3 Comparative average strength (of 3 specimens per sample) under the same cyclical exposure but having different cement contents. Error bars represent one standard deviation.

Again, the statistical analysis of the significance of these differences is summarized in the table below. The F-test to check for differences in variance is presented in Appendix $\mathrm{C}$. The $3 \% \mathrm{CaCl}_{2}$ FT sample was not included in the analysis because not enough samples were available for analysis (some samples broke before the test was completed).

Table 4-9 One-tailed t-test analysis for $30 \mathrm{MPa}$ mix samples and $55 \mathrm{MPa}$ mix samples (relative strength).

\begin{tabular}{|c|c|c|c|c|c|}
\hline $\begin{array}{c}\text { Exposure } \\
\text { Type }\end{array}$ & $\mathbf{t}$ Stat & $\mathbf{t}$ Critical & $\mathbf{P}(\mathbf{T} \leq \mathbf{t})$ & \multicolumn{2}{|c|}{ Difference is statistically significant? } \\
\cline { 4 - 6 } & & & $\begin{array}{c}\text { 95\% confidence } \\
\text { interval }\end{array}$ & $\begin{array}{c}\text { 90\% confidence } \\
\text { interval }\end{array}$ \\
\hline $3 \% \mathrm{MgCl} 2 \mathrm{FT}$ & 0.842924 & 2.353363 & 0.230585 & No & No \\
\hline $15 \% \mathrm{NaCl} \mathrm{W}$ & 0.575357 & 2.919986 & 0.311577 & No & Yo \\
\hline $\begin{array}{c}15 \% \mathrm{MgCl} 2 \\
\mathrm{~W}\end{array}$ & 2.5603 & 2.353363 & 0.041596 & Yes & No \\
\hline $15 \% \mathrm{CaCl} 2 \mathrm{~W}$ & 0 & 2.353363 & 0.5 & No & \\
\hline
\end{tabular}


When analyzing the relative strength, most notably, the exposure to magnesium chloride had a greater relative effect on the $55 \mathrm{MPa}$ mix than the $30 \mathrm{MPa}$ mix. This is likely due to the fact that the $55 \mathrm{MPa}$ mix had a lower cement content, and the conversion of calcium silicate hydrate to non-cementitious magnesium silicate hydrate could have been more significant with the lower cement content mix. This difference for the $15 \% \mathrm{MgCl}_{2} \mathrm{~W}$ sample was significant at a $95 \%$ confidence interval.

The effect of cement content and type (PC or PC + Slag) is illustrated in the case of $10 \% \mathrm{CaCl}_{2} \mathrm{FTW}$ slabs. A sample of this exposure was made with both the $45 \mathrm{MPa}$ mix and the $55 \mathrm{MPa}$ mix. This is summarized in Table 4-10, below. 
Table 4-10 Comparisons between $10 \% \mathrm{CaCl}_{2}$ FTW samples of different mixes/ cement contents.

\begin{tabular}{|c|c|c|}
\hline & $\begin{array}{c}10 \% \mathrm{CaCl}_{2} \mathrm{FTW}-350 \mathrm{~kg} / \mathrm{m}^{3} \text { Cement } \\
\text { Content (45 MPa Mix) }\end{array}$ & $\begin{array}{c}10 \% \mathrm{CaCl}_{2} \mathrm{FTW}-270 \mathrm{~kg} / \mathrm{m}^{3} \text { Cement } \\
\text { Content (55 MPa Mix) }\end{array}$ \\
\hline $\begin{array}{l}\% \text { Cement } \\
\text { replaced } \\
\text { with slag }\end{array}$ & 30 & 0 \\
\hline $\begin{array}{c}\text { Sample } \\
\text { Strength }\end{array}$ & $13.8 \mathrm{kN}$ & $\begin{array}{c}0 \mathrm{kN} \text { (sample fell apart before } 50 \\
\text { cycles completed) }\end{array}$ \\
\hline $\begin{array}{l}\text { 28-day } \\
\text { Compressive } \\
\text { Strength of } \\
\text { Cylinders } \\
\text { with no } \\
\text { Exposure }\end{array}$ & $47.2 \mathrm{MPa}$ & $53.12 \mathrm{MPa}$ \\
\hline $\begin{array}{c}\text { Picture of } \\
\text { Sample after } \\
50 \text { Cycles }\end{array}$ & & \\
\hline
\end{tabular}

Firstly, the difference in the damage observed can be attributed to the difference in cement content, and the presence of slag: less Portland cement and more slag both decrease the damage from $\mathrm{CaCl}_{2}$ exposure. This is due to less calcium hydroxide in the system due to less Portand cement, and consumption of calcium hydroxide by the reaction of slag.

The results of this experiment gave rise to a very important finding for using bending strength of the tested slabs as a means of evaluating concrete pavement joint deterioration. The recorded strength values for the $55 \mathrm{MPa}$ mix samples was 0 , because the samples were so deteriorated that they could not be tested, but the strength of the $45 \mathrm{MPa}$ mix samples was very high, despite evidence of damage and scaling at the surface. This shows that the proposed evaluation 
technique is promising at capturing the deterioration of the concrete joints (as it was seen to be in the case with the $55 \mathrm{MPa}$ mix samples). Some damage had taken place in the $45 \mathrm{MPa}$ mix samples, which were more resistant to damage, but their strength was not greatly affected. If more cycles had taken place, more deterioration would have happened, and the test could capture the damage that would happen. Concrete mixes that are more resistant to damage require more exposure. However, the test duration seems appropriate because if the cycles were extended, more damage would take place and it might not have been able to discriminate between different mixes.

\subsubsection{Effects of Testing Exposures}

The results of the strength loss test based on different exposures is examined in this chapter. A list of the key findings is presented below:

- Samples exposed to only wetting had almost no damage.

- Freezing was necessary for at least some damage to take place (perhaps lower temperature could also result in damage).

- FTW was more damaging than FT with high concentration salt solutions.

- $\quad$ FT was more damaging than FTW with low concentration salt solutions.

- The presence of slag in a mix was protective against damage from deicing salts.

\subsubsection{Slabs Exposed to FT Cycles}

The results for the strength loss (in terms of relative strength to the strongest sample) are shown below, with the samples that underwent FT cycles only shown with different markers (squares). 
(a)

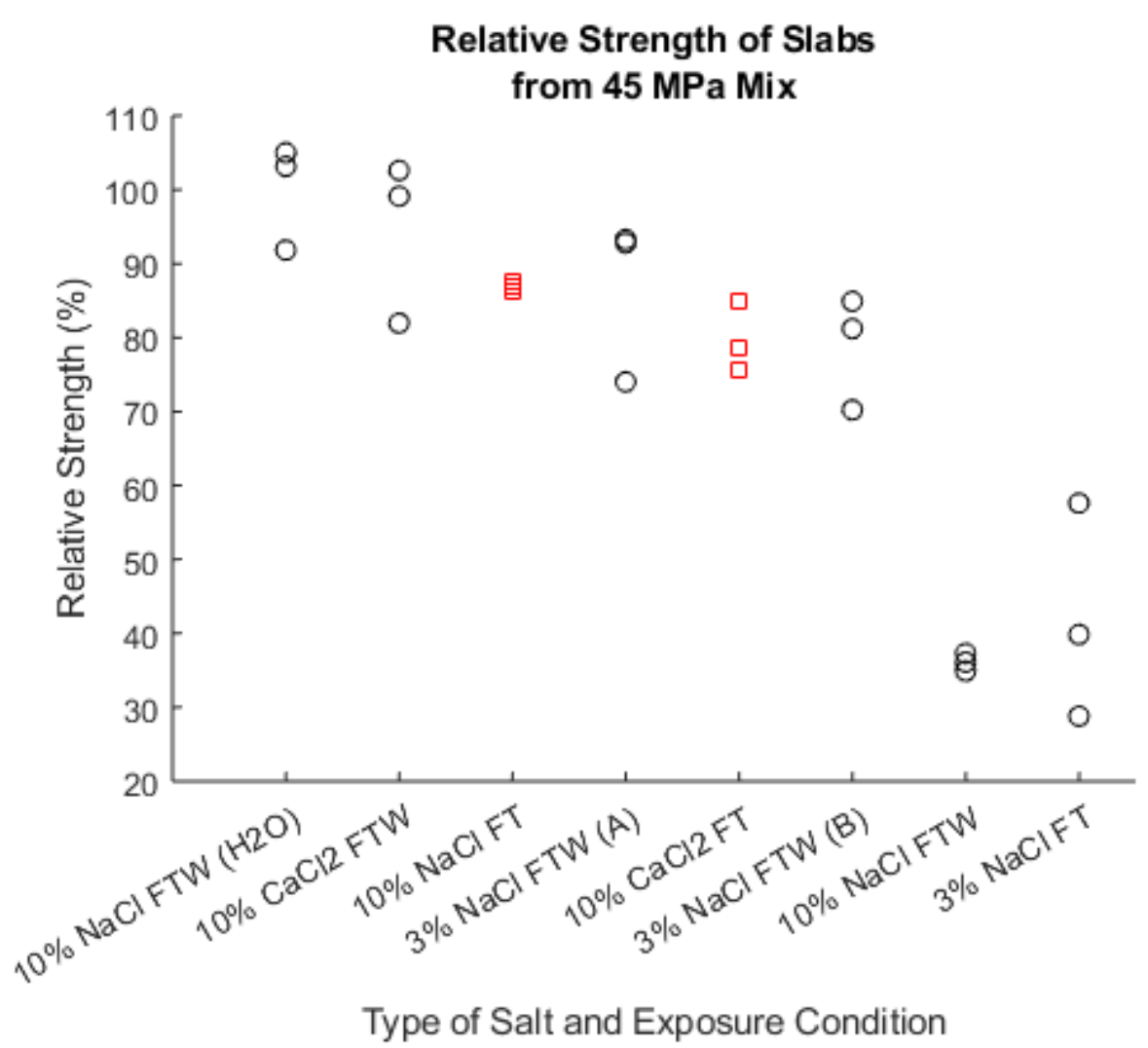

(b)

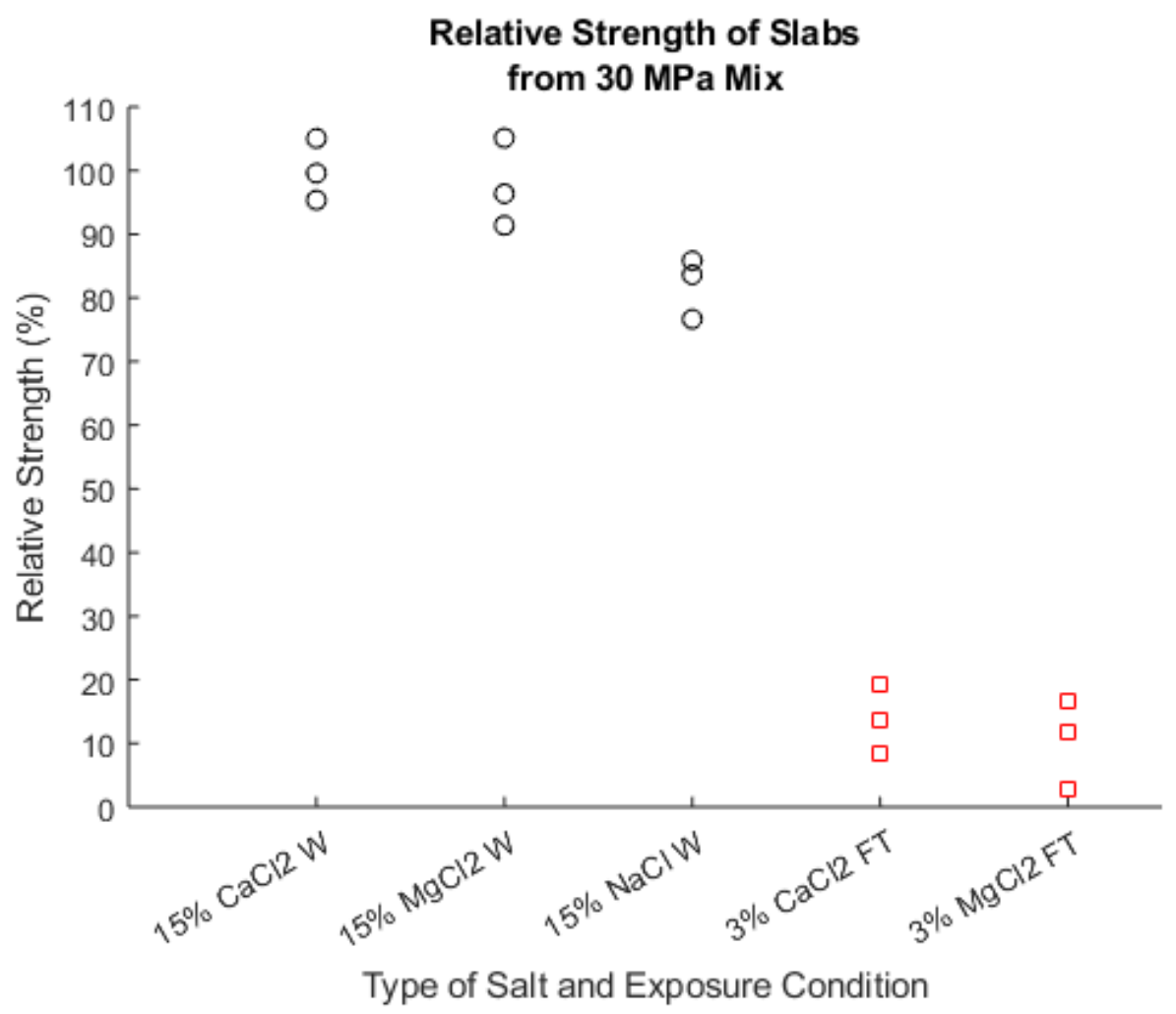


(c)

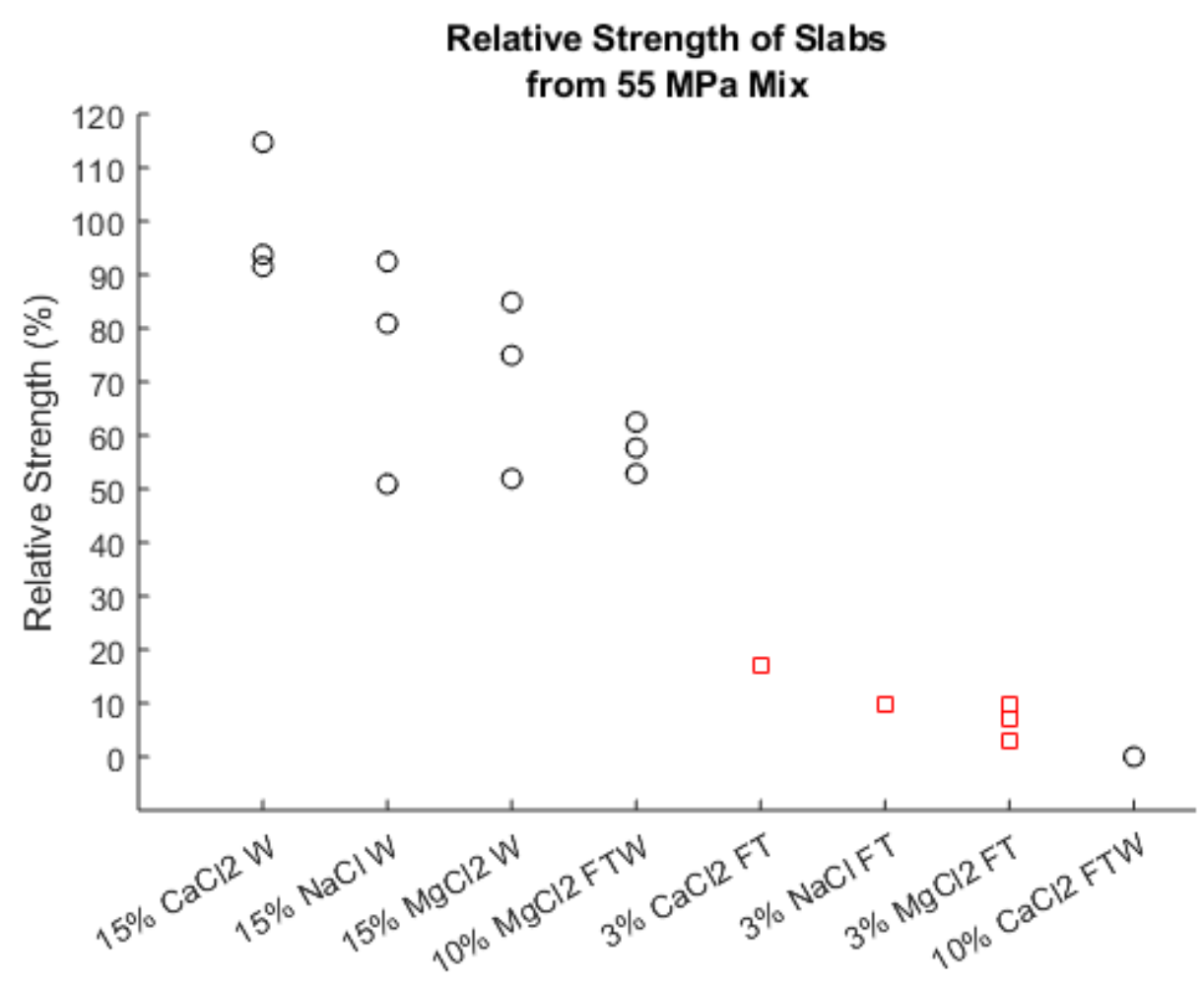

Type of Salt and Exposure Condition

Figure 4-4 Relative strength of tested samples from (a) the $45 \mathrm{MPa}$ mix, (b) the $30 \mathrm{MPa}$, and (c) the 55 MPa mix. FT samples are marked as squares.

As seen in Figure 4-4 above, in the 45 MPa mix, it was observed that the slabs that were exposed to $10 \% \mathrm{NaCl} F \mathrm{FT}$ and $10 \% \mathrm{CaCl}_{2} \mathrm{FT}$ had similar levels of strength loss. Several factors are responsible for this. Firstly, at higher salt concentrations, the temperature required for freezing is lower. Not only is $10 \%$ a higher concentration compared to the $3 \%$ concentration that was used for other samples, but additional applications of the salt solution to replace the lost solution between cycles would further increase the concentration of the salt. Thus, at high concentrations of salt solutions, complete freezing may not occur, so the physical damage from freezing would be more limited. Thus, more damage would occur from freezing at lower temperatures. However, it was initially expected that more damage would have been observed from the slabs exposed to calcium chloride. It has been observed that in this experiment, exposure to calcium chloride at 
low temperatures did not cause as much of a loss of strength as expected, but some visual damage was observed. It may be the case that the formation of calcium oxychloride (from the calcium chloride exposure as it was performed in this experiment) causes expansion, which would result in some visual damage immediately, and this would later result in a decrease in strength.

The slabs exposed to $3 \% \mathrm{NaCl}$ FT required a lower load to fail than the slabs exposed to $10 \% \mathrm{NaCl}$ FT, showing that they had been more damaged from their type of exposure. As discussed in the previous paragraph, this is due to more complete freezing at lower salt concentrations by requiring a temperature that is not as low to freeze. More scaling and more damage were to be expected at a salt concentration of $3 \%$ than $10 \%$, and this was seen to be the case, as is shown in Table 4-11, below.

Table 4-11 Comparisons of mass loss and strength between the $3 \%$ and $10 \% \mathrm{NaCl}$ FT samples (45 MPa mix).

\begin{tabular}{|c|c|c|}
\hline $\begin{array}{c}\text { 28-day Compressive Strength of Cylinders } \\
\text { (MPa) }\end{array}$ & $\mathbf{3 \% ~ N a C l ~ F T ~}$ & $\mathbf{1 0 \% ~ N a C l ~ F T ~}$ \\
\hline Slab Strength after 50 Cycles (kN) & 44.6 & 39.7 \\
\hline Mass loss (g/m $\mathbf{2}$ ) & 5.7 & 12.7 \\
\hline
\end{tabular}

Not only was more scaling observed on the slabs exposed to a lower salt concentration, but the static load required to cause the slabs to fail was lower. This case highlights the role of $\mathrm{NaCl}$ concentration on the damage seen from freezing and what effect it has on the strength loss of the concrete slabs.

FT cycles were also performed to compare $3 \% \mathrm{MgCl}_{2}$ and $3 \% \mathrm{CaCl}_{2}$. The slabs exposed to $3 \%$ $\mathrm{MgCl}_{2} \mathrm{FT}$ conditions were weakened more than the slabs exposed to $3 \% \mathrm{CaCl}_{2} \mathrm{FT}$. It is worthy to 
note here that this is difference exists despite the fact that the batches of concrete used for the $\mathrm{MgCl}_{2}$ had a slightly higher compressive strength than that of the $\mathrm{CaCl}_{2}$ batches. This difference in the strength of the samples after exposure is expected to be due to magnesium chloride not only replacing the calcium in calcium silicate hydrate with magnesium to form non-cementitious magnesium silicate hydrate (Lee et al., 1998; Farnam et al., 2015b; Wang et al., 2018), but also because magnesium chloride's reactions with paste could form calcium chloride, also leading to calcium oxychloride formation (Farnam et al., 2015b). The reason that more damage was seen in the $\mathrm{MgCl}_{2}$ slabs was because the transformation of calcium silicate hydrate to magnesium silicate hydrate (a non cementitious product) would result in direct loss of strength. This direct loss of strength was shown to be more significant than the loss of strength from the expansion of calcium oxychloride formation, which can occur from both $\mathrm{MgCl}_{2}$ exposure and $\mathrm{CaCl}_{2}$ exposure.

\subsubsection{Slabs Exposed to FTW Cycles}

The FTW slabs highlighted the importance of the synergistic role of wetting combined with freezing and thawing, because when slabs were subjected to high concentration salts with just wetting, very little damage took place. During the wetting cycles with exposure to salt solution, products could form in the air voids, rendering their resistance against freezing less effective.

Repeatedly applying salt solution to replace the evaporated solution also essentially increases the salt concentration. This can be detrimental in the case of salts like $\mathrm{CaCl}_{2}$ which tend to form harmful products like calcium oxychloride at lower temperatures and higher concentrations. Although these reaction products can form between about $0^{\circ} \mathrm{C}$ and $40^{\circ} \mathrm{C}$, the rate is much slower at higher temperatures (Farnam et al., 2015a; Monical et al., 2016; Qiao et al., 2018b; Sutter at al., 2002; Wang et al., 2018). During the process of freezing (or incomplete freezing if the salt 
concentration is too high), the concrete is exposed to ideal temperatures for calcium oxychloride formation. Further testing comparing FT cycles with very high salt concentrations to FTW cycles with increasing salt concentrations could more clearly illustrate if the wetting cycles themselves have an important mechanism in the damage formation, or if just the higher salt concentration is necessary.

When examining FT cycles in the previous section, higher salt concentrations resulted in less damage. However, the opposite is true for FTW cycles: higher salt solution concentrations led to more damage with FTW cycles. The high salt concentration may result in more air voids filled with reaction products, making them less resistance against freezing and thawing damage. An example of a sample that was observed under SEM is shown in Figure 4-5, below.

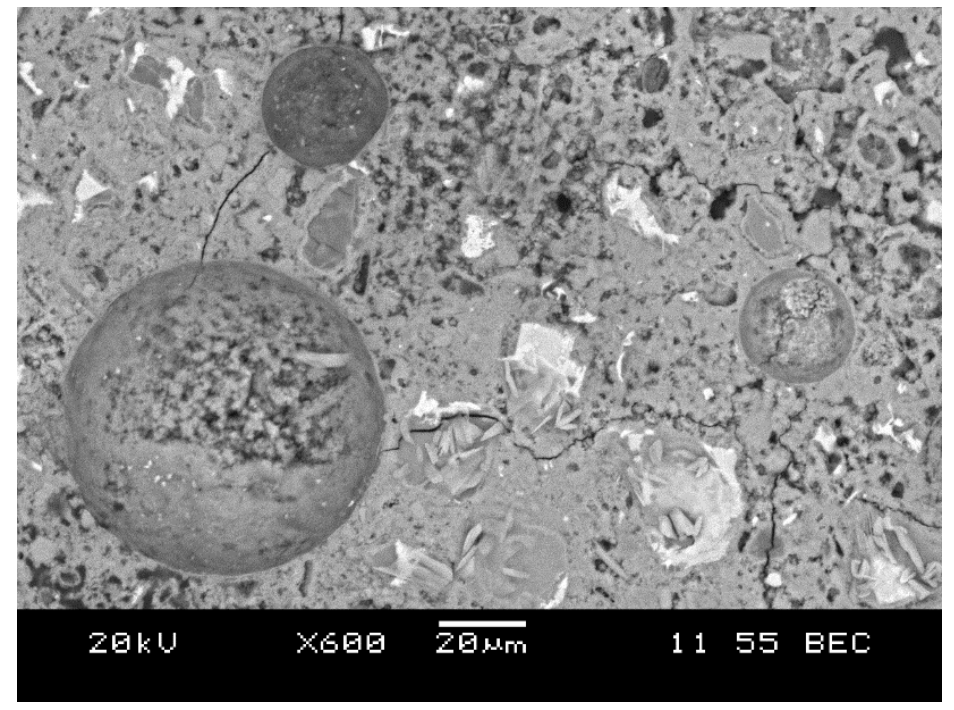

Figure 4-5 SEM image of $3 \% \mathrm{CaCl}_{2} \mathrm{FT}$ sample with cracks between air voids.

There are two important features to note in the above figure: firstly, there is a crack between two air voids, indicative of physical damage which is unlikely to take place during sample preparation as it is a fine and short crack. If the air voids had been filled with reaction products, 
they would be less useful in protection against the damage that would occur from water freezing. Secondly, in the case of FT exposure, not all of the air voids were filled with reaction products because of the low concentration and the short number of cycles. With a higher salt concentration, and repeated applications of salt solution (as seen in the FTW procedure), more salt (and reaction products) would be available to fill in the air voids sooner. As a reminder, the FTW procedure was a total of 25 freeze-thaw and 25 wetting cycles, alternating every 5 cycles. The FT procedure was 50 cycles of freezing and thawing.

Similar results but to a lesser extent were seen in FT samples regardless of the type of salt used. As mentioned, not all air voids would have been filled/ used within 50 cycles of freezing and thawing with a low salt concentration, and some undamaged air voids are shown in Figure 4-6, below.

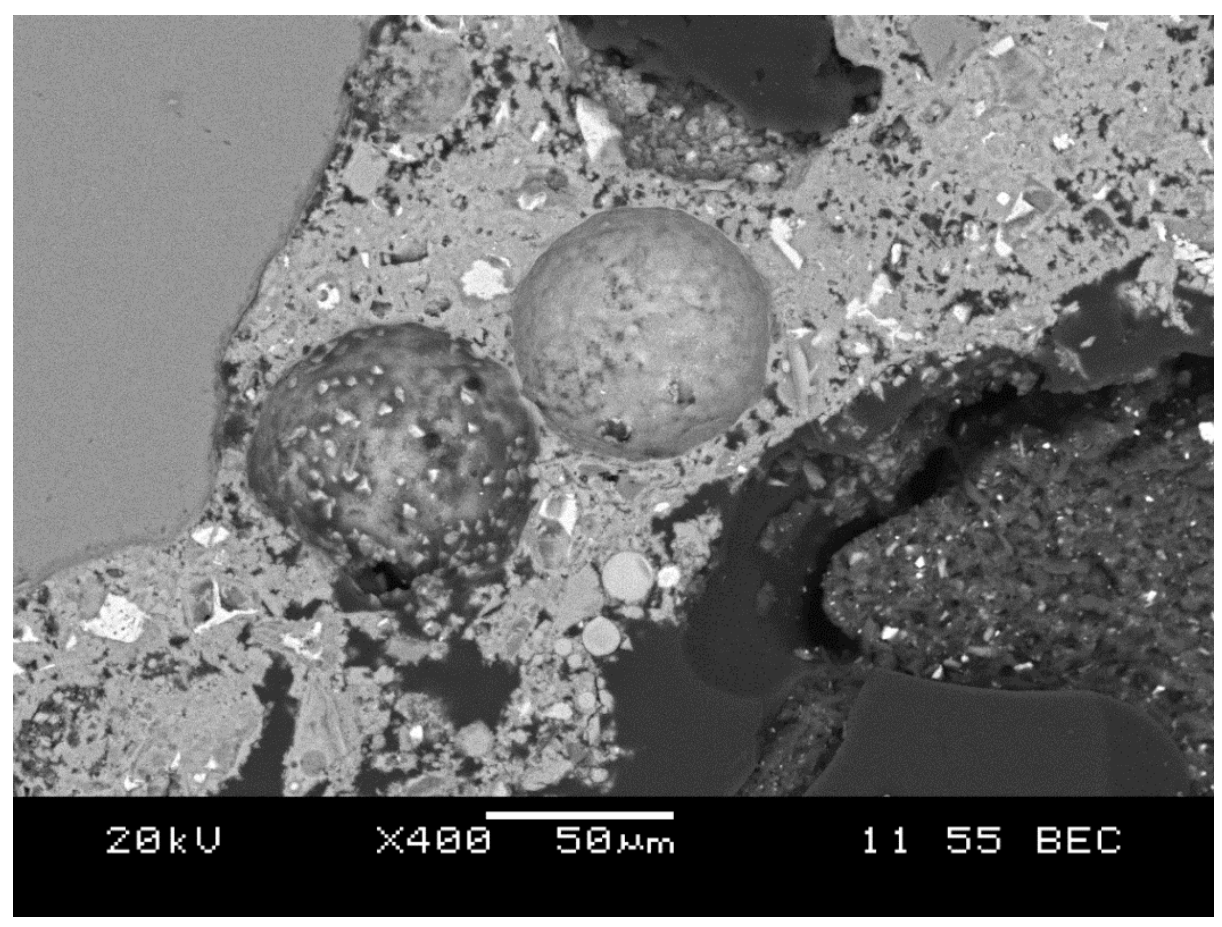

Figure 4-6 SEM image of undamaged entrained air voids in $3 \% \mathrm{CaCl}_{2} \mathrm{FT}$ sample without any cracks in or around the air voids. 
The results of the relative strength of the FTW samples in comparison to other slabs are shown in Figure 4-6, below.

(a)

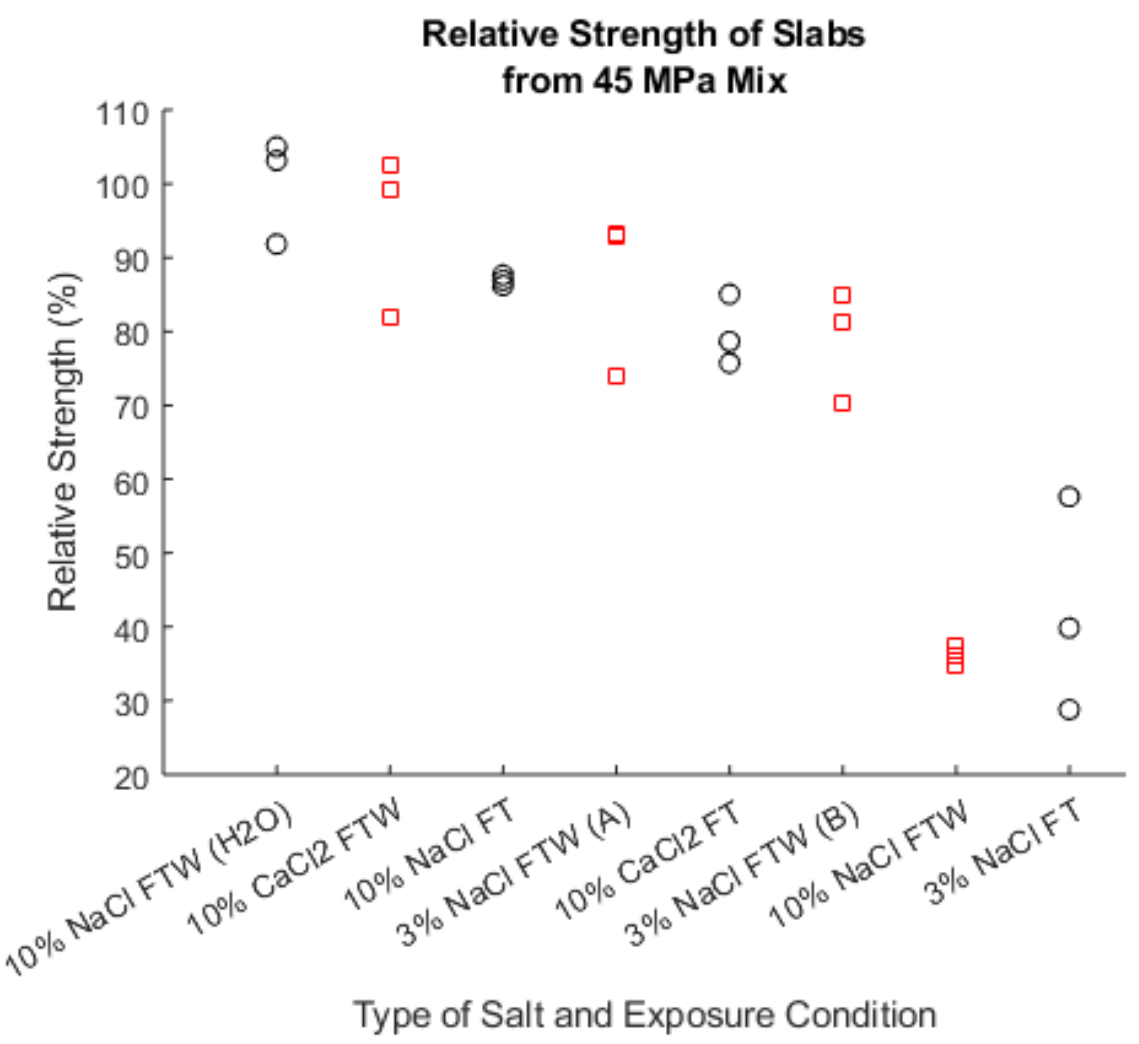


(b)

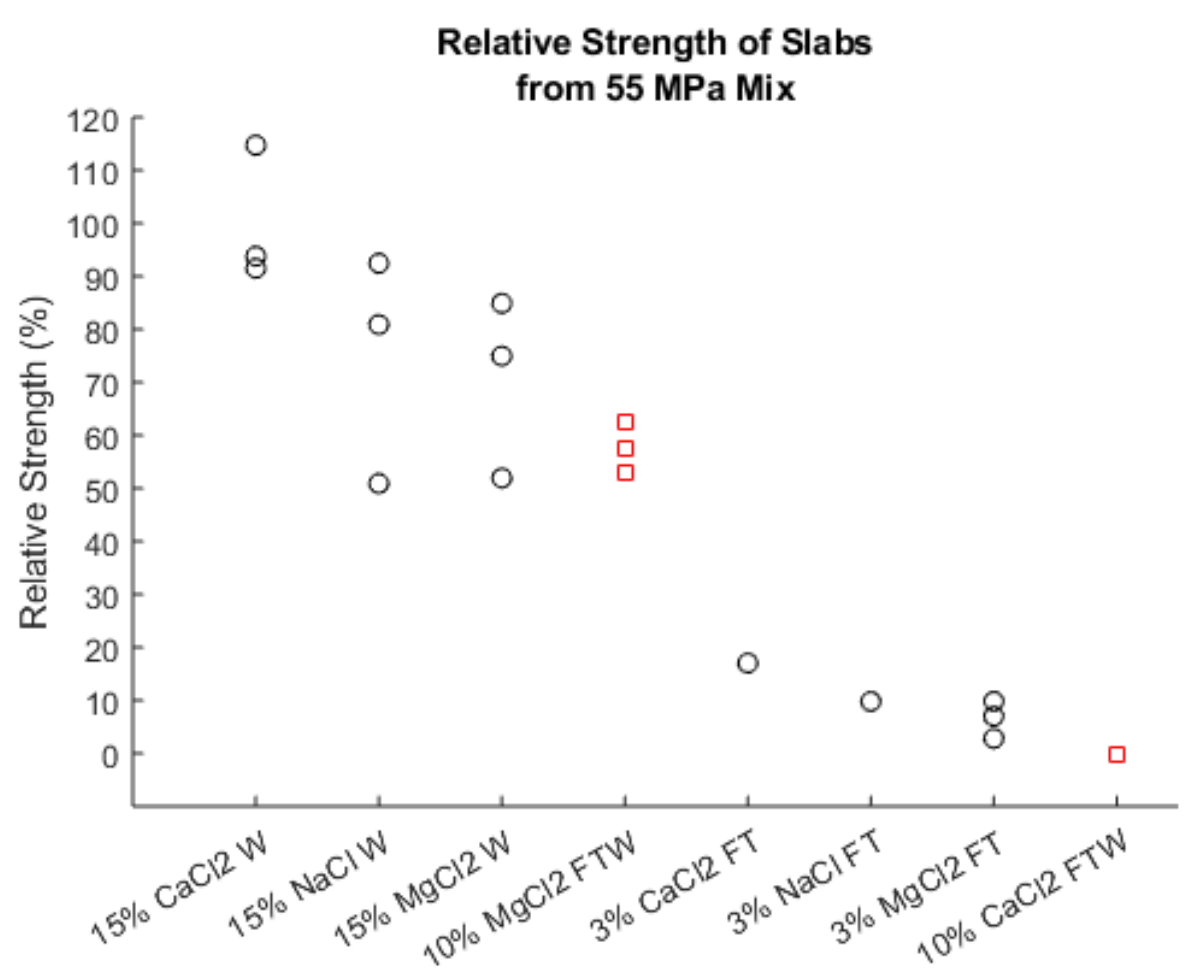

Type of Salt and Exposure Condition

Figure 4-7 Relative strength of tested samples from (a) $45 \mathrm{MPa}$ mix and (b) $55 \mathrm{MPa}$ mix, with FTW samples marked as squares.

The slabs subjected to $10 \% \mathrm{NaCl}$ experienced more damage than the $3 \% \mathrm{NaCl}$ slabs when examining FTW cycles. This shows that higher concentrations salt solutions seem to cause more damage in W cycles when combined with FT cycles. This was highlighted through the example of the $10 \% \mathrm{NaCl}$ FTW sample, which had more damage than the $10 \% \mathrm{NaCl}$ FT slabs (i.e. the higher salt concentration resulted in more damage in FTW than just FT). This example is further illustrated with the $10 \% \mathrm{NaCl}\left(\mathrm{H}_{2} \mathrm{O}\right)$ FTW sample. This sample had water used instead of $10 \% \mathrm{NaCl}$ solution during the wetting phase, with water essentially being a $0 \%$ concentration salt solution, and it was one of the least damaged samples. This shows that the concentration of the salt solution used during the wetting phase in FTW cycles can make the difference between one of the most damaged samples and one of the least damaged samples. This highlights the 
importance of using a high salt concentration solution during wetting when also combined with freezing cycles in developing an accelerated test method.

With low salt concentrations, the observations were also as expected, as was seen when examining the $3 \% \mathrm{NaCl}$ slabs: the slabs subjected to $3 \% \mathrm{NaCl}$ FTW were less damaged than the $3 \% \mathrm{NaCl}$ FT slabs, showing that FTW cycles are more damaging at high salt solution concentrations, and less damaging at low salt solution concentrations. All samples had experienced a total of 50 cycles, and the exposure was either 50 freeze-thaw cycles for the FT samples, or 25 freeze-thaw and 25 wetting cycles for the FTW samples.

The slabs subjected to $10 \% \mathrm{CaCl}_{2}$ FTW cycles were also an interesting case. The figure below illustrates the visual differences between two $10 \% \mathrm{CaCl}_{2} \mathrm{FTW}$ samples from different mixes, and an explanation follows below. Also included in the figure is a photo of a $10 \% \mathrm{MgCl}_{2} \mathrm{FTW}$ sample. 

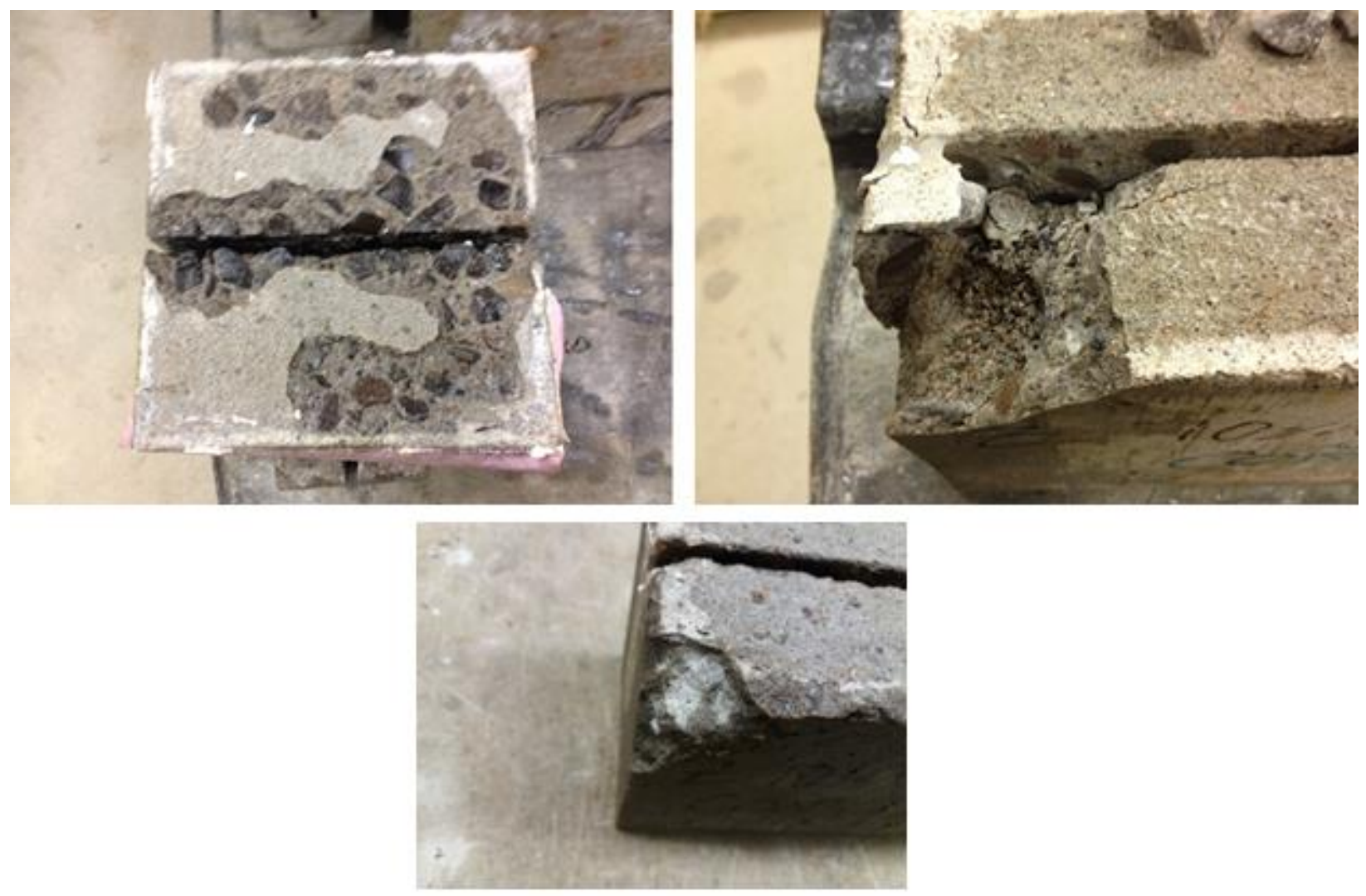

Figure 4-8 10\% $\mathrm{CaCl}_{2}$ FTW samples after 50 total cycles, $45 \mathrm{MPa}$ mix (top left) $55 \mathrm{MPa}$ mix (top right), and $55 \mathrm{MPa}$ mix $10 \% \mathrm{MgCl}_{2} \mathrm{FTW}$ (bottom).

The $10 \% \mathrm{CaCl}_{2}$ FTW samples from both mixes experienced the most visible deterioration with spalling and cracking around the surface and sides of the joints, including aggregate that had spalled off. In the case of the $55 \mathrm{MPa}$ mix rectangular slabs, the damage was so severe that large portions of the slab had fallen off, making the loading test impossible to conduct. However, in the case of the $45 \mathrm{MPa}$ mix square slabs (with $30 \%$ cement replaced with slag), although there was also a high degree of visible damage, the loading test was carried out, and it was much stronger than what was initially expected. Its strength was comparable to the $\mathrm{NaCl} \mathrm{FTW} \mathrm{slabs}$ that used water during wetting, which had experienced almost no damage/ weakening. As explained earlier, this may be because expansion was caused, which when significant enough 
would decrease the strength of the concrete. The concrete's high resistance to permeability due to the replacement of some cement with slag had prolonged its resistance to this damage, and it is likely that this damage would have been more severe if cycles were continued (as was seen in the case of lower quality concrete). This case shows that the proposed evaluation technique here can distinguish between different mixtures especially in terms of the presence of SCM.

\subsubsection{Slabs Exposed to W Cycles}

The slabs exposed to only wetting cycles and high concentrations were valuable to the experiment because they showed that wetting at high temperatures was not enough to contribute any damage to the joints, but when combined with freezing, the combined effects were very detrimental. The results of the strength of the wetting cycles are discussed below.

Of all the slabs and conditions that had been tested, the slabs exposed to just wetting had experienced the least observable damage, and the least strength loss. As a comparison, the slabs exposed to just freezing had approximately one tenth the strength of the slabs that had experienced only wetting. The strength of the slabs that had experienced only wetting was comparable to the slabs that had not underwent any exposure cycles at all. 
(a)

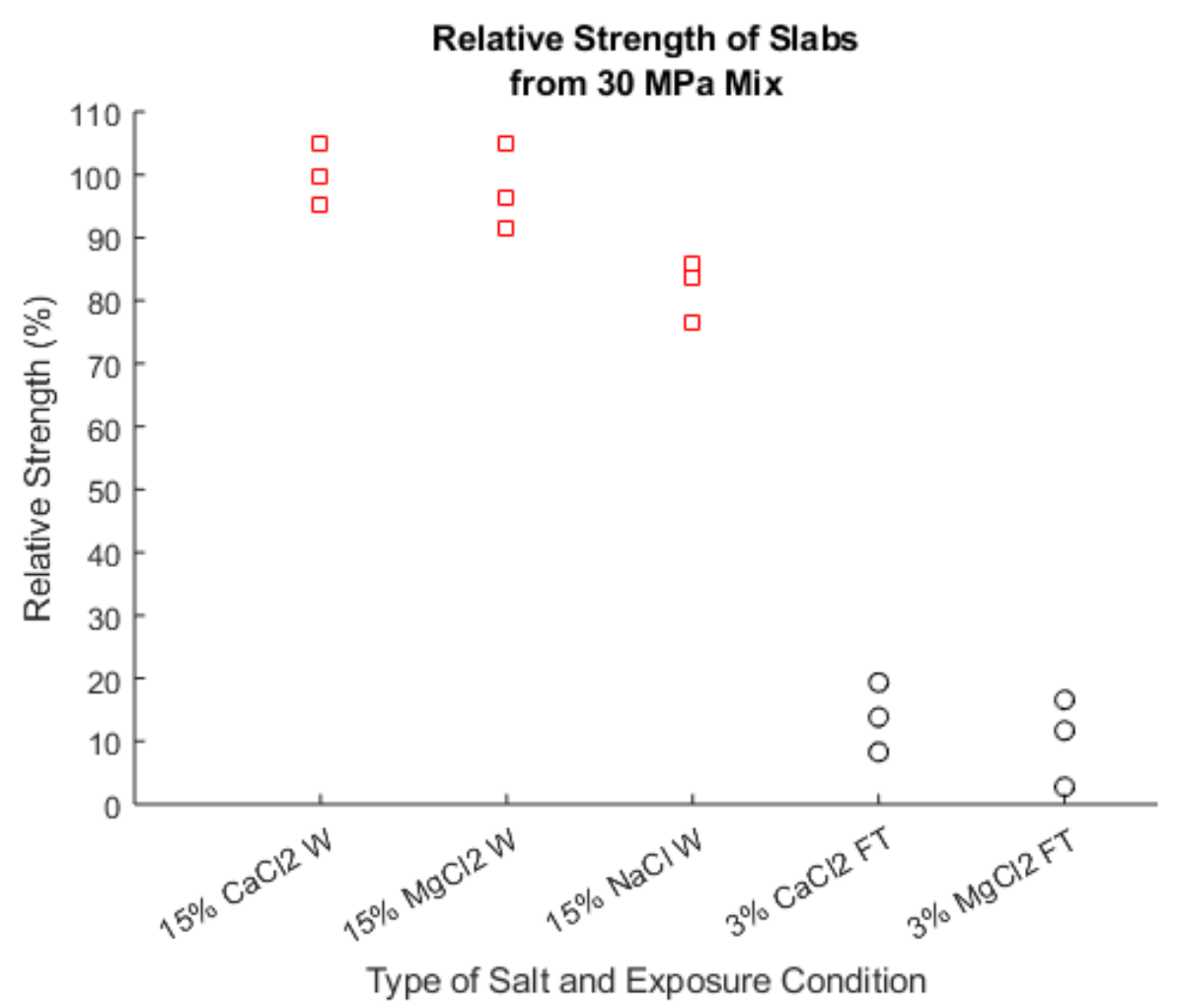

(b)

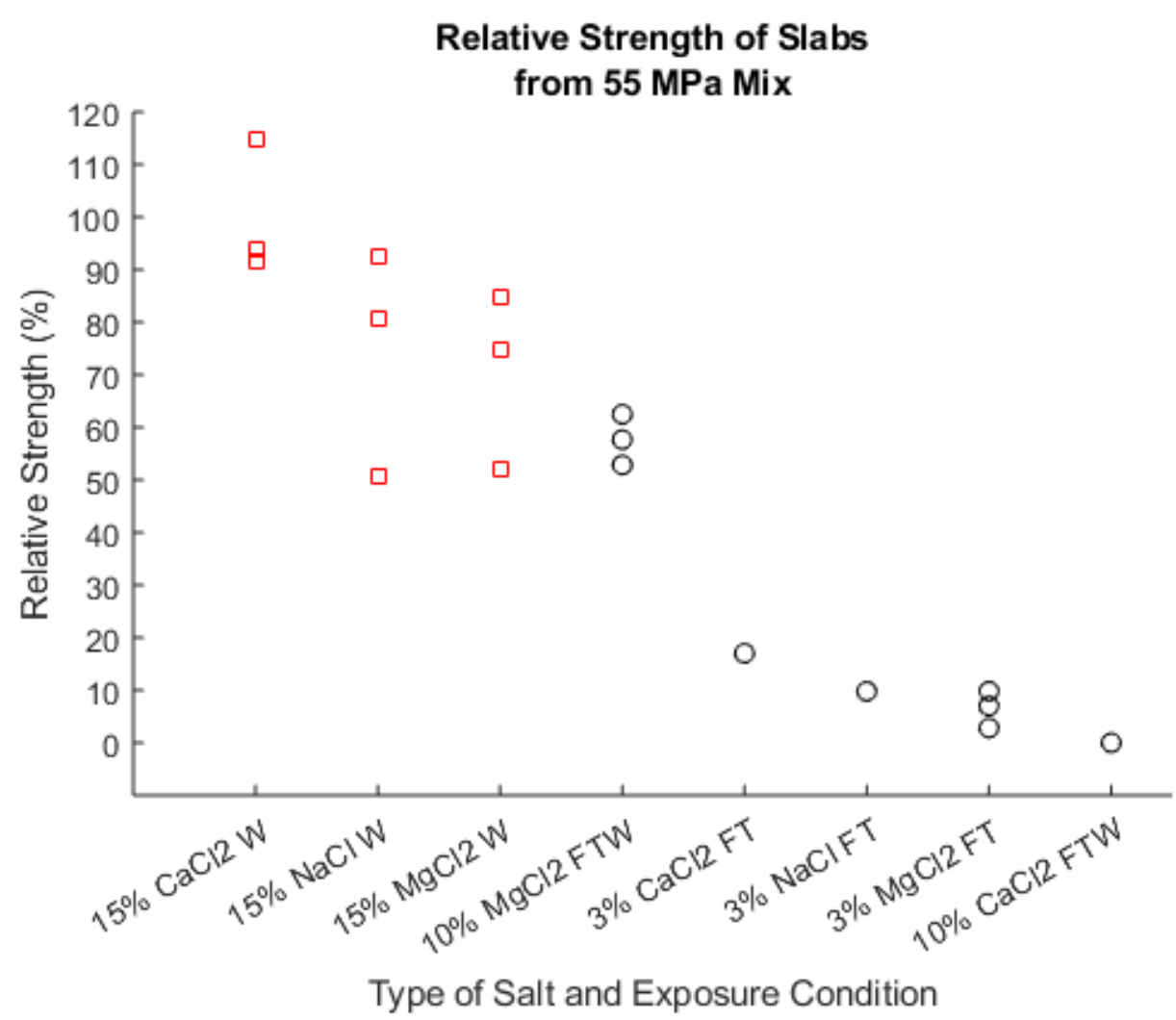

Figure 4-9 Relative strength of samples from (a) the $35 \mathrm{MPa}$ mix and (b) the $55 \mathrm{MPa}$ mix, with the samples exposed to only wetting marked as squares. 
As was explained, it is not just freezing that contributes to the degradation of the concrete slabs/ joints, but a low temperature (near $\left.0^{\circ} \mathrm{C}\right)$ is preferable for calcium oxychloride formation, which is an expansive product. In these wetting cycles, the concrete is held almost constantly at a high temperature of close to $36^{\circ} \mathrm{C}$. Calcium oxychloride formation can take place around $0^{\circ} \mathrm{C}$ to $40^{\circ} \mathrm{C}$, but the reaction is faster at lower temperatures, and slower at higher temperatures. This means that there is less damage in the wetting cycles not only because freezing does not take place, but the formation of calcium oxychloride is very limited.

It is important to note here that although it seems that high salt concentrations in the wetting procedure are responsible for more damage (if examining the FTW data), this is not necessarily the case if they are not paired with any freezing. The reason that high salt concentrations in the FTW slabs had experienced more degradation was because the high salt concentration solutions were thought to contribute to making the air voids ineffective at resisting damage from freezing. The slabs undergoing only wetting have experienced almost no damage, regardless of the type of deicing salt used. This suggests that the mechanism of wetting at a high temperature itself is not sufficient to weaken the concrete slabs, at least within the period of testing encountered here. Freezing and/ or lower temperatures are also necessary, and perhaps even more damaging when combined with the wetting cycles.

During the soaking at a higher temperature part of the wetting phase, the sodium chloride solution was the only one to continuously fully evaporate/ dry. On the other hand, the calcium chloride and magnesium chloride slabs stayed wet for even days after the testing had finished. 
Because of the differences in surface tension between these different salt solutions, the rate of evaporation differed. These differences in evaporation necessitated the replacement of sodium chloride solution sooner than the others, and thus resulted in the sodium chloride samples having a higher concentration than the other salt exposure samples.

To further comment on the results in the previous figure, the differences in strength between samples exposed to wetting are not in conflict with the results from past research. Table 4-12 below, summarizes some of these results, followed by a further discussion.

Table 4-12 Relative strength compared with 28-day compressive strength (30 MPa mix, wetting cycles)

\begin{tabular}{|c|c|c|}
\hline $\begin{array}{c}\text { Sample (Salt Solution and } \\
\text { Type of Cycles) }\end{array}$ & $\begin{array}{c}\text { Relative Strength (from } \\
\text { centre-point loading slabs) }\end{array}$ & $\begin{array}{c}\text { 28-day compressive strength } \\
\text { of cylinders without any } \\
\text { exposure to salt }\end{array}$ \\
\hline $15 \% \mathrm{CaCl}_{2} \mathrm{~W}$ & $100 \%$ & $28.1 \mathrm{MPa}$ \\
\hline $15 \% \mathrm{MgCl}_{2} \mathrm{~W}$ & $97.6 \%$ & $32.0 \mathrm{MPa}$ \\
\hline $15 \% \mathrm{NaCl}_{\mathrm{W}}$ & $82.0 \%$ & $26.6 \mathrm{MPa}$ \\
\hline
\end{tabular}

In the $30 \mathrm{MPa}$ mix samples, although the $\mathrm{NaCl}$ slabs were weaker than the $\mathrm{MgCl}_{2}$ and the $\mathrm{CaCl}_{2}$ for the wetting cycles, this was likely due to the strength of the concrete batches themselves. The $\mathrm{NaCl}$ batch was had the lowest 28-day compressive strength of the $30 \mathrm{MPa}$ mix design (26.6 $\mathrm{MPa}$ ), while the $\mathrm{MgCl}_{2}$ batch had the highest 28-day compressive strength (32.0 MPa). This shows that the initial strength of the concrete used is important in cases like $\mathrm{W}$ cycles, where very little damage took place.

It was seen that wetting at $36^{\circ} \mathrm{C}$ caused insignificant damage to the slabs. This was consistent across all proposed evaluation techniques in this experiment, not just for strength loss. Despite these results, past research has shown that concrete soaking in $\mathrm{CaCl}_{2}$ solution at low 
temperatures (closer to $0^{\circ} \mathrm{C}$, but still above $0^{\circ} \mathrm{C}$ ) caused significant deterioration after longer periods of time (Farnam et al., 2015a; Monical et al., 2016; Sutter et al., 2002; Wang et al., 2018). This suggests that damage could be seen from the wetting cycles if the duration of the test is extended or if the temperature is reduced. It is likely that temperature is a more important factor in this case because calcium oxychloride, which is an expansive reaction product, forms in the temperature range of about $0^{\circ} \mathrm{C}-40^{\circ} \mathrm{C}$, but forms faster at lower temperatures (Qiao et al., 2018b). Extending the test duration with more cycles may make it more likely that damage will take place, but this defeats the purpose of it being an accelerated test, and these results highlight the importance of low temperatures for deterioration.

Concentrations of salt solutions above $10 \%$ were not used for the FTW samples because it was observed that starting with a higher concentration and gradually increasing it as the test went along would result in a solution that would not freeze. It was thought that the freezing of the solution and the resulting physical damage was necessary for deterioration to take place in the FTW samples. The wetting samples were tested with a higher salt solution, although also at a higher temperature, so further investigation into higher concentration salt solutions (perhaps even to the point of no freezing) at lower temperatures is recommended. This would provide valuable information on the contribution of freezing (as opposed to just low temperatures) to deterioration when combined with wetting cycles. 


\subsubsection{Testing Under Flexural Fatigue}

Although the loading data was reported as relative ultimate strength from a static load required for failure, a few samples were first tested under fatigue loading, as was described in Chapter 3. These results are shown below.

Table 4-13 Samples that underwent fatigue loading.

\begin{tabular}{|c|c|c|c|c|}
\hline \multirow{2}{*}{$\begin{array}{l}\text { Mix Design } \\
\text { Name }\end{array}$} & \multirow{2}{*}{$\begin{array}{c}\text { Exposure \& } \\
\text { Cement Content }\end{array}$} & \multicolumn{3}{|c|}{ Loading Cycles to Failure } \\
\hline & & Sample A & Sample B & Sample C \\
\hline $45 \mathrm{MPa}$ & $\begin{array}{c}3 \% \mathrm{NaCl} \mathrm{FT} \\
\left(350 \mathrm{~kg} / \mathrm{m}^{3}\right)\end{array}$ & Not tested & Not tested & $125000^{a}$ \\
\hline $30 \mathrm{MPa}$ & $\begin{array}{l}3 \% \mathrm{CaCl}_{2} \mathrm{FT} \\
\left(300 \mathrm{~kg} / \mathrm{m}^{3}\right)\end{array}$ & Not tested & $0^{\mathrm{b}}$ & $0^{c}$ \\
\hline $55 \mathrm{MPa}$ & $\begin{array}{l}3 \% \mathrm{MgCl}_{2} \mathrm{FT} \\
\left(270 \mathrm{~kg} / \mathrm{m}^{3}\right)\end{array}$ & $0^{d}$ & $0^{\mathrm{b}}$ & $0^{\mathrm{b}}$ \\
\hline $55 \mathrm{MPa}$ & $\begin{array}{c}3 \% \mathrm{NaCl} F T \\
\left(270 \mathrm{~kg} / \mathrm{m}^{3}\right)\end{array}$ & $0^{\mathrm{b}}$ & $0^{\mathrm{b}}$ & 100215 \\
\hline $55 \mathrm{MPa}$ & $\begin{array}{l}3 \% \mathrm{CaCl}_{2} \mathrm{FT} \\
\left(270 \mathrm{~kg} / \mathrm{m}^{3}\right)\end{array}$ & Not tested & Not tested & $125000^{a}$ \\
\hline \multicolumn{5}{|c|}{$\begin{array}{l}\text { a Sample underwent } 125000 \text { cycles and did not fail. } \\
\text { b Sample failed at a load of } 7 \mathrm{kN} \text { before cyclical load application started. } \\
\text { c Sample failed at a load of } 3 \mathrm{kN} \text { before cyclical load application started. } \\
\text { d Sample failed at a load of } 2 \mathrm{kN} \text { before cyclical load application started. } \\
\text { e Sample underwent } 125,000 \text { cycles and did not fail. }\end{array}$} \\
\hline
\end{tabular}

Overall, fatigue testing was an attempt to quantify the damage in the weakened slabs that was not effective for one main reason: a single, ultimate static load would be more effective at giving an indication of the relative strength loss. For fatigue loading to have been effective, an idea of the ultimate strength would have to have been known beforehand to select an appropriate loading range, but simply testing for the ultimate strength immediately was found to be a more effective and efficient quantification of the strength of the samples. The loads tested for fatigue loading would result in either an immediate failure of the sample before the peak load of the first 
cycle could be reached, or 125,000 loading cycles would take place without failure. Thus, a single static load gave more appropriate results.

\subsection{Visual Observations}

In addition to the quantitative data that was collected in the testing of the deteriorated slabs, a visual inspection was performed on the slabs. This was to examine any signs of deterioration that would be helpful in developing an accelerated test method for concrete joint deterioration. This visual inspection included observing any noticeable differences between slabs such as the shape and size of cracks, scaling, salt accumulation, discolouration, or any other signs of damage or deterioration. The surfaces of the slabs, the outside of the slabs, and the inside of the joints were all examined.

\subsubsection{Types of Cracks from Loading}

The types of cracks that occurred from loading the samples to failure were analyzed to ensure that a consistent mode of failure was taking place. For developing the accelerated test method, it is necessary that the samples all fail in the same way: either all in shear or all in moment, so that the values can be compared.

\subsubsection{Slab Failure}

It was expected that from fatigue and/ or static loading that the failure mode would be a crack extending from the saw cut, across the length of the joint, and confined within the section immediately above the saw cut. This was always the case, with a few exceptions. In some slabs tested, the crack extended beyond the section immediately above the saw cut, but the crack was 
not always confined within the region immediately above the saw cut. An example of this is shown in Figure 4-10, below.

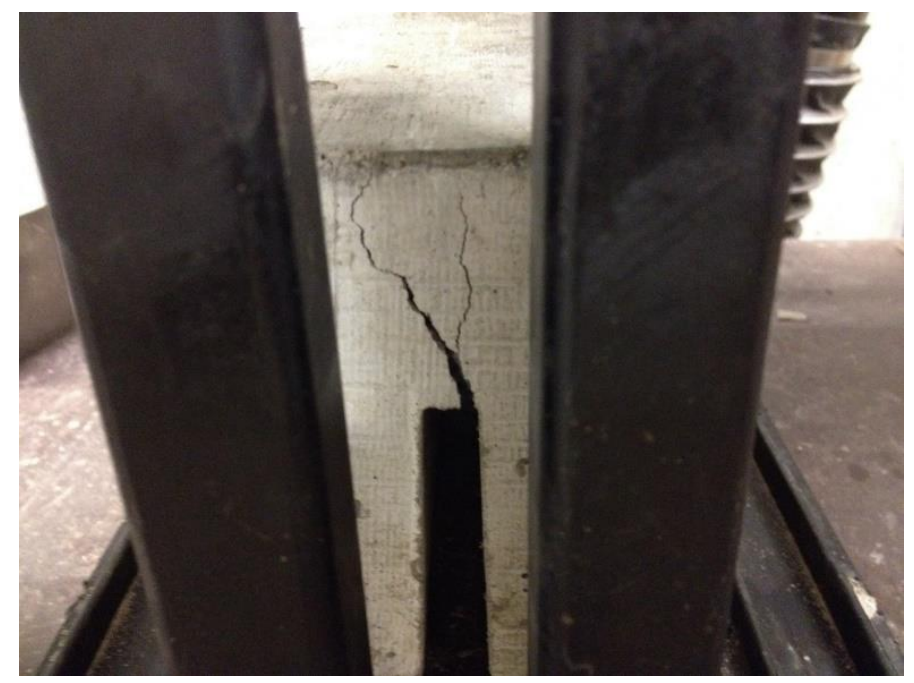

Figure 4-10 Control slab tested to ultimate failure with rollers, in which the crack that had formed was not confined to the section immediately above the saw cut.

In this example, a control slab (that had not undergone any freeze-thaw or wetting cycles, and was also not exposed to any salts) was tested to failure using centre-point loading. The crack was not confined to just the area immediately above the saw cut, as was expected. Rather, the crack had formed from the joint and had extended slightly beyond this area as the crack propagated upward.

This crack extending outwards is a sign that the crack did begin from the weakest point (i.e. the saw cut, which created a weak section). The crack did not propagate directly upwards because it moved through what was the weakest section. Another example of this is shown in Figure 4-11, below. 


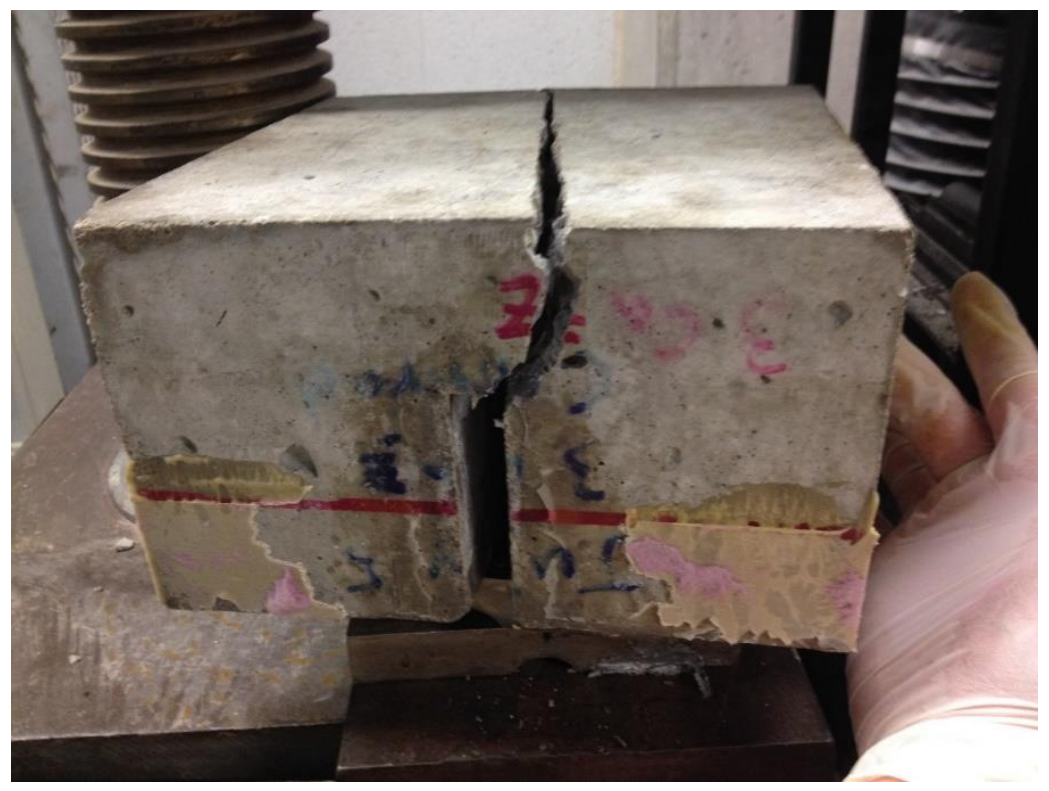

Figure 4-11 $10 \% \mathrm{CaCl}_{2}$ FT sample with the crack extending up and away from the joint rather than staying confined within the area directly above the saw cut.

This sample $\left(10 \% \mathrm{CaCl}_{2} \mathrm{FT}\right)$ underwent 50 cycles of freezing and thawing. The loading crack started to form at the joint, but rather than propagate upwards, the crack extended up and away from the saw cut. The load required to break this sample was $11.04 \mathrm{kN}$. Again, this is an indication that the crack started to form at what was the weakest location (i.e. the section above the saw cut), and it continued to propagate through the weakest section (which may have been weakened from its cyclical exposure).

\subsubsection{Cracks at Supports}

The cracks of another control sample loaded to failure were examined. The cracks above the saw cut again extended slightly beyond the boundaries of being within the area directly above the saw cut. However, another point of interest was that cracks had formed above the roller supports on one side of the slab, as seen in Figure 4-12, below. The cracks forming above the roller were formed as shear cracks; the shear is the highest and the moment is the lowest at the supports in 
this loading setup, which would explain the cracks. It should be noted that this is the only sample in which this had occurred, and this was a control sample that had not experienced any cyclical exposure to salts and freezing/ thawing/ wetting.

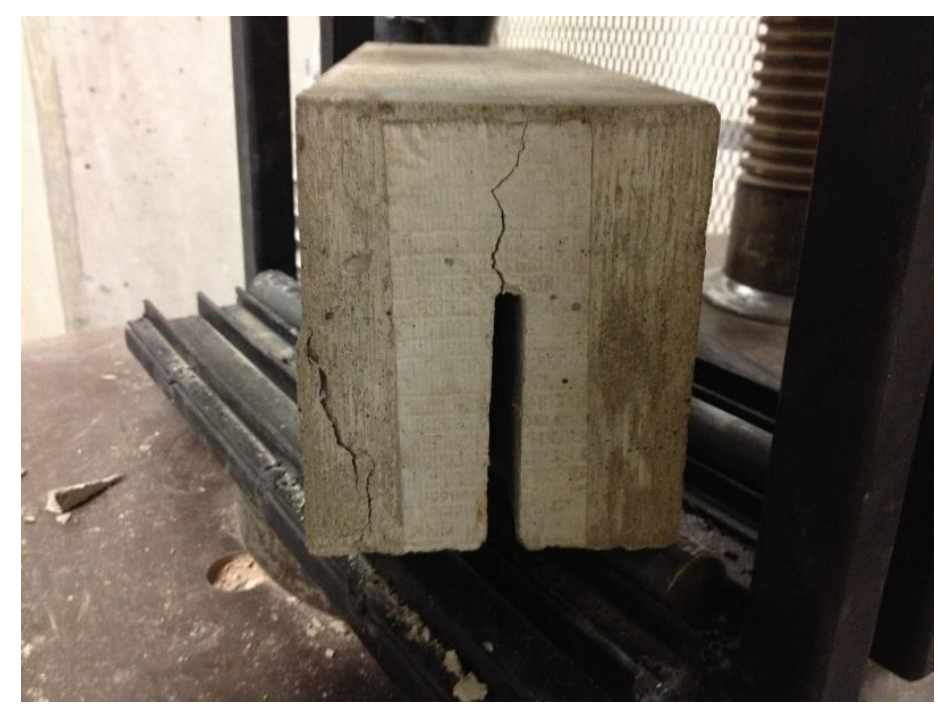

Figure 4-12 Control slab tested to ultimate failure, which had experienced some cracking above the roller support (left side of the image).

Seeing that this type of failure had only occurred in a control sample further strengthens using this method of loading for developing an accelerated test method for concrete pavement joint deterioration. A control sample would not have had any exposure to salts or freezing/ thawing, so the weakest section (i.e. immediately above the saw cut) would not have gotten any weaker. In every sample that had been tested, no shear cracks around the support were seen. This suggests that the salt solution sitting in the joint had weakened that section further, making the sample fail exactly where it was planned to have failed. 


\subsubsection{Cracks in and around Joints}

The visual joint inspection of cracks around joints (before loading) provided some evidence to suggest that deterioration around the joint is a very significant factor in the strength of a concrete sample. This is important in discussing the efficacy of using strength to determine premature joint deterioration. Figure 4-13, below, illustrates various cases of this, and an explanation follows.
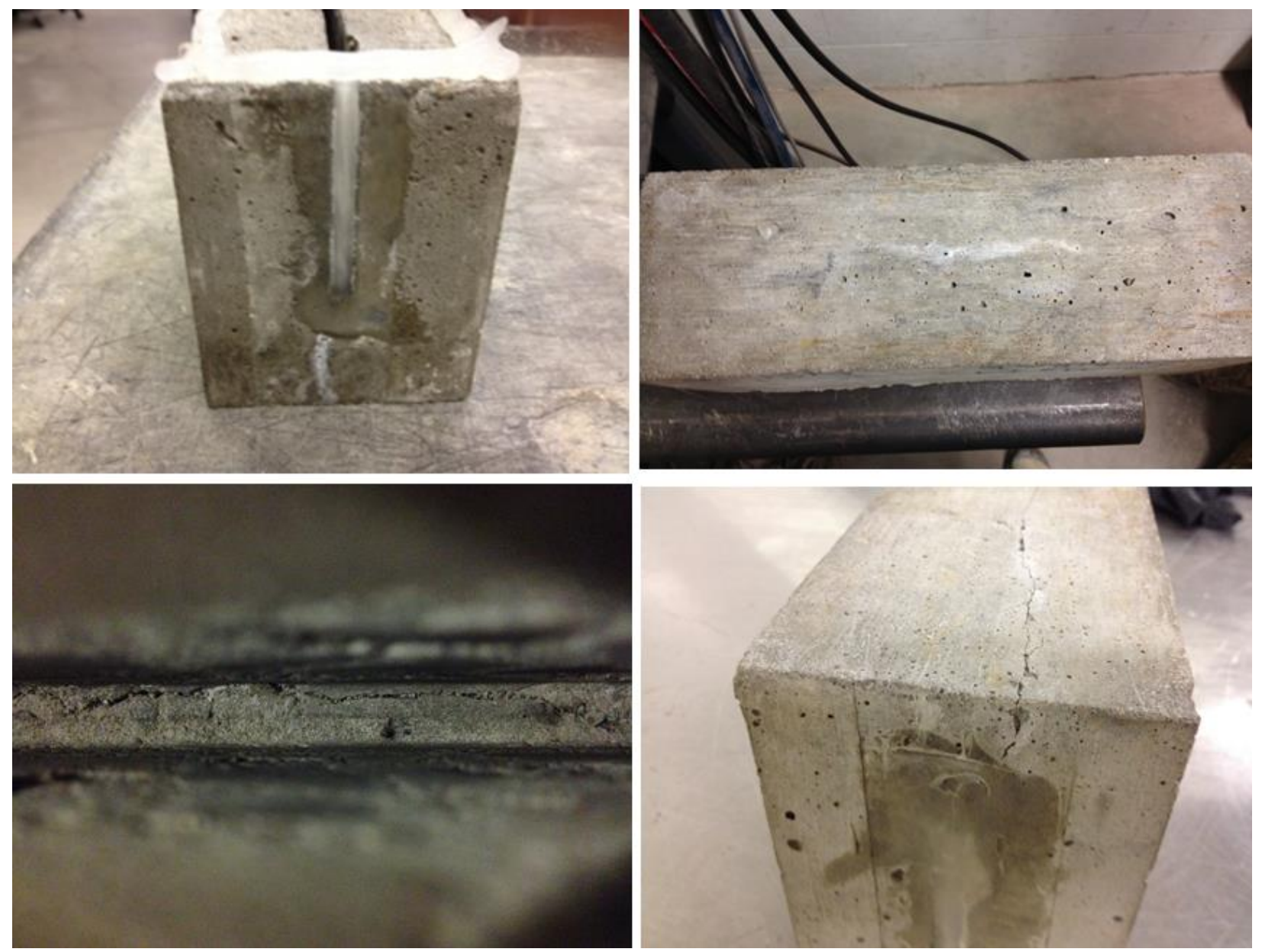

Figure 4-13 Cracks in and around the joint of slabs exposed to FT before loading. A crack and efflorescence below the joint of a $3 \% \mathrm{CaCl}_{2} \mathrm{FT}$ sample (top left), some efflorescence and a thin crack on the bottom surface of a $3 \% \mathrm{MgCl}_{2} \mathrm{FT}$ sample (top right), cracks inside the joint of a $3 \% \mathrm{CaCl}_{2}$ sample (bottom left), and a crack visible on the bottom surface of a slab connecting to the saw cut of a $3 \%$

$\mathrm{CaCl}_{2}$ sample (bottom right). 
Before being loaded, some samples had some cracks that were visible from the outside, along the side faces of the slab extending from the joint, from inside the joint, or in the worst cases, from the bottom surface of the slab. In the cases of thinner cracks, efflorescence was visible along the cracks.

Cracks were observed around the joints of some of the $30 \mathrm{MPa}$ mix and $55 \mathrm{MPa}$ mix samples (the rectangular slabs), but not in any of the $45 \mathrm{MPa}$ mix samples (the square slabs). This is due to either sample geometry (explained later in this chapter) or differences in the mix design (the 45 MPa mix samples had more cement and some slag, while the other samples did not).

Cracks were only observed in samples that had underwent at least some freezing and thawing cycles, suggesting that this is a necessary mechanism for this damage, and that wetting cycles by themselves are not sufficient to cause this damage.

Table 4-14 The presence of cracks around the joints of samples from different mixes

\begin{tabular}{|c|c|c|c|}
\hline & 45 MPa Mix & 30 MPa Mix & 55 MPa Mix \\
\hline Sample shape & Square & Rectangle & Rectangle \\
\hline $\begin{array}{c}\text { 28-day Compressive } \\
\text { Strength (MPa) }\end{array}$ & 45.49 & 29.62 & No \\
\hline Slag used in mix? & $\begin{array}{c}\text { Yes, 30\% cement } \\
\text { replacement }\end{array}$ & No & Yes \\
\hline $\begin{array}{c}\text { Cracks present in FT } \\
\text { samples? }\end{array}$ & No & Yes & Yes \\
\hline $\begin{array}{c}\text { Cracks present in } \\
\text { FTW samples? }\end{array}$ & No & Not tested & No \\
\hline $\begin{array}{c}\text { Cracks present in W } \\
\text { samples? }\end{array}$ & No & No & \\
\hline
\end{tabular}


These results warrant further investigation into whether the geometry of the slabs is responsible for the cracks forming, or if a more resistant concrete (from the presence of slag) is responsible for resisting the formation of these cracks.

It is unlikely that these are shrinkage cracks, because the larger samples (i.e. the square samples, from the 45 MPa mix) would be more susceptible to shrinkage cracks because of their larger size. Secondly, these cracks had only occurred in samples in the presence of at least some freezing taking place, so that seems to be necessary for these cracks to form.

It also seems that compressive strength is not the sole factor, because although the $55 \mathrm{MPa}$ mix was stronger than the $45 \mathrm{MPa}$ mix, cracks were still present around the joints of the $55 \mathrm{MPa}$ mix.

However, this coincides with what was observed in the previous section when types of cracking from loading was analyzed: the crack that formed from above the saw cut did not always propagate immediately above the saw cut. It is likely that the crack formed at what was the weakest section (i.e. the location of the saw cut) and it continued to form through what was the weakest section in the concrete. These results suggest that this proposed technique of testing concrete pavement joint deterioration is effective in capturing what happens to a weakened section, but further investigation should be made to ensure that the cracks are indeed forming for this reason.

\subsubsection{Inside Surface of the Joint}

The inside surfaces of the joints were examined (after loading) to see what kind of deterioration had taken place from different salt solutions, and if any observations could be used for developing the visual index for the accelerated concrete pavement joint deterioration test. After 
loading had taken place and the samples were loaded to failure, a clear view of the inside faces of the joints were available. Some clear distinctions were observed between different types of exposure, and some of these differences are shown in Figure 4-14, below.
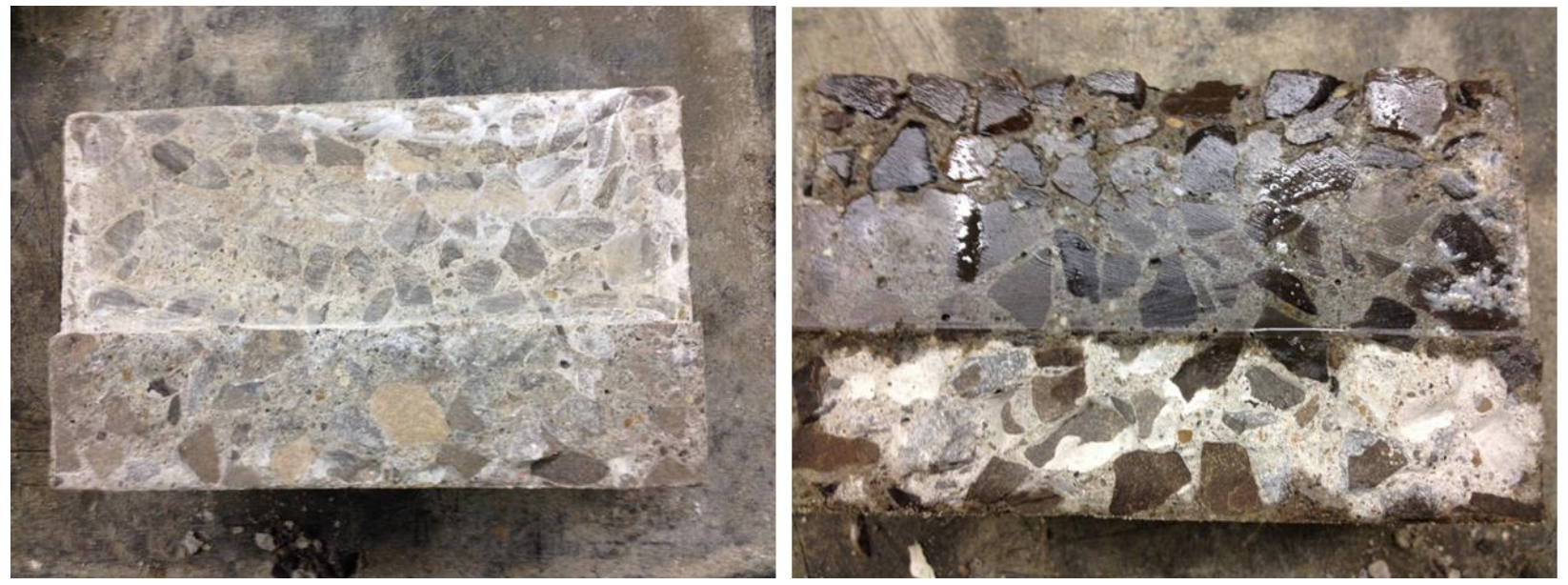

Figure 4-14 A view inside the joint (after loading) of the $10 \% \mathrm{NaCl} F \mathrm{FTW}\left(\mathrm{H}_{2} \mathrm{O}\right)$ sample (left) and the $10 \%$ $\mathrm{CaCl}_{2} \mathrm{FTW}$ sample (right), both from the $45 \mathrm{MPa}$ mix.

When making a visual comparison between two slabs like these, it seems evident that it should be part of the criteria for developing an accelerated test method for concrete joint deterioration. The sample on the left was one that had experienced very little damage and very little scaling, while the sample on the right experienced some spalling near the surface of the joint, and it even appears that some paste has deteriorated away from near the top of the joint. Comparisons of other samples are shown below. 

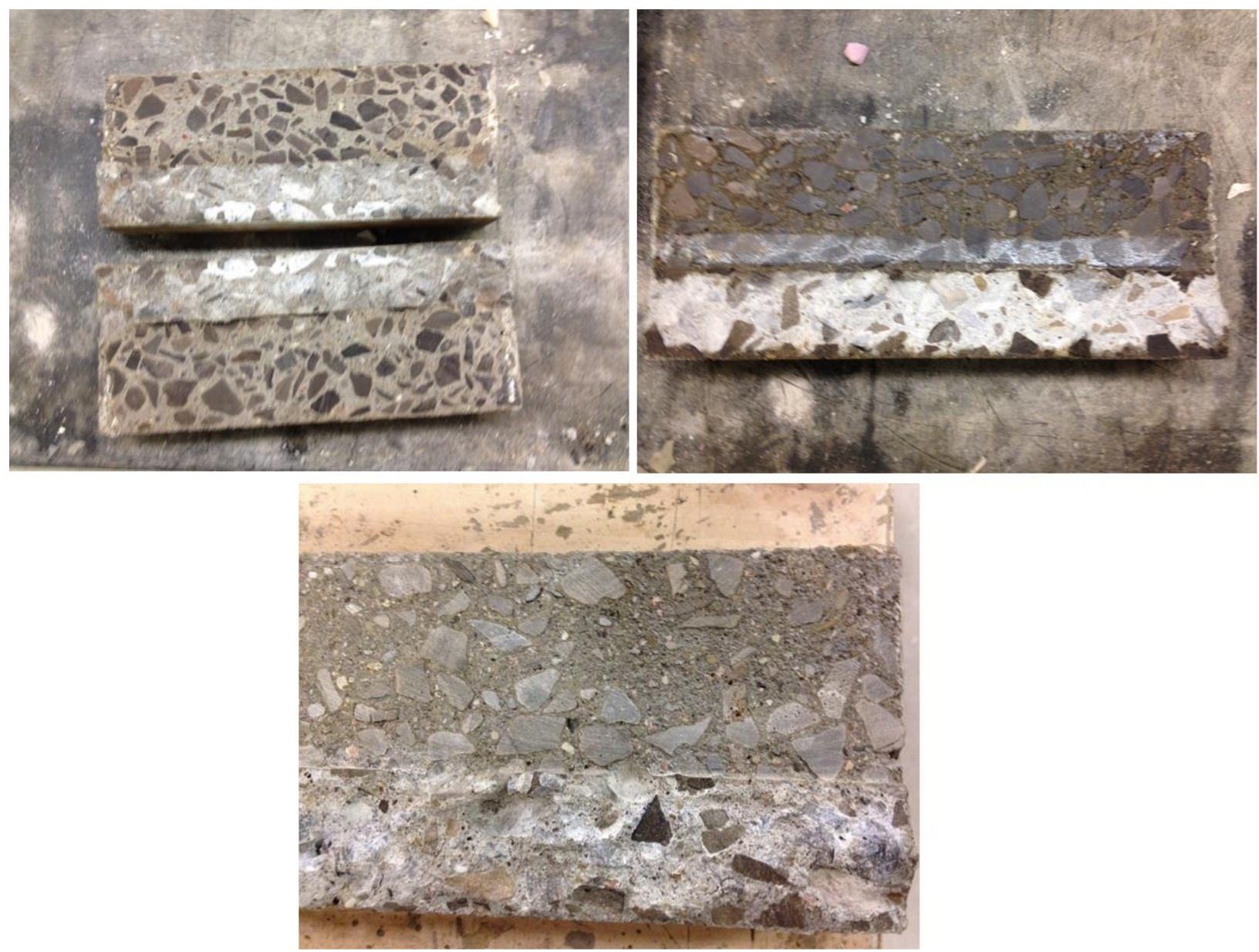

Figure 4-15 Inside the joints of different samples after loading: $15 \% \mathrm{NaCl} W$ (top left), $15 \% \mathrm{MgCl}_{2} \mathrm{~W}$ (top right), and $3 \% \mathrm{MgCl}_{2} \mathrm{FT}$ (bottom).

The $\mathrm{NaCl}$ samples consistently had the least damaged inside surfaces, as was seen with the example of $15 \% \mathrm{NaCl} \mathrm{W}$ in the above figure. The $\mathrm{MgCl}_{2}$ samples, on the other hand, had a visibly recessed paste, and a discoloured paste in the case of $\mathrm{MgCl}_{2}$ exposed to $\mathrm{FT}$. The paste experienced discolouration, turning a slightly blue colour closer to the bottom of the joint. The cracked section below the joint, although apparently intact before loading, was almost completely white (except for the aggregate), suggesting that salt buildup was in progress. 
Past research has also shown that $\mathrm{MgCl}_{2}$ had the most deteriorated paste when compared to exposure with $\mathrm{CaCl}_{2}$ and $\mathrm{NaCl}$ (Lee et al., 1998; Sutter et al., 2002; Suraneni et al., 2017; Wang et al., 2018). Significant differences were also observed in the samples exposed to $\mathrm{MgCl}_{2}$ compared to the other salt solutions, as is illustrated in an SEM image in Figure 4-16, below. 

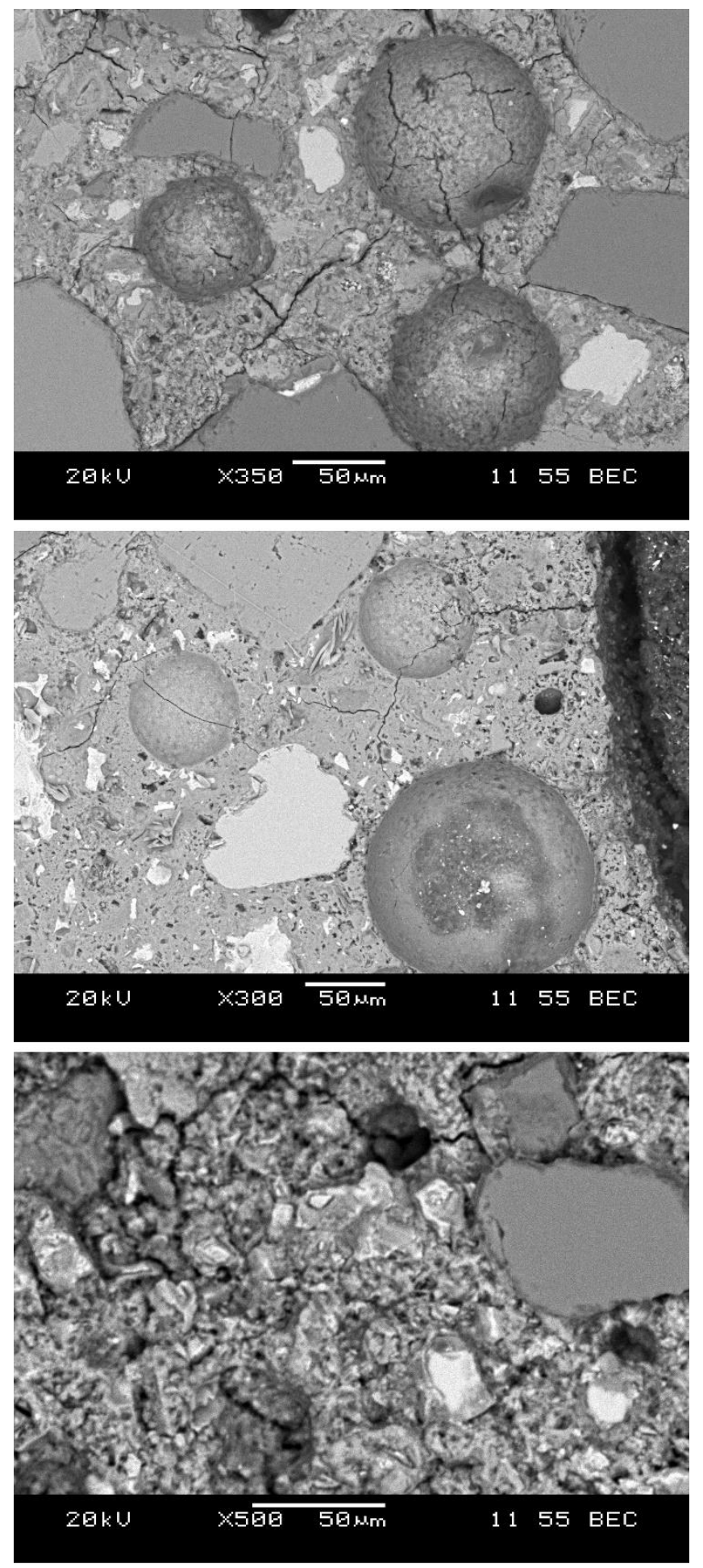

Figure 4-16 SEM images showing differences in paste of samples exposed to different salt solutions, from top to bottom: $3 \% \mathrm{NaCl} \mathrm{FT,} 3 \% \mathrm{CaCl}_{2} \mathrm{FT}$, and $3 \% \mathrm{MgCl}_{2} \mathrm{FT}$. 
The paste of the $\mathrm{MgCl}_{2} \mathrm{FT}$ samples looks not only different to the naked eye, but it looks significantly different when examined under SEM. In addition to the significant loss in strength experienced by the samples exposed to $\mathrm{MgCl}_{2}$, this further illustrates the ability of the test to evaluate samples with different salt exposures.

To further show that the damage present in the samples exposed to $\mathrm{MgCl}_{2}$ is chemical and not completely physical, the following figure is another SEM image of the paste of a sample exposed to $\mathrm{MgCl}_{2}$.
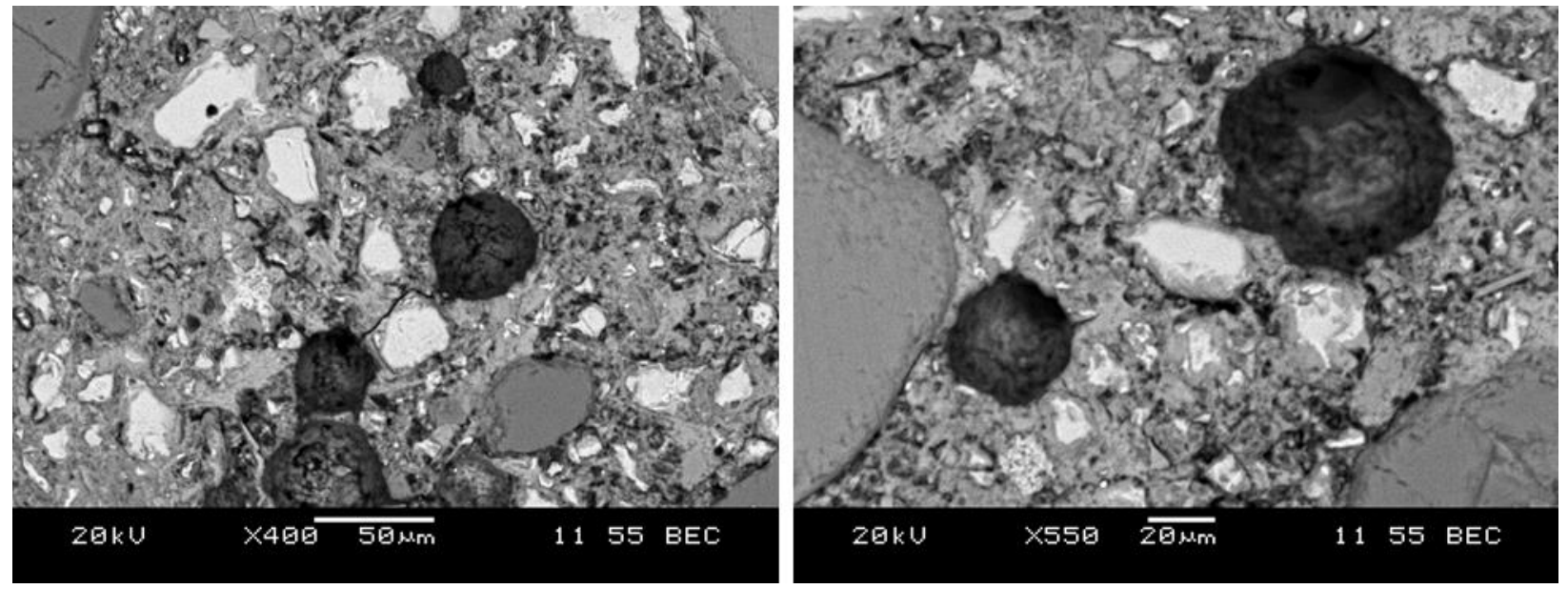

Figure 4-17 SEM images of a sample exposed to $3 \% \mathrm{MgCl}_{2}$ FT with a crack present between entrained air voids (left) and entrained air voids without a connecting crack (right).

The presence of cracks between entrained air voids suggests that physical damage (i.e. water freezing) had taken place. However, as is seen in the above figure, this did not happen in every case, and the paste is seen to be deteriorated, so there is more than just physical damage taking place in the samples exposed to $\mathrm{MgCl}_{2}$.

All of the samples that were subject to only wetting cycles at high temperatures (i.e. $36^{\circ} \mathrm{C}$ ) did not have any visual indications of deterioration at all (with the exception of the $\mathrm{MgCl}_{2}$ samples). 
This again highlights the importance of including low temperatures during exposure to salt solution. Additionally, examining the inside surface of the joint (and not just the surface of the slab) may provide additional useful information to make a more accurate assessment of the deterioration that had taken place.

\subsubsection{Visual Index Development}

As was concluded in the previous section, examining the inside surface of a joint can provide addition useful information when developing a visual index for determining concrete pavement joint deterioration. Suggestions are made in this section for developing an index for both the top surface and inside of the joints, based on the results that were observed.

\subsubsection{Visual Index: Surface Deterioration}

There are limitations of using a surface inspection to determine how deteriorated a concrete joint is: in past research, some concrete pavements have appeared to be fine at the surface, but have been deteriorated near the bottom of the joint. No instances of this were observed in these experiments, but a suggestion is made for future research into this topic to perhaps consider wetting/ soaking the base of slabs to see if a bottom-up deterioration takes place. Another major limitation is that unless severe deterioration takes place, as was the case in the $10 \% \mathrm{CaCl}_{2} \mathrm{FTW}$ $55 \mathrm{MPa}$ mix samples, surface deterioration will not really take place if a dike is not included on the sample. Regardless, a visual index based on the results that were obtained is presented below. 
Table 4-15 Visual index created for rating concrete joint deteriorated based on the surface.

\begin{tabular}{|c|c|}
\hline $\begin{array}{l}\text { Damage Rating ( } 5 \\
=\text { most, } 1 \text { = least) }\end{array}$ & Example and Explanation \\
\hline 1 & $\begin{array}{l}\text { Little/ no surface scaling, no damage along the joint. } \\
\text { (Example: } 10 \% \mathrm{NaCl} F \mathrm{FW}, 45 \mathrm{MPa} \text { mix) }\end{array}$ \\
\hline 2 & $\begin{array}{l}\text { (Example: } 3 \% \mathrm{NaCl} \mathrm{FT}, 45 \mathrm{MPa} \text { mix) } \\
\text { Some scaling/ damage around the joint, some paste missing, no }\end{array}$ \\
\hline 3 & $\begin{array}{l}\text { Some scaling/ minor spalling around the joint, little to no aggregate } \\
\text { missing. } \\
\text { (Example: } 10 \% \mathrm{CaCl}_{2} \mathrm{FTW}, 45 \mathrm{MPa} \text { mix) }\end{array}$ \\
\hline
\end{tabular}




\begin{tabular}{|c|c|}
\hline $\begin{array}{l}\text { Damage Rating (5 } \\
=\text { most, } 1=\text { least) }\end{array}$ & Example and Explanation \\
\hline 4 & $\begin{array}{l}\text { Some spalling around the joint, most aggregate exposed, some aggregate } \\
\text { missing. } \\
\text { (Example: } 10 \% \mathrm{CaCl}_{2} \text { FTW, } 45 \mathrm{MPa} \text { mix) }\end{array}$ \\
\hline 5 & $\begin{array}{c}\text { Excessive spalling, large masses of concrete cracking off starting from the } \\
\text { joint. } \\
\text { (Example: } 10 \% \mathrm{CaCl}_{2} \mathrm{FTW}, 55 \mathrm{MPa} \text { mix) }\end{array}$ \\
\hline
\end{tabular}

\subsubsection{Visual Index: Deterioration Inside Joint}

Viewing the inside of the joint can provide additional information to the visual index that was obtained from observing the surface of the concrete slabs. Since very severe deterioration was not observed inside the joints, a rating scale of 1-3 was proposed using the results of this research. 
Table 4-16 Visual index created for rating concrete joint deteriorated based on the inside of the joint

\begin{tabular}{|c|c|}
\hline $\begin{array}{c}\text { Damage Rating ( } 5=\text { most, } \\
1=\text { least) }\end{array}$ & Example and Explanation \\
\hline 1 & $\begin{array}{l}\text { isible damage. } \\
\text { 3\% NaCl FT, } 30 \mathrm{MPa} \text { mix) }\end{array}$ \\
\hline 2 & $\begin{array}{c}\text { Slight visible damage or discolouration/ recessed paste. } \\
\text { (Example: } 3 \% \mathrm{MgCl}_{2} \mathrm{FT}, 55 \mathrm{MPa} \text { mix) }\end{array}$ \\
\hline 3 & $\begin{array}{c}\text { Discolouration and/ or recessed paste with visible damage/ } \\
\text { spalling. } \\
\text { (Example: } 10 \% \text { CaCl } 2 \text { FTW, } 45 \text { MPa mix) }\end{array}$ \\
\hline
\end{tabular}




\subsection{Mass Loss}

\subsubsection{Mass Loss Results and Issues}

Mass loss was originally performed because it was thought that it would give some indication of damage that is representative of the deterioration seen in pavements failing early in their life cycle. However, in most cases, mass loss was more indicative of scaling damage. Slabs that had experienced more surface scaling had greater mass loss values but did not necessarily have damage indicative of premature joint failure (i.e. cracks forming from the bottom of the joint, excessive spalling). More scaling was seen across the entire surface of the slab. In other words, the quantified damage from mass loss was more representative of the scaling of the entire surface, not just the damage around the joint itself.

Mass loss in this experiment was only performed on the $45 \mathrm{MPa}$ mix for several reasons. Firstly, all of the square slabs were from this mix, and these samples had a dike to ensure that the level of the solution was a few millimeters above the surface of the concrete. This is in contrast to the later rectangular slabs, which had solution filled only up to the joint, and not above the surface. This is because it was originally thought that solution on the surface would contribute to the deterioration that was expected, but it only led to more surface scaling. With this knowledge, the solution was targeted to be within the joint, which is where deteriorated was expected to occur. Since the solution in the rectangular slabs was filled only within the joints, and not above the surface, no surface scaling or mass loss occurred. However, the results were still normalized to show mass loss per area for meaningful comparisons between slabs of different sizes. The values obtained for mass loss were very small. The results are shown in Figure 4-18, below. 


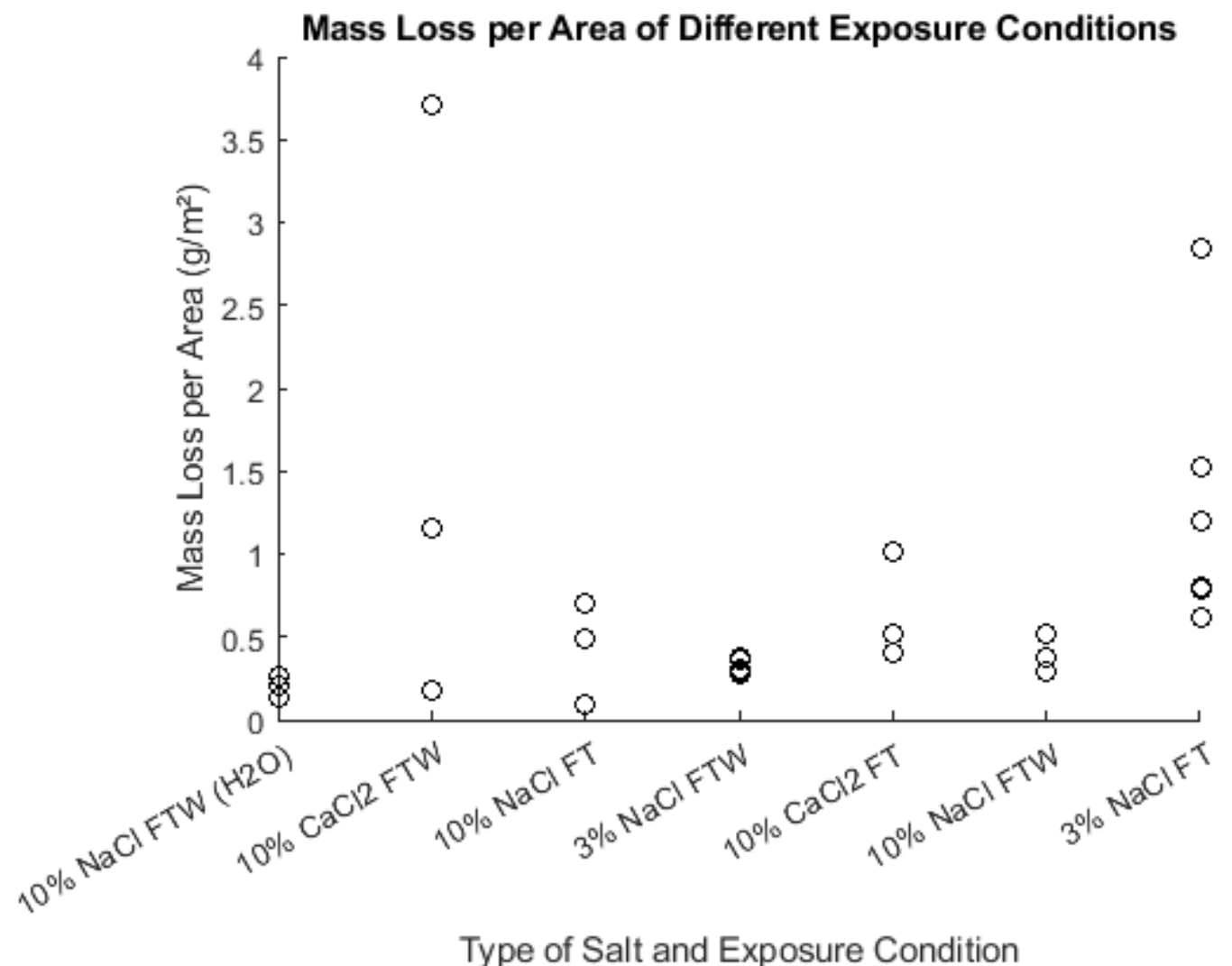

Figure 4-18 Average mass loss $\left(\mathrm{g} / \mathrm{m}^{2}\right)$ of the different conditions that slabs underwent.

Note that the observed mass loss values were very low. The figure above shows the average mass loss for the $45 \mathrm{MPa}$ mix concrete slabs exposed to different salts and freezing/ wetting conditions. The greater the average mass loss from scaling, the greater the range of values. Also, the samples with the least mass loss had the least variation between values. The $10 \% \mathrm{CaCl}_{2} \mathrm{FTW}$ sample stands out as the highest average value and highest maximum value. This slab had experienced the most significant deterioration, visible as surface scaling and some spalling around the joint. The $3 \% \mathrm{NaCl}$ FT slabs, on the other hand, had a very high mass loss value, but this was largely from surface scaling. A comparison of these samples is shown in Figure 4-19, below. 

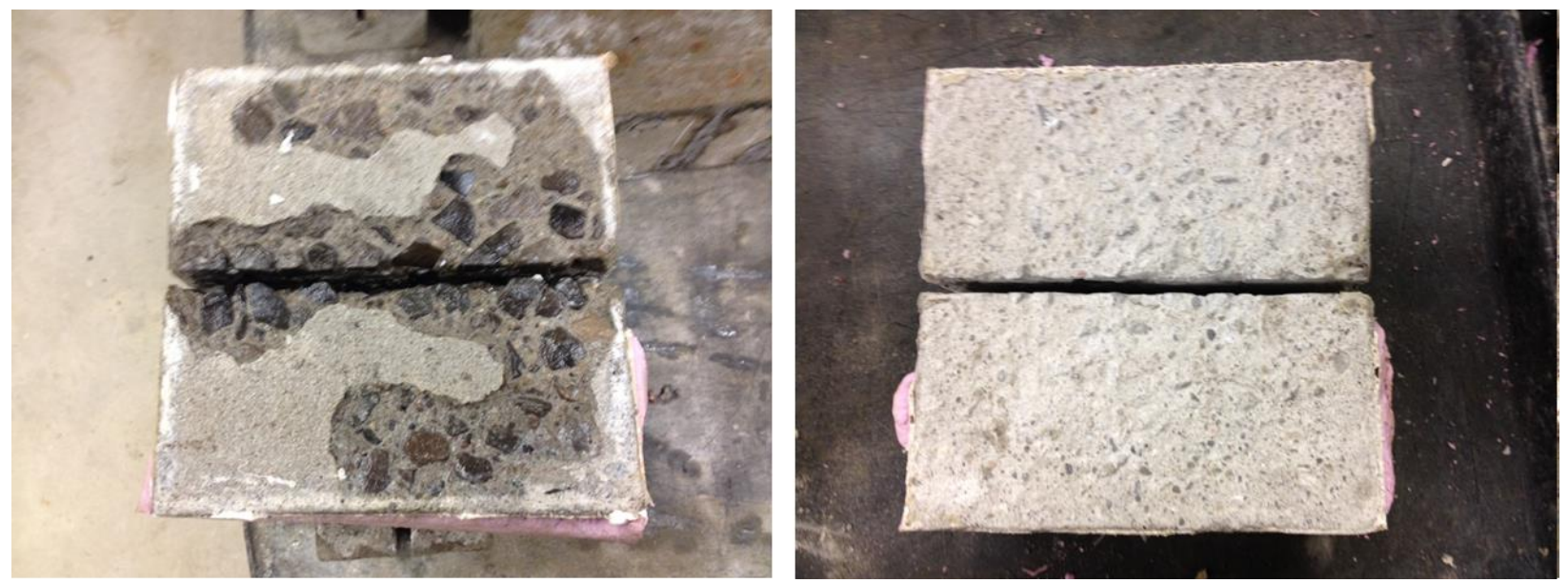

Figure 4-19 Comparison of the slabs with the most mass loss from surface scaling: $10 \% \mathrm{CaCl}_{2} \mathrm{FTW}$ (1.68 $\mathrm{g} / \mathrm{m}^{2}$ mass loss) with spalling around the joint and surface scaling (left) and $3 \% \mathrm{NaCl} F \mathrm{FT}\left(1.30 \mathrm{~g} / \mathrm{m}^{2}\right.$ mass loss) with mostly surface scaling (right).

A significant drawback of using mass loss as a measure of concrete joint deterioration is that similar values for mass loss are obtained from the two samples in the above figure (Figure 4-19), despite one obviously being much more damaged at the joint. This is the main reason that mass loss was considered ineffective at measuring concrete pavement joint durability. The proposed mass loss test does not differentiate between damage specifically localized around the joint, and general surface scaling.

Past research has shown that concrete slabs exposed to $\mathrm{NaCl}$ solutions had the most scaling damage at a concentration of 3\% (Verbek \& Klieger, 1957). The 3\% NaCl FTW samples had much less mass loss than the $3 \% \mathrm{NaCl}$ FT samples, suggesting that the wetting cycles were not important in contributing to mass loss or scaling at low concentrations of sodium chloride. A similar result was seen when examining the mass loss from the $10 \% \mathrm{NaCl}$ slabs: the $10 \% \mathrm{NaCl}$ slabs exposed to just FT had a similar mass loss when compared to the $10 \% \mathrm{NaCl}$ slabs exposed 
to FTW. However, at salt concentrations that were this high, mass loss was even lower than the already low reported values.

When examining the $\mathrm{CaCl}_{2}$ slabs for mass loss, a comparison could be made between the FT and the FTW slabs. The FT slabs were $15.5 \%$ weaker than the FTW slabs when tested for strength, but the FTW were much more visually deteriorated, and the mass loss was much higher (average of $67.1 \mathrm{~g}$ mass loss compared to an average of $25.7 \mathrm{~g})$. This shows that at the same concentration of $\mathrm{CaCl}_{2}$, there is more strength loss after 50 total cycles in FT compared to FTW, although from a visual inspection, the FTW slabs appear to be more damaged, and have a much higher mass loss value. This can be explained by looking at the total number of freeze-thaw cycles: both samples had underwent 50 total cycles of exposure, with the FT samples undergoing 50 cycles of freezing and thawing, while the FTW samples underwent 25 cycles of freezing and thawing, and 25 cycles of wetting. This is summarized in Table 4-17, below.

Table 4-17 Freeze-thaw cycles experienced by different cyclical exposures

\begin{tabular}{|c|c|c|}
\hline & FT Exposure & FTW Exposure \\
\hline Total freeze-thaw cycles & 50 & 25 \\
\hline Total wetting cycles & 0 & 25 \\
\hline
\end{tabular}

It was seen in other slabs that wetting cycles at high concentrations contributed to greater damage when freezing cycles were also present, so it was thought that the same would be true of these $10 \% \mathrm{CaCl}_{2}$ samples. It is likely that this discrepancy was seen because not enough cycles had taken place in a more sound concrete: the concrete with $30 \%$ of the cement replaced by slag had greater resistance to this damage, so more exposure would be needed to observe an equal amount of damage. It is likely that if the FT and FTW cycles continued, then the strength loss 
experienced by the FTW would eventually match or overtake that of the FT slabs. This hypothesis is based on both past research on supplementary cementing materials' ability to resist damage (Monical et al., 2016; Sutter et al., 2002; Zhang et al., 2015) and what was seen in this experiment on the $55 \mathrm{MPa}$ mix slabs: the most damaged slabs by far were the $10 \% \mathrm{CaCl}_{2} \mathrm{FTW}$ samples. These slabs were so damaged and had experienced such severe spalling that they had almost completely fallen apart, so it was not possible to test their strength. Since that concrete mix (i.e. the $55 \mathrm{MPa}$ mix slabs) was less resistant to the damage from the salt solution (because it did not have slag replacing some of the cement), the damage was seen to occur sooner. This highlights the inefficacy of using mass loss alone to capture these differences in deterioration when developing an accelerated test method for concrete pavement joint deterioration.

\subsection{Expansion of Prisms Soaking in Salt Solution Results}

To supplement the data that was used for developing an accelerated test for concrete pavement joint deterioration, concrete prisms were cast and soaked in different salt solutions, with measurements taken to examine their expansion. The salt solutions used were those seen in this experiment: $15 \% \mathrm{NaCl}, 15 \% \mathrm{CaCl}_{2}$, and $15 \% \mathrm{MgCl}_{2}$. The volume change was calculated as the change in length divided by the original length. Three specimens were used for each sample (i.e. each type of salt), and the average value is presented in Figure 4-20, below. 


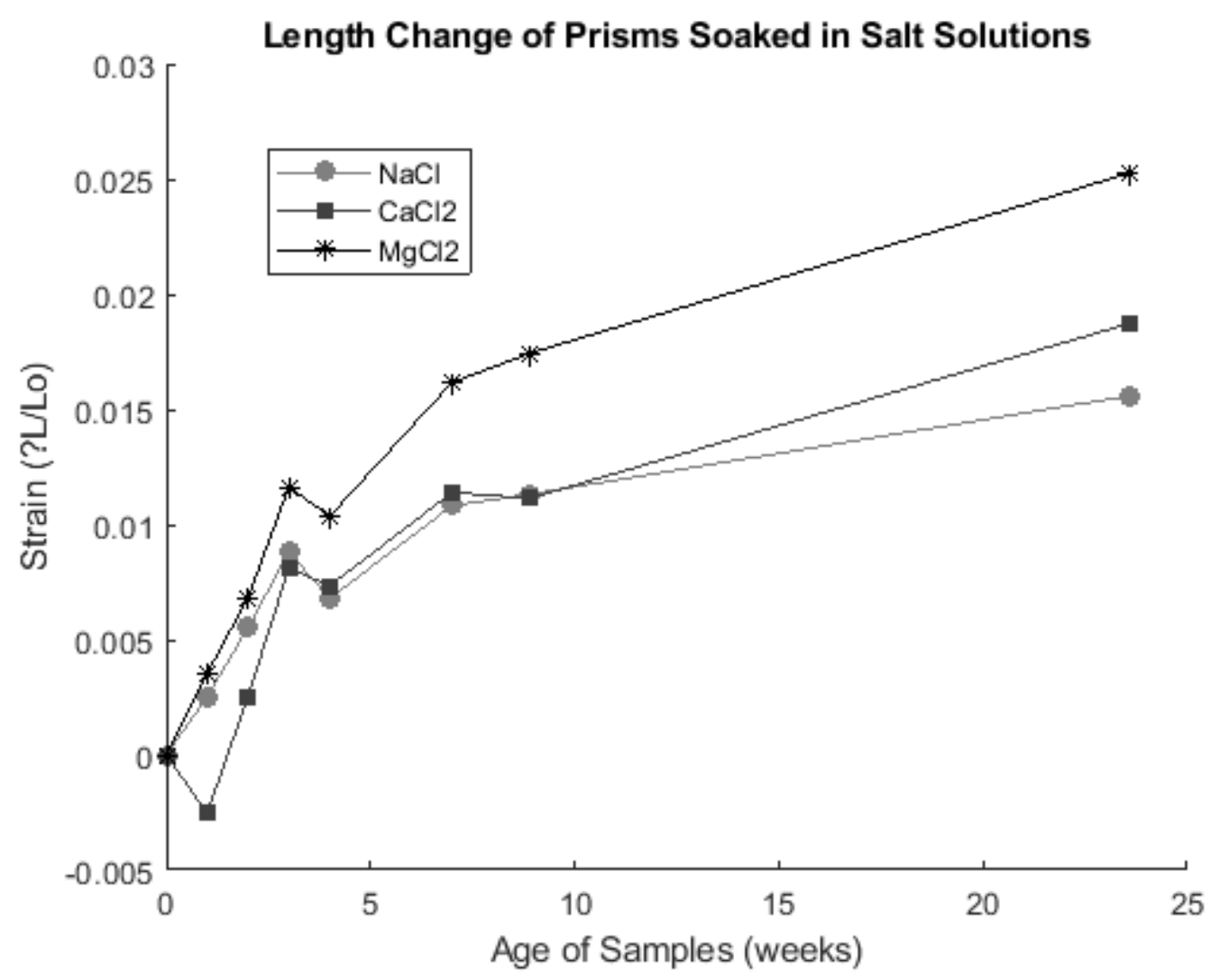

Figure 4-20 Average strain (change in length divided by initial length) for concrete prisms exposed to $15 \%$ salt solutions at room temperature.

With the $\mathrm{CaCl}_{2}$ samples, there was a slight shrinkage observed after the first week, after which expansion continued, as was seen in the rest of the samples.

The greatest expansion was seen in the prisms soaking in $\mathrm{MgCl}_{2}$, followed by the $\mathrm{CaCl}_{2}$ prisms, and lastly the $\mathrm{NaCl}$ prisms. This was as expected according to which salt solutions were observed to be the most damaging from past research. If the prisms were kept at a lower temperature (e.g. $5^{\circ} \mathrm{C}$ ) instead of room temperature, perhaps more expansion would have been seen in the prisms soaking in $\mathrm{CaCl}_{2}$. 
Since the expansion seen was greater in the prisms soaking in $\mathrm{MgCl}_{2}$ and $\mathrm{CaCl}_{2}$ compared to the expansion seen in the $\mathrm{NaCl}$, this test additionally shows that some expansive reaction is taking place between concrete and $\mathrm{MgCl}_{2} / \mathrm{CaCl}_{2}$ at room temperature. 


\section{Chapter 5: Conclusions, Limitations, \& Recommendations}

\subsection{Summary \& Conclusions}

Strength loss and visual deterioration (visual index) were promising in measuring concrete pavement joint durability, while mass loss was not an effective measure. The results of these experiments provide valuable data for the development of an accelerated test method for concrete pavement joint durability.

\subsubsection{Methods of Evaluation:}

\section{- Strength Loss}

Significant differences in strength were observed between different types of exposure and different salt solutions, showing that the test can measure different levels of deterioration of concrete slabs exposed to simulated field conditions.

As was seen in past research on concrete pavement deterioration, $\mathrm{NaCl}$ solution was the most benevolent, with $\mathrm{CaCl}_{2}$ and $\mathrm{MgCl}_{2}$ being the most harmful to concrete (Lee et al., 1998; Sutter et al., 2002; Suraneni et al., 2017; Wang et al., 2018). Thus, the proposed evaluation technique can be considered successful for measuring concrete pavement joint deterioration between different types of salt solutions.

The proposed technique can effectively capture differences in strength between samples of the same exposure (i.e. same salt solution and freezing cycles) but different cement content. These results highlight the importance of mix properties in its ability to resist deterioration due to deicing salts. 


\section{- Mass Loss}

Mass loss was ultimately seen as an ineffective assessment technique because it mostly captured the effect of surface scaling, not damage specifically around the joint. In addition, mass loss also fails as a test for measuring premature concrete pavement deterioration in not capturing deterioration if severe weakening takes place without physical spalling/ mass loss.

\section{- Visual Deterioration Index}

Visual inspection, although a qualitative result and not a quantitative result, was found to be an appropriate measure of concrete pavement joint deterioration. A visual inspection, and further development of a visual index is important for classifying the level of deterioration because it gives insight into what damage has taken place.

Past research has shown that there were cases where the pavement surface did not appear damaged but there was joint deterioration when cores were taken (Zhang, 2013). This means that surface examination is not sufficient, and that the inside surface of the joints should also be examined. This was done in the experiments of this thesis, and two visual indices were created: one for the surface view of the joint, and one for examining the surface inside the joint after the sample had split.

\subsubsection{Effects of Different Exposure and Concrete Strength:}

- Samples exposed to only wetting had almost no damage. The strength of samples exposed to only wetting cycles had no loss in strength, no mass loss, and no visual deterioration in most cases. An exception was exposure to $\mathrm{MgCl}_{2}$; these samples experienced some weakening and deterioration in the low cement mix. 
- Freezing was necessary for at least some damage to take place (perhaps lower temperature could also result in damage). The samples exposed to only wetting cycles (at $36^{\circ} \mathrm{C}$ ) experienced little to no deterioration. The samples with exposure to freezing cycles had either some damage or significant damage depending on the mix design and salt solution. This shows the importance of freezing in the development of damage in the samples. However, because some harmful reaction products like calcium oxychloride prefer to form at lower temperatures, wetting cycles at lower temperatures may also result in damage.

- FTW was more damaging than FT with high concentration salt solutions. FT cycles were less damaging at higher salt concentrations than lower concentrations. Additionally, the high salt concentrations during wetting cycles were more harmful when paired with freezing cycles. This may be caused by the high concentration salts producing damage at lower temperatures, or the wetting cycles reducing the effectiveness of the air voids to resist freeze-thaw damage.

- FT was more damaging than FTW with low concentration salt solutions. The FTW cycles were most harmful at high concentrations, and less damaging as concentrations decreased. This was further illustrated with the FTW samples with water used instead of salt solution during the wetting phase. Low salt solution concentrations led to more complete freezing in the FT samples compared to higher concentrations, resulting in more deterioration. 
- The presence of slag in a mix was protective against damage from deicing salts. The mix with slag experienced less strength loss and visual deterioration than samples of the same type of exposure but without slag in the mix design.

\subsection{Research Limitations}

A limitation of this research is that this thesis is not the final iteration of the development of a test method for measuring concrete pavement durability because further investigation of other systems is required. Factors such as joint sealants, saturated bases, different wetting cycle temperatures, different salt solution concentrations, and fatigue testing representing vehicular loading should also be analyzed in the development of this standard. It would also be valuable to study and compare mixes with lower quality concrete (lower strength, higher permeability, and/ or higher w/c ratio).

Although damage was observed in slab samples of both dimensions (i.e. square and rectangular), more data is required on what effects different slab sizes have on the development of damage.

Also, with three samples being tested, the author believes that more samples would have provided more idea about variability within the test. This helps with identifying potential outliers and establishing statistical significance.

\subsection{Recommendations for Further Studies}

Recommendations for further studies on developing an accelerated test for concrete pavement joint durability include investigating the following:

- Joint sealants 
- Saturated bases

- Different wetting cycles

- $\quad$ Fatigue testing

- Comparing transverse and longitudinal joints by studying the effects of loading

The effects of joint sealants in preventing or delaying damage were not studied in this research. Some discussion on joint sealants was included in the literature review (chapter 2) of this thesis. This thesis provides insights into the efficacy of the proposed evaluation techniques at measuring concrete pavement joint durability. This knowledge can be used in developing further tests for examining how different joint sealants can prevent or delay damage in PCC pavements.

The effects of a saturated base were also not examined in this research. The literature review of this thesis (chapter 2) examined cases of bases having poor drainage in pavements with early deterioration. The effects of saturated bases could be incorporated in future experimental designs to study the additional damage of this mechanism. This could be achieved by placing the slabs above a base with poor drainage and performing the proposed testing in this condition.

Performing wetting cycles at lower temperatures (without freezing) and/ or higher salt concentrations may give further insights into the role wetting cycles play in premature PCC pavement durability issues. The wetting cycles (when on their own) did not produce any damage in the experiments in this thesis. Temperatures closer to $0^{\circ} \mathrm{C}$ with higher salt concentrations can be examined to see if this would produce more damage. This would examine if wetting cycles can produce any damage on their own, or if they only contribute to more damage when combined with freezing cycles at high concentrations. 
The effect of fatigue loading on the development of deterioration was not part of the scope of this research. However, its effect should be included in studying the further development of this test because vehicular loading may play a role in the development of the deterioration being studied. This is likely especially true as the concrete weakens from deicing salt exposure. There may be a synergistic effect: the vehicular load has a greater impact as the concrete is weakened from deicing salt exposure. Additionally, as more cracks form from vehicular loads, the deicing salts can more easily penetrate deeper into the concrete, further weakening it. This can be tested by including a number of fatigue cycles (that can be representative of the expected traffic loading on a road) between the cyclical freeze-thaw/ wetting exposure. The combined contribution of simulated vehicular loading and exposure to salt solution and freezing may lead to earlier or more severe deterioration.

The proposed evaluation techniques can be modified to study how the deterioration of transverse joints compares to the deterioration of longitudinal joints. Transverse joints have added load applications around the joint. However, transverse joints also have the added protective effect of the suction from tires passing over joints and removing some material from inside the joint. 
Appendices 


\section{Appendix A - Data}

Table A-1: Loading data for the $45 \mathrm{MPa}$ mix slabs exposed to different salt solutions and exposure conditions.

\begin{tabular}{|l|c|c|c|c|}
\hline $\begin{array}{c}\text { Salt Solution \& Type of } \\
\text { Exposure }\end{array}$ & Specimen A (kN) & Specimen B (kN) & Specimen C (kN) & Average (kN) \\
\hline $3 \% \mathrm{NaCl} \mathrm{FT} \mathrm{June25}$ & 5.81 & N/A & N/A & 5.81 \\
\hline $3 \% \mathrm{NaCl} \mathrm{FT} \mathrm{July9}$ & 4.20 & 8.40 & N/A & 5.66 \\
\hline $10 \% \mathrm{NaCl} \mathrm{FT}$ & 12.57 & 12.78 & 11.47 & 12.68 \\
\hline $10 \% \mathrm{CaCl}$ FT & 11.04 & 12.4 & 13.60 & 11.64 \\
\hline $3 \% \mathrm{NaCl} \mathrm{FTW} \mathrm{June27}$ & 10.79 & 13.53 & 11.84 & 12.64 \\
\hline $3 \% \mathrm{NaCl} \mathrm{FT} \mathrm{July11}$ & 12.38 & 10.24 & 14.94 & 11.49 \\
\hline $10 \% \mathrm{NaCl} \mathrm{FTW}$ & 5.44 & 5.09 & 15.31 & 8.49 \\
\hline $10 \% \mathrm{NaCl} \mathrm{FTW}(\mathrm{H} 2 \mathrm{O})$ & 13.39 & 15.04 & 11.95 & 14.58 \\
\hline $10 \% \mathrm{CaCl}_{2} \mathrm{FTW}$ & 14.96 & 14.45 & & 13.79 \\
\hline
\end{tabular}

Table A-2: Relative strength of the $45 \mathrm{MPa}$ mix samples exposed to different salt solutions and exposure conditions.

\begin{tabular}{|l|c|c|c|c|}
\hline $\begin{array}{c}\text { Salt Solution \& Type of } \\
\text { Exposure }\end{array}$ & Specimen A (\%) & Specimen B (\%) & Specimen C (\%) & Average (\%) \\
\hline $3 \% \mathrm{NaCl} \mathrm{FT} \mathrm{June25}$ & 39.85 & N/A & N/A & 39.85 \\
\hline $3 \% \mathrm{NaCl} \mathrm{FT} \mathrm{July9}$ & 28.81 & 57.61 & 30.04 & 38.82 \\
\hline $10 \% \mathrm{NaCl} \mathrm{FT}$ & 86.21 & 87.65 & 78.67 & 86.93 \\
\hline $10 \% \mathrm{CaCl}_{2} \mathrm{FT}$ & 75.72 & 85.05 & 93.28 & 89.81 \\
\hline $3 \% \mathrm{NaCl} \mathrm{FTW} \mathrm{June27}$ & 74.01 & 92.80 & 81.21 & 78.78 \\
\hline $3 \% \mathrm{NaCl} \mathrm{FT} \mathrm{July11}$ & 84.91 & 70.23 & 102.47 & 58.23 \\
\hline $10 \% \mathrm{NaCl}$ FTW & 37.31 & 34.91 & 103.16 & 100.00 \\
\hline $10 \% \mathrm{NaCl}$ FTW (H2O) & 105.01 & 91.84 & 99.11 & 94.56 \\
\hline $10 \% \mathrm{CaCl}_{2}$ FTW & 102.61 & 102.61 & & \\
\hline
\end{tabular}


Table A-3: Loading data for the $30 \mathrm{MPa}$ slabs exposed to different salt solutions and exposure conditions.

\begin{tabular}{|l|c|c|c|c|}
\hline $\begin{array}{c}\text { Salt Solution \& Type of } \\
\text { Exposure }\end{array}$ & Specimen A (kN) & Specimen B (kN) & Specimen C (kN) & Average (kN) \\
\hline $3 \% \mathrm{CaCl}_{2} \mathrm{FT}$ & $\mathrm{N} / \mathrm{A}$ & 7.00 & 3.00 & 5.00 \\
\hline $3 \% \mathrm{MgCl}_{2} \mathrm{FT}$ & 1.00 & 4.23 & 6.00 & 3.74 \\
\hline $15 \% \mathrm{NaCl} \mathrm{W}^{15 \% \mathrm{MgCl}_{2} \mathrm{~W}}$ & 31.07 & 27.75 & 30.27 & 29.70 \\
\hline $15 \% \mathrm{CaCl}_{2} \mathrm{~W}$ & 38.05 & 34.88 & 33.08 & 35.34 \\
\hline
\end{tabular}

Table A-4: Relative strength of the $30 \mathrm{MPa}$ samples exposed to different salt solutions and exposure conditions.

\begin{tabular}{|l|c|c|c|c|}
\hline $\begin{array}{c}\text { Salt Solution \& Type of } \\
\text { Exposure }\end{array}$ & Specimen A (\%) & Specimen B (\%) & Specimen C (\%) & Average (\%) \\
\hline $3 \% \mathrm{CaCl}_{2} \mathrm{FT}$ & $\mathrm{N} / \mathrm{A}$ & 19.34 & 8.29 & 13.81 \\
\hline $3 \% \mathrm{MgCl}_{2} \mathrm{FT}$ & 2.76 & 11.69 & 16.57 & 10.34 \\
\hline $15 \% \mathrm{NaCl}_{\mathrm{W}}$ & 85.83 & 76.66 & 83.62 & 82.03 \\
\hline $15 \% \mathrm{MgCl}_{2} \mathrm{~W}$ & 105.11 & 96.35 & 91.38 & 97.62 \\
\hline $15 \% \mathrm{CaCl}_{2} \mathrm{~W}$ & 95.36 & 105.06 & 99.59 & 100.00 \\
\hline
\end{tabular}


Table A-5: Loading data for the $55 \mathrm{MPa}$ mix slabs exposed to different salt solutions and exposure conditions.

\begin{tabular}{|l|c|c|c|c|}
\hline $\begin{array}{c}\text { Salt Solution \& Type of } \\
\text { Exposure }\end{array}$ & Specimen A (kN) & Specimen B (kN) & Specimen C (kN) & Average (kN) \\
\hline $3 \% \mathrm{NaCl}_{\mathrm{FT}}$ & 7.00 & 7.00 & 7.00 & 7.00 \\
\hline $3 \% \mathrm{CaCl}_{2} \mathrm{FT}$ & $\mathrm{N} / \mathrm{A}$ & $\mathrm{N} / \mathrm{A}$ & 12.18 & 12.18 \\
\hline $3 \% \mathrm{MgCl}_{2} \mathrm{FT}$ & 2.00 & 5.00 & 7.00 & 4.67 \\
\hline $15 \% \mathrm{CaCl}_{2} \mathrm{~W}$ & 65.43 & 82.03 & $\mathrm{~N} / \mathrm{A}$ & 71.51 \\
\hline $10 \% \mathrm{MgCl}_{2} \mathrm{FTW}$ & $\mathrm{N} / \mathrm{A}$ & 56.74 & 37.13 & 56.74 \\
\hline $15 \% \mathrm{MgCl}_{2} \mathrm{~W}$ & 53.6 & 60.70 & 0.00 & 50.48 \\
\hline $10 \% \mathrm{CaCl}_{2} \mathrm{FTW}$ & 0.00 & 0.00 & 44.67 & 0.00 \\
\hline $15 \% \mathrm{MgCl}_{2} \mathrm{~W}$ & $\mathrm{~N} / \mathrm{A}$ & 37.78 & 36.40 & 41.23 \\
\hline $15 \% \mathrm{NaCl} \mathrm{W}$ & 66.1 & 57.83 & & 53.44 \\
\hline
\end{tabular}

Table A-6: Relative strength of the $55 \mathrm{MPa}$ mix samples exposed to different salt solutions and exposure conditions.

\begin{tabular}{|l|c|c|c|c|}
\hline $\begin{array}{c}\text { Salt Solution \& Type of } \\
\text { Exposure }\end{array}$ & Specimen A (\%) & Specimen B (\%) & Specimen C (\%) & Average (\%) \\
\hline $3 \% \mathrm{NaCl} \mathrm{FT}$ & 9.79 & 9.79 & 9.79 & 9.79 \\
\hline $3 \% \mathrm{CaCl}_{2} \mathrm{FT}$ & $\mathrm{N} / \mathrm{A}$ & $\mathrm{N} / \mathrm{A}$ & 17.03 & 17.03 \\
\hline $3 \% \mathrm{MgCl}_{2} \mathrm{FT}$ & 2.80 & 6.99 & 9.79 & 6.53 \\
\hline $15 \% \mathrm{CaCl}_{2} \mathrm{~W}$ & 91.50 & 114.72 & 93.78 & 100.00 \\
\hline $10 \% \mathrm{MgCl}_{2} \mathrm{FTW}$ & $\mathrm{N} / \mathrm{A}$ & 79.35 & 51.93 & 79.35 \\
\hline $15 \% \mathrm{MgCl}_{2} \mathrm{~W}$ & 74.96 & 84.89 & 0.00 & 70.59 \\
\hline $10 \% \mathrm{CaCl}_{2} \mathrm{FTW}$ & 0.00 & 0.00 & 62.47 & 0.00 \\
\hline $15 \% \mathrm{MgCl}_{2} \mathrm{~W}$ & $\mathrm{~N} / \mathrm{A}$ & 52.83 & 50.90 & 57.65 \\
\hline $15 \% \mathrm{NaCl} \mathrm{W}$ & 92.44 & 80.87 & & 74.74 \\
\hline
\end{tabular}


Table A-7: Mass loss per area $\left(\mathrm{g} / \mathrm{m}^{2}\right)$ of different salt solutions and types of exposure.

\begin{tabular}{|c|c|c|c|c|}
\hline $\begin{array}{c}\text { Salt Solution \& Type of } \\
\text { Exposure }\end{array}$ & Specimen $A\left(g / m^{2}\right)$ & Specimen B $\left(\mathrm{g} / \mathrm{m}^{2}\right)$ & Specimen $\mathrm{C}\left(\mathrm{g} / \mathrm{m}^{2}\right)$ & Average $\left(\mathrm{g} / \mathrm{m}^{2}\right)$ \\
\hline $3 \% \mathrm{NaCl} F \mathrm{FT}$ June25 & 2.8425 & 0.6175 & 0.7900 & 1.4167 \\
\hline 3\% NaCl FT July9 & 1.5300 & 0.8025 & 1.1950 & 1.1758 \\
\hline $10 \% \mathrm{NaCl} F \mathrm{~F}$ & 0.0900 & 0.7000 & 0.4875 & 0.4258 \\
\hline $10 \% \mathrm{CaCl}_{2} \mathrm{FT}$ & 1.0100 & 0.4000 & 0.5175 & 0.6425 \\
\hline $3 \% \mathrm{NaCl} F T W$ June27 & 0.3725 & 0.2750 & 0.2700 & 0.3058 \\
\hline 3\% NaCl FT July11 & 0.2875 & 0.3625 & 0.3000 & 0.3167 \\
\hline $10 \% \mathrm{NaCl} F T W$ & 0.5200 & 0.2900 & 0.3775 & 0.3958 \\
\hline $10 \% \mathrm{NaCl} F T W(\mathrm{H} 2 \mathrm{O})$ & 0.1325 & 0.2650 & 0.2000 & 0.1992 \\
\hline $10 \% \mathrm{CaCl}_{2} \mathrm{FTW}$ & 3.7100 & 1.1500 & 0.1750 & 1.6783 \\
\hline
\end{tabular}


Appendix B - Images

$45 \mathrm{MPa}$ mix Slabs after 50 Cycles

June $25 \mathrm{X}-3 \% \mathrm{NaCl} F \mathrm{~F}$
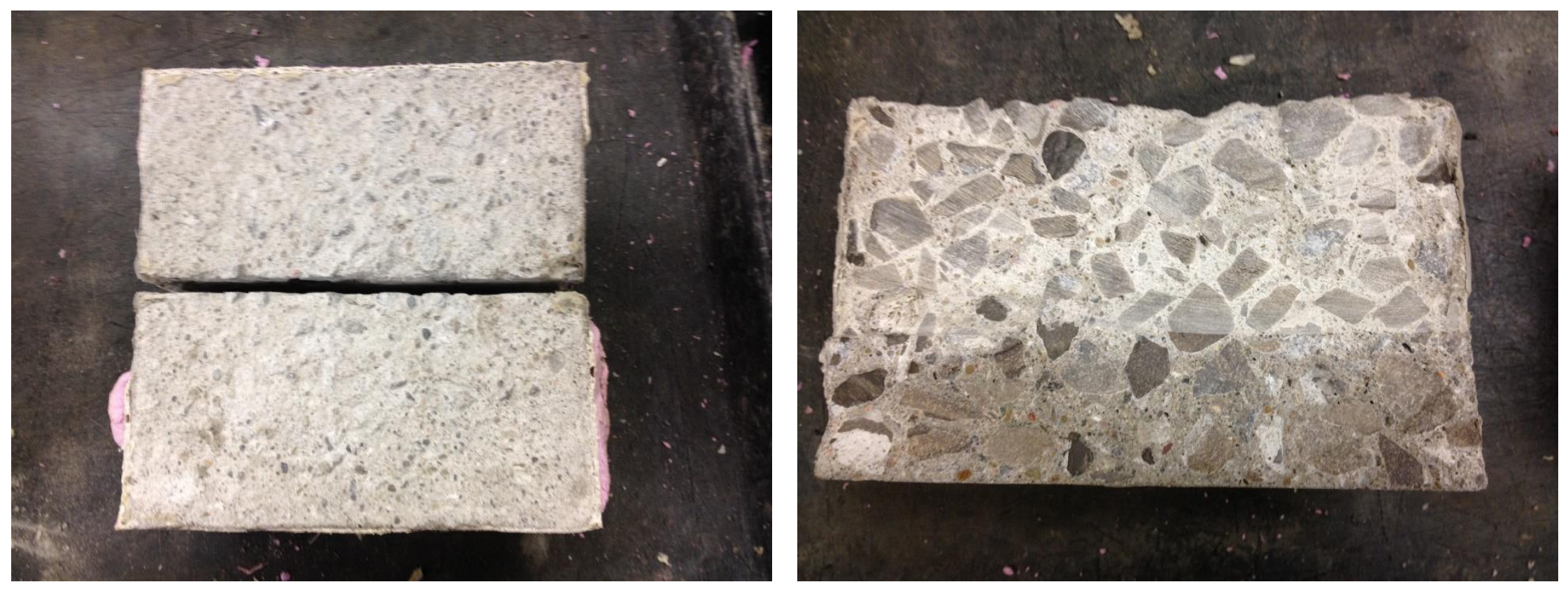
June $26 \mathrm{Z}-10 \% \mathrm{NaCl} F \mathrm{FT}$
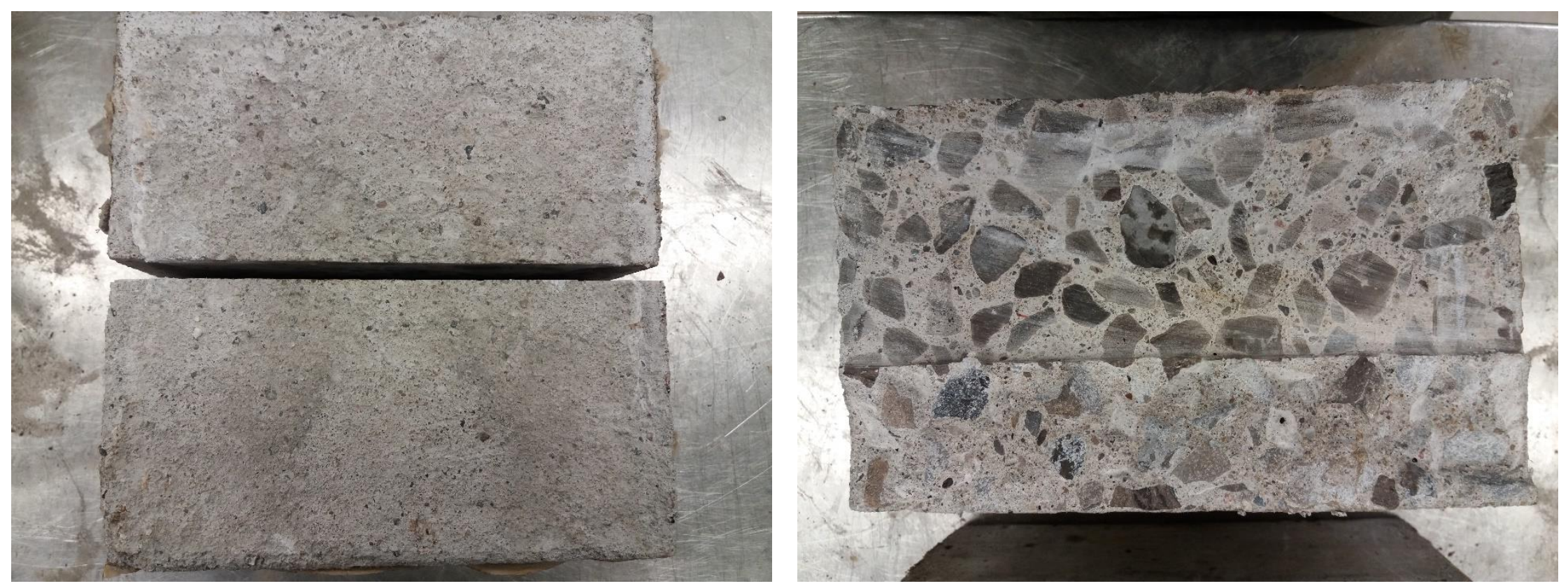
June $27 \mathrm{Z}-3 \% \mathrm{NaCl}$ FTW
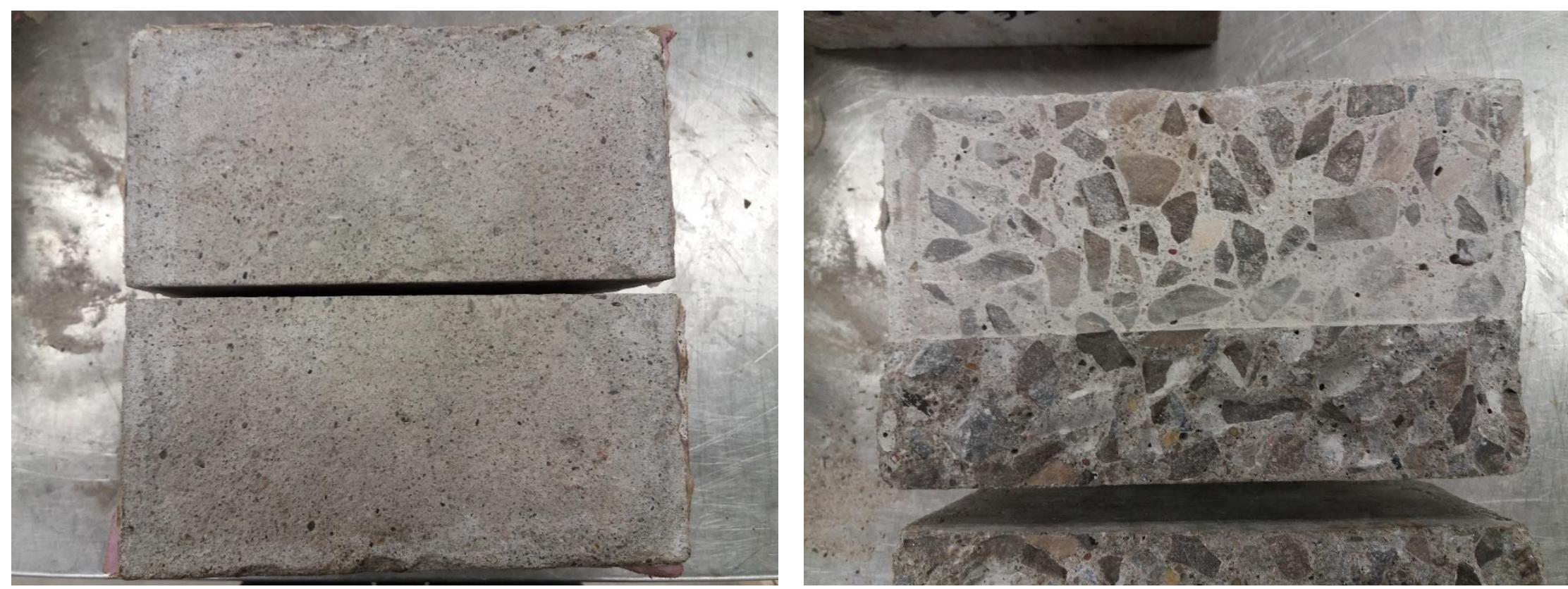
June $27 \mathrm{Y}-3 \% \mathrm{NaCl}$ FTW
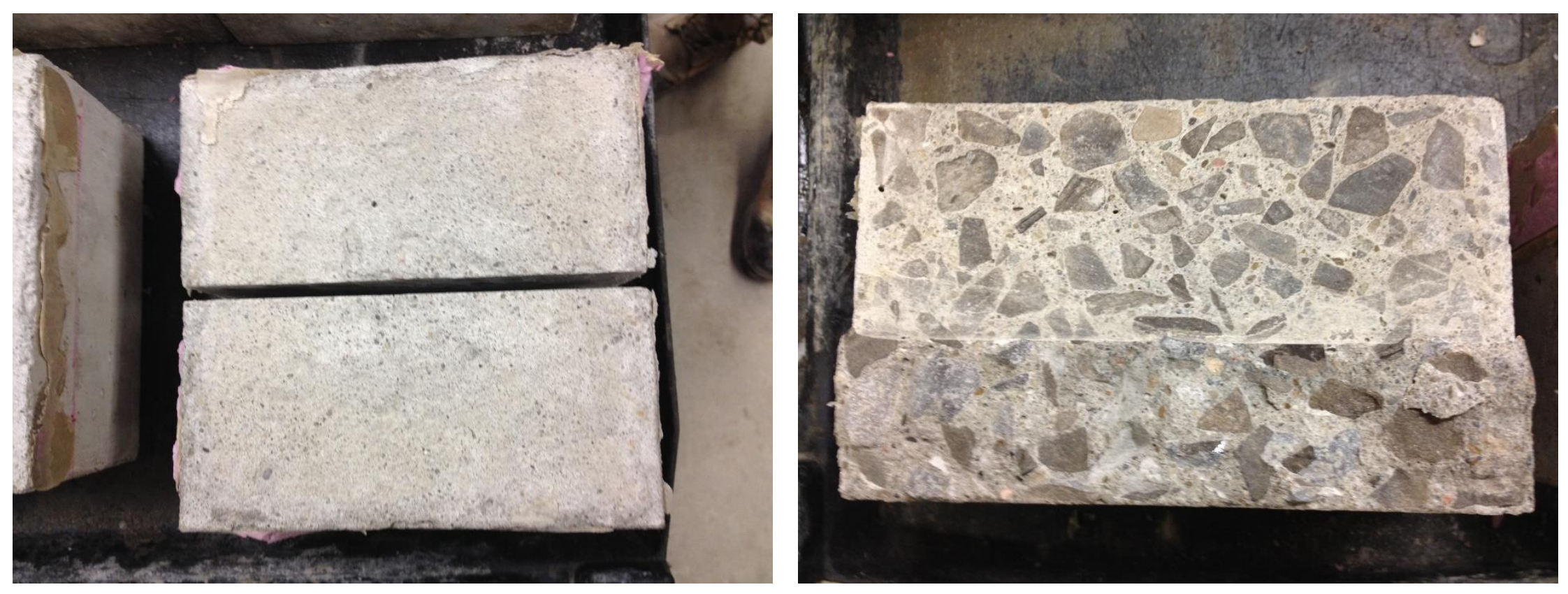
July $3 \mathrm{Z}-10 \% \mathrm{NaCl}$ FTW
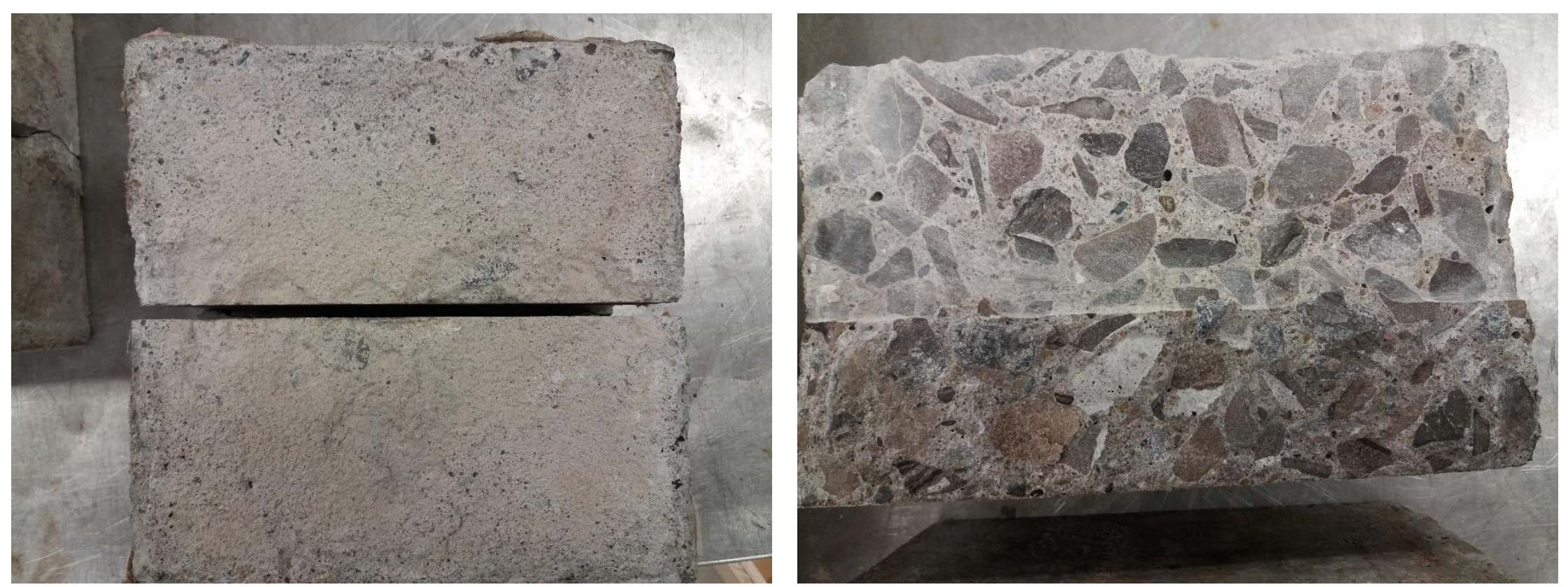
July $4 \mathrm{Z}-10 \% \mathrm{NaCl}$ FTW $\left(\mathrm{H}_{2} \mathrm{O}\right)$
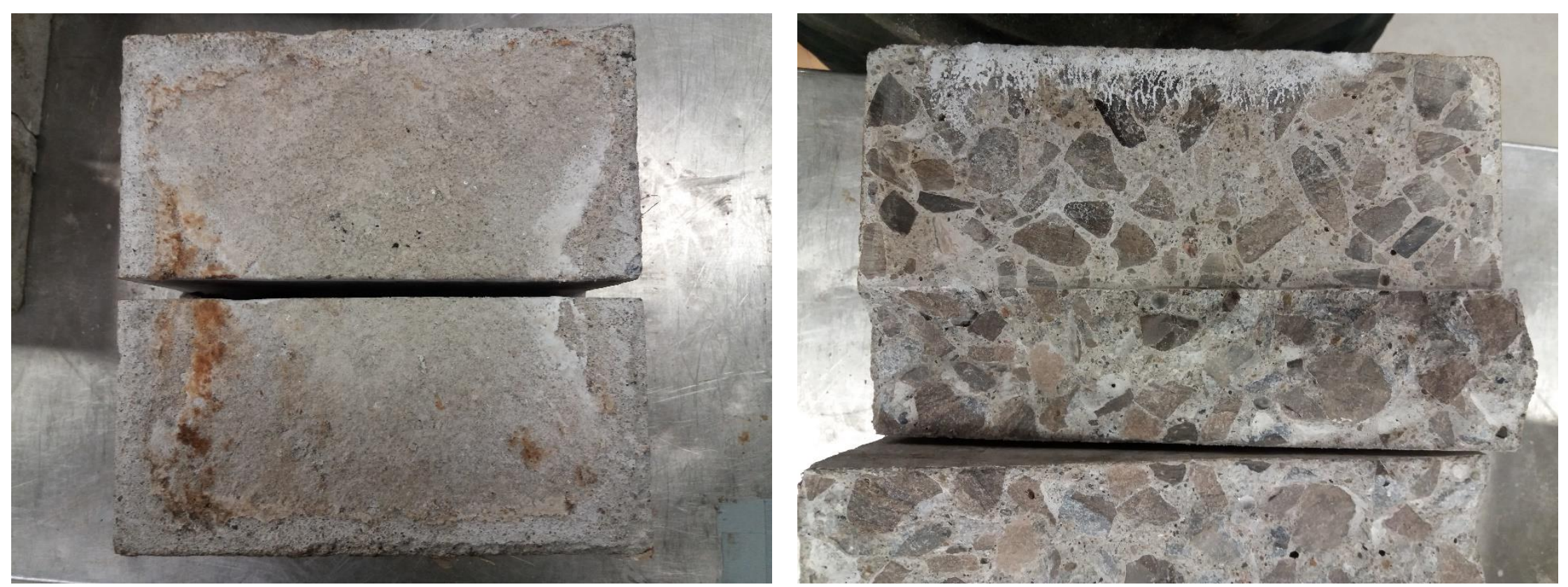
July $5 \mathrm{X}-10 \% \mathrm{CaCl}_{2} \mathrm{FT}$
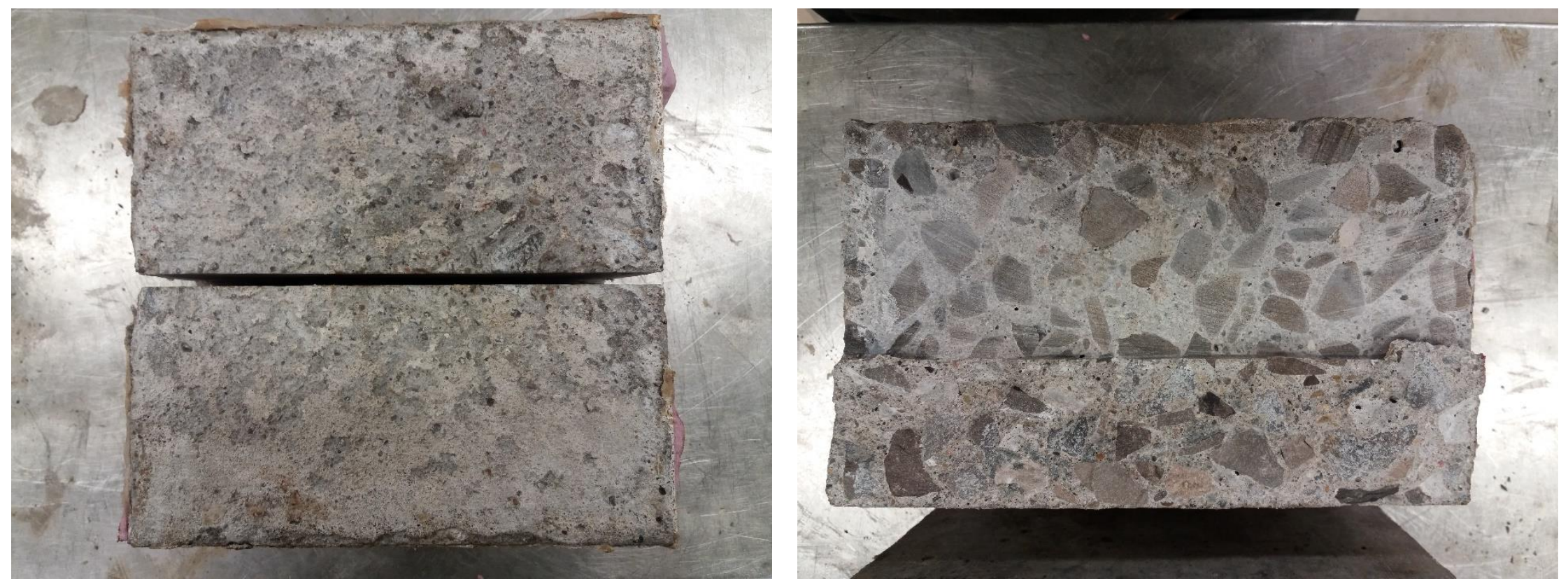
July 9 Z -3\% NaCl FT
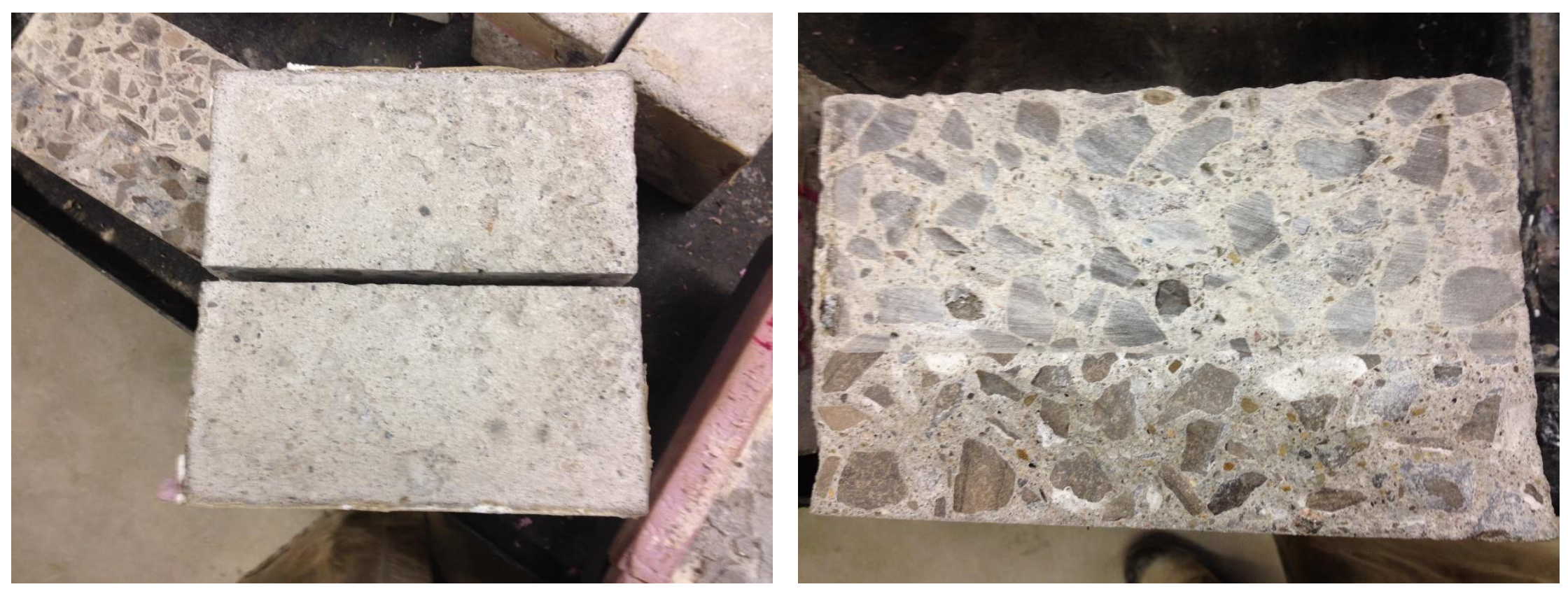
July $9 \mathrm{Y}-10 \% \mathrm{CaCl}_{2}$ FTW
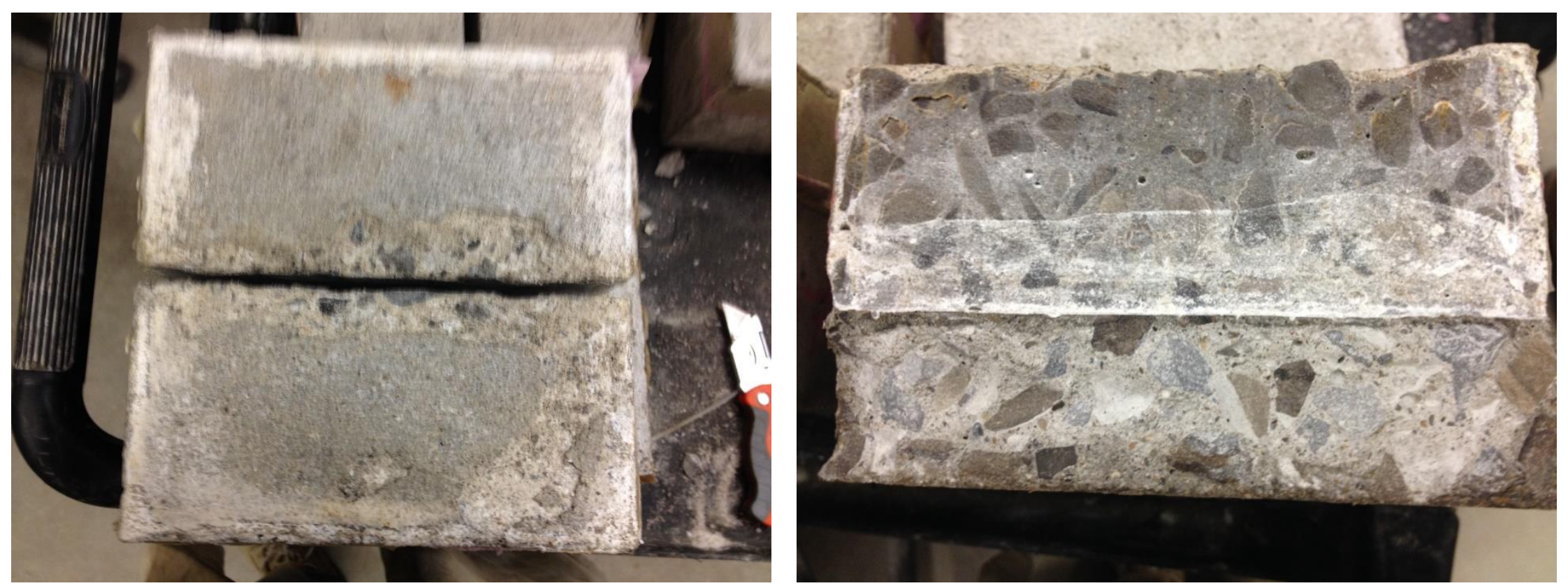
July $9 \mathrm{X}-10 \% \mathrm{CaCl}_{2} \mathrm{FTW}$
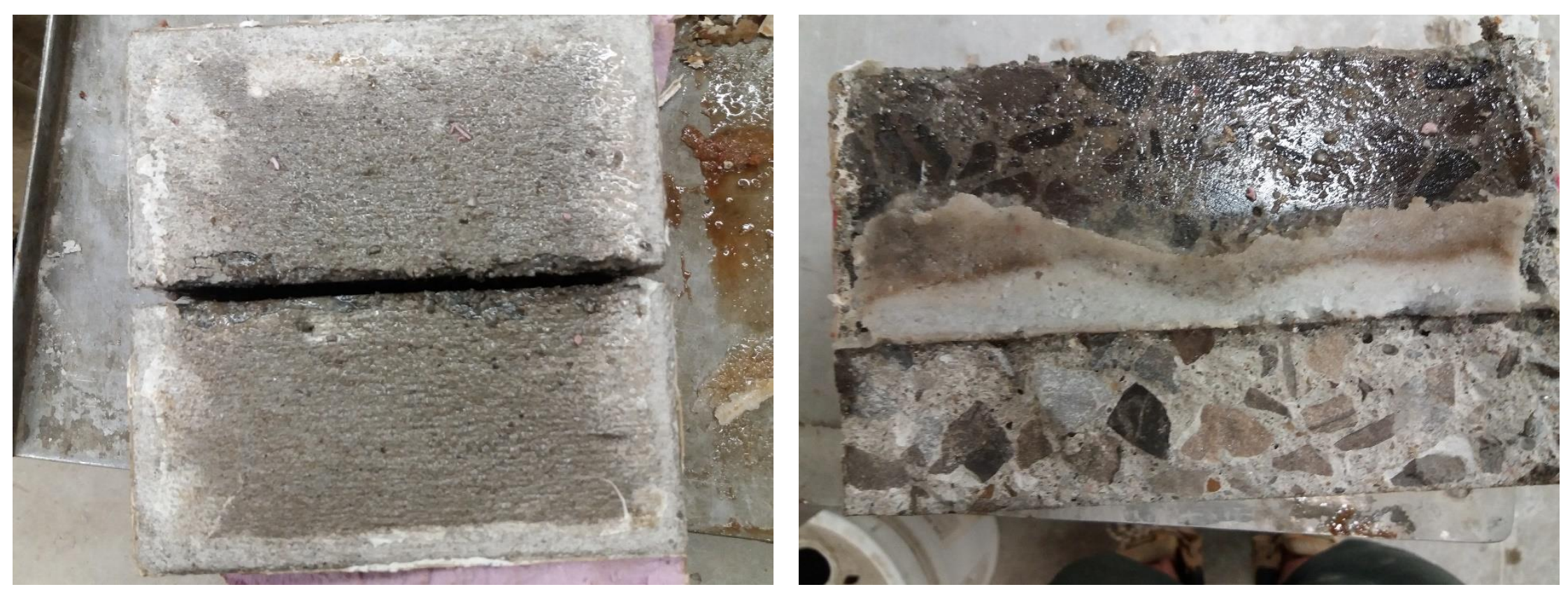
July $11 \mathrm{Z}-3 \% \mathrm{NaCl}$ FTW
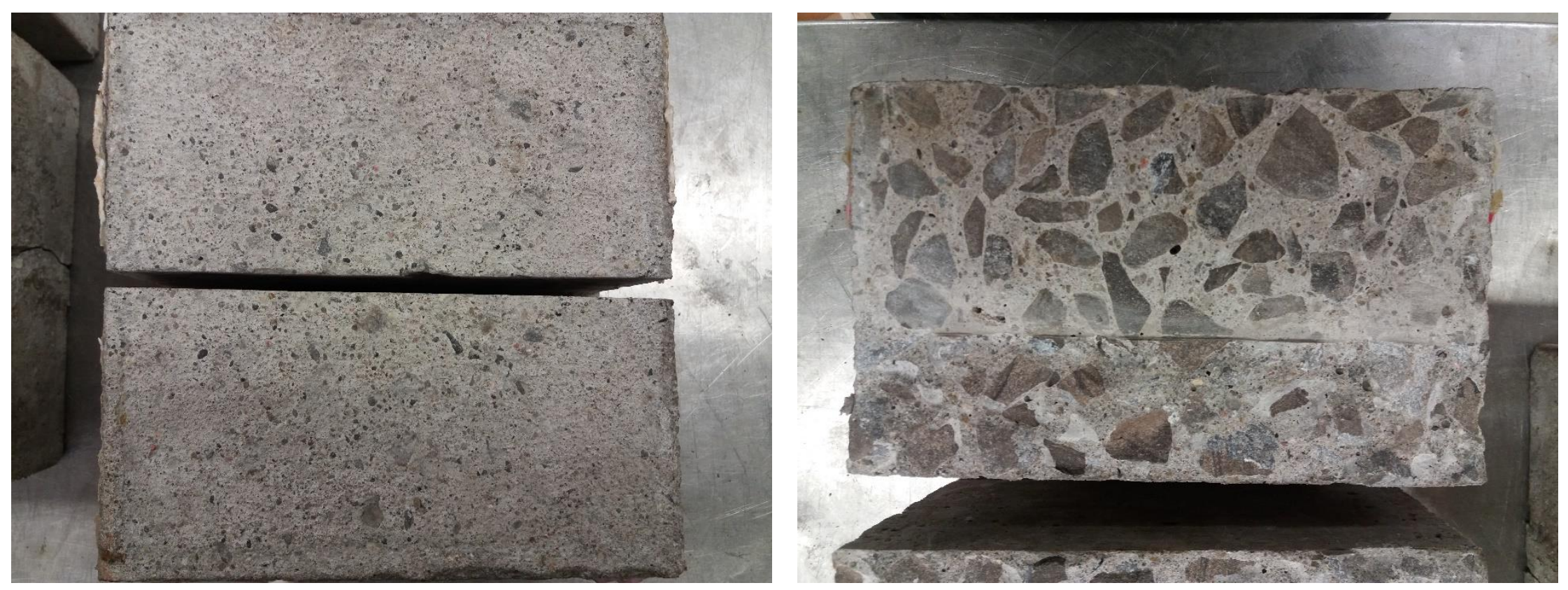
30 MPa mix Slabs after 50 Cycles

August $16 \mathrm{Z}-3 \% \mathrm{MgCl}_{2} \mathrm{FT}$
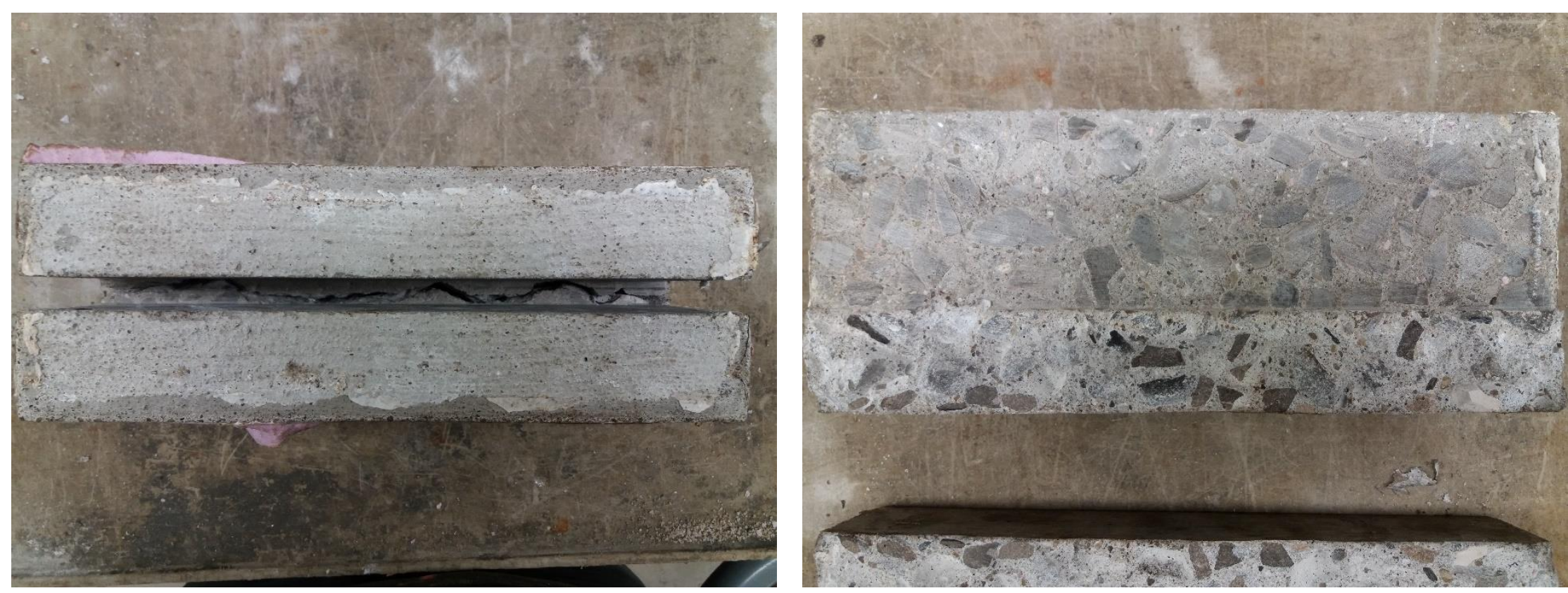
August $21 \mathrm{Y}-15 \% \mathrm{NaCl} \mathrm{W}$
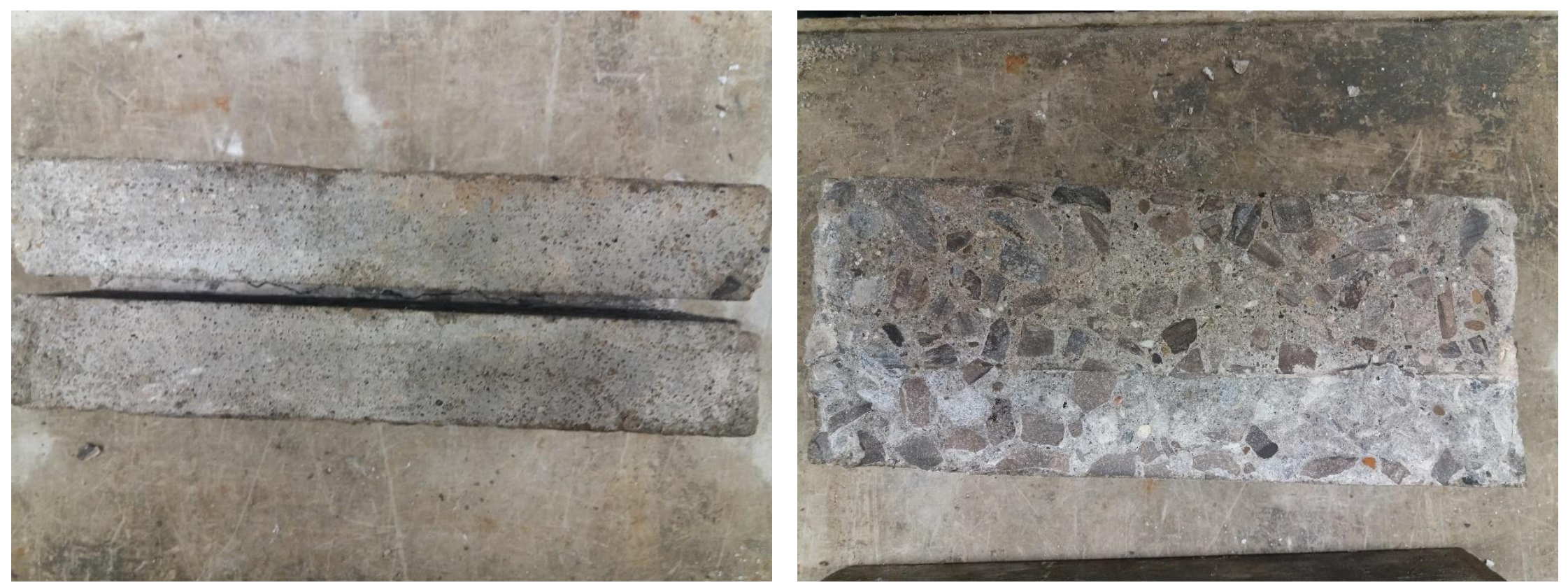
August $21 \mathrm{Z}-15 \% \mathrm{NaCl} \mathrm{W}$
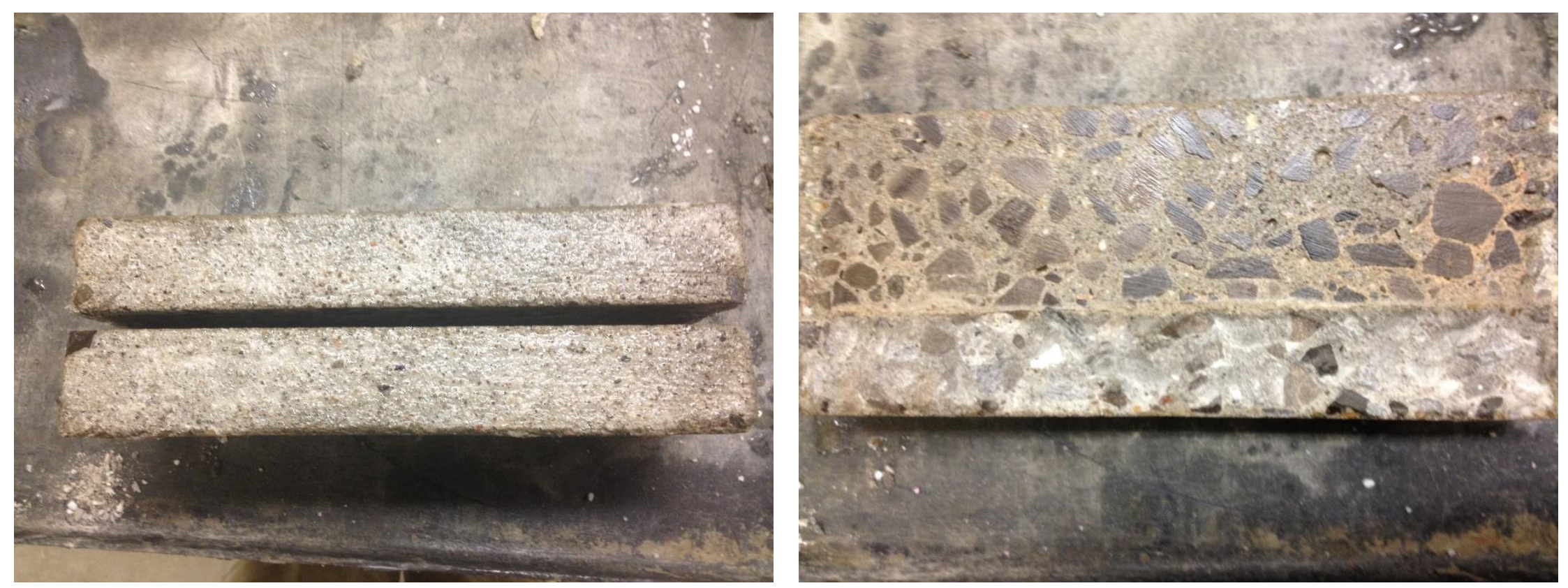
August $23 \mathrm{X}-15 \% \mathrm{MgCl}_{2} \mathrm{~W}$
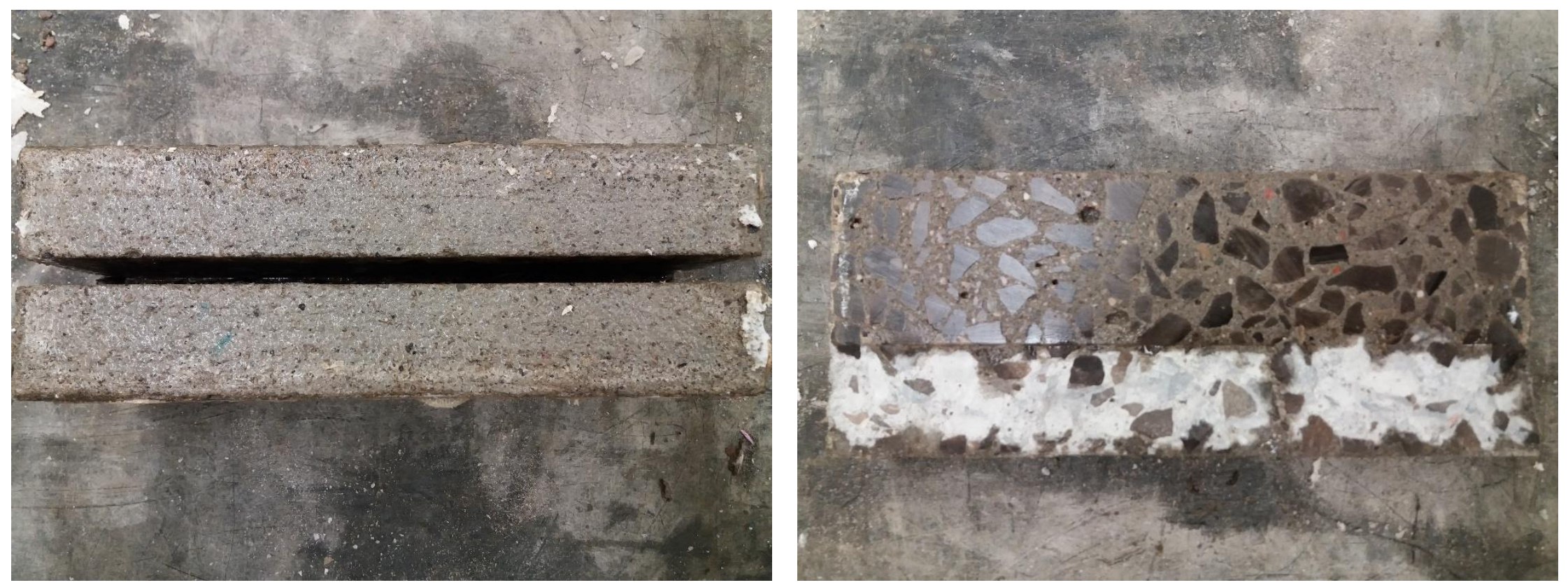
August $23 \mathrm{Y}-15 \% \mathrm{MgCl}_{2} \mathrm{~W}$
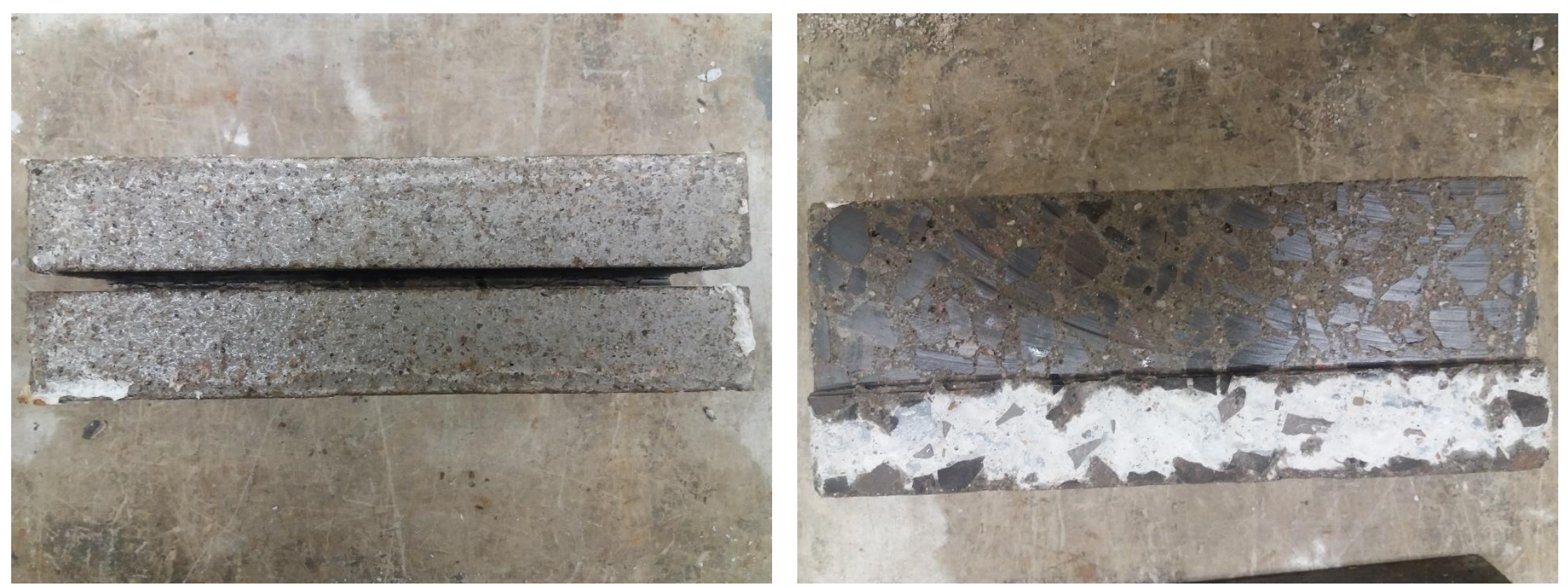
August $29 \mathrm{Y}-15 \% \mathrm{CaCl}_{2} \mathrm{~W}$
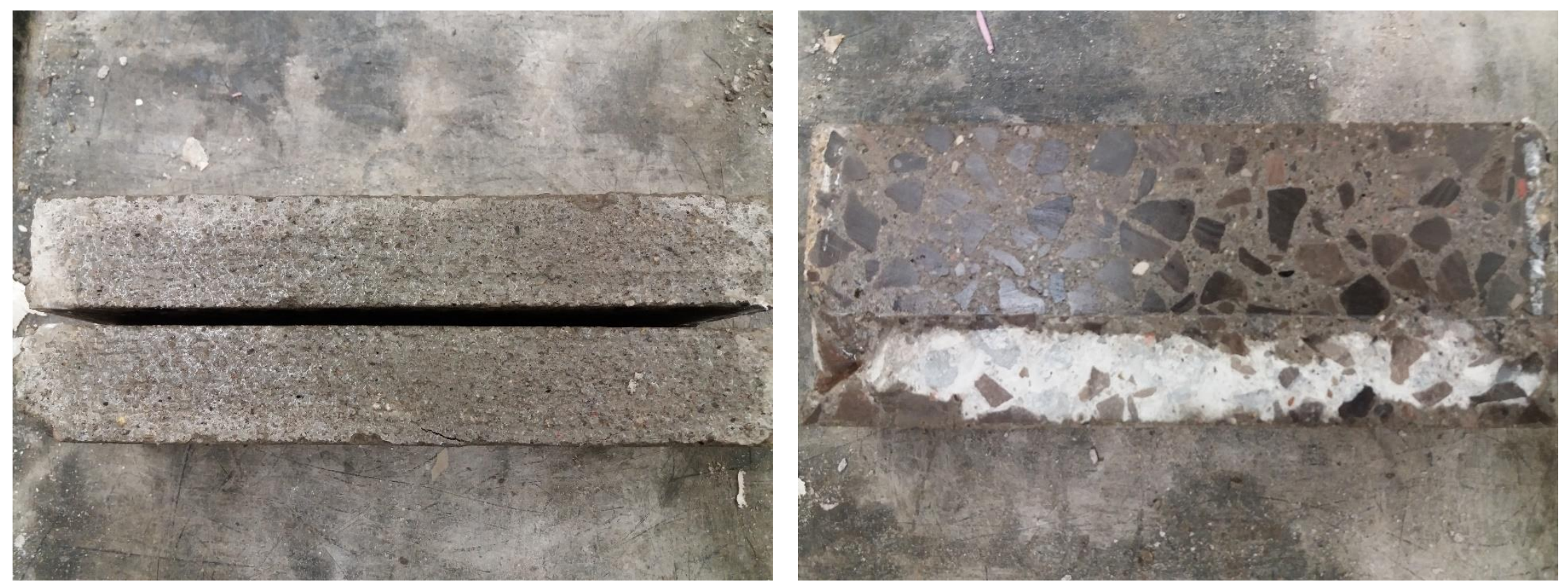
August $29 \mathrm{X}-15 \% \mathrm{CaCl}_{2} \mathrm{~W}$
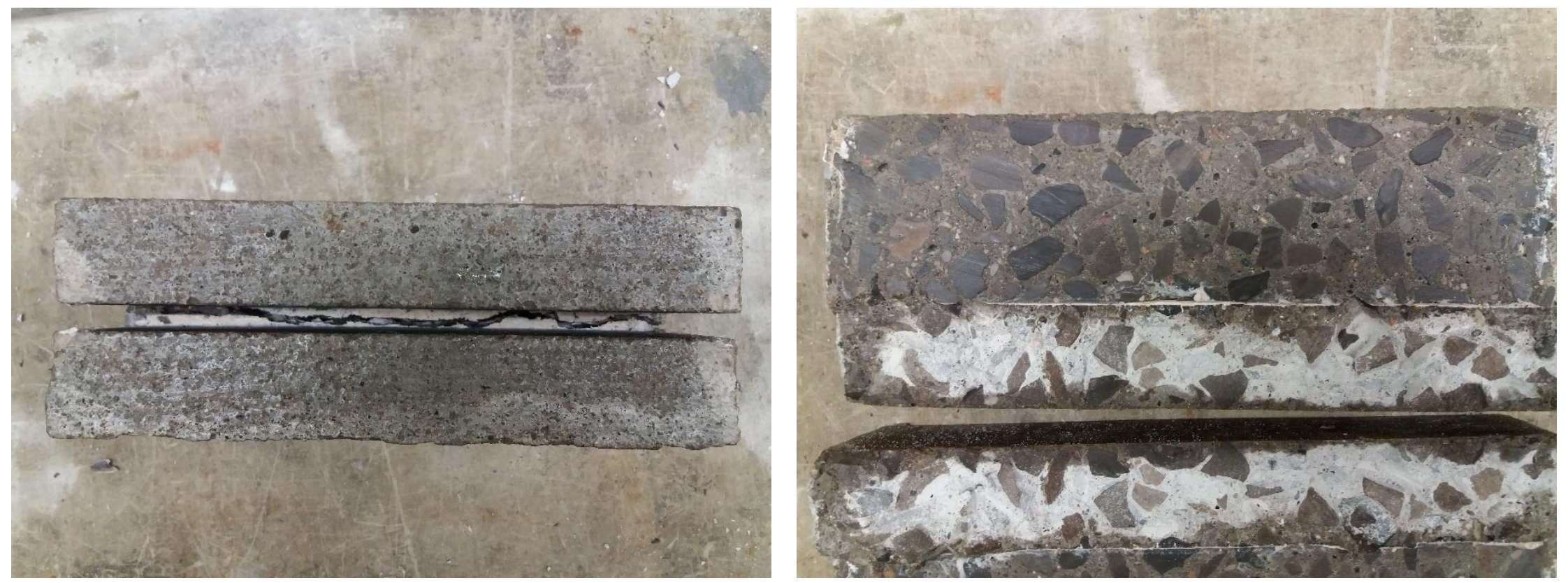
August $29 \mathrm{Z}-3 \% \mathrm{CaCl}_{2} \mathrm{FT}$
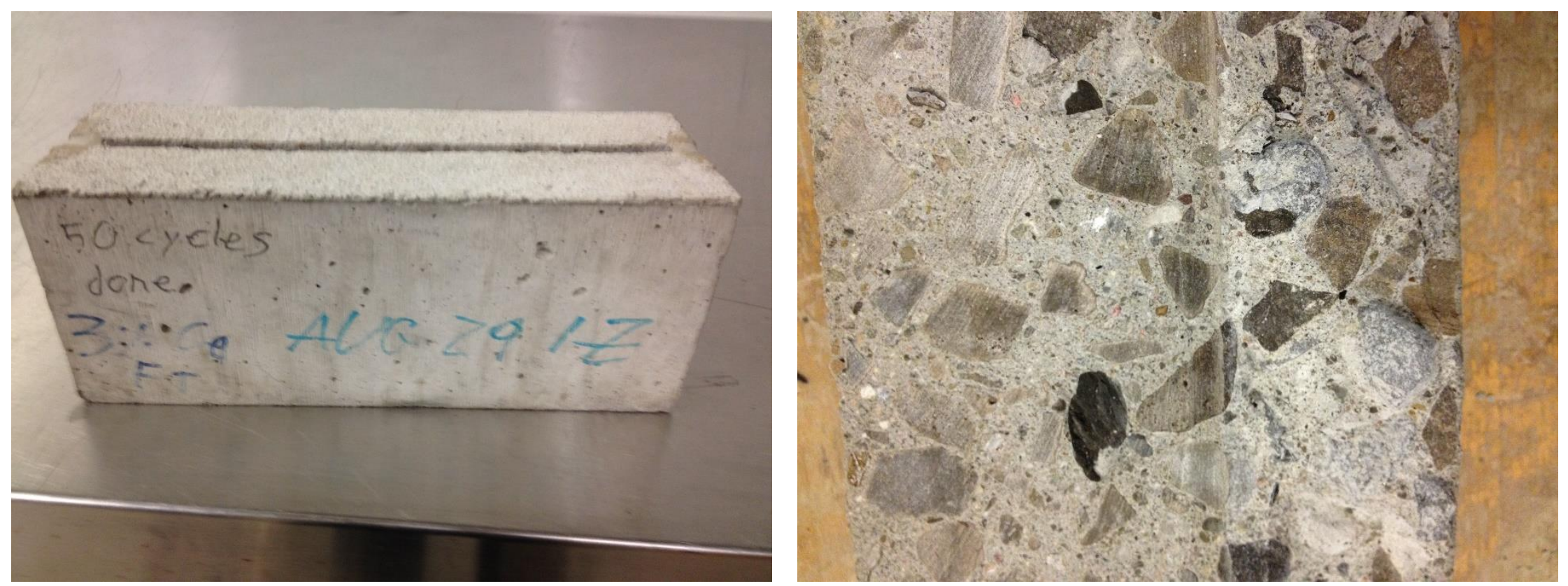
$55 \mathrm{MPa}$ mix Slabs after 50 Cycles

October $20 \mathrm{X}-15 \% \mathrm{MgCl}_{2} \mathrm{~W}$
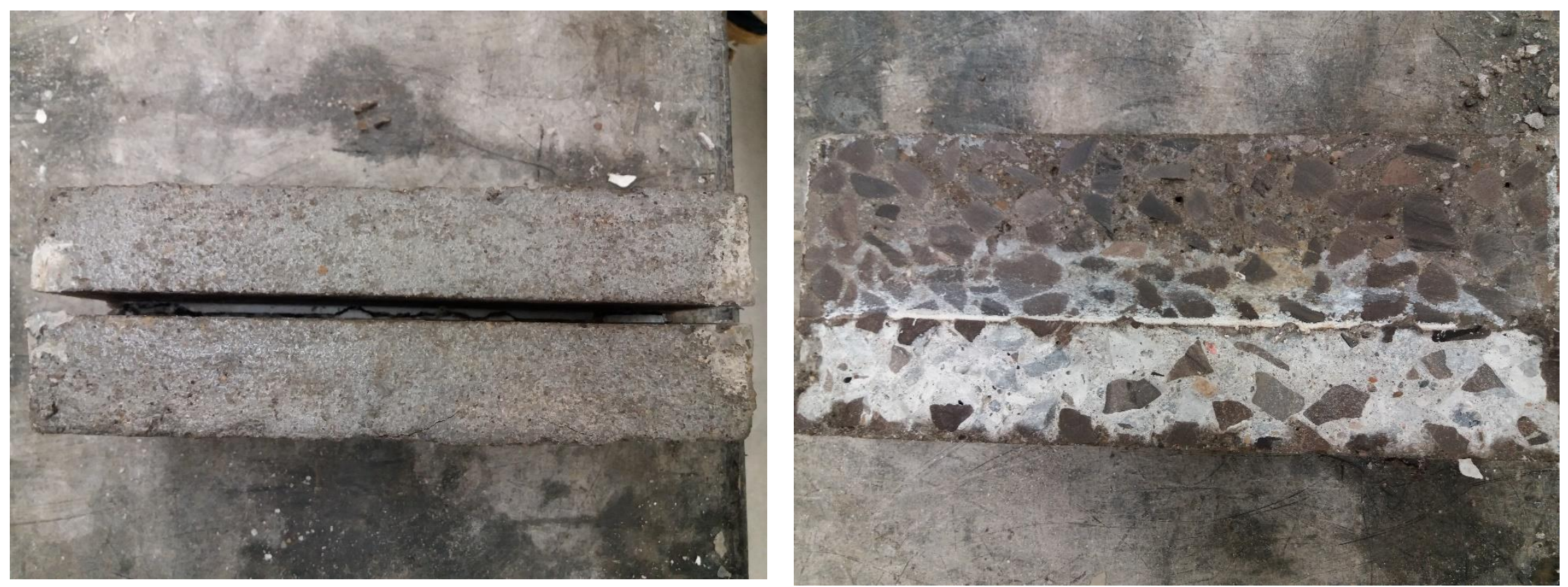
October $20 \mathrm{X}-3 \% \mathrm{MgCl}_{2} \mathrm{FT}$
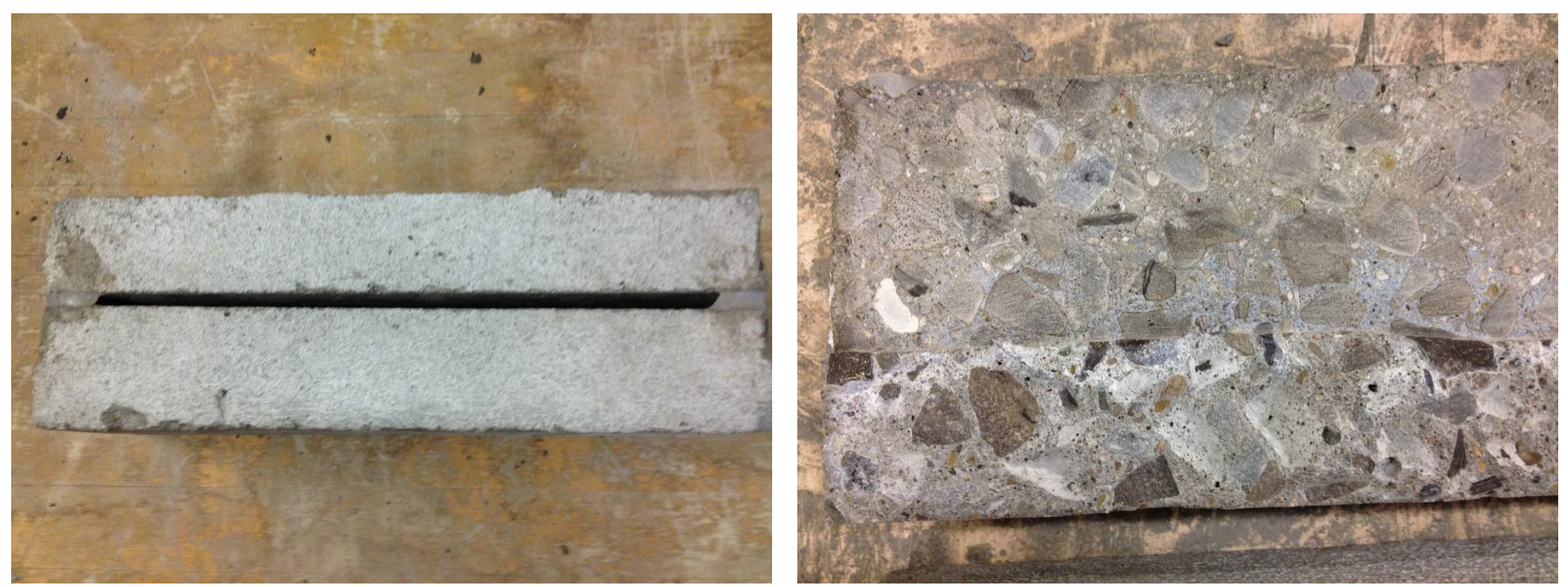
October $20 \mathrm{Y}-3 \% \mathrm{MgCl}_{2} \mathrm{FT}$
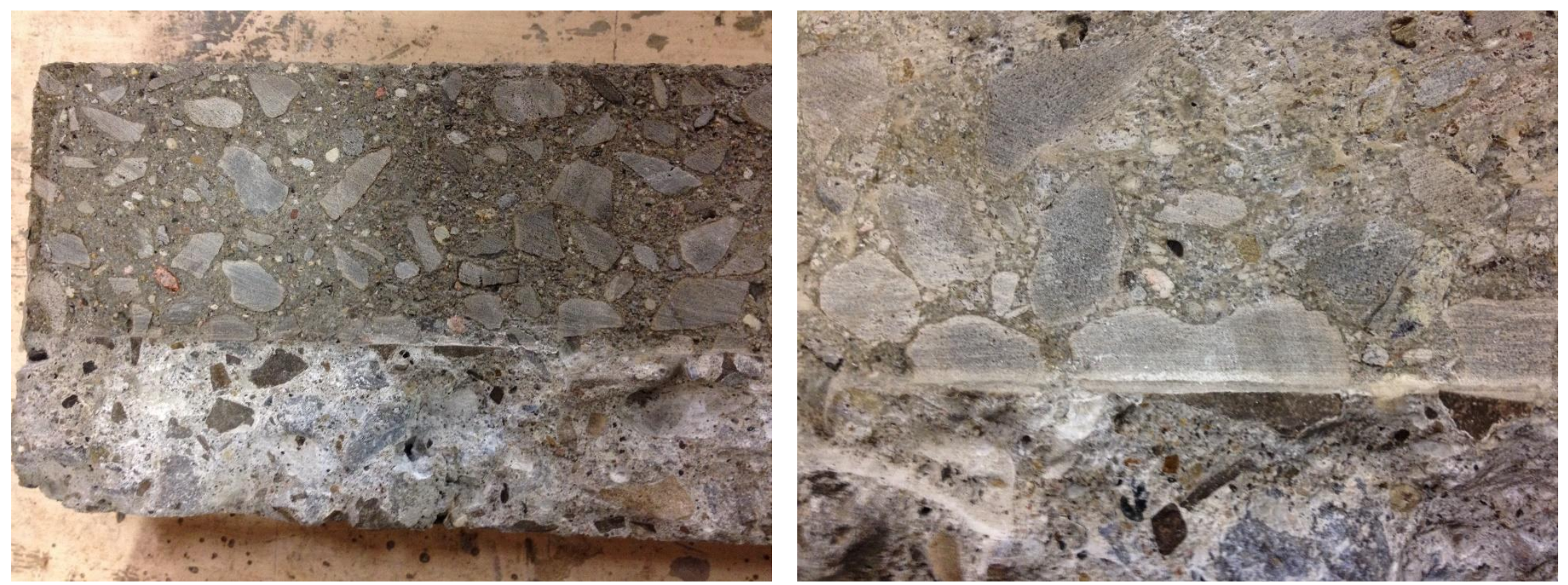
October $27 \mathrm{Y}-15 \% \mathrm{NaCl}$ W
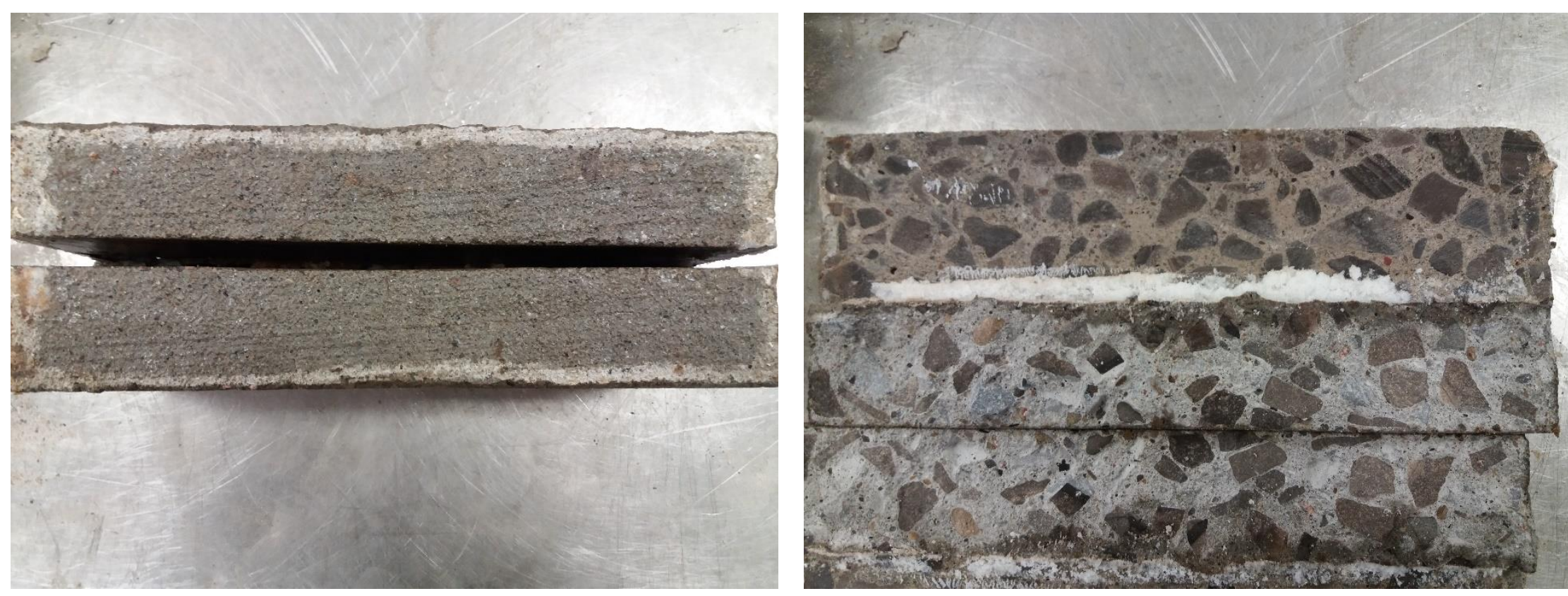
October $27 \mathrm{Z}-15 \% \mathrm{NaCl}$ W
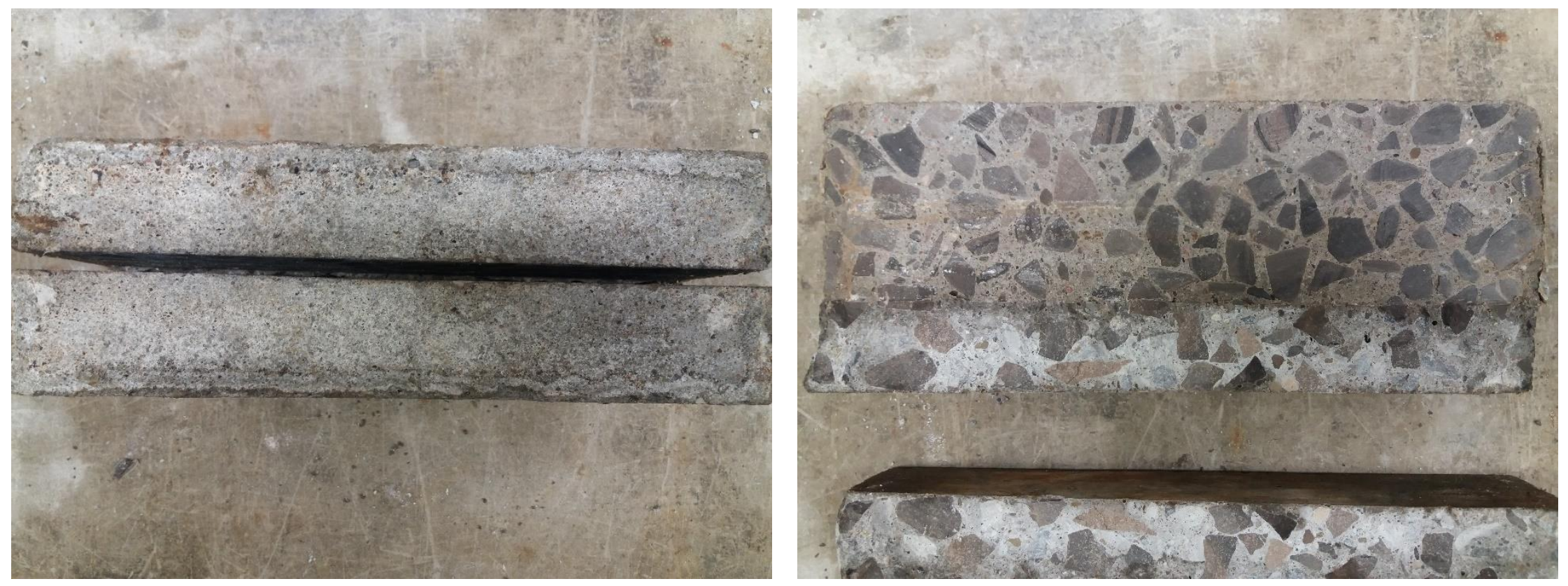
October $27 \mathrm{Y}-3 \% \mathrm{NaCl} F \mathrm{~F}$
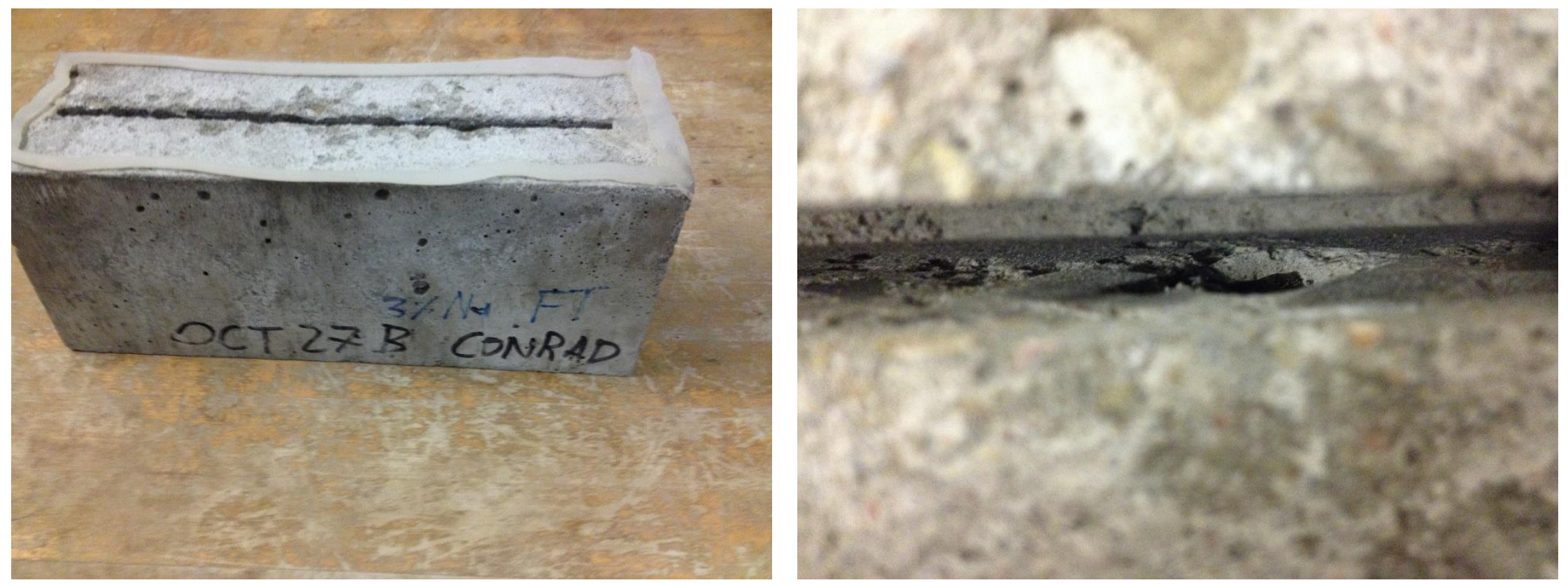
November $3 \mathrm{X}-15 \% \mathrm{CaCl}_{2} \mathrm{~W}$
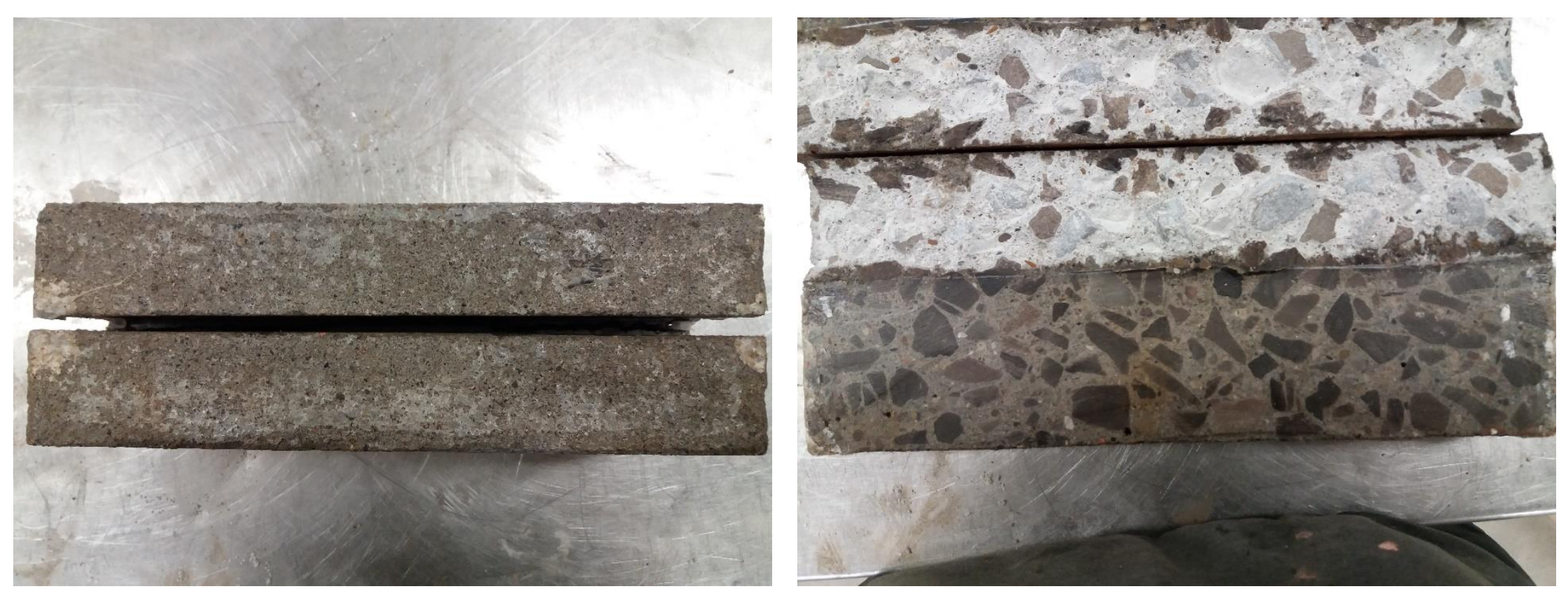
November $3 \mathrm{Z}-15 \% \mathrm{CaCl}_{2} \mathrm{~W}$
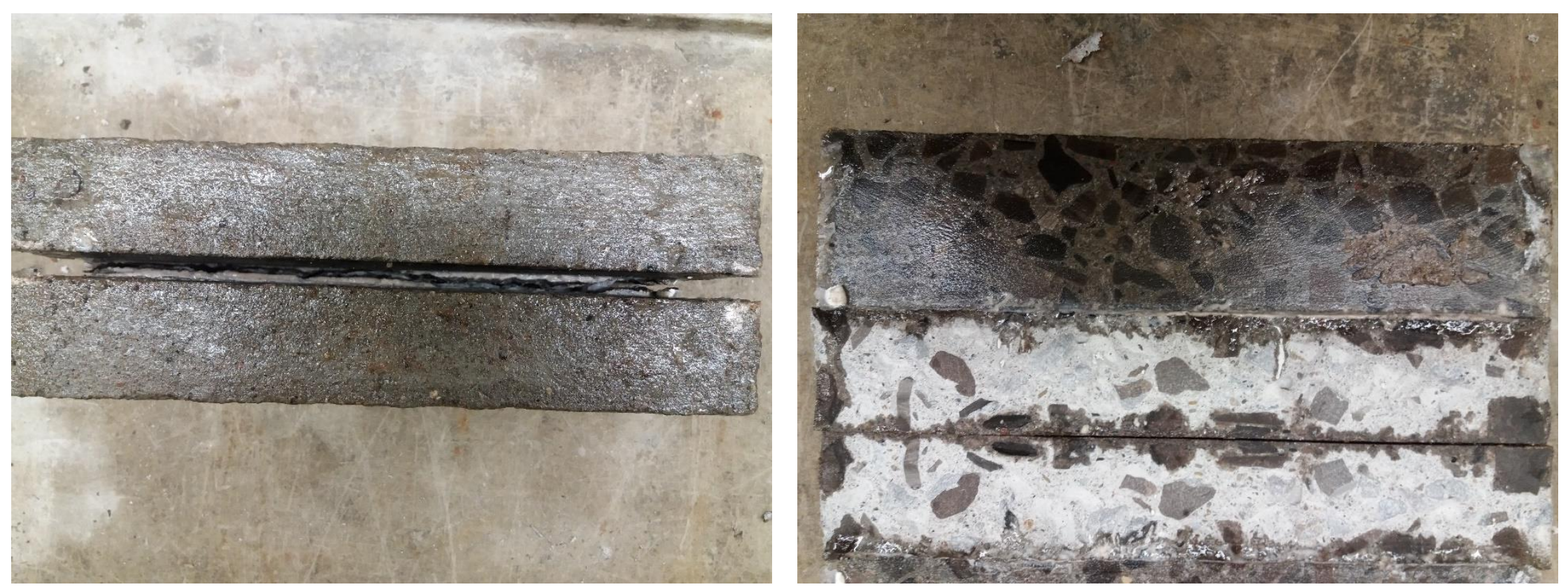
November $3 \mathrm{Z}-10 \% \mathrm{MgCl}_{2} \mathrm{FTW}$
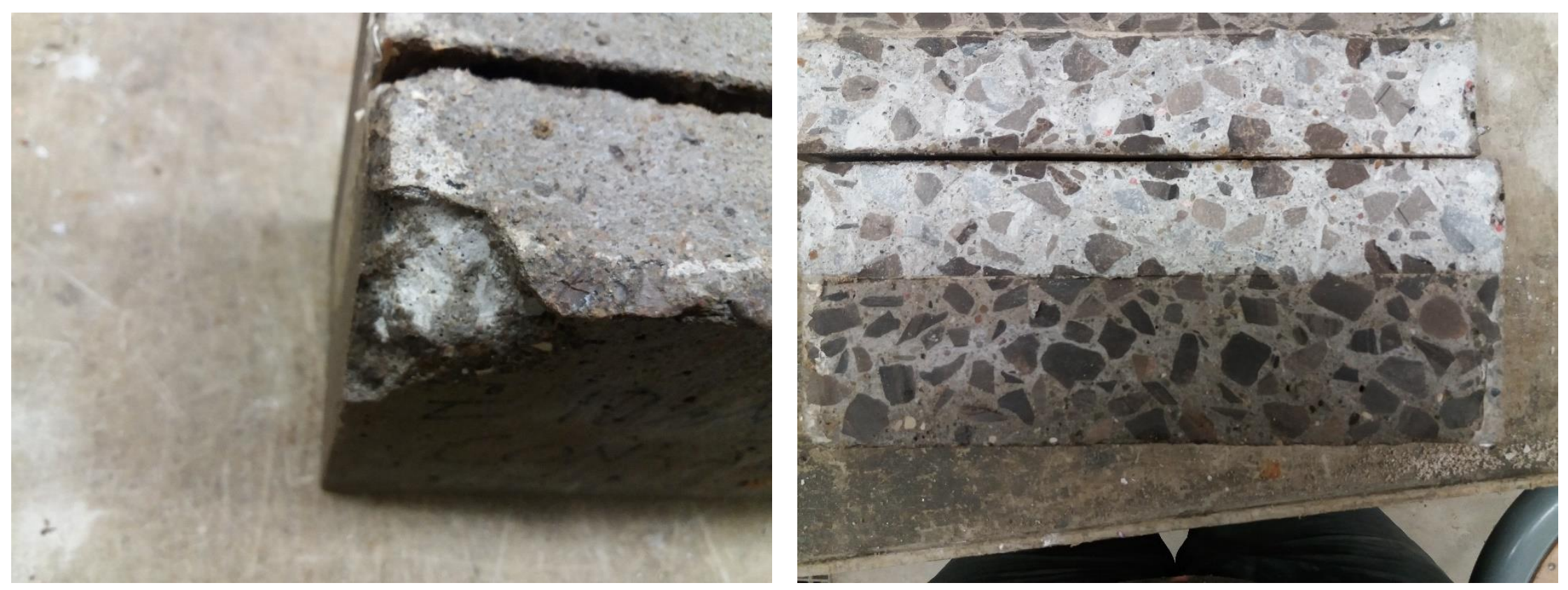
November $3 \mathrm{Y}-15 \% \mathrm{CaCl}_{2} \mathrm{~W}$
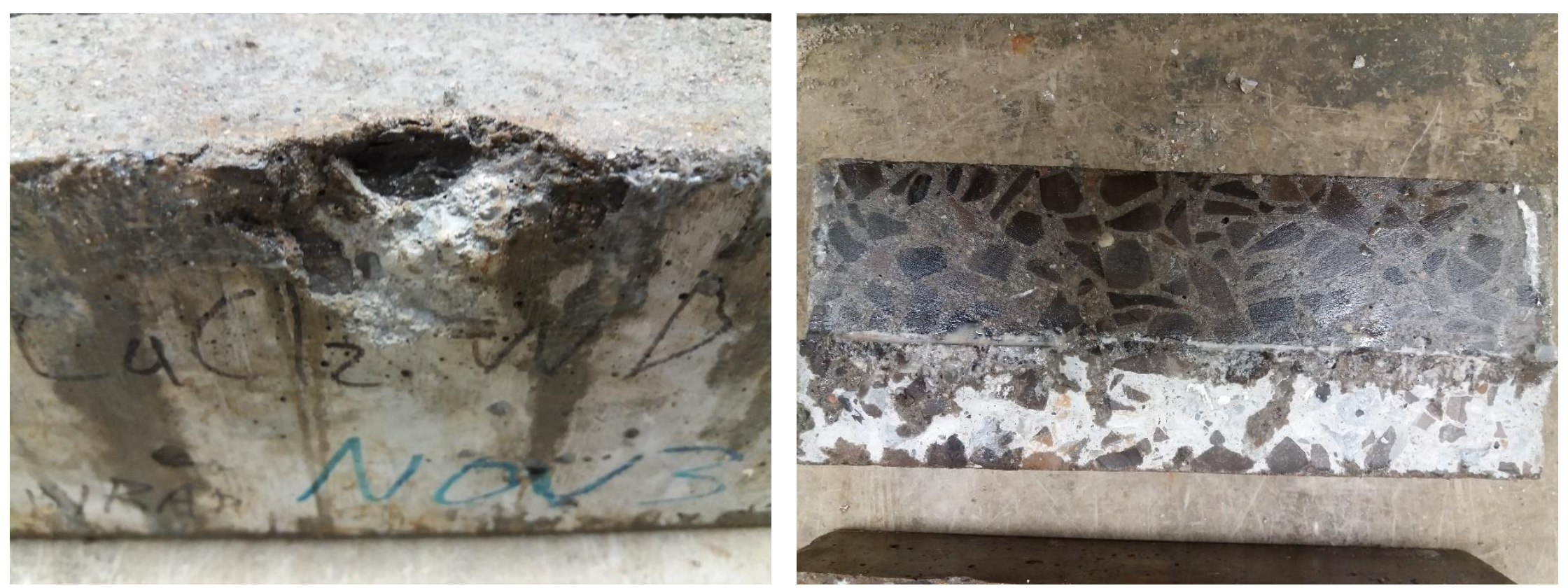
November $10 \mathrm{X}-15 \% \mathrm{MgCl}_{2} \mathrm{~W}$
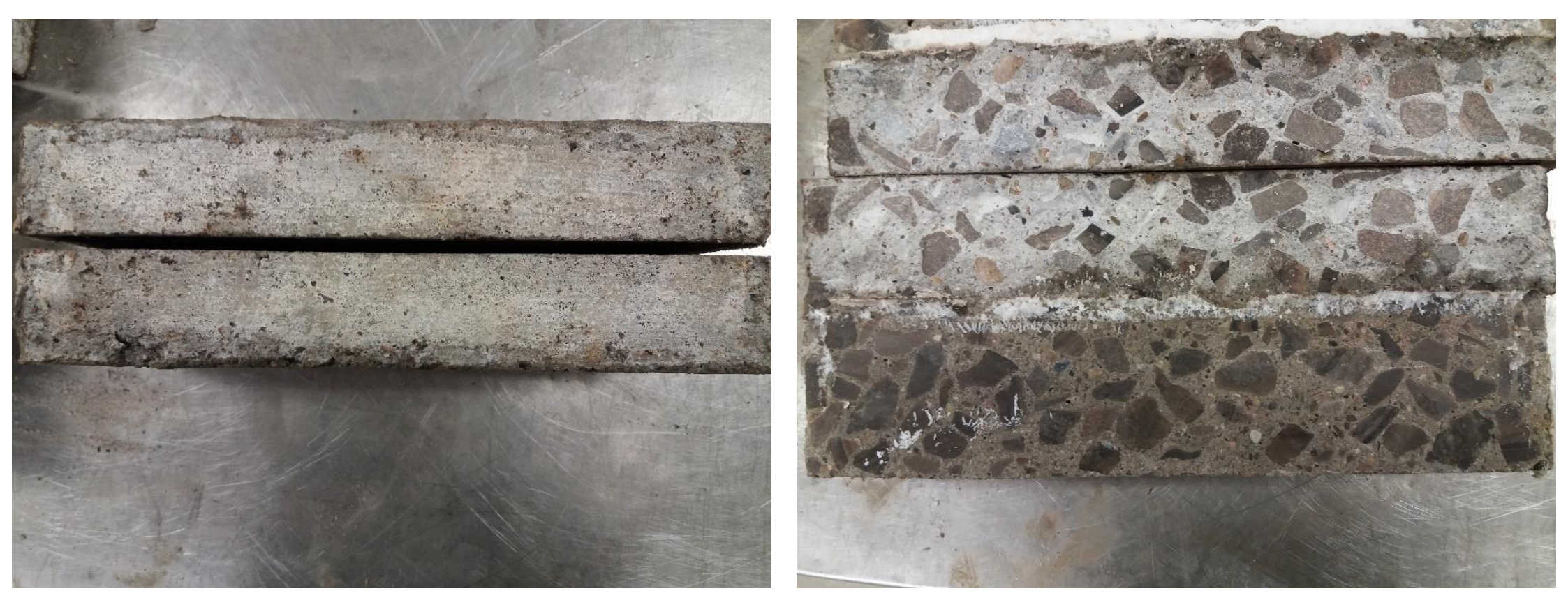
November $10 \mathrm{Y}-15 \% \mathrm{MgCl}_{2} \mathrm{~W}$
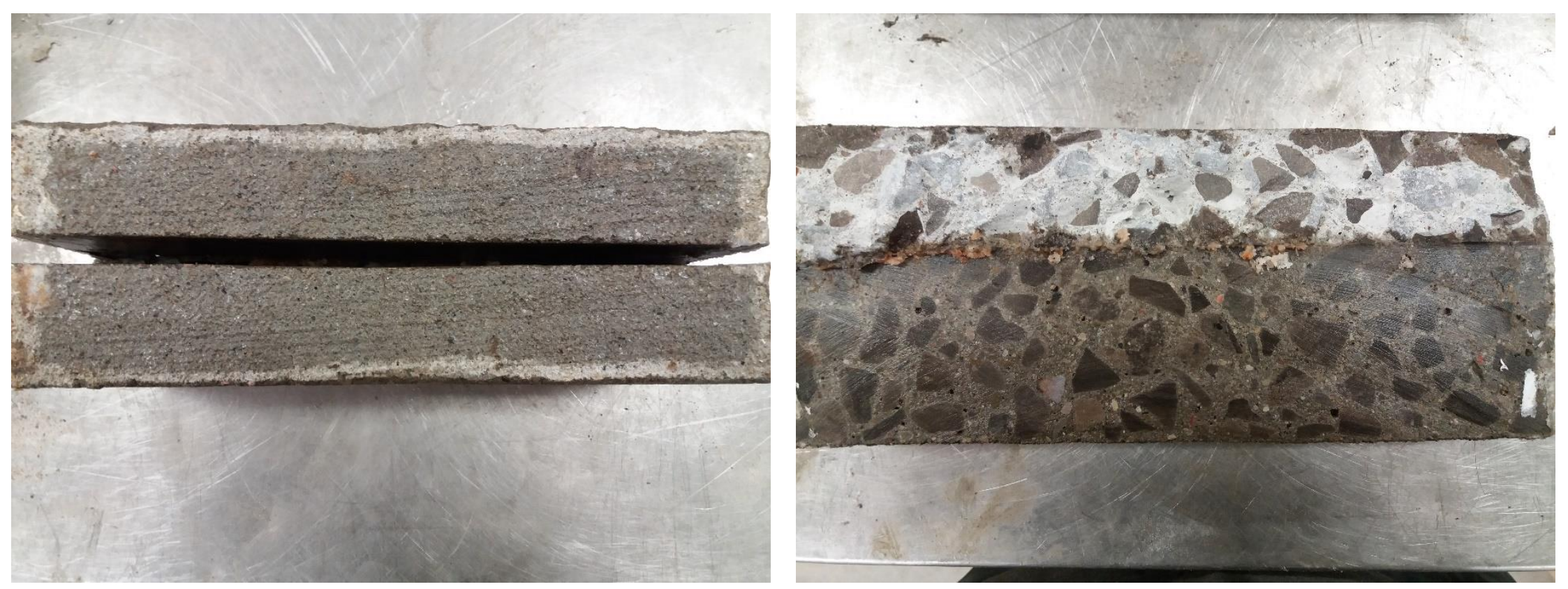


\section{Appendix C-Statistical Analysis}

Table C-1: F-test analysis for $30 \mathrm{MPa}$ mix samples and $55 \mathrm{MPa}$ mix samples (load values).

\begin{tabular}{|c|c|c|c|c|}
\hline Exposure Type & $\mathbf{F}$ & $\mathbf{F ~ C r i t i c a l ~}$ & $\mathbf{P}(\mathbf{F} \leq \mathbf{f})$ & Same variance? \\
\hline $3 \% \mathrm{MgCl} 2 \mathrm{FT}$ & 1.014889 & 19 & 0.496305 & Yes \\
\hline $15 \% \mathrm{NaCl}$ WD & 78.26256 & 19 & 0.012616 & No \\
\hline $15 \% \mathrm{MgCl} 2 \mathrm{WD}$ & 23.09082 & 19 & 0.04151 & No \\
\hline $15 \% \mathrm{CaCl} 2 \mathrm{WD}$ & 27.03337 & 19 & 0.035672 & No \\
\hline
\end{tabular}

Table C-2: F-test analysis for $30 \mathrm{MPa}$ mix samples and $55 \mathrm{MPa}$ mix samples (relative strength values).

\begin{tabular}{|c|c|c|c|c|}
\hline Exposure Type & $\mathbf{F}$ & $\mathbf{F}$ Critical & $\mathbf{P}(\mathbf{F} \leq \mathbf{f})$ & Same variance? \\
\hline $3 \% \mathrm{MgCl} 2 \mathrm{FT}$ & 3.959995 & 19 & 0.201613 & Yes \\
\hline $15 \% \mathrm{NaCl}$ WD & 20.05756 & 19 & 0.047489 & No \\
\hline $15 \% \mathrm{MgCl} 2 \mathrm{WD}$ & 5.917844 & 19 & 0.144554 & Yes \\
\hline $15 \% \mathrm{CaCl} 2 \mathrm{WD}$ & 6.928261 & 19 & 0.126131 & Yes \\
\hline
\end{tabular}




\section{References}

ACl Committee 201. (2008). Guide for Conducting a Visual Inspection of Concrete in Service. American Concrete Institute.

Ahmed, M. S., Kayali, O., \& Anderson, W. (2008). Chloride penetration in binary and ternary blended cement concretes as measured by two different rapid methods. Cement and Concrete Composites, 30(7), 576-582.

Alexander, M., \& Mindess, S. (2014). Aggregates in concrete. CRC Press.

American Concrete Pavement Association (2018). Concrete Pavement Joint Sealing/Filling.

Akyurt, M., Zaki, G., \& Habeebullah, B. (2002). Freezing phenomena in ice-water systems. Energy conversion and management, 43(14), 1773-1789.

Albright, R. O. (1987). GUIDE FOR DESIGN AND CONSTRUCTION OF CONCRETE PARKING LOTS. ACI Materials Journal, 84(6).

Aldea, C. M., Young, F., Wang, K., \& Shah, S. P. (2000). Effects of curing conditions on properties of concrete using slag replacement. Cement and Concrete Research, 30(3), 465-472.

Antoni, M., Rossen, J., Martirena, F., \& Scrivener, K. (2012). Cement substitution by a combination of metakaolin and limestone. Cement and Concrete Research, 42(12), 1579-1589.

ASTM C1202 (2019). Electrical indication of concrete's ability to resist chloride ion penetration.

ASTM C1293-18 (2018). Standard test method for determination of length change of concrete due to alkali-silica reaction. Annual Book of ASTM Standards, Section Four Construction, 4.

ASTM C138. (2017). C138/C138M-17a Standard Test Method for Density (Unit Weight), Yield, and Air Content (Gravimetric) of Concrete. Retrieved from https://doi-

org.ezproxy.lib.ryerson.ca/10.1520/C0138_C0138M-17A

ASTM C157. (2017). C157/C157M-17 Standard Test Method for Length Change of Hardened HydraulicCement Mortar and Concrete. Retrieved from https://doiorg.ezproxy.lib.ryerson.ca/10.1520/C0157_C0157M-17

ASTM C1645-16. (2016). C1645-16 Standard Test Method for Freeze-thaw and De-icing Salt Durability of Solid Concrete Interlocking Paving Units. Retrieved from https://doiorg.ezproxy.lib.ryerson.ca/10.1520/C1645-16 
ASTM C39. (2018). C39/C39M-18 Standard Test Method for Compressive Strength of Cylindrical Concrete Specimens. Retrieved from https://doiorg.ezproxy.lib.ryerson.ca/10.1520/C0039_C0039M-18

ASTM C490. (2017). C490/C490M-17 Standard Practice for Use of Apparatus for the Determination of Length Change of Hardened Cement Paste, Mortar, and Concrete. Retrieved from https://doiorg.ezproxy.lib.ryerson.ca/10.1520/C0490_C0490M-17

ASTM C672 (2012). Standard test method for scaling resistance of concrete surfaces exposed to deicing chemicals. West Conshohocken, PA: American Society for Testing and Materials.

Balendran, R. V., Pang, H. W., \& Wen, H. X. (1998). Use of scanning electron microscopy in concrete studies. Structural Survey, 16(3), 146-153. doi:10.1108/02630809810232718

Bertolini, L., Elsener, B., Pedeferri, P., Redaelli, E., \& Polder, R. (2013). Corrosion of steel in concrete (Vol. 392). Weinheim, Germany: Wiley-Vch.

Bhowmik, S., \& Ray, S. (2018). An improved crack propagation model for plain concrete under fatigue loading. Engineering Fracture Mechanics, 191, 365-382.

Birnin-Yauri, U. A., \& Glasser, F. P. (1998). Friedel's salt, Ca2Al (OH) 6 (Cl, OH) - 2H2O: its solid solutions and their role in chloride binding. Cement and Concrete Research, 28(12), 1713-1723.

Brake, N. A., \& Chatti, K. (2013). Prediction of size effect and non-linear crack growth in plain concrete under fatigue loading. Engineering Fracture Mechanics, 109, 169-185.

Brown, P., Hooton, R. D., \& Clark, B. (2004). Microstructural changes in concretes with sulfate exposure. Cement and Concrete Composites, 26(8), 993-999.

Carloni, C., Santandrea, M., Baietti, G., Influence of the width of the specimen on the fracture response of concrete notched beams, Engineering Fracture Mechanics (2018), doi: https://doi.org/10.1016/j.engfracmech.2018.04.045

Castro, J., Bentz, D., \& Weiss, J. (2011). Effect of sample conditioning on the water absorption of concrete. Cement and Concrete Composites, 33(8), 805-813.

Coleman, N. J., \& Page, C. L. (1997). Aspects of the pore solution chemistry of hydrated cement pastes containing metakaolin. Cement and Concrete Research, 27(1), 147-154.

Cope, J. L., Cannon, R. W., Abdun-Nur, E. A., Diaz, L. H., Oury, R. F., Anderson, F. A., ... \& Schrader, E. K. (2002). Effect of Restraint, Volume Change, and Reinforcement on Cracking of Mass Concrete. ACl Manual of Concrete Practice. 
Correns, C. W. (1949). Growth and dissolution of crystals under linear pressure. Discussions of the Faraday society, 5, 267-271.

Curcio, F., \& DeAngelis, B. A. (1998). Dilatant behavior of superplasticized cement pastes containing metakaolin. Cement and Concrete Research, 28(5), 629-634.

Cwirzen, A., \& Penttala, V. (2005). Aggregate-cement paste transition zone properties affecting the salt-frost damage of high-performance concretes. Cement and Concrete Research, 35(4), 671679.

De Weerdt, K., Justnes, H., \& Geiker, M. R. (2014). Changes in the phase assemblage of concrete exposed to sea water. Cement and Concrete Composites, 47, 53-63.

De Weerdt, K., Colombo, A., Coppola, L., Justnes, H., \& Geiker, M. R. (2015). Impact of the associated cation on chloride binding of Portland cement paste. Cement and Concrete Research, 68, 196202.

Deboucha, W., Leklou, N., Khelidj, A., \& Oudjit, M. N. (2017). Hydration development of mineral additives blended cement using thermogravimetric analysis (TGA): Methodology of calculating the degree of hydration. Construction and Building Materials, 146, 687-701.

Del Mar Arribas-Colon, M. (2008). Investigation of premature distress around joints in PCC pavements (Doctoral dissertation, Purdue University).

Del Mar Arribas-Colón, M., M. Radliński, J. Olek, and N. M. Whiting. (2012) Investigation of Premature Distress Around Joints in PCC Pavements: Parts I \& II. Publication FHWA/IN/JTRP-2012/25 \& FHWA/IN/JTRP-2012/26. Joint Transportation Research Program, Indiana Department of Transportation and Purdue University, West Lafayette, Indiana. doi: 10.5703/1288284315019.

Detwiler, R. J., \& Powers-Couche, L. J. (1999). Effect of sulfates in concrete on their resistance to freezing and thawing. Special Publication, 177, 219-248.

Diamond, S. (2004). Special issue on scanning electron microscopy of cements and concretes. Cement and Concrete Composites, 26(8), 917-918 https://doi.org/10.1016/j.cemconcomp.2004.02.027.

Diamond, S. (1996). Delayed ettringite formation-processes and problems. Cement and concrete Composites, 18(3), 205-215.

Farnam, Y., Dick, S., Wiese, A., Davis, J., Bentz, D., \& Weiss, J. (2015). The influence of calcium chloride deicing salt on phase changes and damage development in cementitious materials. Cement and Concrete Composites, 64, 1-15. 
Farnam, Y., Wiese, A., Bentz, D., Davis, J., \& Weiss, J. (2015). Damage development in cementitious materials exposed to magnesium chloride deicing salt. Construction and Building Materials, 93, 384-392.

Farnam, Y., Todak, H., Spragg, R., \& Weiss, J. (2015). Electrical response of mortar with different degrees of saturation and deicing salt solutions during freezing and thawing. Cement and Concrete Composites, 59, 49-59.

French, W. J. (1991). Concrete petrography: a review. Quarterly Journal of Engineering Geology and Hydrogeology, 24(1), 17-48.

Galan, I., \& Glasser, F. P. (2015). Chloride in cement. Advances in Cement Research, 27(2), 63-97.

Galan, I., Perron, L., \& Glasser, F. P. (2015). Impact of chloride-rich environments on cement paste mineralogy. Cement and Concrete Research, 68, 174-183.

Geng, J., Easterbrook, D., Li, L. Y., \& Mo, L. W. (2015). The stability of bound chlorides in cement paste with sulfate attack. Cement and Concrete Research, 68, 211-222.

Ghantous, R. M., Farnam, Y., Unal, E., \& Weiss, J. (2016). The influence of carbonation on the formation of calcium oxychloride. Cement and Concrete Composites, 73, 185-191.

Grishchenko, R. O., Emelina, A. L., \& Makarov, P. Y. (2013). Thermodynamic properties and thermal behavior of Friedel's salt. Thermochimica acta, 570, 74-79.

Gulati, S. T., \& Hagy, H. E. (1982). Analysis and Measurement of Glue-Spall Stresses in Glass-Epoxy Bonds. Journal of the American Ceramic Society, 65(1), 1-5.

Hasan, M., Ueda, T., \& Sato, Y. (2008). Stress-strain relationship of frost-damaged concrete subjected to fatigue loading. Journal of Materials in Civil Engineering, 20(1), 37-45.

Haselbach, L., \& Thomas, A. (2014). Carbon sequestration in concrete sidewalk samples. Construction and Building Materials, 54, 47-52.

He, C., Osbaeck, B., \& Makovicky, E. (1995). Pozzolanic reactions of six principal clay minerals: activation, reactivity assessments and technological effects. Cement and concrete research, 25(8), 1691-1702.

lowa State University, (2004) “Concrete Paving workforce reference no.3: Concrete Pavement Joint Sawing, Cleaning and Sealing"

Jain, R. P. (2004). Develop statewide recommendations for application of PCC joint reflective cracking rehabilitation strategies (Doctoral dissertation, Texas A\&M University). 
Jain, J. A., \& Neithalath, N. (2010). Chloride transport in fly ash and glass powder modified concretesinfluence of test methods on microstructure. Cement and Concrete Composites, 32(2), 148-156.

Justnes, H. (1998). A review of chloride binding in cementitious systems. NORDIC CONCRETE RESEARCH-PUBLICATIONS-, 21, 48-63.

Kjellsen, K. O., Detwiler, R. J., \& Gjørv, O. E. (1990). Backscattered electron imaging of cement pastes hydrated at different temperatures. Cement and concrete research, 20(2), 308-311.

Kjellsen, K. O., Detwiler, R. J., \& Gjørv, O. E. (1991). Development of microstructures in plain cement pastes hydrated at different temperatures. Cement and concrete research, 21(1), 179-189.

Klieger, P. (1978). - Air-Entraining Admixtures. In Significance of Tests and Properties of Concrete and Concrete-Making Materials. ASTM International.

Klimesch, D. S., \& Ray, A. (1997). Use of the second-derivative differential thermal curve in the evaluation of cement-quartz pastes with metakaolin addition autoclaved at $180 \mathrm{C}$. Thermochimica acta, 307(2), 167-176.

Klimesch, D. S., \& Ray, A. (1998). Autoclaved cement-quartz pastes with metakaolin additions. Advanced Cement Based Materials, 7(3-4), 109-118.

Lee, H. Y. O. M. I. N., Cody, A. M., Cody, R. D., \& Spry, P. G. (1998). PCC Pavement deterioration and expansive mineral growth. In Transportation Conference Proceedings (pp. 71-75).

Li, G., Ji, G., \& Meng, H. (2014). Shape memory polymer-based sealant for a compression sealed joint. Journal of Materials in Civil Engineering, 27(6), 04014196.

Li, W., Sun, W., \& Jiang, J. (2011). An analytical method to detect the coupling damage relationship of concrete subjected to bending fatigue and temperature actions. Journal of Wuhan University of Technology-Mater. Sci. Ed., 26(3), 573-577.

Li, W., Pour-Ghaz, M., Castro, J., \& Weiss, J. (2011). Water absorption and critical degree of saturation relating to freeze-thaw damage in concrete pavement joints. Journal of Materials in Civil Engineering, 24(3), 299-307.

Loser, R., Lothenbach, B., Leemann, A., \& Tuchschmid, M. (2010). Chloride resistance of concrete and its binding capacity-Comparison between experimental results and thermodynamic modeling. Cement and Concrete Composites, 32(1), 34-42.

Lu, J., Zhu, K., Tian, L., \& Guo, L. (2017). Dynamic compressive strength of concrete damaged by fatigue loading and freeze-thaw cycling. Construction and Building Materials, 152, 847-855. 
Luping, T., \& Nilsson, L. O. (1993). Chloride binding capacity and binding isotherms of OPC pastes and mortars. Cement and concrete research, 23(2), 247-253.

Marks, V. J., \& Dubberke, W. (1982). Durability of concrete and the lowa pore index test (No. 853).

Marks, V. J., \& Dubberke, W. G. (1996). A different perspective for investigation of portland cement concrete pavement deterioration. Transportation research record, 1525(1), 91-96.

Mehta, P. K. (1986). Concrete. Structure, properties and materials.

Meng, W., Yao, Y., Mobasher, B., \& Khayat, K. H. (2017). Effects of loading rate and notch-to-depth ratio of notched beams on flexural performance of ultra-high-performance concrete. Cement and Concrete Composites, 83, 349-359.

Mindess, S., Young, F. J., \& Darwin, D. (2003). Concrete 2nd Edition. Technical Documents.

Mondal, P., Shah, S. P., \& Marks, L. D. (2009). Nanomechanical properties of interfacial transition zone in concrete. In Nanotechnology in Construction 3 (pp. 315-320). Springer, Berlin, Heidelberg.

Monical, J., Unal, E., Barrett, T., Farnam, Y., \& Weiss, W. J. (2016). Reducing joint damage in concrete pavements: Quantifying calcium oxychloride formation. Transportation Research Record, 2577(1), 17-24.

Monosi, S., \& Collepardi, M. (1990). Ricerca sul 3CaOCaCl215H2O identificato nei calcestruzzi attaccati dal $\mathrm{CaCl}$ 2. Il Cimento, 87, 3-8.

Monteagudo, S. M., Moragues, A., Gálvez, J. C., Casati, M. J., \& Reyes, E. (2014). The degree of hydration assessment of blended cement pastes by differential thermal and thermogravimetric analysis. Morphological evolution of the solid phases. Thermochimica acta, 592, 37-51.

Orr, D. M. F. (1983). Application of the scanning electron microscope to the study of the initial hydration of portland cement paste. Cement and Concrete Research, 13(1), 146-148.

Osman, B. H. (2008). Shear in RC deep beams (Doctoral dissertation, M. Sc. thesis, University of Khartoum, Sudan).

Ouyang, C. (1999). Effect of infilling of air voids by ettringite on resistance of concretes to freezing and thawing. Special Publication, 177, 249-262.

Patel, R., Dubey, S. K., \& Pathak, K. K. (2014). Effect of depth span ratio on the behaviour of beams. International Journal of Advanced Structural Engineering (IJASE), 6(2), 3. 
Peterson, K., Julio-Betancourt, G., Sutter, L., Hooton, R. D., \& Johnston, D. (2013). Observations of chloride ingress and calcium oxychloride formation in laboratory concrete and mortar at $5 \mathrm{C}$. Cement and Concrete Research, 45, 79-90.

Pigeon, M., \& Pleu, R. (1995). Durability of concrete in cold climates. ed. Great Britain.

Powers, T. C. (1954, May). Void space as a basis for producing air-entrained concrete. In Journal Proceedings (Vol. 50, No. 5, pp. 741-760).

Qiao, C., Suraneni, P., \& Weiss, J. (2018). Damage in cement pastes exposed to $\mathrm{NaCl}$ solutions. Construction and Building Materials, 171, 120-127.

Qiao, C., Suraneni, P., \& Weiss, J. (2018). Flexural strength reduction of cement pastes exposed to $\mathrm{CaCl} 2$ solutions. Cement and Concrete Composites, 86, 297-305.

Qiao, C., Suraneni, P., Chang, M. T., \& Weiss, J. (2018). Damage in cement pastes exposed to $\mathrm{MgCl} 2$ solutions. Materials and Structures, 51(3), 74.

Qiao, Y., Sun, W., \& Jiang, J. (2015). Damage process of concrete subjected to coupling fatigue load and freeze/thaw cycles. Construction and Building Materials, 93, 806-811.

Radlinski, M., Olek, J., Del Mar Arribas, M., Rudy, A., Nantung, T. E., \& Byers, C. M. (2008). Influence of Air-Void System Parameters on Freeze-Thaw Resistance of Pavement Concrete: Lessons Learned from Field and Laboratory Observations (No. 08-3029).

Rangaraju, P. R. (2002). Investigating premature deterioration of a concrete highway. Transportation research record, 1798(1), 1-7.

Ramezanianpour, A. A., \& Jovein, H. B. (2012). Influence of metakaolin as supplementary cementing material on strength and durability of concretes. Construction and Building materials, 30, 470479.

Raoufi, K., Their, T., Weiss, W. J., Olek, J., \& Nantung, T. E. (2009). Saw-cutting guidelines for concrete pavements: examining the requirements for time and depth of saw-cutting.

Riley, W. F., Sturges, L. D., \& Morris, D. H. (2007). Mechanics of materials (6th ed.). Hoboken, NJ: John Wiley \& Sons.

Sahu, S., Badger, S., Thaulow, N., \& Lee, R.J. (2004). Determination of water-cement ratio of hardened concrete by scanning electron microscopy. Cement and Concrete Composites, 26(8), 987-992, https://doi.org/10.1016/j.cemconcomp.2004.02.032. 
Schollbach, K., Pöllmann, H. (2010). Comparison of transmission XRD with reflectiongeometry for lattice constant determination of calcium oxychloride, 3rd IntIWorkshop, Layered Materials: Design and Function, Intl Zeolite Association andRuhr University, Bochum, Germany.

Scrivener, K. L. (2004). Backscattered electron imaging of cementitious microstructures: understanding and quantification. Cement and concrete Composites, 26(8), 935-945.

Scrivener, K. L., \& Pratt, P. L. (1984). Backscattered electron images of polished cement sections in the scanning electron microscope. In Proceedings of the International Conference on Cement Microscopy (No. CONF, pp. 145-155).

Scrivener, K., Snellings, R., \& Lothenbach, B. (Eds.). (2018). A practical guide to microstructural analysis of cementitious materials. Crc Press.

Seigneur, N., Voutilainen, M., \& Dauzères, A. (2016). Transport properties of cement model system (C3S and CSH): Experiments dedicated to implement a new approach of the microstructure/diffusion properties relation in the reactive transport code. In 4th International Workshop on Mechanisms and Modelling of Waste/Cement Interactions May 22-25, 2016, Murten, Switzerland.

Shi, C. (2001). Formation and stability of $3 \mathrm{CaO} \cdot \mathrm{CaCl} 2 \cdot 12 \mathrm{H} 2 \mathrm{O}$. Cement and Concrete Research, 31(9), 1373-1375.

Shi, Z., Geiker, M. R., Lothenbach, B., De Weerdt, K., Garzón, S. F., Enemark-Rasmussen, K., \& Skibsted, J. (2017). Friedel's salt profiles from thermogravimetric analysis and thermodynamic modelling of Portland cement-based mortars exposed to sodium chloride solution. Cement and Concrete Composites, 78, 73-83.

Shi, C., Stegemann, J. A., \& Caldwell, R. J. (1998). Effect of supplementary cementing materials on the specific conductivity of pore solution and its implications on the rapid chloride permeability test (AASHTO T277 and ASTM C1202) results. Materials Journal, 95(4), 389-394.

Smith, S. H., Qiao, C., Suraneni, P., Kurtis, K. E., \& Weiss, W. J. (2019). Service-life of concrete in freezethaw environments: Critical degree of saturation and calcium oxychloride formation. Cement and Concrete Research, 122, 93-106.

Soroushian, P., \& Elzafraney, M. (2004). Damage effects on concrete performance and microstructure. Cement and Concrete Composites, 26(7), 853-859.

Spragg, R. P., Castro, J., Li, W., Pour-Ghaz, M., Huang, P. T., \& Weiss, J. (2011). Wetting and drying of concrete using aqueous solutions containing deicing salts. Cement and Concrete Composites, 33(5), 535-542. 
Stanish, K. D., Hooton, R. D., \& Thomas, M. D. (2001). Testing the Chloride Penetration Resistance of Concrete: A Literature Review (No. FHWA Contract DTFH61-97-R-00022). United States. Federal Highway Administration.

Stark, J., \& Bollmann, K. (1997). Ettringite formation-a durability problem of concrete pavements. In Proceedings of the 10th International Congress of the Chemistry of Cement, Gothenburg, Schweden (Vol. 4, p. 4iv062).

Stark, J., \& Bollmann, K. (2000). Delayed ettringite formation in concrete. NORDIC CONCRETE RESEARCH-PUBLICATIONS-, 23, 4-28.

Struble, L. (1987). Microstructure and fracture at the cement paste-aggregate interface. MRS Online Proceedings Library Archive, 114.

Sutter, L., Peterson, K., Julio-Betancourt, G., Hooton, D., Dam, T. V., \& Smith, K. (2008). The deleterious chemical effects of concentrated deicing solutions on Portland cement concrete (No. SD2002-01F). South Dakota Department of Transportation, Office of Research.

Sutter, L. L., Peterson, K. R., Van Dam, T. J., \& Smith, K. (2002). Using epifluorescence optical microscopy to identify causes of concrete distress: Case study. Transportation research record, 1798(1), 22-30.

Suraneni, P., Monical, J., Unal, E., Farnam, Y., \& Weiss, J. (2017). Calcium oxychloride formation potential in cementitious pastes exposed to blends of deicing salt. ACI Mater. J, 114(4), 631641.

Suraneni, P., Azad, V. J., Isgor, O. B., \& Weiss, J. (2018). Role of supplementary cementitious material type in the mitigation of calcium oxychloride formation in cementitious pastes. Journal of Materials in Civil Engineering, 30(10), 04018248.

Tang, L., Nilsson, L. O., \& Basheer, P. M. (2011). Resistance of concrete to chloride ingress: Testing and modelling. CRC Press.

Taylor, P., Sutter, L., \& Weiss, J. (2012). Investigation of deterioration of joints in concrete pavements.

Tepfers, R., Hedberg, B., \& Szczekocki, G. (1984). Absorption of energy in fatigue loading of plain concrete. Matériaux et Construction, 17(1), 59.

Thaulow, N., \& Sahu, S. (2004). Mechanism of concrete deterioration due to salt crystallization. Materials Characterization, 53(2-4), 123-127.

Thiery, M. (2006). Modélisation de la carbonatation atmosphérique des matériaux cimentaires: prise en compte des effets cinétiques et des modifications microstructurales et hydriques. ETUDES ET RECHERCHES DES LABORATOIRES DES PONTS ET CHAUSSEES-SERIE OUVRAGES D'ART, (OA 52). 
Valenza II, J. J., \& Scherer, G. W. (2007). A review of salt scaling: I. Phenomenology. Cement and Concrete Research, 37(7), 1007-1021.

Valverde, J. M., Perejon, A., Medina, S., \& Perez-Maqueda, L. A. (2015). Thermal decomposition of dolomite under CO 2: insights from TGA and in situ XRD analysis. Physical Chemistry Chemical Physics, 17(44), 30162-30176.

Van Dam, F. J., Peterson, K. R., Sutter, L. L., Panguluri, A., Sytsma, J., Buch, N., ... \& Desaraju, P. (2005). Final Report for Early-Opening-to-Traffic Portland Cement Concrete for Pavement Rehabilitation. TRB.

Verbeck, G. J., \& Klieger, P. (1957). Studies of 'salt' scaling of concrete. Highway Research Board Bulletin, (150).

Wang, L., \& Ueda, T. (2011). Mesoscale modeling of water penetration into concrete by capillary absorption. Ocean Engineering, 38(4), 519-528.

Wang, X., Zhang, J., Wang, X., Taylor, P., Wang, K., \& Sun, X. (2018). Exploration of Mechanisms of Joint Deterioration in Concrete Pavements regarding Interfacial Transition Zone. Advances in Civil Engineering, 2018.

Wei, H. J. M. C. H., \& Yun, L. J. W. (2012). Influence of freeze-thaw damage on the fatigue life of concrete [J]. China Civil Engineering Journal, 6.

Weiss, W. J., \& Chariton, T. (2002). Using Acoustic Emission to Monitor Damage Development in Mortars Restrained from Volumetric Changes, Concrete: Material Science to Application, A Tribute to Surendra P. Shah, ed. P. Balaguru, A. Namaan, W. Weiss, ACI SP-206, 205-218.

Winslow, D., \& Liu, D. (1990). The pore structure of paste in concrete. Cement and concrete research, $20(2), 227-235$.

Yuan, Q., Shi, C., De Schutter, G., Audenaert, K., \& Deng, D. (2009). Chloride binding of cement-based materials subjected to external chloride environment-a review. Construction and building materials, 23(1), 1-13.

Zanuy, C., Albajar, L., \& De la Fuente, P. (2009). Sectional Analysis of Concrete Structures under Fatique Loading. ACl Structural Journal, 106(5).

Zhan, B., Poon, C., \& Shi, C. (2013). CO2 curing for improving the properties of concrete blocks containing recycled aggregates. Cement and Concrete Composites, 42, 1-8.

Zhang, J. (2013). Investigation of deterioration of joints in concrete pavements. 
Zhang, J., Taylor, P. C., \& Shi, C. (2015). Investigation of approaches for improving interfacial transition zone-related freezing-and-thawing resistance in concrete pavements. ACI Materials Journal, $112(5), 613-617$.

Zhang, J., White, D., Taylor, P. C., \& Shi, C. (2015). A case study of evaluating joint performance in relation with subsurface permeability in cold weather region. Cold Regions Science and Technology, 110, 19-25.

Zhang, M. H., \& Malhotra, V. M. (1995). Characteristics of a thermally activated alumino-silicate pozzolanic material and its use in concrete. Cement and concrete research, 25(8), 1713-1725.

Zibara, H. (2001). Binding of external chlorides by cement pastes (Doctoral dissertation, National Library of Canada $=$ Bibliothèque nationale du Canada). 